\title{
REFORÇO DE VIGAS DE CONCRETO ARMADO POR MEIO DE BARRAS DE AÇO ADICIONAIS OU CHAPAS DE AÇO E ARGAMASSA DE ALTO DESEMPENHO
}

\author{
Andréa Prado Abreu Reis
}

Dissertação apresentada à Escola de Engenharia de São Carlos da Universidade de São Paulo, como parte dos requisitos para obtenção do título de Mestre em Engenharia de Estruturas.

Orientador: João Bento de Hanai

São Carlos

1998 


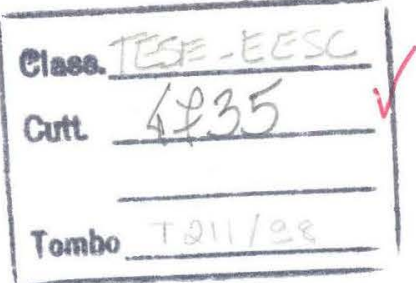

st 09872194

Ficha catalográfica preparada pela Seção de Tratamento da Informação do Serviço de Biblioteca - EESC-USP

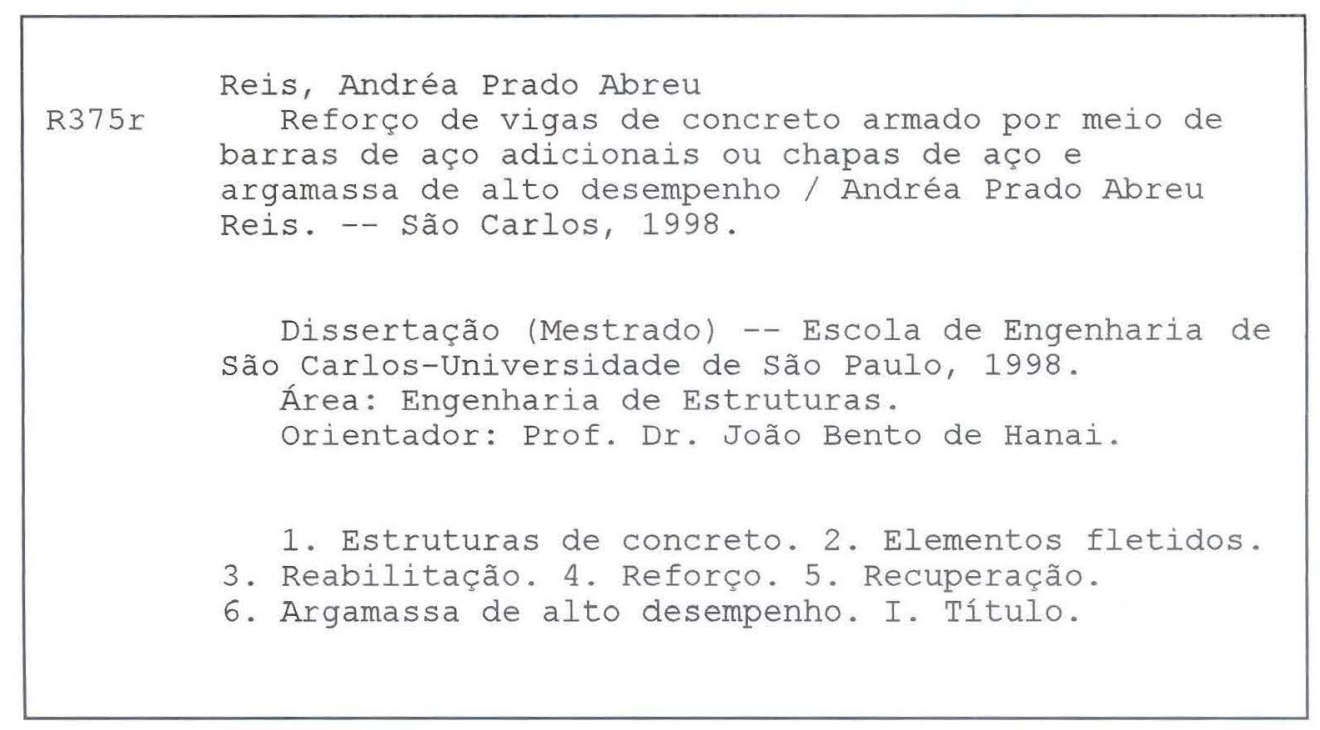




\begin{abstract}
A Deus
"Senhor, Tu me sondas e me conheces. Sabes quando me sento e quando me levanto, de longe vês os meus pensamentos. Esquadrinhas o meu andar e o meu deitar e conheces todos os meus caminhos. Ainda a palavra não me chegou à língua, e Tu, Senhor, já a conheces toda. Tu me cercas por trás e pela frente, abrange meu passado e meu futuro e sobre mim repousas Tua mão. Tal conhecimento é maravilhoso demais para mim, tão sublime que não posso atingi-lo. Assim, só me resta ao menos dizer-te OBRIGADO"

sl. 139: 1-7
\end{abstract}




\section{AGRADECIMENTOS}

Ao Prof. João Bento de Hanai pelo inestimável incentivo, amizade, apoio e pela excelente orientação que foram fundamentais para a elaboração deste trabalho.

Ao Prof. Toshiaki Takeya pela enorme paciência e colaboração dadas durante a realização dos ensaios experimentais.

Aos professores José Samuel Giongo e Jefferson B.L. Libório pelas sugestões feitas ao trabalho no Exame de Qualificação.

Aos técnicos do Laboratório de Estruturas pela dedicação dispensada durante a realização dos ensaios experimentais.

Aos professores da COPPE/UFRJ e UFF que me ajudaram a complementar minha pesquisa bibliográfica.

Ao Prof. Ronaldo Barros Gomes pelos importantes ensinamentos dados durante a orientação no programa de iniciação científica e pelo incentivo no ingresso no curso de mestrado.

A Universidade Federal de Goiás pela formação acadêmica.

A todos os amigos e companheiros do Departamento de Engenharia de Estruturas e também a todos os professores e funcionários que de uma forma ou de outra contribuíram para a elaboração deste trabalho.

Ao Fernando M. Torres pelo carinho e compreensão dispensados durante várias fases da minha vida.

Às amigas Dálim G. Paniago, Nilza Aparecida Bessa, Anamaria M. Miotto e Ana Maria da S. Brandão pela excelente convivência, apoio e amizade que sempre esteve presente durante o período em que moramos juntas.

Ao Luiz Liserre pelo grande incentivo, amor, ternura e apoio dados durante a fase final desse trabalho.

À empresa VULKAN DO BRASIL LTDA, Divisão HAREX, que doaram as fibras de aço utilizadas em alguns dos ensaios experimentais.

À FAPESP e à CAPES pelo apoio financeiro, sem o qual este trabalho não poderia ter sido realizado.

A meus pais, Leila e Ronan, ao meu irmão Ricardo e a minha tia Carmem, que sempre me incentivaram a prosseguir nesta jornada, fossem quais fossem os obstáculos. 


\section{SUMÁRIO}

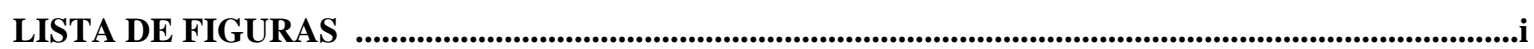

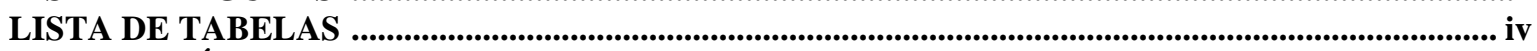

LISTA DE SÍMBOLOS .........................................................................................................................................................

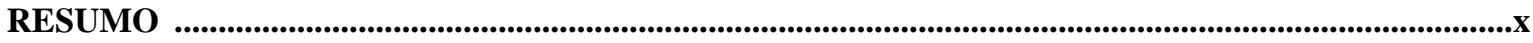

ABSTRACT …….................................................................................................................................................. xi

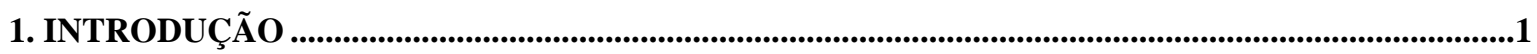

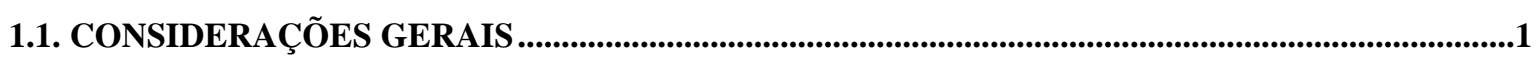

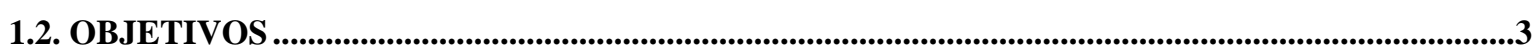

1.3. APRESENTAÇÃO DO TRABALHO ..........................................................................................................

2. REABILITAÇÃO DE ESTRUTURAS DE CONCRETO .........................................................6

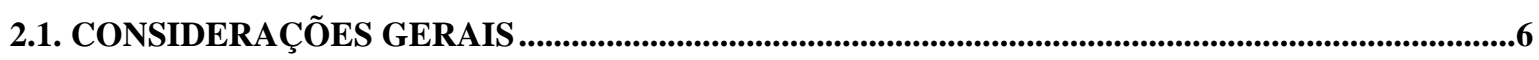

2.2. PROPRIEDADES DOS MATERIAIS ...................................................................................................... 11

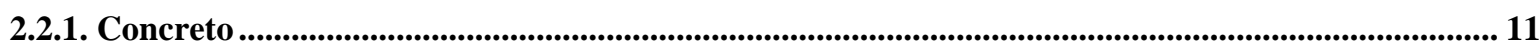

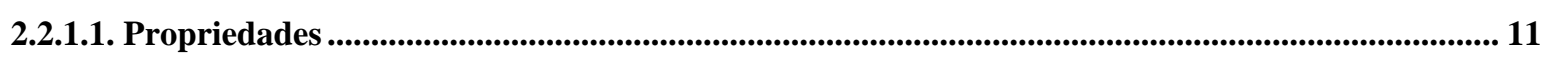

2.2.1.2. Concreto reforçado com fibras............................................................................................... 16

2.2.1.3. Concreto de alto desempenho ...................................................................................................................... 19

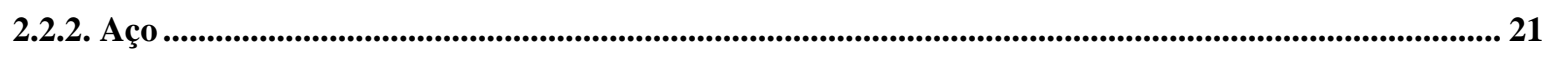

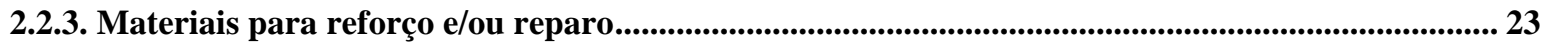

2.3. TÉCNICAS DE RECUPERAÇÃO DE ESTRUTURAS DE CONCRETO ARMADO...................... 28

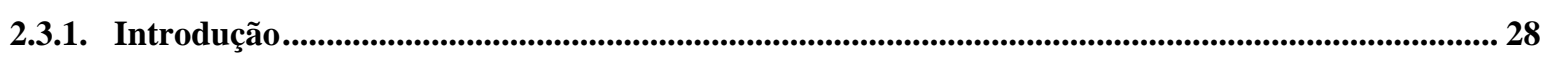

2.3.2. Dimensionamento do reforço e/ou reparo ................................................................................................... 30

2.3.2.1. Coeficientes de Segurança ............................................................................................................... 30

2.3.2.2. Características residuais ........................................................................................................33

2.3.2.3. Hipóteses de Cálculo ............................................................................................................................... 36

2.4. TRANSFERÊNCIA DE ESFORÇOS................................................................................. 38

2.4.1. Transferência de força pela interface do concreto ......................................................................... 39

2.4.2. Transferência de força pelas armaduras......................................................................................................... 43

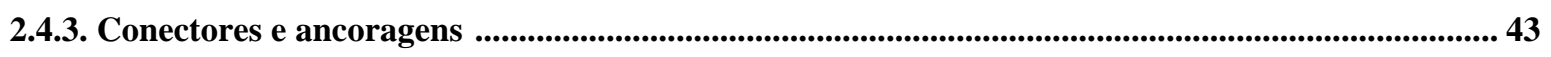

2.5. ENSAIOS PARA AVALIAR A ADERÊNCIA ENTRE SUBSTRATO/REPARO ............................54

2.6. TECNICAS DE REFORÇO ESTUDADAS ........................................................................................... 58

2.6.1. Reforço mediante encamisamento de concreto armado/argamassa.................................................61

2.6.1.1. Reforço mediante aumento de seção transversal ................................................................................... 63

2.6.1.2. Reforço mediante substituição do material danificado .......................................................................... 66

2.6.2. Reforço mediante uso de chapas de aço......................................................................................................... 66

2.7. MECANISMOS DE RUÍNA EM VIGAS............................................................................................ 71

3. ENSAIOS REALIZADOS POR OUTROS PESQUISADORES ………………………............................. 76

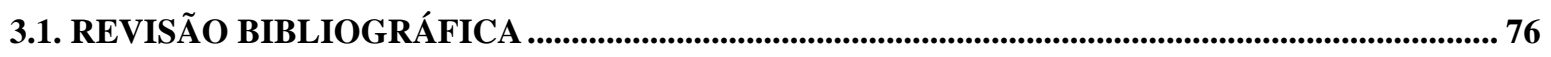


3.2. REABILITAÇÃO ATRAVÉS DE ADIÇÃO DE ARMADURA LONGITUDINAL CONVENCIONAL

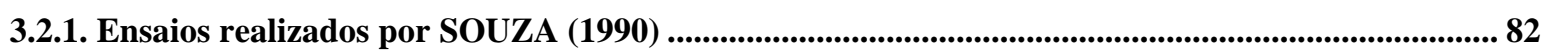

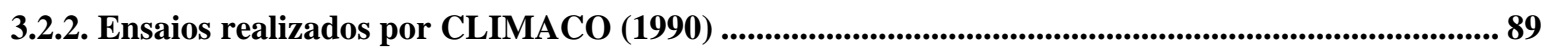

3.2.3. Ensaios realizados por PIANCASTELLI (1997) ..................................................................................... 95

3.3. REABILITAÇÃO ATRAVÉS DE CHAPAS DE AÇO...........................................................100

3.3.1. Ensaios realizados por ALFAIATE (1986) ............................................................................................. 101

3.3.2. Ensaios realizados por CAMPAGNOLO (1997) …………………………………................................ 106

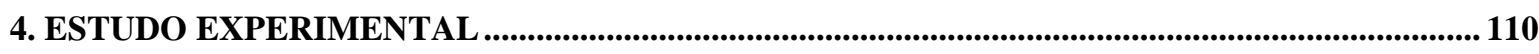

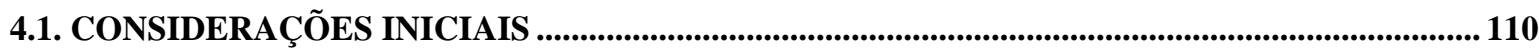

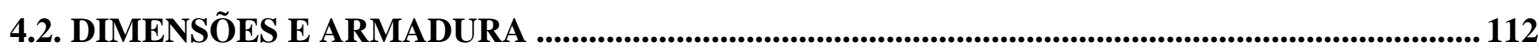

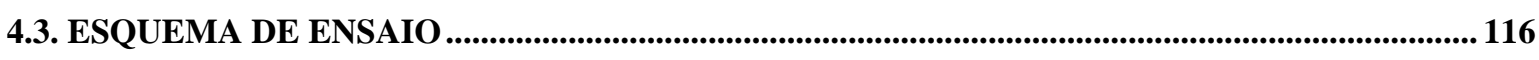

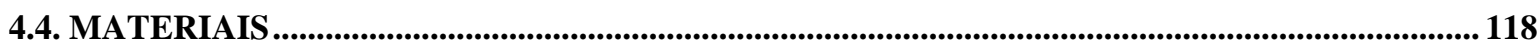

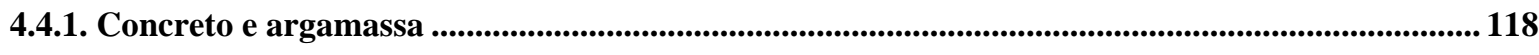

4.4.2. Aço …........................................................................................................................................................... 121

4.5. EXECUÇÃO DAS VIGAS............................................................................................................... 121

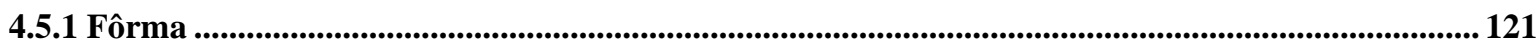

4.5.2 Preparação do substrato, moldagem e cura ............................................................................... 122

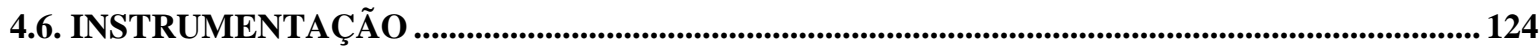

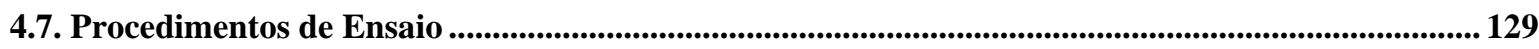

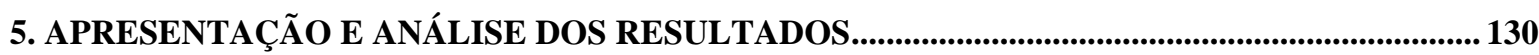

5.1. MODO DE RUÍNA E FORÇAS DE FISSURAÇÃO E DE RUÍNA ............................................... 130

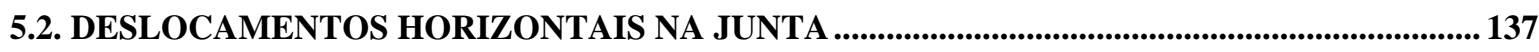

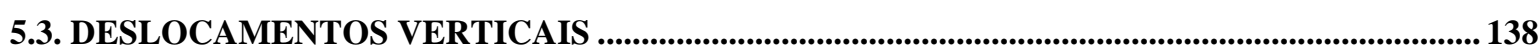

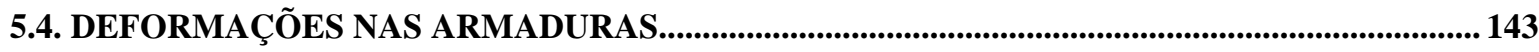

5.3.1. Armadura Longitudinal............................................................................................................................. 143

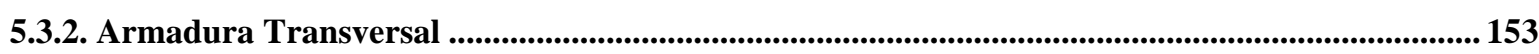

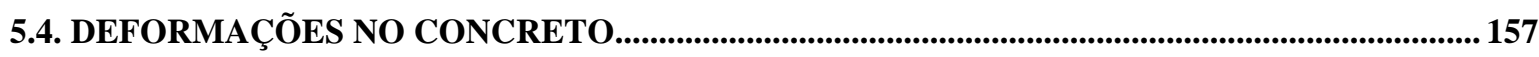

5.4.1. Mesa Comprimida .......................................................................................................................................... 157

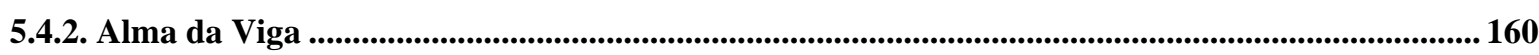

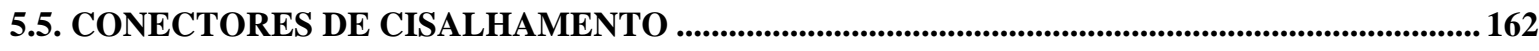

5.6. COMPARAÇÕES COM OS RESULTADOS ENCONTRADOS NA BIBLIOGRAFIA ................. 163

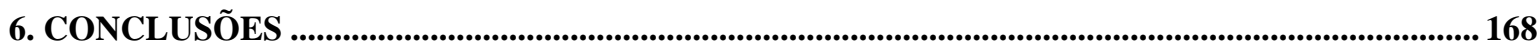

REFERÊNCIAS BIBLIOGRÁFICAS ................................................................................................... 174

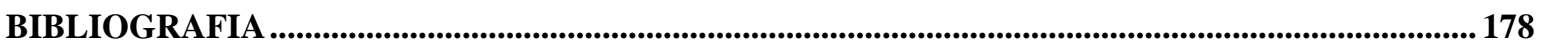

APÊNDICE I - ANÁLISE TEÓRICA PARA PREVISÃO DO COMPORTAMENTO DAS VIGAS ENSAIADAS

APÊNDICE II - DADOS COLETADOS PELO SISTEMAS DE AQUISIÇÃo DE DADOS 


\section{LISTA DE FIGURAS}

FIGURA 2.1 - Origem dos problemas patológicos .

FIGURA 2.2 - Etapas do processo de reforço e/ou reparo ......................................................... 10

FIGURA 2.3 - Progresso da retração e expansão em função da idade .......................................... 13

FIGURA 2.4 - Evolução da deformação imediata e fluência ao longo do tempo-deformações recuperáveis e residuais ............................................................................................ 13

FIGURA 2.5 - Desvio de tensões em uma peça reforçada ..................................................... 14

FIGURA 2.6 - Deformações de peça composta por materiais com módulos de elasticidade diferentes .................................................................................................................. 15

FIGURA 2.7 - Diagrama tensão-deformação do concreto............................................................... 15

FIGURA 2.8 - Mecanismo do controle de fissuração das fibras de aço ....................................... 18

FIGURA 2.9 - Diagramas tensão-deformação recomendados pela NBR-6118............................ 22

FIGURA 2.10 - Fatores que influenciam o comportamento conjunto dos materiais ................... 24

FIGURA 2.11 - Fatores que afetam o desempenho dos reparos ..................................................... 227

FIGURA 2.12 - Fatores que influenciam nas atividades de recuperação .................................... 27

FIGURA 2.13 - Operações de descarregamento da estrutura .................................................... 29

FIGURA 2.14 - Relação entre momento x curvatura para um elemento de concreto armado danificado................................................................................................................................. 33

FIGURA 2.15 - Transferência integral de tensões de cisalhamento horizontais em vigas compostas .............................................................................................................................. 38

FIGURA 2.16 - Transferência de força através de interface concreto novo x concreto antigo.. 39

FIGURA 2.17 - Mecanismo natural de ligação entre material do reparo e o substrato .............. 40

FIGURA 2.18 - Modelo idealizado de um sistema de reparo superficial .................................... 41

FIGURA 2.19 - Mecanismo de transferência de esforços de cisalhamento numa interface de concreto com superfície rugosa e com armadura .................................................. 42

FIGURA 2.20 - Chumbadores para ligar concreto-concreto .................................................... 44

FIGURA 2.21 - Conectores de barras soldadas para ligar armadura-armadura ......................... 44

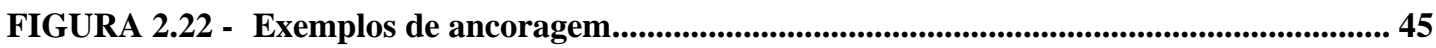

FIGURA 2.23 - Viga ou laje pré-moldada ligada por conector....................................................... 46

FIGURA 2.24 - Avaliação da tensão na interface por equilíbrio de forças.................................. 48

FIGURA 2.25 - Avaliação da tensão de cisalhamento horizontal na interface ............................ 50

FIGURA 2.26 - Testes de tração para avaliação de aderência......................................................... 55

FIGURA 2.27 - Testes de cisalhamento ......................................................................................57

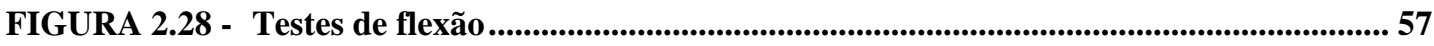

FIGURA 2.29 - Teste compressão-cisalhamento de junta inclinada............................................... 58

FIGURA 2.30 - Estados de tensão e deformação em uma viga reforçada ................................... 59

FIGURA 2.31 - Reforço de viga com nova armadura atada à mesma......................................... 64

FIGURA 2.32 - Reforço com aumento da base com danos à laje.................................................... 64 
FIGURA 2.33 - Reforço de viga mediante "denteamento"

FIGURA 2.34 - Reforço realizado por meio de sulcos longitudinais

FIGURA 2.35 - Tipos de ancoragem estudadas por CAMPAGNOLO (1993)

FIGURA 2.36 - Modos de ruptura prematura em vigas reforçadas com chapas de aço ............. 70

FIGURA 2.37 - Tipos de ruptura em vigas de concreto armado

FIGURA 3.1 - Fôrmas das vigas a serem ensaiadas antes do reforço (FC1, FC2,FP1, FP2 e DF) e da viga de referência após o reforço $(\mathrm{RF})$

FIGURA 3.2 - Armadura de reforço das vigas FC1R, FC2R, FP1R E FP2R............................ 83

FIGURA 3.3 - Armadura das vigas a serem ensaiadas antes do reforço (FC1, FC2, FP1, FP2 e DF)

FIGURA 3.4 - Armadura da viga de referência após o reforço (RF) ......................................... 85

FIGURA 3.5 - Forma de recuperação nas vigas ensaiadas por CLIMACO (1990) .................... 90

FIGURA 3.6 - Características das vigas reforçadas por CLIMACO (1990) ............................... 92

FIGURA 3.7 - Características das vigas originais de PIANCASTELLI ..................................97

FIGURA 3.8 - Características das vigas reforçadas por PIANCASTELLI .................................98

FIGURA 3.9 - Detalhes das vigas ensaiadas por ALFAIATE (1986)- ......................................... 104

FIGURA 3.10 - Detalhamento das vigas ensaiadas por CAMPAGNALO (1997) ....................... 108

FIGURA 3.11 - Nomenclatura dos parâmetros utilizados nas vigas........................................... 109

FIGURA 4.1 - Conectores tipo 1 e 2 ....................................................................................... 114

FIGURA 4.2 - Dimensões da seção transversal e detalhamento das armaduras ...................... 115

FIGURA 4.3 - Esquema de treliça modificada após a reabilitação da peça.............................. 116

FIGURA 4.4 - Esquema de ensaio....................................................................................................... 117

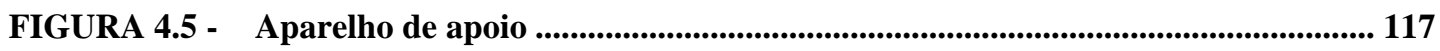

FIGURA 4.6 - Dados sobre a fibra de aço................................................................................ 119

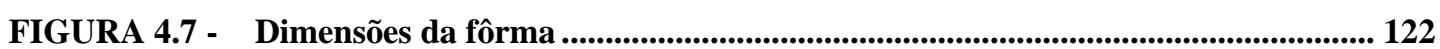

FIGURA 4.8 -- Preparação da superfície à ser reforçada............................................................. 123

FIGURA 4.9 - Posicionamento das armaduras do reforço ................................................... 123

FIGURA 4.10 - Moldagem do reforço ...................................................................................... 124

FIGURA 4.11 - Cura com espuma umedecida.................................................................................. 124

FIGURA 4.12 - Posição dos instrumentos de leitura nas vigas tipo VA e VM............................ 126

FIGURA 4.13 - Posição dos instrumentos de leitura nas vigas tipo VC ................................... 127

FIGURA 4.14 - Posição dos instrumentos nas seções transversais das vigas tipo VC................ 128

FIGURA 4.15 - Detalhes da instrumentação ................................................................................ 128

FIGURA 5.1 - Esquema de fissuração _................................................................................... 134

FIGURA 5.2 - Detalhe da região em que ocorreu a ruína da peça .............................................. 135

FIGURA 5.3 - Gráfico força x deslocamento relativo entre reforço e substrato para VA-1 .. 137

FIGURA 5.4 - Gráfico da força x deslocamento vertical para vigas tipo VA ........................... 139

FIGURA 5.5 - Gráfico da força x deslocamento vertical para vigas tipo VC ........................... 140 
FIGURA 5.6 - Gráfico da força $x$ deslocamento vertical para viga VM ................................... 141

FIGURA 5.7 - Gráfico da força $x$ flecha para todas vigas ...........................................................141

FIGURA 5.8 - Gráfico da força x deformação na armadura longitudinal para VM ............... 146

FIGURA 5.9 - Gráfico da força x deformação na armadura longitudinal para VA-1 ............ 147

FIGURA 5.10 - Gráfico da força $x$ deformação na armadura longitudinal para VA-2 ............ 148

FIGURA 5.11 - Gráfico da força x deformação na armadura longitudinal para VA-3............ 149

FIGURA 5.12 - Gráfico da força x deformação na armadura longitudinal para VC-1 ............ 150

FIGURA 5.13 - Gráfico da força x deformação na armadura longitudinal para VC-2 ............ 151

FIGURA 5.14 - Gráfico da força x deformação na armadura longitudinal para VC-3............ 152

FIGURA 5.15 - Gráfico da força x deformação nos estribos para vigas tipo VA....................... 154

FIGURA 5.16 - Gráfico da força x deformação nos estribos para viga tipo VC ...................... 155

FIGURA 5.17 - Gráfico da força x deformação nos estribos para VM ........................................ 156

FIGURA 5.18 - Gráfico da força x deformação nos estribos na série 1 e 3................................. 156

FIGURA 5.19 - Gráfico da força $x$ deformação no concreto para vigas tipo VA....................... 158

FIGURA 5.20 - Gráfico da força $x$ deformação no concreto para vigas tipo VC ..................... 159

FIGURA 5.21 - Gráfico da força x deformação no concreto para viga VM ............................. 160

FIGURA 5.22 - Gráfico da força x tensões máximas e mínimas ............................................. 161

FIGURA 5.23 - Gráficos força x deformação nos conectores para VC-2 e VC-3...................... 163 


\section{LISTA DE TABELAS}

TABELA 2.1- Valores de $\gamma^{\prime} / \gamma_{c}$ para concreto moldado no local, sendo $\gamma_{c}=1,5 \ldots . . . . . . . . . . . . . . . . . .332$

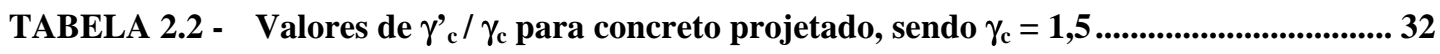

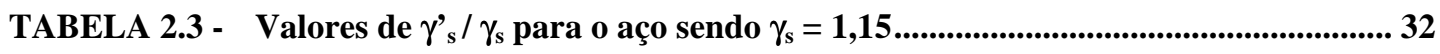

TABELA 3.1 - Características das vigas ensaiadas por SOUZA (1990) ........................................ 82

TABELA 3.2 - Momentos de fissuração e ruptura das vigas ensaiadas por SOUZA (1990)..... 86

TABELA 3.3 - Características das vigas ensaiadas por CLÍMACO (1990) .............................. 91

TABELA 3.4 - Resultados dos ensaios de CLÍMACO (1990) ............................................................ 91

TABELA 3.5 - Altura da linha neutra no meio do vão $(\mathbf{m m})$................................................. 94

TABELA 3.6 - Deformações da armadura de tração no meio do vão $(\mathrm{mm} / \mathrm{m})$........................... 94

TABELA 3.7 - Resultados experimentais e resultados teóricos segundo a NBR-6118 ............... 99

TABELA 3.8 - Características das vigas ensaiadas por ALFAIATE (1986) ........................... 103

TABELA 3.9 - Momentos de ruína das vigas ensaiadas por ALFAIATE (1986) ..................... 103

TABELA 3.10 - Características das vigas ensaiadas por CAMPAGNOLO (1997) ..................... 107

TABELA 3.11 - Propriedades do concreto e força de ruína das vigas reabilitadas por CAMPAGNOLO (1997) ........................................................................................... 109

TABELA 4.1 - Características gerais das vigas e condição inicial de ensaio.............................. 114

TABELA 4.2 - Traços usados na confecção do concreto do substrato.......................................... 118

TABELA 4.3 - Traços usados na confecção da argamassa de reforço ..................................... 118

TABELA 4.4 - Características do concreto e argamassa e idade no dia do ensaio ................... 120

TABELA 4.5 - Características das armaduras usadas nas vigas................................................... 121

TABELA 4.6 - Equipamentos e instrumentos de medição ......................................................... 129

TABELA 5.1 - Força de fissuração real e prevista das vigas ensaiadas.................................... 131

TABELA 5.2 - Característica das vigas ensaiadas.......................................................................... 133 


\section{LISTA DE SÍMBOLOS}

\section{- Letras romanas maiúsculas}

A - $\quad$ área de aço inicial;

$\mathrm{A}_{\mathrm{c} 2}$ - área da seção de concreto moldada no local;

$A_{R}$ - área de aço do reforço;

$\mathrm{A}_{\mathrm{s}}$ - área de aço da armadura passiva;

$\mathrm{A}_{\mathrm{sw}}$ - área de aço dos conectores $\left(\mathrm{cm}^{2}\right)$;

$\mathrm{A}_{\text {swmin- }}$ armadura mínima de conectores;

$\mathrm{E}_{\mathrm{co}}$ - módulo de elasticidade ou de deformação tangente inicial do concreto;

$E_{c}$ - módulo de elasticidade ou de deformação secante do concreto;

$\mathrm{E}_{\mathrm{s}}$ - módulo de elasticidade do aço;

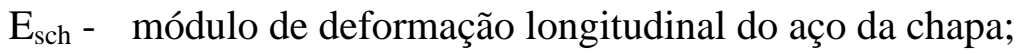

I - $\quad$ momento de inércia da seção transversal;

$\mathrm{I}_{\mathrm{e}}$ - momento de inércia equivalente;

$\mathrm{I}_{\mathrm{I}}$ - momento de inércia referente ao estádio I;

III - momento de inércia referente ao estádio II;

$I_{x}$ - momento de inércia da seção homogeneizada de concreto;

$\mathrm{K}_{\text {inicial- }}$ característica inicial de rigidez antes da deterioração;

$\mathrm{K}_{\text {final }}$ - características de rigidez das estruturas reforçadas;

$\mathrm{K}_{\mathrm{m}}$ - características monolíticas de rigidez consideradas as intervenções;

$\mathrm{K}_{\text {residual- }}$ característica residual de rigidez da peça deteriorada ;

$\mathrm{K}_{\mathrm{II}}$ - $\quad$ rigidez de estrutura para o Estádio II;

$\mathrm{M}_{\mathrm{g}}$ - momentos fletores produzidos pelas ações permanentes;

$\mathrm{M}_{\mathrm{q}}$ - momentos fletores produzidos pelas sobrecargas de uso;

$\mathrm{M}_{\mathrm{r}}$ - momento de fissuração;

$\mathrm{M}_{\mathrm{u}, \mathrm{ref}}$ - momento resistente último da estrutura reforçada;

$\mathrm{M}_{\mathrm{u}, \mathrm{m}}$ - momento resistente último da estrutura monolítica;

$\mathrm{N}_{1}$ e $\mathrm{N}_{2}$ - resultantes de compressão no concreto em relação à $\mathrm{M}_{\mathrm{q}}$ e $\mathrm{M}_{\mathrm{g}}$;

$R_{c c 2}$ - força de compressão no concreto moldado no local $\left(R_{c c 2}=0,85 \cdot f_{c d} \cdot A_{c 2}\right)$;

$\mathrm{R}_{\mathrm{cc}}$ - força total de compressão na seção composta; 
$R_{d}$ - valor de cálculo dos esforços resistentes atuantes na estrutura;

$\mathrm{R}_{\text {inicial- }}$ característica inicial de resistência antes da deterioração;

$\mathrm{R}_{\mathrm{final}}$ - características de resistência das estruturas reforçadas;

$\mathrm{R}_{\mathrm{m}}$ - características monolíticas de resistência consideradas as intervenções;

$\mathrm{R}_{\text {residual- }}$ característica residual de resistência da peça deteriorada;

$\mathrm{R}_{\mathrm{rd}}$ - força resistente de cálculo na interface;

$\mathrm{R}_{\mathrm{st}}$ - força total de tração $\left(\mathrm{R}_{\mathrm{st}}=\mathrm{A}_{\mathrm{s}} \cdot \mathrm{f}_{\mathrm{y}}\right)$;

S - momento estático;

$\mathrm{S}_{\mathrm{d}}$ - valor de cálculo das solicitações atuantes na estrutura original;

V - esforço cortante a ser absorvido pelo elemento depois de reforçado; esforço cortante na seção;

$\mathrm{V}_{\mathrm{u}, \text { ref }}$ - cortante resistente último da estrutura reforçada;

$\mathrm{V}_{\mathrm{u}, \mathrm{m}}$ - cortante resistente último da estrutura monolítica;

\section{- Letras romanas minúsculas}

a - distância do final da chapa até o eixo do apoio;

$a_{v}$ - distância entre os pontos de momento máximo e momento nulo;

b - largura da seção transversal na fibra em estudo; largura da viga;

$\mathrm{d}_{1}$ - $\quad$ altura útil devido à armadura do substrato;

$\mathrm{d}_{2}$ - $\quad$ altura útil devido à armadura de reforço;

$\mathrm{d}_{\mathrm{ch}}$ - altura útil da chapa;

$\mathrm{f}_{\mathrm{c}}$ - $\quad$ resistência média à compressão do concreto;

$\mathrm{f}_{\mathrm{cd}}$ - resistência de cálculo do concreto à compressão;

$\mathrm{f}_{\mathrm{cj}}$ - resistência média do concreto à compressão na idade de $\mathrm{j}$ dias;

$f_{c k}$ - resistência característica do concreto antigo à compressão em MPa;

$\mathrm{f}_{\mathrm{ck}, \mathrm{c}}$ - resistência característica do concreto medida em corpos-de-prova cúbicos;

$\mathrm{f}_{\mathrm{ct}, \mathrm{m}}$ - resistência do concreto à tração na flexão;

$\mathrm{f}_{\mathrm{k}}$ - valor característico das resistências dos materiais, consideradas na estrutura original;

$f_{t}$ - $\quad$ resistência média à tração do concreto;

$\mathrm{f}_{\mathrm{td}, \mathrm{c}}$ - resistência de cálculo do concreto a tração indicada pela FIP (MPa); 
$\mathrm{f}_{\mathrm{y}}$ - resistência característica à tração do aço;

$f_{y c h}$ - tensão de escoamento da chapa;

$\mathrm{f}_{\mathrm{yd}}$ - resistência de cálculo do aço à tração $(\mathrm{MPa})$;

$l_{b}$ - comprimento de ancoragem da chapa;

s - deslizamento relativo entre duas superfícies em contato;

$\mathrm{S}_{\mathrm{k}}$ - $\quad$ valor característico das ações a serem consideradas no projeto;

x - $\quad$ altura da zona comprimida; Altura da linha neutra;

$\mathrm{x}_{\mathrm{e}}$ - posição da linha neutra equivalente;

$\mathrm{x}_{\mathrm{I}}$ - $\quad$ posição da linha neutra para o estádio I;

$\mathrm{X}_{\text {II }}$ - posição da linha neutra para o estádio II;

$\mathrm{z}_{1}$ - braço de alavanca da armadura inicial devido $\mathrm{M}_{\mathrm{g}}$;

$\mathrm{Z}_{2}$ - $\quad$ braço de alavanca da armadura inicial devido $\mathrm{M}_{\mathrm{q}}$;

$\mathrm{Z}_{3}$ - braço de alavanca da armadura inicial devido $\mathrm{M}_{\mathrm{q}}$ e $\mathrm{M}_{\mathrm{g}}$;

$Z_{r}$ - braço de alavanca da armadura do reforço;

\section{- Letras gregas minúsculas}

$\alpha_{e^{-}} \quad$ relação entre os módulos de elasticidade do aço e do concreto;

$\beta_{1}$ e $\beta_{2}$ - coeficientes multiplicadores da resistência que dependem da armadura e da superfície de contato, fornecidos pela FIP;

$\varepsilon_{\mathrm{c}}$ - deformação específica do concreto a compressão;

$\varepsilon_{\mathrm{d}}-\quad$ deformação recuperável retardada;

$\varepsilon_{\mathrm{e}}$ - deformação recuperável instantânea;

$\varepsilon_{\mathrm{s}}$ - deformação específica do aço;

$\varepsilon_{\mathrm{t}}$ - deformação residual;

$\varepsilon_{\mathrm{cc}}\left(\mathrm{t}, \mathrm{t}_{\mathrm{o}}\right)$ - deformação lenta especifica do concreto do tempo $\mathrm{t}$ a $\mathrm{t}_{\mathrm{o}}$;

$\varepsilon_{\text {ce }}\left(\mathrm{t}_{\mathrm{o}}\right)$ - deformação instantânea;

$\varepsilon_{\mathrm{cg}}$ - deformação do concreto para cargas permanentes;

$\varepsilon_{\mathrm{cq}}$ - $\quad$ deformação do concreto para cargas de uso;

$\varepsilon_{\mathrm{sg}}$ - deformação do aço do substrato para cargas permanentes;

$\varepsilon_{\text {srg }}$ - deformação do aço do reforço para cargas permanentes; 
$\varepsilon_{\mathrm{sq}}$ - deformação do aço do substrato para cargas de uso;

$\varepsilon_{\text {srq }}$ - deformação do aço do reforço para cargas de uso;

$\gamma_{c}$ - coeficiente de minoração da resistência do concreto;

$\gamma_{\mathrm{f}}$ - coeficientes de segurança relativos às ações na estrutura;

$\gamma_{m}$ - coeficientes de segurança relativos às características resistentes dos materiais respectivamente;

$\gamma_{\mathrm{Sd}}-\quad$ coeficiente parcial de segurança;

$\gamma_{R d}-\quad$ coeficiente parcial de segurança;

$\gamma_{n, R}-$ coeficientes de correção do comportamento monolítico de resistência;

$\gamma_{\mathrm{n}, \mathrm{K}}-$ coeficiente de correção do comportamento monolítico de rigidez;

$v_{\mathrm{K}}-\quad$ coeficientes de correção da capacidade de rigidez;

$v_{R}-\quad$ coeficientes de correção da capacidade resistente;

$\tau_{\alpha, \max }$ - tensão tangencial limite;

$\tau_{\alpha}{ }^{-} \quad$ tensão tangencial existente na interface reforço/substrato;

$\tau_{\mathrm{sd}}$ - tensão solicitante de cálculo na interface;

$\tau_{\mathrm{u}}-\quad$ tensão de cisalhamento última na interface;

$\sigma_{\mathrm{c}}$ - tensão normal de compressão no concreto;

$\sigma_{\mathrm{cg}}$ - tensão do concreto para cargas permanentes;

$\sigma_{\mathrm{cq}}$ - tensão do concreto para cargas de uso;

$\sigma_{\mathrm{n}}$ - tensão normal à interface entre duas superfícies;

$\sigma_{\mathrm{s}}-\quad$ tensão normal de tração na armadura;

$\sigma_{\mathrm{sg}}$ - tensão do aço do substrato para cargas permanentes;

$\sigma_{\text {srg }}$ - tensão do aço do reforço para cargas permanentes;

$\sigma_{\mathrm{sq}}$ - tensão do aço do substrato para cargas de uso;

$\sigma_{\text {srq }}$ - tensão do aço do reforço para cargas de uso;

\section{- abreviaturas}

ABNT: Associação Brasileira de Normas Técnicas;

$\mathrm{ACl}$ : American Concrete Institute;

BS: British Standard; 
CEB: Commite Euro-International du Beton;

EESC: Escola de Engenharia de São Carlos;

FIP: Federal Internationale de la Precontrainte;

LEME: Laboratório de Ensaios e Modelos Estruturais;

NBR: Norma Brasileira;

PCl: Prestressed / Precast Concrete Institute;

REBAP: Regulamento de Estruturas de Betão Armado e Pré-Esforçado.

UFF: Universidade Federal Fluminense;

UFRJ: Universidade Federal do Rio de Janeiro;

UFRGS: Universidade Federal do Rio Grande do Sul;

USP: Universidade de São Paulo. 


\section{RESUMO}

REIS, A. P. A. (1998). Reforço de vigas de concreto armado por meio de barras de aço adicionais ou chapas de aço e argamassa de alto desempenho. São Carlos, 179p. Dissertação (Mestrado). Escola de Engenharia de São Carlos, Universidade de São Paulo.

Neste trabalho estuda-se o comportamento de vigas de concreto armado reforçadas mediante duas técnicas distintas de reabilitação: adição de armadura longitudinal no bordo tracionado envolvida com argamassa de alto desempenho com ou sem fibras de aço, ou fixação de chapa de aço, também no bordo tracionado, por meio de argamassa de alto desempenho e conectores de aço. Inicialmente foi efetuado um levantamento dos principais materiais usados em reparo/reforço e dos procedimentos e recomendações indicados na literatura, para a reabilitação de elementos estruturais de concreto armado. Apresentou-se ainda uma síntese dos estudos mais recentes realizados nesta área de pesquisa e os resultados de alguns ensaios de vigas recuperadas realizados por outros pesquisadores. Na sequiência, foram realizados sete ensaios experimentais em vigas de concreto armado com seção transversal " $T$ ", de tamanho real, para avaliar a eficiência das duas técnicas de reabilitação propostas. De acordo com os resultados obtidos percebe-se que vigas reabilitadas através da adição de fibras de aço na argamassa que envolve a armadura complementar e de conectores metálicos soldados na chapa de aço são eficientes. Além disso, é imprescindível, nas vigas com chapas de aço, realizar uma boa ancoragem desses elementos para evitar a ruptura prematura da peça. Finalmente foi constatado que os resultados experimentais de outros pesquisadores indicam a viabilidade da reabilitação por meio de técnicas semelhantes as empregadas neste trabalho.

Palavras chaves: estruturas de concreto, argamassa de alto desempenho, elementos fletidos, reabilitação, reforço, recuperação. 


\begin{abstract}
REIS, A. P. A. (1998). Rehabilitation of reinforced concrete beams by means of additional steel bars or steel plate and high performance mortar. São Carlos, 179p. Master Degree Thesis. Escola de Engenharia de São Carlos, Universidade de São Paulo.
\end{abstract}

This work deals with the behaviour of reinforced concrete beams rehabilitated using two different techniques. One of these techniques consists of the addition of longitudinal reinforcement embedded in a plain or steel fiber reinforced high performance mortar at the tensioned face of the member. The second technique refers to the attachment of a steel plate to the bottom face of the beam, using a high performance mortar and steel connectors. Firstly, it was performed a research about the materials that are most commonly used on repair/strengthening and the recommendations prescribed in the available literature for reinforced concrete members. The work also presents a synthesis of the recent researches in this area, showing the results of some tests carried out by several authors. Next, seven experimental tests were carried out on reinforced concrete T-beams, in full-scale, in order to assess the efficiency of the two techniques mentioned. According to the results obtained on these tests, it can be concluded that beams rehabilitated through addition of steel fibers to the mortar used to cover the complementary reinforcement and metallic connectors welded to the steel plate are efficient. Also, when using steel plate, a good anchorage must be provided to prevent premature failure of the member. Finally, it can be stated that the results obtained by other researchers indicate that the rehabilitation of beams by means of the two techniques presented is feasible.

Keywords: reinforced concrete, high performance concrete, beams, rehabilitation, strengthening, restoration. 


\section{INTRODUÇÃO}

\subsection{Considerações Gerais}

Os problemas patológicos e a necessidade de reabilitação afetam as construções desde os primórdios das civilizações e dependem principalmente da qualidade da edificação construída. Entretanto, a necessidade de reabilitar certas estruturas pode ser causada por outros fatores que não estejam relacionados com a qualidade ou a durabilidade da edificação, mas sim com a mudança do uso da estrutura, com a inviabilidade de demolição e reconstrução, com a recuperação para aumento do valor do imóvel ou com a necessidade de ampliação da estrutura. Nos últimos tempos, tem-se observado uma grande preocupação com aspectos relacionados a durabilidade, a manutenção das obras civis e a adequação das edificações a novos usos. Isso tem estimulado o desenvolvimento de tecnologias destinadas a solucionar problemas em peças deterioradas, danificadas ou tornadas obsoletas. Todavia, apesar desse ramo da Engenharia estar se desenvolvendo com relativa rapidez, os profissionais ainda contam essencialmente com técnicas baseadas na experiência empírica acumulada. Isto porque os processos de reabilitação apresentam, em sua maioria, um caráter artesanal e particular, pois cada problema enfrentado tem características próprias. Além disso, não existe uma metodologia específica de análise do comportamento estrutural da peça reabilitada e há poucas diretrizes que orientam o projetista durante o processo de redimensionamento e reprojeto. Portanto, apesar de várias obras terem sido reabilitadas com sucesso, ainda existem vários fatores que merecem ser investigados para avaliar melhor o comportamento da estrutura reabilitada. 
Estudos e investigações científicas ainda são necessárias principalmente para definir melhor as regras do dimensionamento, o comportamento das estruturas reabilitadas ao longo do tempo e as formas de se avaliar a aderência entre os materiais envolvidos, bem como suas propriedades. Tais pesquisas possibilitariam determinar quais os materiais, técnicas, procedimentos e normas mais adequadas a serem adotadas durante a realização de uma recuperação estrutural.

Estudos sobre as características dos materiais usados nas construções e reabilitações, principalmente em relação aos baseados em cimento portland, são de extrema relevância. Segundo dados de um relatório americano (High-Performance Construction Materials and Systems: an essential program for America and its infrastructure, CERF-Civil Engineering Research Foundation, 1993), o produto mais usado feito pelo homem é o concreto. As mais de 500 milhões de toneladas de concreto produzidas nos EUA cada ano destinam-se a quase todos os tipos de estruturas, incluindo edifícios, pavimentações, pontes, sistemas de água e esgoto e construções marítimas. Ainda segundo o mesmo relatório, embora as estruturas de concreto sejam freqüentemente vistas como permanentes, pode-se observar pelo estado da infra-estrutura da nação que elas não estão livres de problemas. Enquanto muitos pavimentos de concreto e tabuleiros de pontes têm se comportado bem durante sua vida útil de projeto, outras estruturas têm sofrido falhas prematuras. Muitas falhas ocorreram porque as estruturas foram submetidas a uso mais intenso do que o previsto, ou foram submetidas a tratamentos com sais de degelo que não foram previstos quando projetadas. Em qualquer caso, as implicações econômicas da degradação de estruturas de concreto são demonstradas por uma estimativa feita em 1985, em que 400 bilhões de dólares seriam necessários até o final do século para a reabilitação das pontes e estradas dos EUA. Outra estimativa, feita em 1987, indicou que entre um e três trilhões de dólares seriam necessários para recuperar estruturas de concreto nos EUA nos 20 anos seguintes. Considerando-se que no Brasil o concreto e outros produtos à base de cimento são materiais preponderantemente empregados na Construção Civil, possivelmente em proporções maiores do que em outros países, como os EUA, a pesquisa e a formação de recursos humanos nessa área são de grande importância e capazes de produzir reflexos econômicos imediatos. Apesar de 
não haver dados do mesmo tipo sobre a aplicação e o estado das construção de concreto no Brasil, acredita-se que se fosse feito um estudo, este revelaria um quadro também assustador. A partir daí, percebe-se que a durabilidade, os problemas patológicos e a recuperação das estruturas de concreto são assuntos que preocupam a comunidade em geral e, portanto, que o domínio completo dos métodos e técnicas de reabilitação de estruturas é de interesse nacional e mundial.

Nesse sentido, diversos projetos de pesquisa estão sendo realizados na EESC-USP para desenvolver modelos teóricos e processos práticos para a reabilitação de estruturas de concreto de modo geral. No caso, o projeto proposto se interliga a outras pesquisas em andamento visando colaborar para o aumento do conhecimento nessa área. Tendo em vista essa carência de conhecimento sobre o comportamento de peças reabilitadas e dos mecanismos de transferência de esforços entre a estrutura antiga e o reforço, propôs-se o estudo de vigas reforçadas mediante duas técnicas de reabilitação distintas que seriam: adição de armadura longitudinal no bordo tracionado envolvidas com argamassa ou fixação de chapa de aço, também no bordo tracionado, por meio de argamassa e conectores metálicos. Dentro desse contexto, está prevista a aplicação de alguns tipos de concretos especiais (na forma de argamassas de alto desempenho com ou sem fibras) e de conectores de aço para permitir a análise das influências desses elementos na resistência mecânica e na rigidez global da estrutura, bem como na capacidade de adesão e transferência de esforços entre os diferentes materiais.

\subsection{Objetivos}

Diante da necessidade permanente de racionalização e melhoria da confiabilidade na definição de estratégias de reabilitação e no projeto tecnológico (conjugando a análise estrutural com os procedimentos de seleção de materiais, processos de execução, etc.), pretende-se, com esse trabalho, contribuir ao conhecimento das técnicas de reabilitação de peças fletidas, estabelecendo-se como principais objetivos: 
1. Efetuar um levantamento dos procedimentos e recomendações indicados na literatura para a reabilitação de elementos estruturais de concreto, especialmente os elementos sujeitos a esforços de flexão, bem como os métodos de avaliar a resistência ao cisalhamento da interface entre substrato e material do reforço.

2. Apresentar uma síntese dos estudos mais recentes sobre a reabilitação de estruturas de concreto e os principais resultados de ensaios de vigas recuperadas encontrados na literatura.

3. Avaliar experimentalmente a eficiência das duas técnicas de reforço propostas para vigas de concreto armado. Estas técnicas consistem em adicionar barras de aço convencionais ou fixar chapa de aço no bordo tracionado da viga utilizando argamassa de alto desempenho com e sem fibras de aço e conectores metálicos.

4. Verificar a possibilidade de melhoria da ancoragem e dos mecanismos de transferência de esforços entre o substrato e a região recuperada. Estas análises devem ser feitas observando o comportamento dos conectores metálicos soldados nas chapas de aço e a eficiência da argamassa de alto desempenho que envolve a armadura convencional adicionada ao banzo tracionado.

\subsection{Apresentação do Trabalho}

Além desse primeiro capítulo referente à Introdução, o trabalho aqui apresentado divide-se em seis capítulos, mais as referências bibliográficas e dois apêndices.

O Capítulo 2 contém uma revisão bibliográfica sobre a reabilitação de estruturas de concreto em geral. Nesse capítulo descreve-se as principais propriedades dos materiais utilizados na moldagem e reabilitação de peças de concreto, as técnicas mais comuns de recuperação de estruturas e mecanismos de transferência de esforços, os ensaios mais utilizados para avaliar a aderência entre o substrato e o reparo e os principais mecanismos de ruína em vigas.

No Capítulo 3 faz-se uma breve discussão sobre o estado da arte e reúnem-se alguns resultados de ensaios de vigas reabilitadas, estudadas por outros pesquisadores. Estes resultados são importantes, pois permitem a comparação entre o 
comportamento das vigas reabilitadas por REIS (1998) com os dados disponíveis na literatura. Apesar dessas vigas apresentarem características diferentes (dimensões, taxa de armadura, forma de aplicação do carregamento, etc.) entre si, é possível obter conclusões relevantes, uma vez que o comportamento geral deve ser semelhante.

No Capítulo 4 descreve-se o estudo experimental em que se avalia duas técnicas de reforço à flexão em vigas de seção T. Foram realizadas três séries de ensaio com duas vigas cada (uma para cada tipo de reforço estudado) e mais uma viga monolítica. A primeira técnica de reabilitação consiste em reforçar a viga aumentando o número de barras tracionadas no bordo inferior da peça, envolvendo-as com argamassa de alto desempenho. O segundo tipo de reabilitação consiste no reforço por chapas de aço fixadas no bordo tracionado da viga através de conectores de aço e argamassa de alto desempenho. No total foram ensaiadas sete vigas de seção $\mathrm{T}$, biapoiadas e reabilitadas à flexão com o objetivo de obter resultados próprios, indicando o grau de eficiência dessas técnicas em particular. Para verificar essa eficiência, analisaram-se vigas reabilitadas antes de se aplicar qualquer tipo de carregamento e vigas reforçadas já pré-fissuradas. Em relação à forma de realização da intervenção, utilizaram-se dois tipos distintos de conectores de aço para o reforço com chapas de aço e verificou-se a interferência das fibras de aço na argamassa de alto desempenho para o reforço por adição de armadura convencional.

No Capítulo 5 estão as análises dos resultados do programa experimental desenvolvido e algumas comparações com os resultados experimentais encontrados na literatura.

As conclusões e temas propostos para trabalhos de pesquisa futuros estão no Capítulo 6.

No Apêndice I está detalhada a análise teórica efetuada para prever o comportamento das vigas ensaiadas e no Apêndice II estão apresentados todos os dados dos ensaios coletados pelo Sistema de Aquisição de Dados. 


\section{REABILITAÇÃO DE ESTRUTURAS DE CONCRETO}

\subsection{Considerações Gerais}

Apesar do concreto ser considerado um material de grande durabilidade, desde que receba manutenção sistemática e programada, existem vários tipos de manifestações patológicas que podem danificar as edificações. Estes problemas patológicos, salvo raras exceções, apresentam manifestações externas peculiares, as quais permitem deduzir a natureza, a origem e os mecanismos dos fenômenos envolvidos, além de possibilitar a previsão de suas prováveis conseqüências.

Segundo HELENE (1992), os sintomas patológicos de maior incidência nas estruturas de concreto são as fissuras, as eflorescências, as flechas excessivas, as manchas no concreto aparente, a corrosão de armaduras e os ninhos de concretagem gerados pela segregação dos materiais constituintes do concreto. Para identificar em qual fase do processo de construção ocorre o maior índice de problemas patológicos, divide-se o processo de construção em cinco etapas, a saber: planejamento, projeto, fabricação de materiais e componentes fora do canteiro, execução propriamente dita e uso. Os problemas provenientes de qualquer uma dessas etapas são responsáveis pela alteração das condições normais de uso da estrutura, surgindo então a necessidade de se realizar intervenções.

Estudos realizados na Europa indicaram que a maioria das manifestações patológicas tem origem nas etapas de concepção do projeto, gerando falhas geralmente mais graves do que aquelas provenientes da má qualidade dos materiais ou da má execução. CARMONA FILHO, citado por SOUZA (1991), realizou um estudo semelhante no Brasil, no final da década de 80, e constatou que em nosso 
país, a etapa de execução é responsável pelas principais causas das anomalias existentes nas edificações.

Como exemplos de falhas de concepção, execução e utilização pode-se citar o uso de modelos de análise inadequados, hipóteses de cálculo incorretas, detalhamento de armadura inadequado, desconsideração de ações relevantes, subquantificação das ações na estrutura, má especificação dos materiais a serem empregados, deficiência no controle de qualidade dos materiais e da execução, manutenção inadequada entre outros (MORAIS, 1997).

A Figura 2.1 indica a proporção dos problemas patológicos durante o processo de construção, conforme estudos realizados na Espanha e no Brasil.

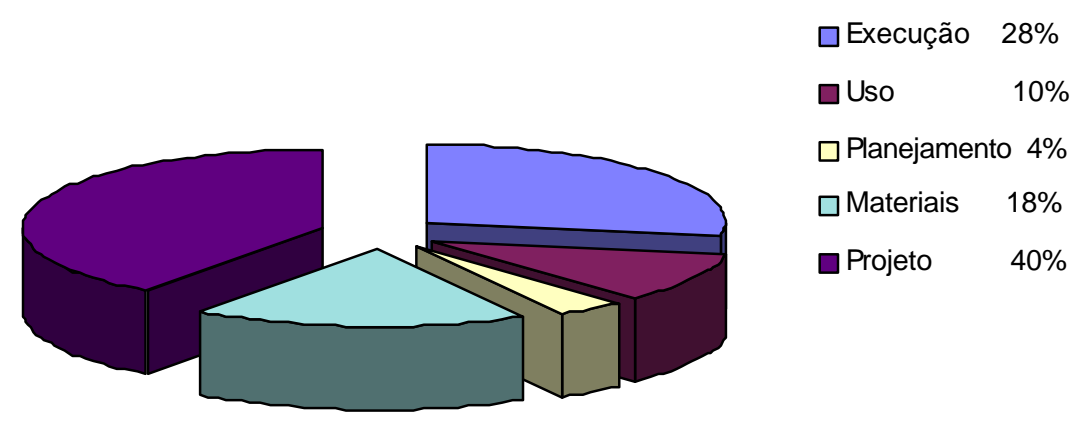

(a) Espanha (HELENE, 1992)
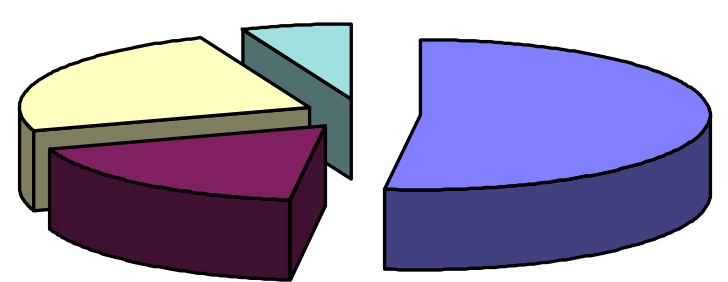

口execução $52 \%$

$\square$ projeto $18 \%$

$\square$ uso $24 \%$

$\square$ materiais $6 \%$

(b) Brasil (SOUZA, 1991)

Figura 2.1 - Origem dos problemas patológicos 
Para entender melhor alguns conceitos utilizados na área de Patologia $e$ Terapia de Estruturas e o tipo de intervenção a que a estrutura está sendo submetida, apresentam-se as seguintes definições:

- Durabilidade é a aptidão de uma construção em desempenhar as funções para as quais foi concebida durante um determinado período de tempo, sem que sejam necessários gastos imprevistos para manutenção e reparo.

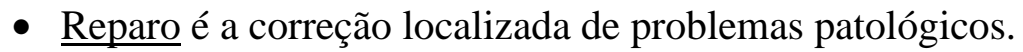

- Reforço é a correção de problemas patológicos com aumento da resistência ou ampliação da capacidade portante da estrutura.

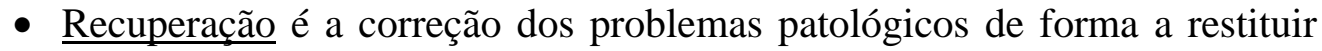
total ou parcialmente o desempenho original da peça.

- Reabilitação ou intervenção abrange as situações em geral, envolvendo tanto o reparo simples como a recuperação e o reforço. Sendo assim, pode ser definida como sendo a ação necessária para habilitar a estrutura a cumprir novamente suas funções originais ou habilitar a estrutura a responder as novas condições de uso.

Para tratar os problemas patológicos de uma estrutura, é necessário conhecer os mecanismos que os provocaram para aplicar uma terapêutica adequada. Sendo assim, deve ser feito um diagnóstico definindo as causas, as consequiências e as possíveis formas de solucionar o problema. Portanto, ao se confrontar com danos na estrutura de concreto, deve-se realizar os seguintes procedimentos:

1. caracterizar os defeitos quanto ao tipo, extensão, localização e intensidade;

2. conhecer as causas procurando determinar os agentes agressores, seja pela observação visual, por contatos com o pessoal envolvido, por ensaios tecnológicos ou outros meios;

3. analisar o problema tanto do ponto de vista estrutural (estabilidade e segurança) quanto de durabilidade; 
4. definir o tipo de reabilitação a ser aplicado, indicando os passos necessários para sua realização e garantindo a estabilidade, segurança e durabilidade desejáveis para a estrutura;

5. realizar uma inspeção final para avaliar os resultados do tratamento aplicado, verificando a qualidade dos serviços.

A Figura 2.2 apresenta um esquema resumido das etapas de um processo de reabilitação. De acordo com essa figura, após a adoção das primeiras medidas, devese fazer uma inspeção cuidadosa, observando tanto os elementos danificados quanto os íntegros e, dependendo da necessidade, podem ser realizadas provas de carga para avaliar as características residuais da estrutura e as causas da degradação. Percebe-se que o levantamento de dados visa obter o maior número possível de informações sobre a obra e que, somente de posse de todas essas informações, parte-se para a especificação e o dimensionamento do tipo de reforço/reparo mais adequado para a estrutura danificada.

De acordo com SOUZA (1990), a análise e a interpretação de todos os resultados obtidos durante o levantamento de dados e a avaliação do comportamento da peça estrutural possibilitam classificar as estruturas danificadas em:

- aceitáveis;

- toleráveis ou aceitáveis sob certas condições;

- não aceitáveis, necessitando de algum tipo de intervenção;

- não reparáveis, devendo ser demolidas. 


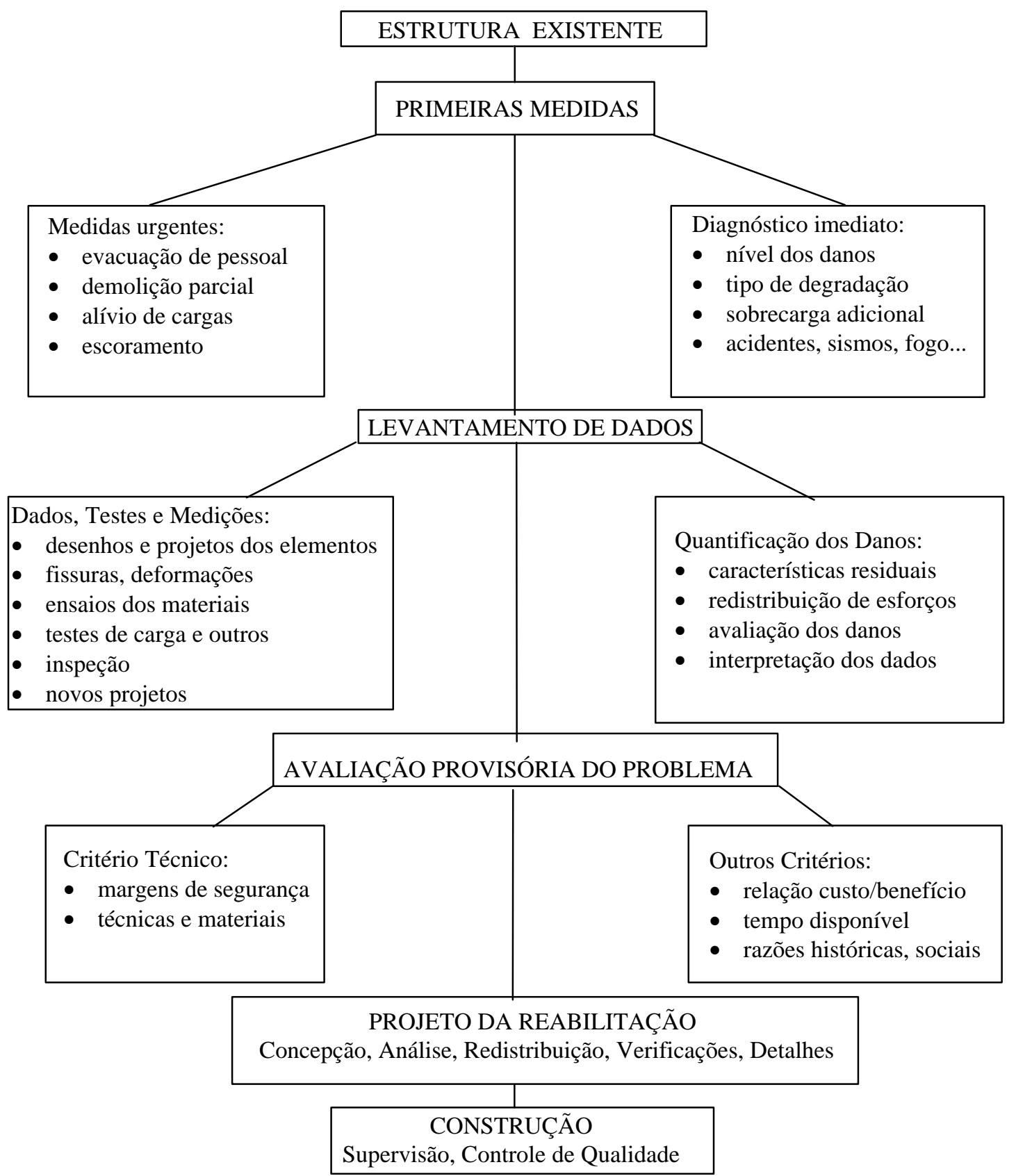

Figura 2.2 - Etapas do processo de reforço e/ou reparo (SOUZA, 1990)

Dessa forma, existe a necessidade de estabelecer um nível mínimo de aceitação dos elementos estruturais. Se a estrutura não estiver aceitável, necessitando ser reforçada ou reparada, deve-se adotar algumas medidas específicas como:

1. restringir a utilização alterando o seu uso ou diminuindo a sobrecarga;

2. reduzir a vida útil requerida e indicar o controle periódico de um perito; 
3. modificar o sistema estrutural e/ou redistribuir os esforços;

4. demolir pisos mais altos ou partes das construções;

5. restaurar apoios ou a capacidade resistente de elementos danificados;

6. substituir elementos fortemente danificados;

7. reforçar a estrutura por adição de novos elementos ou reforço dos elementos existentes.

\subsection{Propriedades dos Materiais}

Antes de realizar qualquer tipo de intervenção em uma estrutura, é necessário conhecer bem os materiais que a constituem, bem como os que serão utilizados para reabilitar a peça estrutural.

\subsubsection{Concreto}

O concreto é um material de construção que possui inúmeras qualidades que têm justificado sua larga aplicação em estruturas em todos os campos da Construção Civil. Todavia, ao mesmo tempo, é um material de estrutura interna e propriedades muito complexas, o que dificulta a previsão do seu comportamento imediato e ao longo do tempo, e conseqüentemente, a avaliação da confiabilidade das estruturas quanto à resistência e à durabilidade.

No caso particular de reabilitação de estruturas de concreto, a ação que se venha a programar para corrigir uma manifestação patológica torna-se ainda mais complexa, pois além de se partir de uma origem problemática, outros materiais estão sendo adicionados.

\subsubsection{Propriedades}

Todas as propriedades do concreto, tanto aquele da estrutura original como o do reparo ou reforço, devem ser, na medida do possível, criteriosamente analisadas, especialmente aquelas relacionadas com a resistência, a deformabilidade e a aderência. Lembra-se que as pesquisas mais recentes avançaram significativamente no conhecimento da microestrutura do material e que os fenômenos físico-químicos 
da estrutura do cimento estão sendo cada vez melhor desvendados. Apesar disso, percebe-se ainda certa dificuldade no que se refere a relacionar consistentemente um conjunto de variáveis relativas à estrutura e propriedades do concreto, capaz de definir com precisão os principais parâmetros a serem abordados.

Sabe-se, no entanto, que além das propriedades de resistência mecânica e da durabilidade, é de grande importância o estudo das propriedades de deformação dos diferentes concretos introduzidos no processo de reabilitação.

A deformabilidade engloba o estudo das deformações intrínsecas tais como a retração, as variações de volume causadas pela variação da umidade e da temperatura e as deformações provocadas por ações externas (deformação imediata e fluência). A deformabilidade do concreto depende dos valores do módulo de deformação longitudinal, do coeficiente de dilatação térmica, do coeficiente de Poisson, de complexas relações entre as propriedades dos materiais constituintes, da estrutura interna do concreto, e ainda da sua interação com o meio ambiente.

A Figura 2.3 ilustra o desenvolvimento da retração e da expansão no concreto em função da idade. A retração corresponde à redução de volume que ocorre no concreto mesmo na ausência de tensões mecânicas e de variações de temperatura. No caso de peça submersa, ocorre o fenômeno inverso denominado de expansão.

A fluência corresponde a um aumento de deformação com o tempo, para um carregamento constante. A Figura 2.4 ilustra as deformações recuperáveis $\left(\varepsilon_{\mathrm{e}}+\varepsilon_{\mathrm{d}}\right) \mathrm{e}$ residuais $\left(\varepsilon_{\mathrm{f}}\right)$ que existem em uma estrutura de concreto quando se retira uma tensão mantida constante durante determinado período de tempo. O conhecimento desse fenômeno é importante já que, geralmente, é necessário aliviar o carregamento da estrutura durante a realização de uma intervenção.

Durante um processo de reabilitação, o conhecimento dessas propriedades é extremamente importante, pois deformações diferenciais entre o concreto do reparo e o substrato podem gerar tensões consideráveis na interface de ligação. Isto ocorre porque, na estrutura a ser recuperada, essas variações de volume e deformações já ocorreram quase totalmente, enquanto que no material de reparo esses fenômenos ainda irão se processar, interferindo na redistribuição de tensões. 


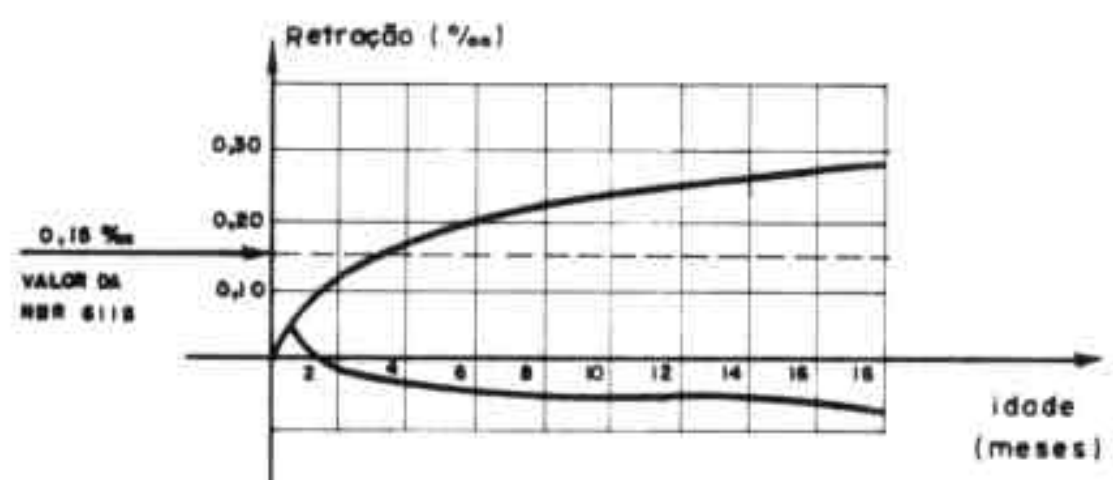

Figura 2.3 - Progresso da retração e da expansão em função da idade (PINHEIRO e GIONGO, 1986)

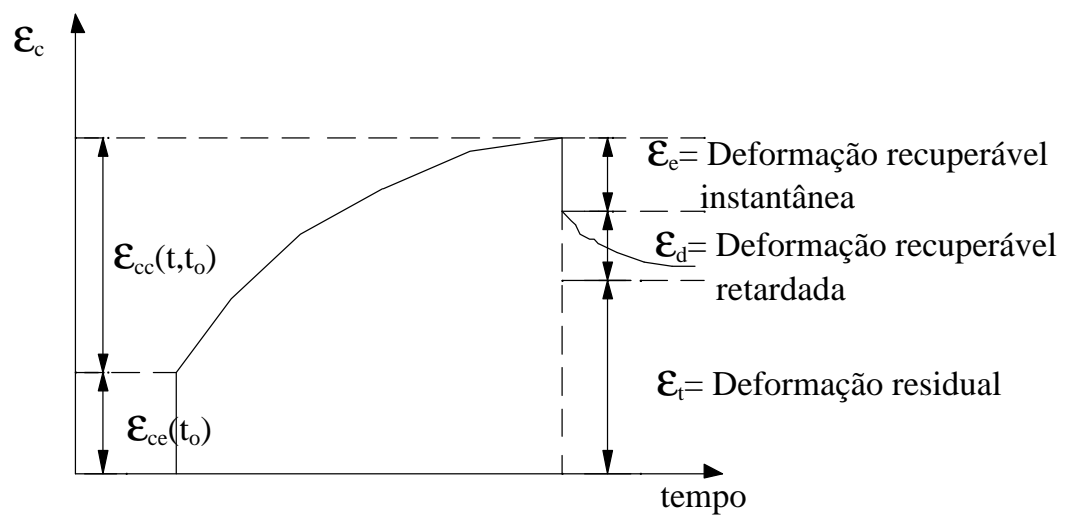

\section{Figura 2.4 - Evolução da deformação imediata e da fluência ao longo do tempo - deformações recuperáveis e residuais (PINHEIRO e GIONGO, 1986)}

De acordo com ROCHA (1995), umas das principais causas do descolamento do material de recuperação da superfície original deve-se à retração diferencial, e não à incapacidade de aderência do novo material ao substrato. A Figura 2.5 ilustra a distribuição de tensões em torno de uma área reabilitada usando materiais com módulos de elasticidade diferentes. Nesse caso, ocorreu uma perda de aderência na junta devido aos efeitos de retração, fazendo com que o material do reforço recebesse pouca ou nenhuma carga, gerando sobrecargas no substrato e prejudicando ainda mais a estrutura que necessitava ser reabilitada.

Mesmo quando a aderência entre o reparo e o substrato é adequada, diferenças no módulo de elasticidade desses materiais também influenciam na distribuição das tensões na seção transversal do elemento estrutural, podendo 
conduzir a consideráveis concentrações de tensões. O trabalho de PEREIRA (1997) aborda mais detalhadamente os efeitos causados pelo uso de materiais com diferentes módulos de elasticidade em reabilitação de estruturas.

Observando a Figura 2.6 constata-se que, dependendo da posição da junta em relação ao carregamento aplicado, é possível ocorrer a ruptura tanto no material de menor módulo quanto no de maior módulo. Tendo em vista esse comportamento, pode-se dizer que o valor do módulo de elasticidade do material de reparo deve ser similar ao do concreto da estrutura original (substrato), de modo a minimizar as tensões originadas por fenômenos diferenciais.

O valor do módulo de elasticidade pode ser calculado a partir do gráfico tensão x deformação do concreto. $\mathrm{O}$ módulo tangente inicial, $\mathrm{E}_{\mathrm{co}}$, é calculado na origem e o módulo secante, $\mathrm{E}_{\mathrm{c}}$, é determinado pela tangente de um segmento de reta que vai desde a origem até o ponto correspondente a uma fração previamente convencionada da resistência última ${ }^{*}$. Para o dimensionamento de seções transversais de concreto armado, a NBR 6118 permite o uso de um diagrama tensão x deformação simplificado (ver Figura 2.7), composto por uma parábola do $2^{\circ}$ grau, que passa pela origem e tem seu vértice no ponto de abcissa $2 \%$ e ordenada $0,85 \mathrm{f}_{\mathrm{cd}}$, e por um segmento de reta paralelo ao eixo das deformações, que segue até a deformação de 3,5\%o. A equação da parábola é calculada pela fórmula 2.1 .

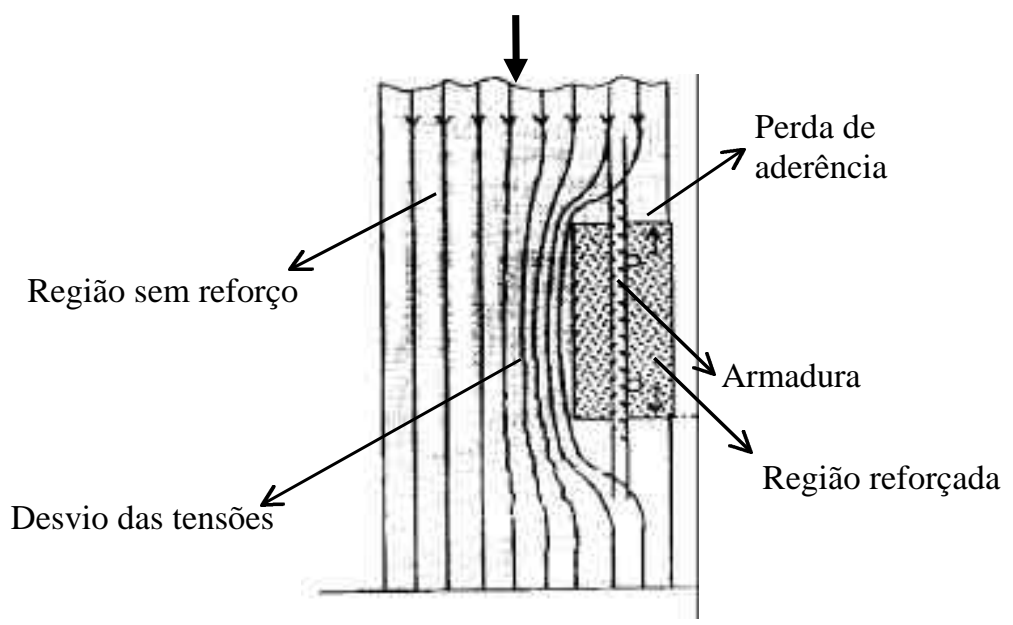

Figura 2.5 - Desvio de tensões em uma peça reforçada (ROCHA, 1997)

\footnotetext{
* Nesse trabalho adotou-se na determinação do módulo de elasticidade secante, um valor de carga correspondente a $40 \%$ da resistência última do elemento $\mathrm{f}_{\mathrm{cu}}$.
} 


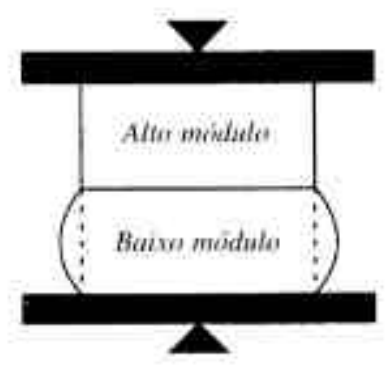

(a) carregamento perpendicular à junta

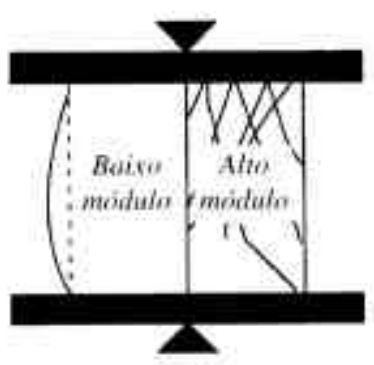

(b) carregamento na direção da junta

Figura 2.6 - Deformações de peça composta por materiais com módulos de elasticidade diferentes (ROCHA, 1997)

$$
\sigma_{\mathrm{c}}=\left(0,85 \cdot \mathrm{f}_{\mathrm{cd}}\right)\left[1-\left(1-\frac{\varepsilon_{\mathrm{c}}}{0,002}\right)^{2}\right]
$$

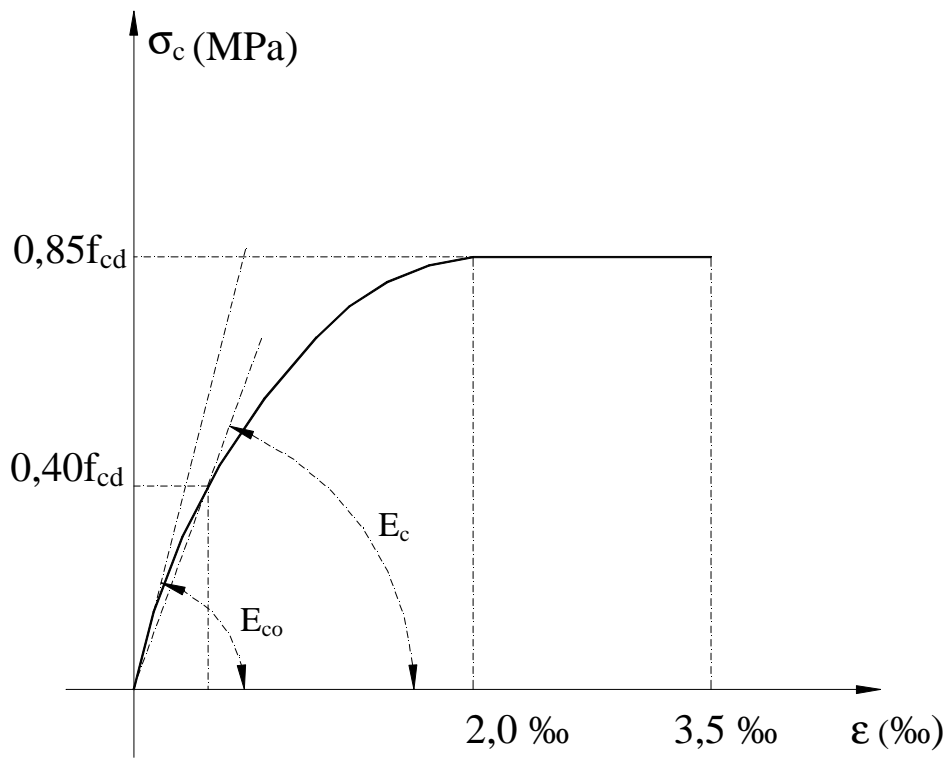

Figura 2.7 - Diagrama tensão-deformação do concreto 


\subsubsection{Concreto reforçado com fibras}

Quando se faz a opção por recuperar uma estrutura de concreto, deve-se procurar empregar técnicas e materiais que proporcionem as propriedades mecânicas desejadas e o maior período de vida útil possível. Por esse motivo, o uso do concreto reforçado com fibras (CRF) tem se mostrado uma alternativa interessante, pois sua adição no concreto comum melhora algumas das propriedades desse material tais como: a tenacidade, a retenção à propagação de fissuras e acréscimo da resistência à tração. Isto ocorre tanto para solicitações estáticas como para solicitações dinâmicas, conferindo ao reparo maior ductilidade e uma maior durabilidade, pois dificulta a penetração de água e agentes agressivos dissolvidos. Além disso, o CRF apresenta propriedades mecânicas (resistência à compressão e resistência à tração) similares ao concreto convencional, tornando esse compósito compatível para ser usado como material de reparo/reforço. De acordo com NUNES et al. (1997), mesmo que a adição de fibras possa gerar acréscimos nos custos unitários iniciais do material de reparo/recuperação, as suas potencialidades de desempenho e durabilidade podem compensar esses custos, gerando uma economia de recursos globais.

As alterações geradas pela incorporação de fibras curtas no comportamento do concreto dependem da quantidade de fibras adicionadas à matriz. Para volumes reduzidos, ou seja, até $2 \%$, ressalta-se que a resistência à tração do concreto praticamente não se altera. Entretanto, ocorrem melhoras significativas em relação à ductilidade e ao controle da fissuração.

Segundo FURLAN (1995), a influência das fibras na resistência ao cisalhamento deve-se a dois fatores: atuação direta junto às fissuras inclinadas (processo semelhante ao comportamento dos estribos) e contribuição indireta na transferência de forças transversais pois aumenta a parcela de resistência do concreto decorrente dos mecanismos alternativos de resistência tais como efeito de pino da armadura longitudinal e atrito nas fissuras. Entretanto, as fibras, por serem descontínuas, são menos eficientes que as armaduras transversais convencionais quando se trata de resistir aos esforços de tração e cisalhamento. Porém, são mais eficientes no controle da fissuração em função do espaçamento reduzido entre elas, permitindo que atuem como ponte de transferência de forças através das fissuras e, 
conseqüentemente, preservando uma certa capacidade portante na seção, conforme ilustra a Figura 2.8.

Ao interceptar as microfissuras que surgem durante a cura da pasta de cimento, as fibras impedem sua progressão e evitam o aparecimento prematuro de macrofissuras. Sendo assim, durante a retração, as fibras proporcionam ainda uma diminuição das deformações (quando livres) ou alteração da fissuração (quando há alguma restrição à deformação). Quando a pasta já está endurecida, as fibras também limitam a abertura e o comprimento das fissuras melhorando, portanto, as condições de permeabilidade do concreto e conseqüentemente a durabilidade da peça.

A quantidade máxima de fibras que pode ser adicionada ao concreto é influenciada pela dimensão máxima dos agregados, os quais podem dificultar a distribuição uniforme das fibras. O ACI-544, apesar de limitar essa dimensão em 19 $\mathrm{mm}$, recomenda utilizar valores próximos de $10 \mathrm{~mm}$. Outro problema comum às fibras é a tendência de inibir a fluidez do concreto, embora esse problema possa ser minimizado pela dosagem adequada e pela vibração da peça.

Existem diversos tipos de fibras que podem ser incorporados a uma matriz de cimento, tais como: fibras de aço, de polipropileno, de vidro, vegetais e outras. No caso das fibras de aço, existem diferentes geometrias: forma reta e lisa, com ganchos nas extremidades e fibras onduladas ou retorcidas, entre outras. No decorrer desse trabalho, foram utilizadas fibras curtas de aço com ganchos nas extremidades, especialmente para melhorar o desempenho da ligação entre o substrato e o reforço na resistência aos esforços tangenciais.

A melhoria no desempenho de elementos de concreto submetidos a solicitações tangenciais com a introdução das fibras tem sido registrada por diversos pesquisadores, devido ao aumento da capacidade resistente e, eventualmente, pela alteração da forma de ruptura. É praticamente consensual a possibilidade de substituir parcialmente os estribos por um volume conveniente de fibras. De acordo com o trabalho de FURLAN JR. (1995), é possível substituir os estribos por fibras de aço curtas desde que em quantidades compatíveis. Isto é vantajoso pois permite obter: resistência igual em todas as direções; maior resistência à fissuração e redução na propagação das fissuras; manutenção da integridade da peça na ruptura e maior 
facilidade na moldagem das peças, possibilitando reduzir a taxa de armadura uma vez que evita o uso de armaduras muito densas. A limitação das fissuras e dos deslocamentos são particularmente importantes nos estados de utilização, pois melhoram a proteção da armadura e a transferência da força cortante pelos mecanismos de pino e de atrito, vantagens estas que podem trazer benefícios para os casos de reabilitação de estruturas.

SEM FIBRAS:

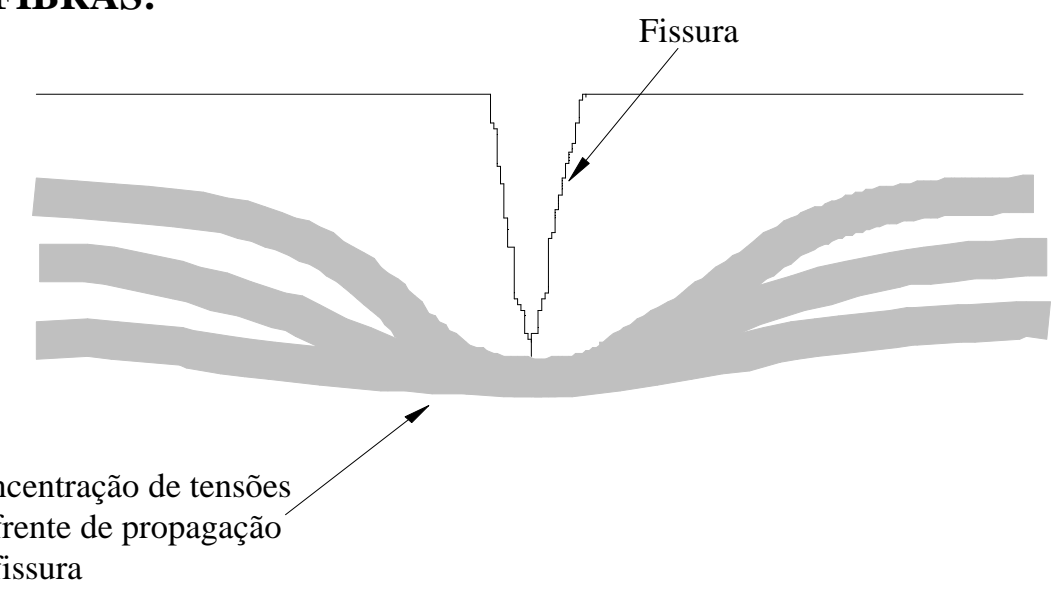

COM FIBRAS:

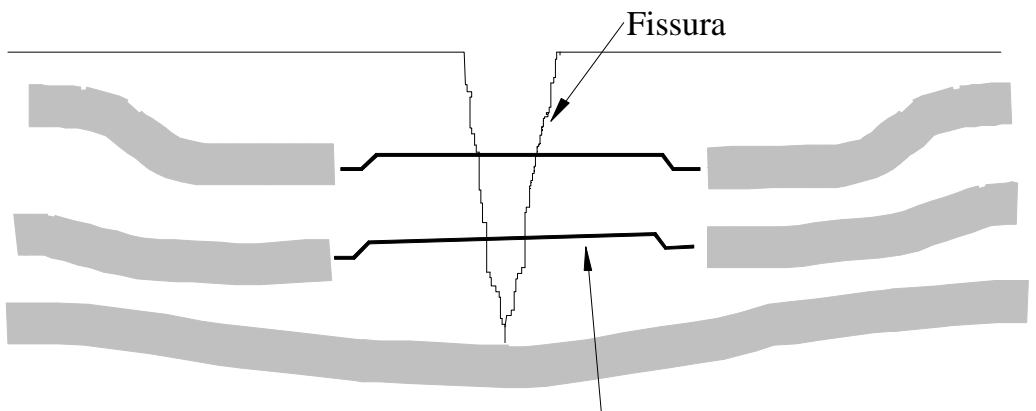

Fibra atuando como ponte de transferência de tensões

Figura 2.8- Mecanismo do controle de fissuração das fibras de aço (NUNES et al., 1997)

As fibras influem ainda nas deformações da armadura longitudinal e do concreto nessa região. A capacidade de deformação desses materiais aumenta, mas as deformações diminuem para um mesmo nível de tensão. No caso da armadura, isso 
se deve à preservação da aderência. Além disso, as fibras podem retardar o aparecimento da primeira fissura visível, que ocorre sob maior deformação no concreto, e controlam o seu desenvolvimento. Por isso os deslocamentos verticais sob os pontos de aplicação do carregamento diminuem quase linearmente com o aumento na quantidade de fibras adicionados ao concreto.

\subsubsection{Concreto de alto desempenho}

Nos últimos anos, os avanços tecnológicos dos materiais tornaram viáveis a produção de concreto com elevada resistência à compressão, baixíssima permeabilidade, alta resistência química, aumento da resistência à abrasão e erosão e redução da segregação além de outras melhorias em suas propriedades. Este material, denominado de Concreto de Alto Desempenho (CAD), é obtido a partir da mistura do cimento com aditivos superplastificantes associados a pozolanas como a sílica ativa, cinzas volantes, escória de alto forno e outras.

De acordo com MEHTA (1994), estudos experimentais mostram que, em muitos aspectos, a microestrutura e as propriedades do concreto de alto desempenho (segundo MEHTA - concreto com resistência à compressão maior que $40 \mathrm{MPa}$ ) são consideravelmente diferentes das do concreto convencional. Portanto, o projetista deve estar sempre alerta quando se trabalha com esse tipo de material.

A sílica ativa é um pó extremamente fino, com grãos de forma esférica que preenche os vazios da matriz do cimento hidratado, aumentando a densidade do concreto. Durante o processo de hidratação do cimento, a sílica ativa, em se tratando de uma pozolana altamente reativa, combina facilmente com o hidróxido de cálcio, um produto resultante da hidratação do cimento, alterando a microestrutura e a morfologia da zona de transição na interface matriz-agregado, reagindo e formando cristais de silicato de cálcio hidratado. Este subproduto é mais fino que os cristais dos grãos de cimento e se constitui no principal elemento responsável pelo aumento da resistência do concreto. Através dessa reação com a sílica ativa, obtém-se uma matriz muito densa que vincula fortemente as partículas dos agregados e preenche os espaços entre elas, com isso, tem-se um material resultante muito resistente e relativamente homogêneo. 
O uso da sílica ativa interfere diretamente na durabilidade do concreto, reduzindo a exsudação no concreto fresco e tornando o concreto endurecido mais impermeável a ataques químicos. No caso de recuperações de estruturas que usam concretos, argamassas ou pastas com porções de sílica ativa como material de reparo, percebe-se também um aumento significativo na aderência desses materiais ao substrato (concreto existente).

As principais características que podem ser exploradas com o uso do concreto de alto desempenho em recuperações são:

- excelente aderência ao substrato e ao aço;

- baixa permeabilidade;

- exsudação praticamente nula;

- grande coesão proporcionando menor problemas de segregação;

- alta resistividade elétrica;

- alta resistência mecânica à baixa idade;

- alta resistência ao ataque de cloretos e sulfatos;

- alta resistência à abrasão.

Segundo AMARAL FILHO, apud PEREIRA (1997), o uso de concreto de alto desempenho está tornando obsoleto o uso de reparos feitos a base de resina epóxi, pois sobre a superfície do substrato limpa, rugosa e úmida, consegue-se uma aderência de até $100 \%$.

Como pode-se perceber, o uso do concreto de alto desempenho não está limitado apenas a construções novas. Pelo fato de apresentar um ótimo desempenho em condições adversas de exposição, o CAD está sendo cada vez mais recomendado para serviços de recuperação e reforços estruturais. Alguns exemplos do uso desse tipo de concreto na reabilitação de estruturas pode ser visto em recuperações de obras hidráulicas (soleiras, vertedouros, represas, bacias de dissipação, etc.) para combater a erosão causada pela movimentação da água e também em instalações portuárias e plataformas "offshore", pela excelente impermeabilidade que garante a durabilidade da recuperação, grande resistência aos ataques de sulfatos e cloretos, alta resistência 
mecânica. No exterior, o CAD tem sido usado também em recuperações de pavimentos, pontes e túneis.

\subsubsection{Aço}

Os aços encontrados no mercado são classificados segundo a forma, as dimensões da seção transversal e o processo de fabricação. A escolha do tipo de aço a ser usado é função da importância da obra e da disponibilidade de fornecimento pelo fabricante. Para aplicações estruturais, os aços devem sofrer modificações para melhorar a sua resistência e a ductilidade. Estas modificações são feitas por tratamentos a quente ou a frio. Os requisitos fundamentais a que devem obedecer os aços utilizados especificamente em concreto armado são: ductilidade e homogeneidade, elevada relação entre o limite de escoamento e a resistência a tração, soldabilidade e razoável resistência à corrosão.

O conhecimento das propriedades dos aços é importante pois o contato de metais incompatíveis pode provocar corrosão das armaduras devido à formação de pilhas galvânicas. Sendo assim, é importante saber o tipo de aço empregado na obra antes de se adicionar novas armaduras, durante o processo de reabilitação.

Os aços podem ou não apresentar um patamar de escoamento bem definido no diagrama tensão-deformação. Quando esse patamar não é facilmente identificado, a resistência ao escoamento é adotada como um valor convencional. As deformações para o trecho curvo podem ser calculadas através das equações 2.2 e 2.3 recomendadas pela NBR-6118. A Figura 2.9 ilustra as curvas tensão-deformação adotadas no dimensionamento de estruturas de concreto armado de acordo com a NBR-6118.

Região tracionada

$$
\varepsilon_{s}=\frac{\sigma_{\mathrm{s}}}{\mathrm{E}_{\mathrm{s}}}+\frac{1}{45}\left(\frac{\sigma_{\mathrm{s}}}{\mathrm{f}_{\mathrm{yd}}}-0,7\right)^{2}
$$

Região comprimida

$$
\varepsilon_{s}=\frac{\sigma_{\mathrm{s}}}{\mathrm{E}_{\mathrm{s}}}+\frac{1}{45}\left(\left|\frac{\sigma_{\mathrm{s}}}{\mathrm{f}_{\mathrm{ycd}}}\right|-0,7\right)^{2}
$$


Quando se fala de aços para construção, deve-se lembrar que, além das barras de aço convencionais utilizadas em peças de concreto armado, existem vários outros tipos de aços estruturais utilizados basicamente na forma de chapas e perfis metálicos, que são empregados em construções metálicas ou mistas. Estas estruturas devem ser dimensionadas de acordo com a norma NBR-8800/1986 ou por métodos de dimensionamento encontrados em normas estrangeiras, tais como: AISI (American Iron and Steel structural members) e CSA (Canadian Standards Association). As características físicas do aço que compõe o perfil podem ser fornecidas pelo fabricante através de certificados, ou encontradas em normas brasileiras e internacionais.

As chapas e perfis metálicos são muito utilizados na reabilitação de estruturas, principalmente em vigas e pilares deteriorados. No caso de reabilitação de vigas, geralmente se usa elementos metálicos laminados, chapas ou cantoneiras. Maiores informações sobre esse tipo de reforço/reparo podem ser encontradas em CÁNOVAS (1988).

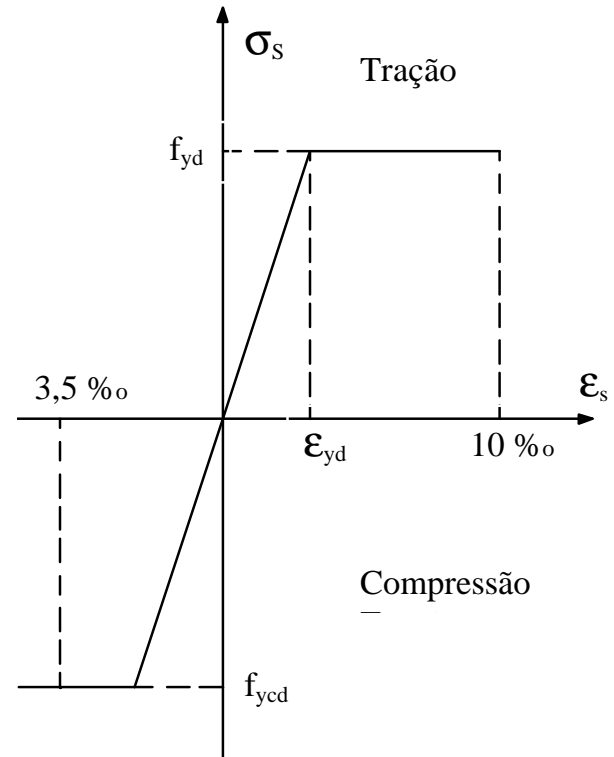

(a) Patamar de escoamento bem definido

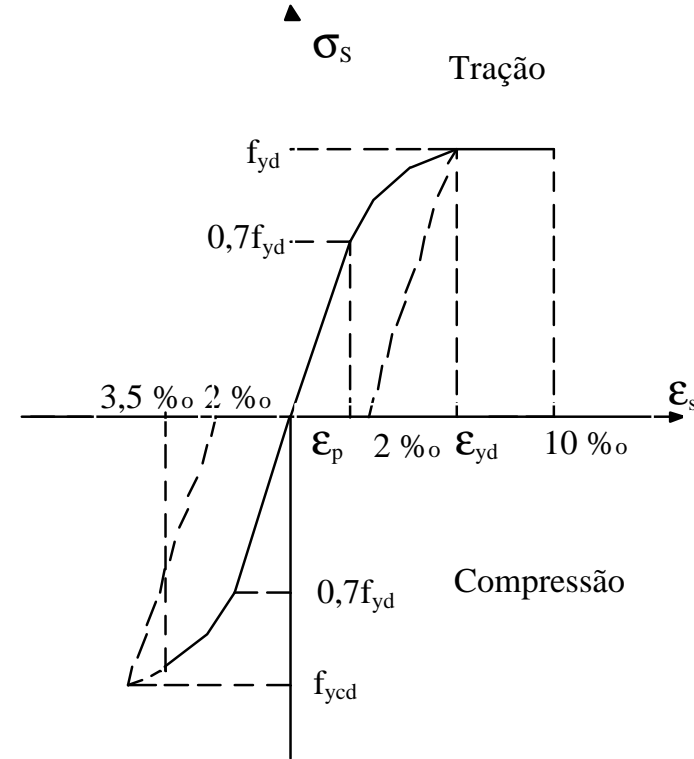

(b) Sem patamar de escoamento bem definido 


\subsubsection{Materiais para reforço e/ou reparo}

Existe um número muito grande de materiais desenvolvidos especificamente para serem utilizados em trabalhos de reabilitação de estruturas de concreto armado. Dentre eles pode-se citar os aditivos ou adições que melhoram, em vários aspectos, o desempenho do material utilizado como reparo, proporcionando melhores condições de durabilidade e resistência. Entretanto, recomenda-se fazer uma análise individual desses materiais pois, apesar de existir vasta literatura comercial a respeito desses produtos, nem sempre as informações se baseiam em pesquisas aprofundadas.

Grande parte dos fornecedores, apesar de indicarem que seus produtos possuem baixos valores de retração, não fornecem informações mais detalhadas a respeito das propriedades referentes à variação volumétrica em função do tempo. EMMONS et al., apud PEREIRA (1997) realizaram ensaios para avaliar alguns materiais de reparo, baseados nas suas características de retração, e constataram que só $15 \%$ dos 46 materiais selecionados apresentavam baixos valores de retração, apesar dos fabricantes afirmarem o contrário. O mesmo fato foi observado por CLÍMACO (1990).

Como o número de materiais disponíveis no mercado é muito grande, não se tem a pretensão, nesse item, de relacionar os inúmeros materiais disponíveis no mercado, mas apenas fornecer uma visão geral dos principais materiais utilizados, bem como as principais características que esses devem possuir para serem usados na reabilitação de peças de concreto armado.

Os materiais de reparo podem ser constituídos basicamente por ligantes hidráulicos ou por ligantes sintéticos. Dentro do grupo dos materiais com base cimentícia (ligantes hidráulicos) pode-se citar o cimento Portland comum ou de endurecimento rápido, que são os materiais tradicionalmente mais usados em trabalhos de reparos e reforços. Para melhorar o desempenho desse material pode-se incorporar na pasta de cimento alguns tipos de aditivos e/ou adições. Entre as adições minerais mais utilizadas estão as pozolanas, cinzas volantes, a escória de alto forno e a sílica ativa. Já em relação aos aditivos pode-se citar os plastificantes, 
aceleradores ou retardadores de pega, redutores de permeabilidade, expansores, inibidores da corrosão nas armaduras, etc.

Os materiais constituídos por ligantes sintéticos (polímeros) substituem parcial ou totalmente os ligantes hidráulicos (cimentos e cimentos especiais) utilizados na confecção dos concretos e argamassas. Os polímeros são produtos sintéticos que se classificam em termoplásticos ou termoendurecedores. Os termoplásticos correspondem às resinas acrílicas, acrilamidos, o estireno-butadieno (SBR), o estireno-acrílico, o acetato de polivinil e o látex. Os termoendurecedores mais usados são as resinas epóxi, poliester e poliuretano (SOUZA, 1990).

Além desses produtos existe ainda uma grande quantidade de materiais de reparo específicos para a proteção das superfícies de concreto.

Antes de escolher determinado produto de reparo, deve-se verificar a compatibilidade entre os materiais novos e o substrato. O fluxograma da Figura 2.10 indica os principais fatores a serem observados antes da escolha do material de reabilitação.

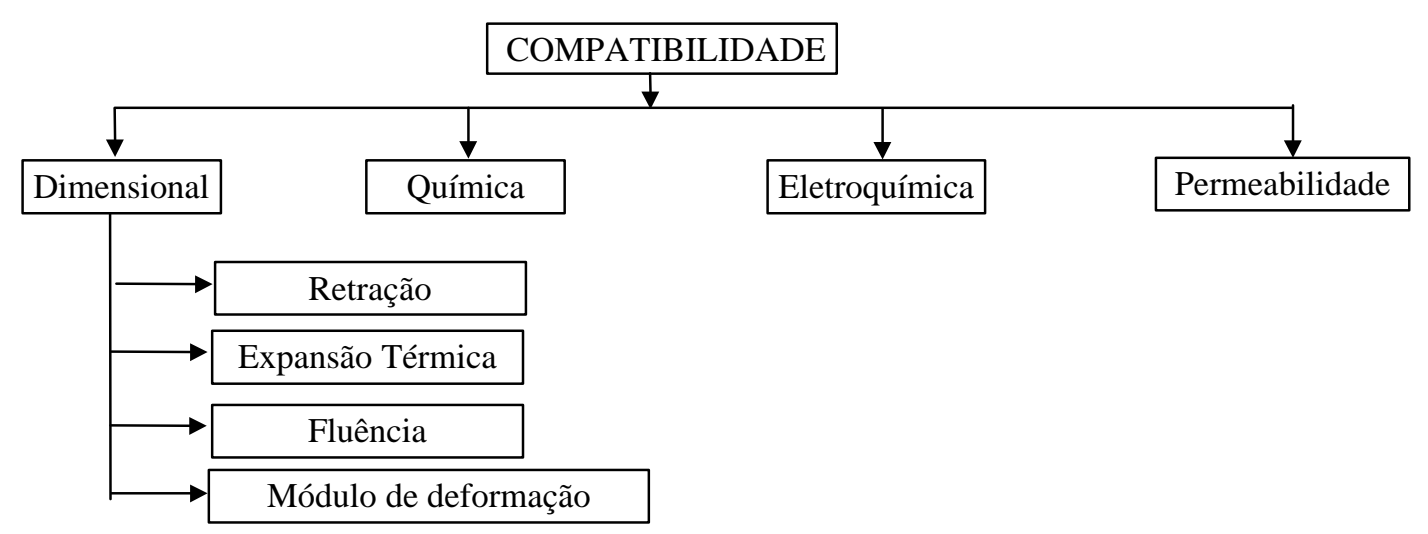

\section{Figura 2.10 - Fatores que influenciam o comportamento conjunto dos materiais (PEREIRA, 1997)}

A compatibilidade dimensional, que já foi abordada no item 2.1.1.1, representa mudanças de volume do material na cavidade do reparo independentemente da ação do carregamento. Essas variações diferenciais de volume entre o substrato e o material de reparo/reforço afetam a durabilidade da reabilitação 
e a capacidade de transmissão de esforços entre os materiais novos e antigos. Isso pode levar à incapacidade do reparo de transferir esforços, causando concentração de tensão em partes da estrutura original. Esta compatibilidade é uma das mais importantes para se garantir uma reabilitação durável e eficiente.

A análise da compatibilidade química e eletroquímica tem a finalidade de estudar a maneira como o material novo irá interagir com o substrato, armaduras, revestimentos de proteção, adesivos e primers. Por exemplo, um material de reabilitação com baixo valor de $\mathrm{pH}$ fornece pouca proteção para as armaduras. Entretanto, análises precisas dessas compatibilidades são difíceis de realizar pois o meio interior de uma estrutura como um todo está constantemente sofrendo mudanças, devido às interações do meio ambiente externo com o substrato e com o reparo simultaneamente (PEREIRA, 1997).

A compatibilidade entre a permeabilidade dos materiais novos e o substrato também interfere na durabilidade da intervenção. Quando esses materiais apresentam grandes diferenças de permeabilidade pode-se impedir a transferência de gases e água entre o substrato e o reparo. No caso de intervenção em grandes áreas, é importante considerar o problema da impermeabilidade e da não condutibilidade, pois alguns pesquisadores, como WARNER, apud PEREIRA (1997), já constataram a ocorrência de insucessos com a utilização de reparos "impermeáveis", em virtude de se impedir a transmissão de vapores no interior do concreto original. Quando o material do reparo de grandes áreas não é condutor, a corrente elétrica se concentra através do concreto remanescente numa seção menor e a taxa de corrosão poderá ser acelerada, conduzindo a falhas prematuras, conforme observado por VANDERLEI, apud PEREIRA (1997).

Segundo RIZZO e SOLBEMAN, apud PEREIRA(1997) o comportamento conjunto do materiais (compatibilidade) ainda é pouco entendido pelos engenheiros e arquitetos. Algumas vezes, verifica-se inclusive uma tendência de atender primeiro à facilidade de lançamento ou aplicação dos materiais de reparo, deixando-se para segundo plano o questionamento da durabilidade. Entretanto, deve-se ficar atento para o fato de que todas essas características devem ser criteriosamente analisadas 
durante a escolha do material de reparo, a fim de se ter uma estrutura reabilitada que apresente um comportamento mais próximo possível de uma peça monolítica.

Dentre os diversos materiais de reparo disponíveis no mercado, deve-se selecionar aquele que for mais conveniente, observando-se as seguintes características:

- durabilidade compatível com a do substrato;

- estabilidade dimensional com uma retração mínima;

- proteção das armaduras, se possível, aumentando a alcalinidade do meio que as envolve;

- baixa permeabilidade para evitar ataque de substâncias químicas agressivas;

- boa aderência com o concreto e com o aço;

- boa trabalhabilidade permitindo fácil aplicação;

- boa resistência estrutural.

De acordo com WARNER apud CLÍMACO (1990), deve-se escolher materiais de reparo que apresentem propriedades similares às do substrato. Portanto, a escolha de concreto de cimento portland ou qualquer outra composição cimentícia semelhante é geralmente a melhor escolha. Todavia, essa regra nem sempre pode ser seguida, pois deve-se levar em consideração outros fatores, tais como: dificuldades nas condições de confecção do reparo, necessidade de ganho de resistência rápido, necessidade de melhorar a resistência ao ataque químico ou obter uma superfície com tratamento estético. Sendo assim, ao escolher um material de reparo, o profissional deve considerar três fatores: condições do reparo, propriedades do material do reparo e a técnica e o equipamento necessário para fazer o trabalho.

Para realizar uma intervenção eficiente, é preciso observar ainda uma série de fatores externos que interferem no comportamento da estrutura restaurada, conforme ilustram as Figuras 2.11 e 2.12. Dentre esses fatores, pode-se citar a tipologia das ações (carregamentos, deformações impostas, forma de aplicação, combinações de ações, etc.) e o seu histórico, inclusive durante as operações de reparo, aspectos 
relativos à segurança estrutural (tipo de estrutura, coeficientes de segurança a adotar) e aspectos econômicos.

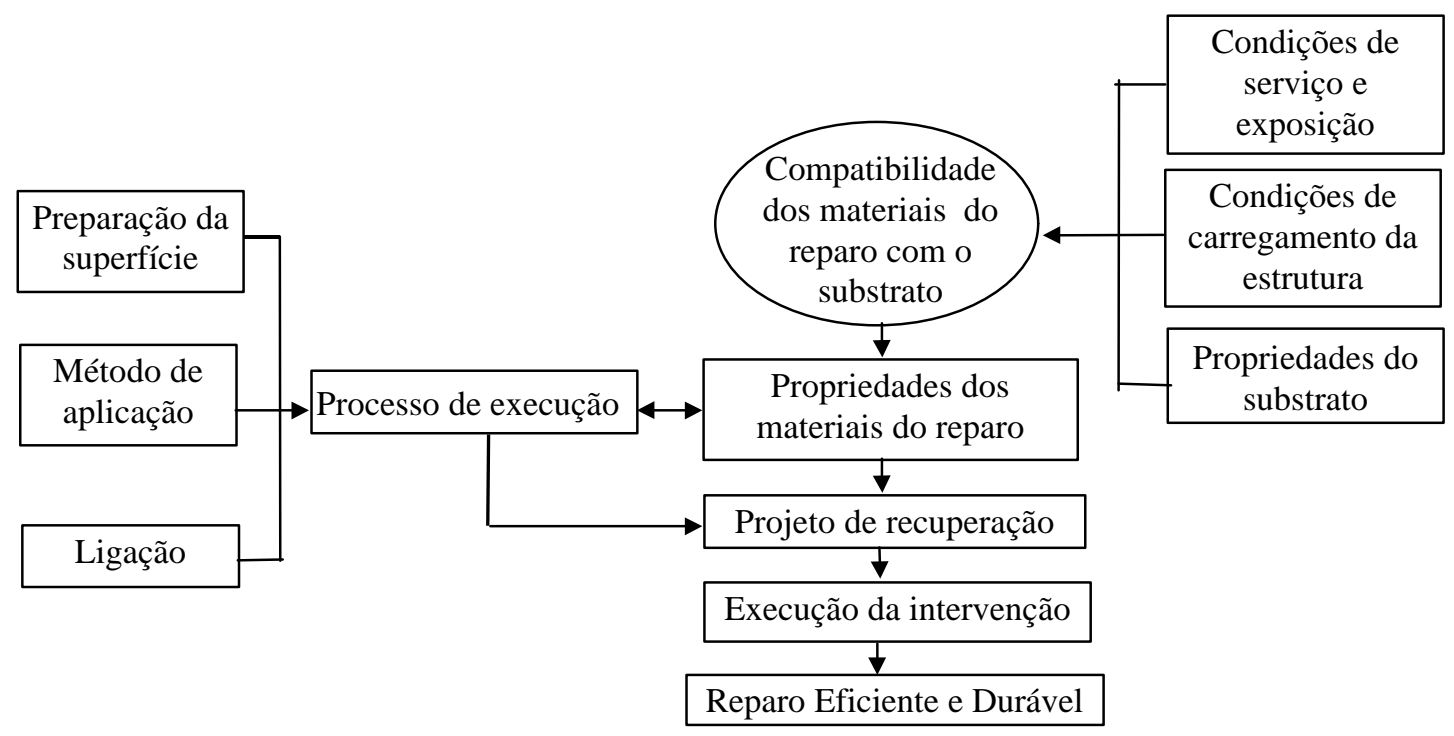

Figura 2.11 - Fatores que afetam o desempenho dos reparos

(EMMONS, apud PEREIRA, 1997)

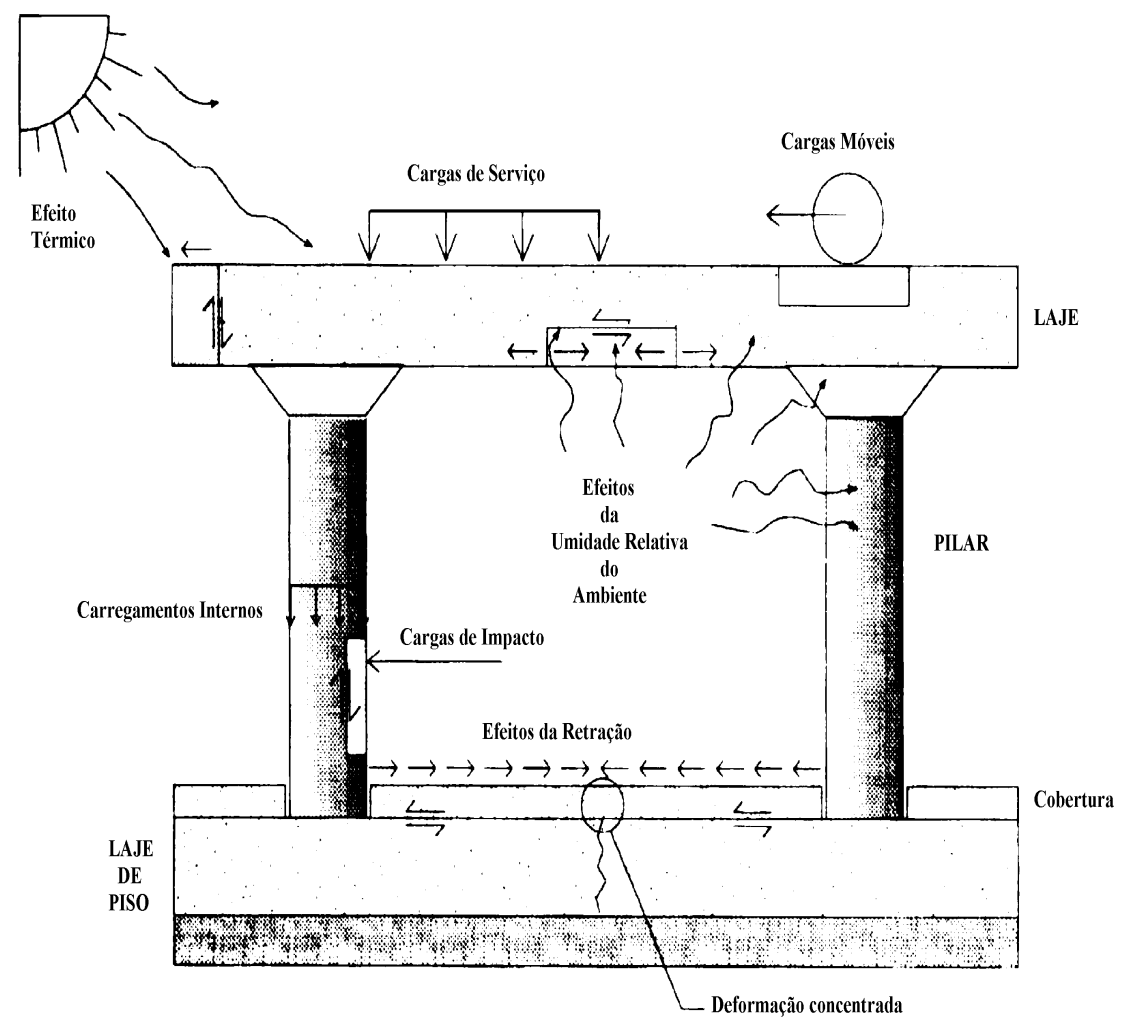

Figura 2.12 - Fatores que influenciam nas atividades de recuperação (PEREIRA, 1997) 


\subsection{Técnicas de Recuperação de Estruturas de Concreto Armado}

\subsubsection{Introdução}

Após o diagnóstico do problema na estrutura danificada, parte-se para a escolha do método de reabilitação a ser aplicado. Cabe ao projetista analisar as particularidades da estrutura que sofrerá a intervenção e, diante das várias técnicas existentes, escolher a que mais se adequa a cada situação. Dentre os inúmeros métodos utilizados para reabilitar elementos estruturais, os mais comuns são:

* reparo por injeção de resinas epóxicas;

* reparo por vedação elástica superficial;

* reforço mediante colagem de perfis metálicos;

* reforço mediante concreto projetado;

* reforço mediante encamisamento de concreto armado;

* reforço mediante colagem de chapas de aço;

* reforço mediante protensão.

Juntamente com a indicação do tipo de reparo/reforço escolhido, deve-se especificar as etapas construtivas necessárias para realizar a intervenção e descrever os dispositivos a serem empregados. Assim sendo, é importante especificar o sistema de escoramento a ser utilizado e sua distribuição, a localização de macacos hidráulicos e o instante em que devem ser acionados, o posicionamento de contraflechas, a extensão e a profundidade de corte de concreto para retirada do material danificado, o detalhe de fôrmas e armaduras, o programa de remoção de escoramento e de alívio de ação dos macacos, a distribuição de injetores e o plano de injeção de resina epóxica, a medição de deformações, etc..

O engenheiro responsável pela reabilitação deve avaliar também as influências dessas etapas construtivas na estrutura existente. Isto é feito observando o efeito do escoramento sobre a edificação, devido à introdução de apoios temporários na estrutura; deixando espaços livres para movimentar materiais; interferindo o 
mínimo possível nas instalações existentes e não danificando outros elementos sadios.

Uma etapa construtiva bastante comum em obras de reabilitação consiste no alívio do carregamento do elemento a ser reabilitado. Geralmente, os elementos da estrutura são escorados com pontaletes e erguidos através de macacos hidráulicos com a finalidade de retornar os elementos com flechas excessivas à posição original e neutralizar as solicitações provenientes do carregamento atuante. Este procedimento é feito antes de executar a reabilitação e garante que a intervenção contribua efetivamente na resistência e controle de deformações causadas pelas ações permanentes (ver Figura 2.13).

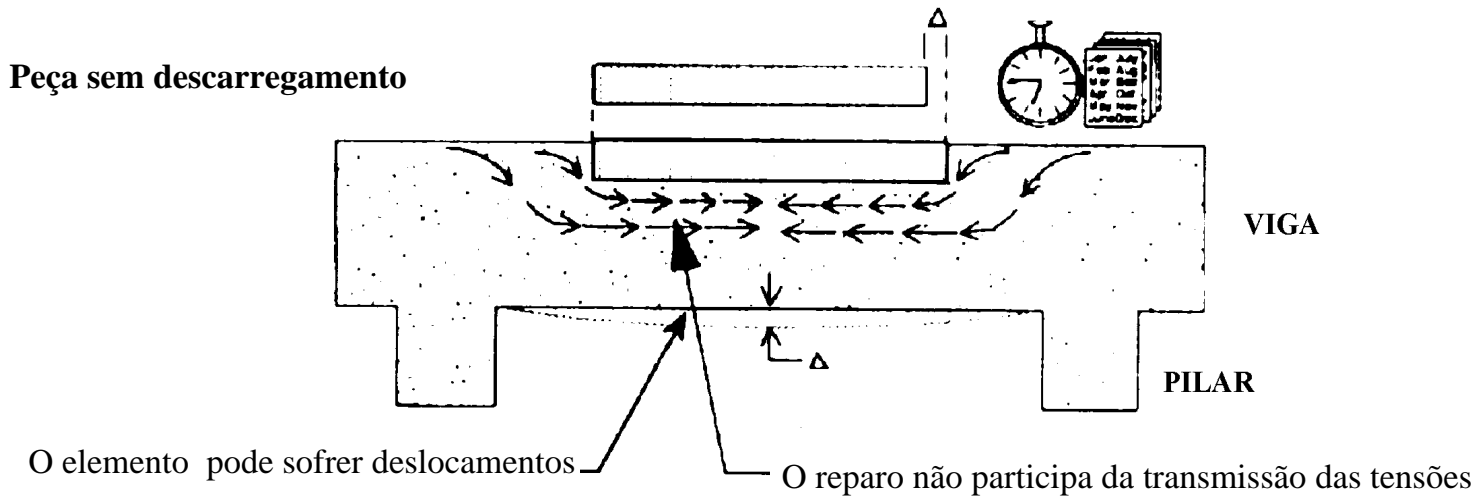

Peça com descarregamento

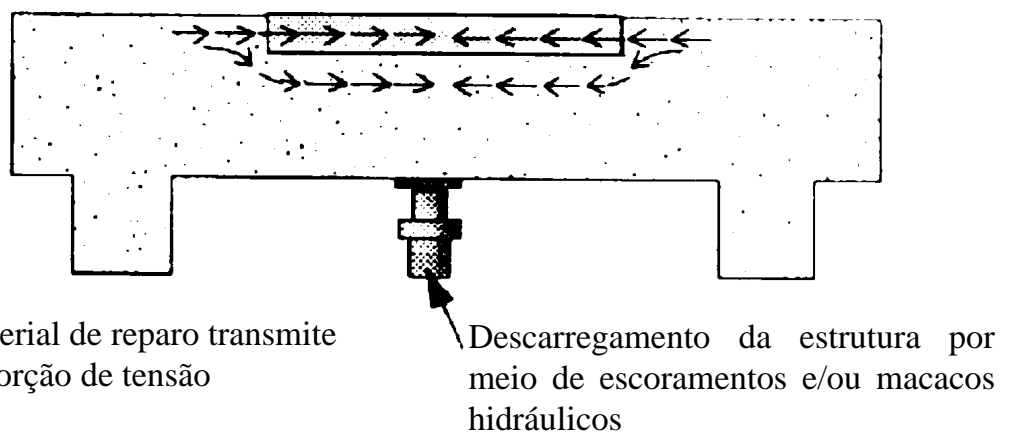

Figura 2.13 - Operações de descarregamento da estrutura

(PEREIRA, 1997) 
É importante ressaltar que a reabilitação de uma estrutura só deve ser feita após determinar, com boa margem de segurança, as causas da deterioração, pois a reparação apenas superficial das fissuras de um componente trincado, às vezes, é a parte menos importante na resolução do problema.

\subsubsection{Dimensionamento do reforço e/ou reparo}

O projeto de reabilitação de uma estrutura de concreto armado deve ser feito de forma a atender às condições de segurança em relação aos estados limites últimos e de utilização e aos critérios de durabilidade. Existe portanto, a necessidade de definir os coeficientes de segurança, as características mecânicas residuais e as hipóteses de dimensionamento mais adequadas para cada situação.

\subsubsection{Coeficientes de Segurança}

Frente a dificuldade de se elaborar regras específicas para reabilitação de estruturas, muitas das normas já estabelecidas para construções novas vêm sendo seguidas ou adaptadas para serem utilizadas no dimensionamento de determinados tipos de intervenção. Contudo, alguns coeficientes de segurança específicos devem ser aplicados a fim de considerar as incertezas em relação às informações obtidas no levantamento de dados, na consideração das características residuais e no desempenho das novas técnicas e materiais usados na reabilitação.

Apesar de ser extremamente importante, a estimativa dos valores dos coeficientes de segurança é bastante complexa, pois ainda não se dispõe de modelos consistentes de cálculo do reforço que esclareçam o comportamento dos elementos estruturais reabilitados com as diferentes técnicas e materiais. Entretanto, pode-se adotar algumas recomendações conforme indica o CEB (1983).

A regra básica para verificação da segurança em estruturas novas é dada pela expressão 2.4. Para estruturas reforçadas", o CEB (1983) recomenda o uso de coeficientes parciais específicos de segurança, obtendo-se a expressão 2.5.

\footnotetext{
*Os parâmetros seguidos de plica' referem-se à estrutura reforçada
} 


$$
\begin{aligned}
& S_{d}=S\left(s_{k} \cdot \gamma_{f}\right)<R\left(f_{k} \cdot \gamma_{m}\right)=R_{d} \\
& S^{\prime}{ }_{d}=\gamma_{S d} \cdot S\left(s^{\prime}{ }_{k} \cdot \gamma_{f_{f}}^{\prime}\right)<\frac{1}{\gamma_{R d}} \cdot R\left(\frac{f^{\prime}{ }_{k}}{\gamma^{\prime}{ }_{m}}\right)=R^{\prime}{ }_{d}
\end{aligned}
$$

onde:

$\mathrm{S}_{\mathrm{d}} \quad$ - Valor de cálculo dos esforços atuantes na estrutura original;

$\mathrm{s}_{\mathrm{k}} \quad$ - Valor característico das ações a serem consideradas no projeto;

$R_{d} \quad$ - Valor de cálculo dos esforços resistentes atuantes na estrutura;

$\mathrm{f}_{\mathrm{k}}$ - Valor característico das resistências dos materiais, consideradas na estrutura original;

$\gamma_{\mathrm{f}}, \gamma_{\mathrm{m}}$ - Coeficientes de segurança relativos às ações e às características resistentes dos materiais respectivamente;

$\gamma_{S d} \quad$ - Coeficiente parcial de segurança que considera as incertezas do modelo de análise previsto;

$\gamma_{\mathrm{Rd}}$ - Coeficiente parcial de segurança que considera as incertezas quanto ao modelo de resistência/rigidez previsto.

Os valores dos coeficientes parciais de segurança $\gamma_{S d}$ e $\gamma_{R d}$ em relação aos materiais adicionados podem ser tomados como os usuais no cálculo das estruturas novas ou serem majorados, a fim de considerar as variáveis extras do processo construtivo, as dificuldades de acesso e as limitações de inspeção e controle de qualidade. Estes coeficientes dependem também do rigor com que foram executados a inspeção e o levantamento de dados da estrutura (SOUZA, 1990). Segundo SOUZA (1990), o coeficiente $\gamma_{S d}$ pode ser estimado em:

- $\gamma_{\mathrm{Sd}}=1,1$ para esforços originados de ações normais;

- $\gamma_{\mathrm{Sd}}=1,2$ para esforços originados de ações acidentais.

No caso de danos severos, propõe-se que esses valores sejam majorados em aproximadamente $20 \%$. 
$O$ coeficiente $\gamma_{R d}$, que estima as incertezas quanto às características mecânicas da peça reabilitada, também pode ser denominado de $1 / \gamma_{\mathrm{n}}$ e será melhor detalhado no item 2.3.2.2.

Além desses coeficientes parciais de segurança, é necessário estimar os coeficientes de segurança $\gamma_{\mathrm{m}}$ para os materiais "novos" utilizados no projeto de reabilitação. O CEB (1983), baseado em estudos teóricos e experimentais, apresenta alguns valores para esses coeficientes de segurança.

Tabela 2.1 - Valores de $\gamma_{c}^{\prime} / \gamma_{c}$ para concreto moldado no local, sendo $\gamma_{c}=1,5$

\begin{tabular}{|c|c|c|c|c|}
\hline \multirow{4}{*}{$\begin{array}{c}\text { Nível } \\
\text { do controle } \\
\text { de qualidade e } \\
\text { inspeção }\end{array}$} & \multicolumn{4}{|c|}{ Espessura adicional } \\
\hline & \multicolumn{2}{|c|}{$<100 \mathrm{~mm}$} & \multicolumn{2}{|c|}{$>100 \mathrm{~mm}$} \\
\hline & \multicolumn{4}{|c|}{ Acessibilidade } \\
\hline & baixa & Normal & baixa & normal \\
\hline Alto & 1,2 & 1,1 & 1,0 & 1,0 \\
\hline Médio & 1,3 & 1,2 & 1,1 & 1,0 \\
\hline
\end{tabular}

Tabela 2.2 - Valores de $\gamma_{c}^{\prime} / \gamma_{c}$ para concreto projetado, sendo $\gamma_{c}=1,5$

\begin{tabular}{|c|c|c|}
\hline \multirow{2}{*}{$\begin{array}{c}\text { Nível do controle de } \\
\text { qualidade e inspeção }\end{array}$} & \multicolumn{2}{|c|}{ acessibilidade } \\
\cline { 2 - 3 } & Baixa & normal \\
\hline \hline Alto & 1,3 & 1,2 \\
\hline Médio & 1,4 & 1,3 \\
\hline
\end{tabular}

Tabela 2.3 - Valores de $\gamma_{\mathrm{s}} / \gamma_{\mathrm{s}}$ para aço, sendo $\gamma_{\mathrm{s}}=1,15$

\begin{tabular}{|c|c|}
\hline $\begin{array}{c}\text { Nível do controle de } \\
\text { qualidade e inspeção }\end{array}$ & $\begin{array}{c}\text { Armaduras novas } \\
\text { (previsão de solda) }\end{array}$ \\
\hline \hline Alto & 1,2 \\
\hline Médio & \\
\hline
\end{tabular}

Para definir os valores dos coeficientes de segurança $\gamma_{\mathrm{f}}$ relacionados com as ações atuantes na peça reabilitada, o CEB (1983) não recomenda especificamente nenhum valor. Esse código indica apenas que, para ações permanentes, o valor de $\gamma_{\mathrm{f}}$ pode ser menor do que os adotados para estruturas usuais, e que para ações variáveis, pode-se adotar valores maiores ou menores que os das construções correntes, dependendo da vida útil requerida para o reparo, da natureza e da freqüência dessas ações após a reabilitação. No caso, o valor de $\gamma_{\mathrm{f}}$ fica a critério de cada projetista e dependem das incertezas sobre a forma de atuação das ações e das condições em que foram feitos o levantamento de dados e a inspeção da estrutura danificada. 


\subsubsection{Características residuais}

A estimativa das características mecânicas da estrutura antes e após a reabilitação pode ser realizada por vários métodos, de acordo com a magnitude dos danos, sua concepção e importância. O conhecimento das características residuais da estrutura danificada permite determinar uma série de dados relacionados à rigidez e à resistência da peça que são necessários durante a definição das hipóteses de cálculo adotadas para o dimensionamento do reforço.

A estimativa da capacidade de resistência residual pode ser obtida de forma analítica, através de prova de carga ou empiricamente.

\section{- Estimativa analítica}

A determinação analítica da capacidade residual de uma estrutura pode ser obtida através de gráficos apresentados no capítulo 2 do CEB (1983), que descrevem o comportamento dos materiais constituintes de uma estrutura de concreto armado quando submetidos a ação do fogo, a efeitos sísmicos e a corrosão.

Pode-se também estimar a resistência residual das peças de concreto armado analisando-se a curvatura dos diagramas de momento, baseados nas leis constitutivas dos materiais. O gráfico da Figura 2.14 mostra um esquema ilustrativo de como se determinam as características residuais de uma estrutura danificada.

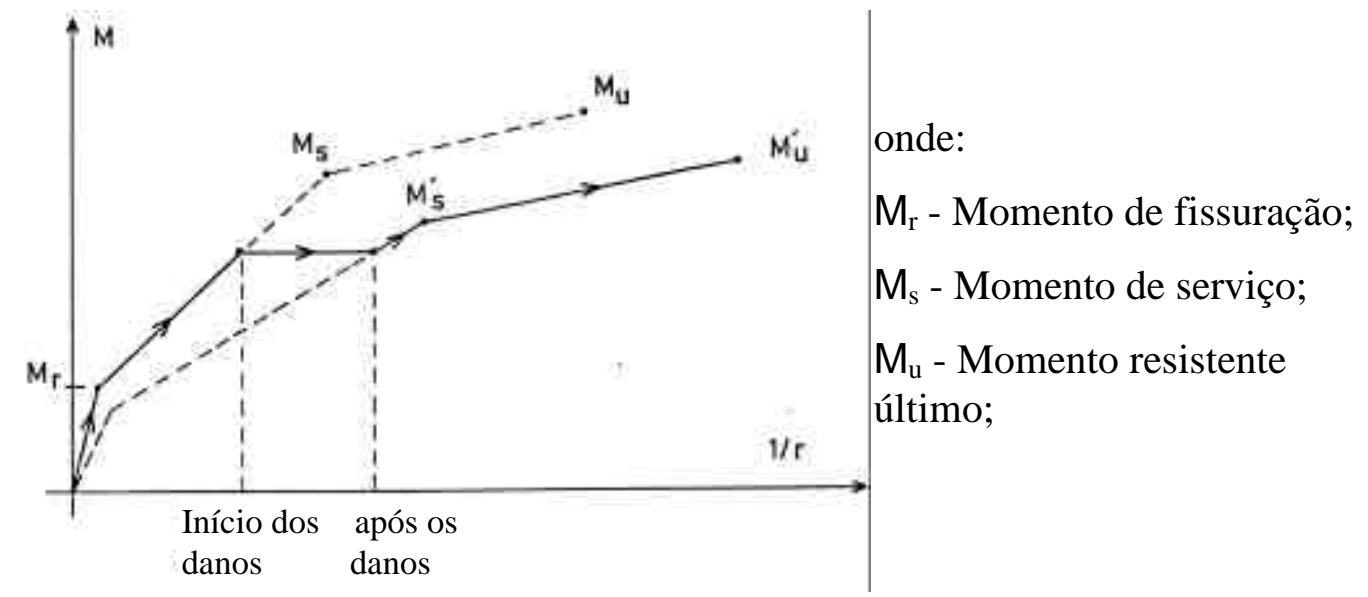

Figura 2.14 - Relação entre momento x curvatura para um elemento de concreto armado danificado (SOUZA, 1990) 
- Estimativa por prova de carga

A prova de carga é realizada em estruturas que podem apresentar uma deformação significativa sob um carregamento possível de aplicar e cuja ruptura ocorre com prévio aviso. Este método é geralmente realizado em vigas, lajes e outros elementos fletidos, porém seu emprego não é conveniente em pilares solicitados predominantemente por compressão, ou em vigas curtas submetidas a esforço cortante, uma vez que a ruptura nem sempre é dúctil.

Normalmente as provas de carga são caras, complexas e, algumas vezes, podem ser até perigosas. Sendo assim, torna-se necessário analisar criteriosamente toda a disposição dos instrumentos e das cargas, além de tomar precauções que garantam a segurança, impedindo a ruptura total caso haja alguma falha na zona ensaiada.

O projeto de norma da ABNT “Concreto Endurecido - Prova de Carga em Estruturas de Concreto Armado e Protendido" indica os procedimentos gerais a serem observados na execução desses ensaios. A norma americana ACI 318 (1992), "Building Code Requirements for Reinforced Concrete", também fornece recomendações importantes para a realização de provas de carga.

\section{- Estimativa empírica}

Esta é uma outra maneira de determinar as características residuais de peças deterioradas, recomendada pelo CEB (1983).

No caso de elementos danificados, as características mecânicas residuais podem ser aferidas através de coeficientes de correção de rigidez e da capacidade resistente. Estes coeficientes também podem ser chamados de relação de capacidade.

$$
\begin{aligned}
\mathrm{R}_{\text {residual }} & =v_{\mathrm{R}} \cdot \mathrm{R}_{\text {inicial }} \\
\mathrm{K}_{\text {residual }} & =v_{\mathrm{K}} \cdot \mathrm{K}_{\text {inicial }} \\
v & \leq 1,0
\end{aligned}
$$

onde:

$\mathrm{R}_{\text {inicial }}$ e $\mathrm{K}_{\text {inicial }}=$ Características iniciais de resistência e rigidez antes da deterioração; 
$\mathrm{R}_{\text {residual }}$ e $\mathrm{K}_{\text {residual }}=$ Características residuais de resistência e rigidez;

$v_{R}$ e $v_{K}=$ Coeficientes de correção da capacidade resistente e de rigidez.

Para elementos reforçados, as características mecânicas finais podem ser aferidas por um coeficiente de correção do comportamento monolítico dada pelas seguintes equações:

$$
\begin{aligned}
\mathrm{R}_{\text {final }} & =\gamma_{\mathrm{n}, \mathrm{R}} \cdot \mathrm{R}_{\mathrm{m}} \\
\mathrm{K}_{\text {final }} & =\gamma_{\mathrm{n}, \mathrm{K}} \cdot \mathrm{K}_{\mathrm{m}} \\
\gamma_{\mathrm{n}} & \leq 1,0
\end{aligned}
$$

onde:

$\mathrm{R}_{\text {final }}$ e $\mathrm{K}_{\text {final }}=$ Características de resistência e rigidez das estruturas reforçadas;

$\mathrm{R}_{\mathrm{m}}$ e $\mathrm{K}_{\mathrm{m}}=$ Características monolíticas de resistência e rigidez consideradas as intervenções;

$\gamma_{\mathrm{n}, \mathrm{R}}$ e $\gamma_{\mathrm{n}, \mathrm{K}}=$ Coeficientes de correção do comportamento monolítico de resistência e

de rigidez.

O coeficiente $\gamma_{n}$ relaciona as características finais dos elementos reforçados com equivalentes monolíticos, tendo por base resultados experimentais. Este coeficiente considera ainda as incertezas do comportamento dos elementos reforçados para cada tipo de elemento estrutural e tecnologia de reforço empregada (RODRIGUES, 1996). Na prática, deve-se considerar os coeficientes de correção do monolitismo relacionando os esforços resistentes da estrutura reforçada com os esforços resistentes de uma estrutura monolítica conforme equações abaixo:

Coeficientes de resistência : $\gamma_{\mathrm{n}, \mathrm{M}}=\frac{\mathrm{M}_{\mathrm{u}, \mathrm{ref}}}{\mathrm{M}_{\mathrm{u}, \mathrm{m}}}$ e $\gamma_{\mathrm{n}, \mathrm{V}}=\frac{\mathrm{V}_{\mathrm{u}, \text { ref }}}{\mathrm{V}_{\mathrm{u}, \mathrm{m}}}$

Coeficientes de rigidez: $\quad \gamma_{\mathrm{n}, \mathrm{K}}=\frac{\mathrm{K}_{\mathrm{II}, \mathrm{ref}}}{\mathrm{K}_{\mathrm{II}, \mathrm{m}}}$ onde: 
$\mathrm{K}_{\mathrm{II}}=$ Rigidez da estrutura para o estádio II;

$\mathrm{M}_{\mathrm{u}, \text { ref }}=$ Momento resistente último da estrutura reforçada;

$\mathrm{M}_{\mathrm{u}, \mathrm{m}}=$ Momento resistente último da estrutura monolítica;

$\mathrm{V}_{\mathrm{u}, \text { ref }}=$ Cortante resistente último da estrutura reforçada;

$\mathrm{V}_{\mathrm{u}, \mathrm{m}}=$ Cortante resistente último da estrutura monolítica.

De acordo com SOUZA (1993), para o dimensionamento à flexão por adição de armaduras e encamisamento com material de reparação pode-se utilizar $\gamma_{\mathrm{n}, \mathrm{K}}=0,70$ e $\gamma_{\mathrm{n}, \mathrm{M}}=0,80$. Para dimensionamento ao esforço cortante por adição de armaduras e encamisamento com material de reparação pode-se adotar $\gamma_{\mathrm{n}, \mathrm{V}}=0,80$.

\subsubsection{Hipóteses de Cálculo}

Estabelecidos os coeficientes de segurança e as características mecânicas residuais, parte-se para a definição das hipóteses de cálculo. Atualmente, o critério utilizado para o dimensionamento do reforço tem se baseado muito mais na experiência e bom senso dos técnicos do que em regras pré-estabelecidas. As dificuldades existentes para a criação de um código ou norma já foram anteriormente abordadas e somente com o desenvolvimento de muitos estudos teóricos e experimentais é que se conseguirá definir regras mais consistentes que facilitem o trabalho do engenheiro e permitam, ao mesmo tempo, um dimensionamento seguro e duradouro.

Por esse motivo, o cálculo das solicitações atuantes em estruturas reabilitadas deve ser feito da mesma forma que para estruturas primárias, baseando-se na Teoria da Elasticidade ou nas hipóteses simplificadoras da Resistência dos Materiais. Apesar desse procedimento não representar, de forma exata o comportamento da peça, pois não considera o aparecimento de deformações não-lineares. As solicitações calculadas com base na Teoria Elástica são redistribuídas para todas as fases de funcionamento da estrutura, que vão desde o aparecimento das primeiras fissuras na parte tracionada do concreto até atingir o estado limite último. Entretanto, os conhecimentos teóricos e experimentais disponíveis ainda não são suficientes para uma boa avaliação das curvaturas e rotações não lineares, não sendo possível 
analisar, com maior precisão, seus efeitos sobre todos os diversos tipos de estruturas quando submetidas às mais variadas ações.

O dimensionamento da armadura do reforço é feito conforme o estado da peça a ser reabilitada. Se os danos existentes não comprometem ou comprometem apenas superficialmente a capacidade resistente, estas devem ser reparadas e o reforço dimensionado para suportar apenas o acréscimo de carga. Caso a peça estrutural tenha sido bastante danificada, pode-se considerar a resistência residual nula e dimensionar o reforço para absorver totalmente o carregamento final. Entretanto, deve-se considerar como fundamentos básicos para qualquer tipo de dimensionamento, os seguintes aspectos:

1 - garantia das condições de segurança;

2 - garantia das condições de utilização;

3 - garantia das condições de durabilidade;

4 - proteção ao fogo;

5 - limitação dos deslocamentos entre os elementos novos e velhos;

6 - limitação da redistribuição dos esforços, através da limitação das tensões do aço e do concreto adicionados;

7 - consideração do grau de monolitismo no comportamento das estruturas reforçadas.

Segundo SOUZA (1990), o alargamento das seções transversais dos elementos promove um aumento significativo da rigidez que deve ser considerado durante a redistribuição dos esforços decorrentes do carregamento aplicado. Além disso, a fluência diferencial entre os materiais novos e velhos também deve ser considerada nessa redistribuição. Dependendo do tipo de intervenção e do número de elementos reforçados, pode ser necessário que algumas áreas não danificadas sejam também reforçadas devido ao aumento dos esforços. 


\subsection{Transferência de esforços}

Para que a redistribuição dos esforços se realize, é preciso que a intervenção seja eficiente de modo a promover a transferência de cargas. A transferência de esforços entre os materiais novos e velhos se realiza, basicamente, através da aderência da interface do substrato com o material de reparação e através das ligações de novas armaduras.

Quando tensões de cisalhamento são transferidas ao longo de uma junta formada pela ligação de concretos com idades diferentes, são desenvolvidas tensões em sentidos contrários que tendem a equilibrar as ações (ver Figura 2.15). Estas tensões de cisalhamento provocam uma tendência de deslizamento na interface, fenômeno caracterizado por movimento de translação entre as duas superfícies. Nesse caso, são mobilizados dois mecanismos de transferência classificados em: transferência de carga pela interface do concreto e transferência de carga pela ligação de armaduras.

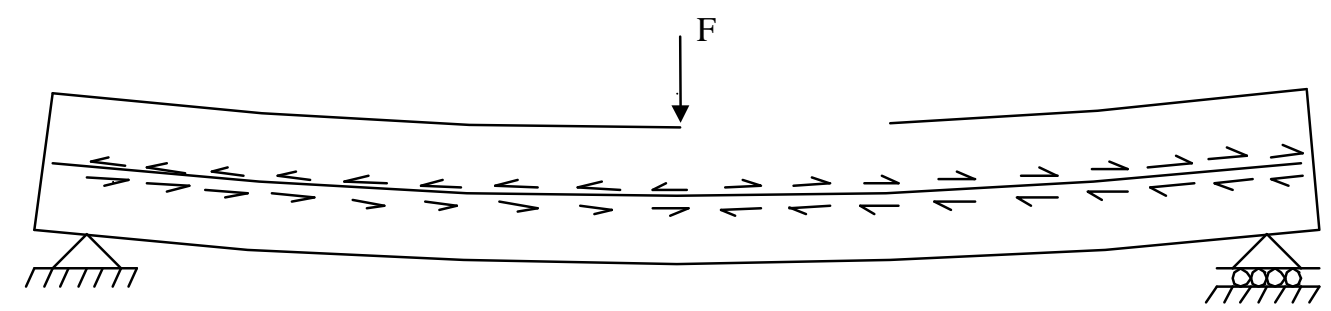

Figura 2.15 - Transferência integral de tensões de cisalhamento horizontais em vigas compostas (ARAÚJO, 1997)

Além das tensões de cisalhamento geradas ao longo da junta devido a transmissão de carregamento entre as partes que compõe a viga recuperada, existe ainda uma parcela correspondente às tensões geradas devido às mudanças de volume diferenciadas entre os materiais novos e antigos (retração e fluência), efeitos térmicos e diferenças entre os módulos de deformação que constituem a peça. 


\subsubsection{Transferência de carga pela interface do concreto}

Os pré-requisitos básicos para se obter uma ligação satisfatória entre os dois materiais são o tratamento da superfície de ligação e a forma de aplicação do material de reparo. A superfície de contato deve ser rugosa, isenta de poeira, graxa ou óleo e, dependendo do caso, deve ser saturada por um período de tempo significativo ou receber uma camada prévia de agentes adesivos. A aplicação do novo material deve ser de tal modo que imprima algum tipo de compactação e garanta continuidade. Os procedimentos de cura também devem ser cuidadosos.

O mecanismo de transferência de esforços de cisalhamento pela superfície de contato é semelhante à transferência de esforços das barras de aço para o concreto por aderência e pode ser dividido em três parcelas: adesão, atrito e ação mecânica.

A Figura 2.16 ilustra a evolução da tensão de aderência em função do deslocamento entre os concretos com idades diferentes e a Figura 2.17 mostra o mecanismo de ligação entre material de reparo e substrato.

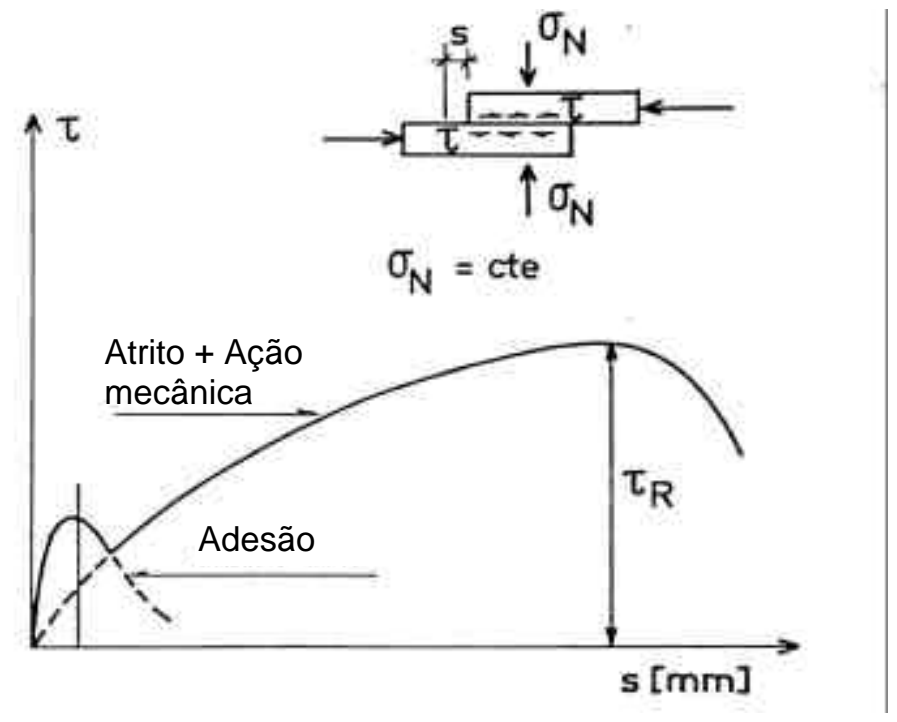

Figura 2.16 - Transferência de força através de interface concreto novo $x$ concreto antigo (SOUZA, 1990) 


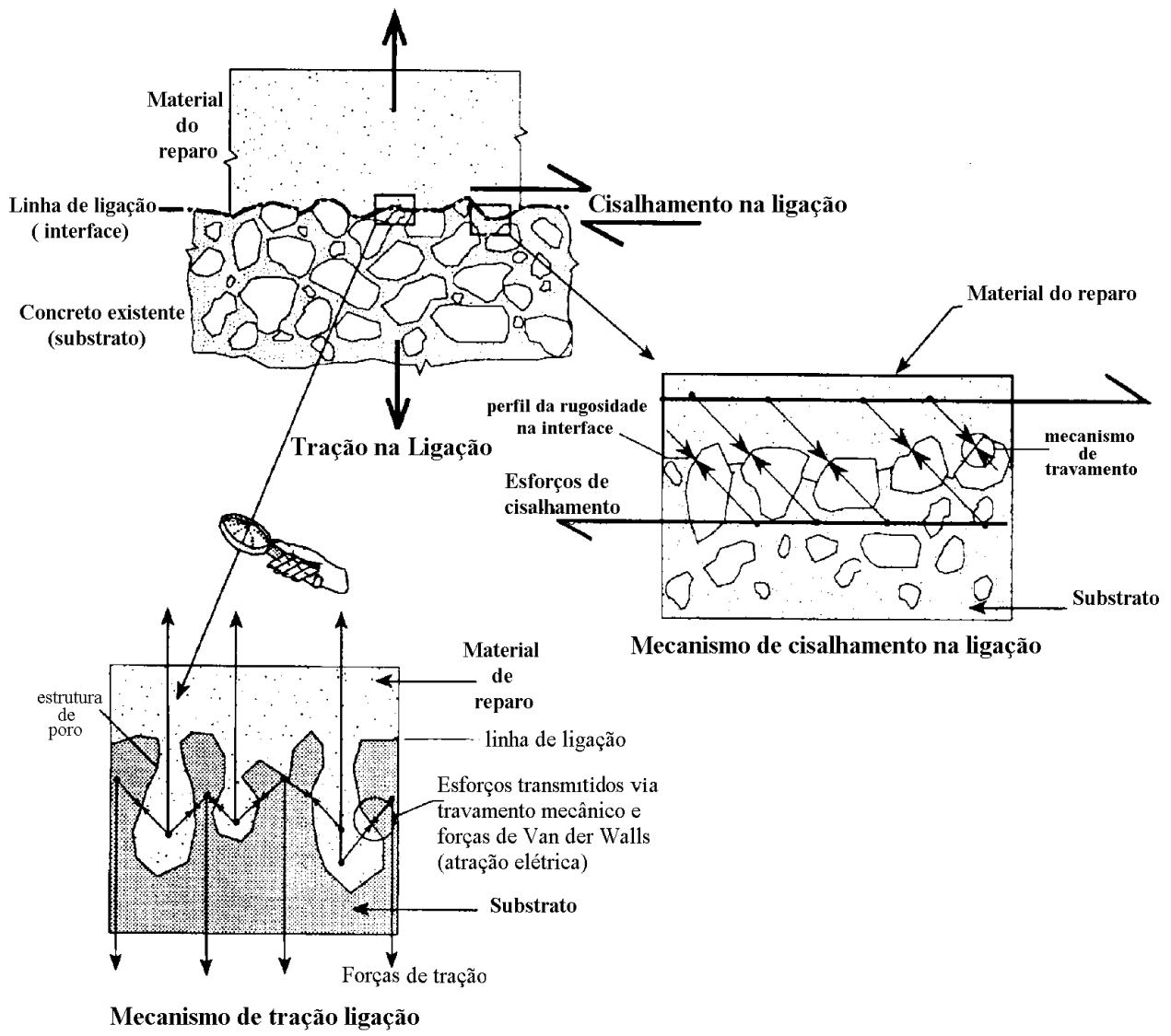

Figura 2.17 - Mecanismo natural de ligação entre material do reparo e o substrato (PEREIRA, 1997)

- $\underline{\text { Transferência por adesão }}$

A adesão entre o concreto novo e o velho ocorre preponderantemente por intertravamento mecânico ou encunhamento. Devido a ação da absorção capilar, as partículas do concreto novo são gradualmente confinadas nos poros capilares do concreto velho. Com a hidratação do concreto novo há um enlace físico desse com as irregularidades do concreto velho (ver Figura 2.18).

Para baixas solicitações, a transferência por adesão ocorre ao se aplicar esforços de cisalhamento em uma junta de concreto. Esse efeito isoladamente não é suficiente para uma boa transferência pois é destruído no caso de pequenos deslocamentos, conforme afirma LEONHARDT (1977). 


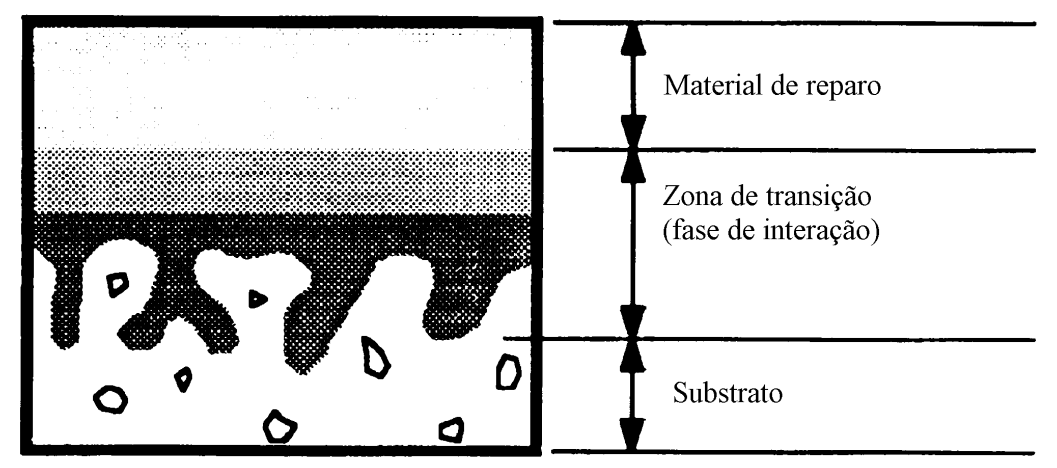

\section{Figura 2.18 - Modelo idealizado de um sistema de reparo superficial}

Acredita-se que a adesão seja influenciada pela rugosidade e tratamento da superfície de ligação, uso de agentes adesivos, uso de concreto ou argamassa especiais e também por métodos de aplicação do material de reparação. Entretanto, estudos desenvolvidos por REHM, STEINWEDE e DASCHNER, apud SOUZA (1990), indicam que a adesão não é influenciada pela resistência, pela retração e pela fluência do concreto. DASCHNER e BATE, apud SOUZA (1990), acreditam ainda que nem a diferença de idade entre os materiais interfere nesse fenômeno. Mesmo assim, alguns autores consideram que a retração é uma das causas da perda de aderência e recomendam a utilização de materiais não retráteis para a realização do reparo.

- Transferência por atrito

Após o rompimento da adesão provocado por qualquer deslizamento relativo entre o reforço e o substrato, mobilizam-se os mecanismos de transferência por atrito entre as superfícies em contato, desde que existam tensões normais à junta. Essas tensões podem ser causadas por forças externas ou pela armadura normal à interface (efeito de costura). Essa parcela de resistência possui um importante papel na transferência dos esforços de cisalhamento após ocorrer o deslizamento entre as partes em contato, sendo diretamente influenciada pela rugosidade da superfície, pela forma e pelo tamanho dos inertes, pela resistência à compressão do concreto, pela 
tensão de compressão aplicada sobre a ligação e também pela existência de cargas cíclicas.

A Figura 2.19 ilustra os mecanismos de transferência de esforços de cisalhamento numa interface de concreto com superfície rugosa com armadura,

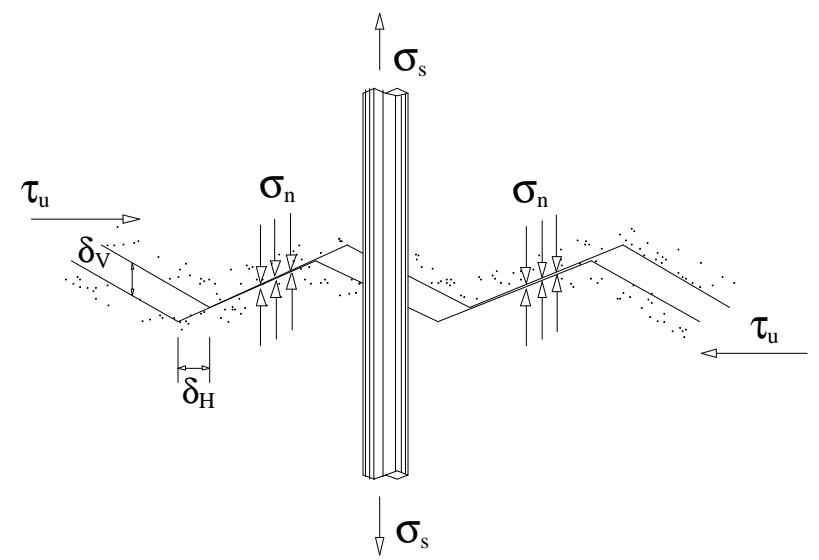

Figura 2.19 - Mecanismo de transferência de esforços de cisalhamento numa interface de concreto com superfície rugosa e com armadura (ARAÚJO, 1997)

\section{- Transferência por ação mecânica}

Esta transferência de esforços ocorre através do engrenamento mecânico proporcionado pelo contato existente entre as duas superfícies de concreto. Este engrenamento corresponde a um tipo de encaixe, semelhante a consolos de concreto, solicitados por cisalhamento quando há deslizamento da interface. O tipo de ligação mais representativo dessa forma de transferência é a ligação por chave de cisalhamento. Entretanto, em superfícies rugosas, essa forma de transferência pode ser garantida pelo agregado graúdo atravessando a interface.

Nas juntas formadas pela ligação de concretos com idades diferentes (caso de reparo/reforço) a primeira parcela de resistência é fornecida pela adesão. Com o aumento dos esforços de cisalhamento, surgem fissuras na interface e posterior deslizamento entre as duas partes em contato. Nesse momento, deixa de existir a 
parcela da adesão e a transferência de esforços é feita pelo atrito e pela ação mecânica.

Apesar da rugosidade da superfície melhorar a transferência de esforços por ação mecânica, vários autores recomendam evitar superfícies excessivamente rugosas, pois dificultam a aplicação da camada de adesivo (quando é o caso), podendo provocar descontinuidades.

\subsubsection{Transferência de carga pelas armaduras}

Este efeito também é conhecido como transferência pela ação de pino da armadura e surge quando a junta de concreto é solicitada por esforços de cisalhamento que provocam um deslizamento entre as duas partes em contato. Se existir armadura atravessando a interface, esse movimento tenderá a cisalhá-la. A armadura, por sua vez, fornecerá uma resistência ao corte que será somada à resistência fornecida pela superfície de contato.

A força transmitida pela ação de pino depende de vários parâmetros como: do cobrimento da armadura, do diâmetro da barra e de seu comprimento de ancoragem, da qualidade do concreto, da forma de carregamento, etc..

Além da ação de pino, gerada pela armadura que cruza a interface, observa-se ainda um aumento da resistência devido ao efeito de costura que essa armadura proporciona. Este efeito contribui na resistência pois aumenta o atrito na interface através das tensões normais que solicitam essas barras de aço.

\subsubsection{Conectores e ancoragens}

No caso de reabilitação de estruturas, o conhecimento dos mecanismos de transferência de esforços é importante para permitir ao projetista a adoção de conectores que garantam a eficácia das intervenções. Nesse item, os conectores são definidos como qualquer peça capaz de promover a ligação, de forma eficiente, entre armadura-concreto, armadura-armadura ou concreto-concreto. Os conectores podem ser classificados em: 
- Chumbadores ou parafusos: Os chumbadores são elementos metálicos, fabricados em aço inoxidável, que podem ser fixados na estrutura por meio de expansão química ou mecânica. A Figura 2.20 ilustra chumbadores mecânicos utilizados para ligar concreto-concreto.

- Barras soldadas: São elementos metálicos soldados nas armaduras novas e velhas, possibilitando a transferência de carga entre ambas, conforme ilustra a Figura 2.21 .

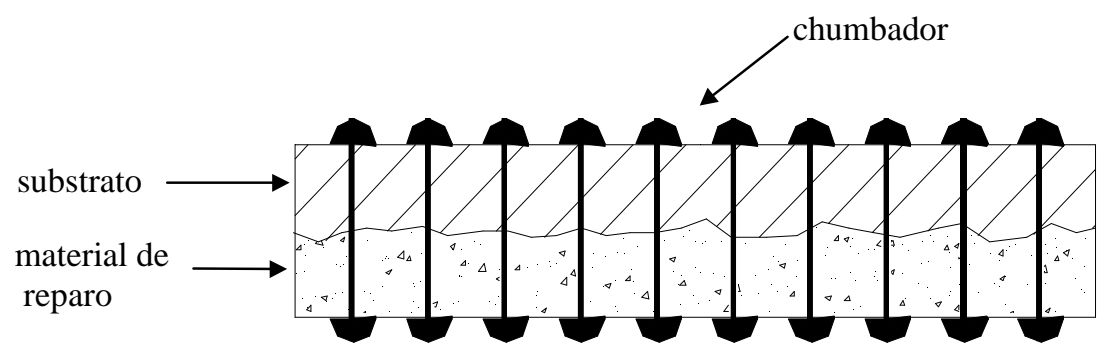

Figura 2.20 - Chumbadores para ligar concreto-concreto (SOUZA, 1990)
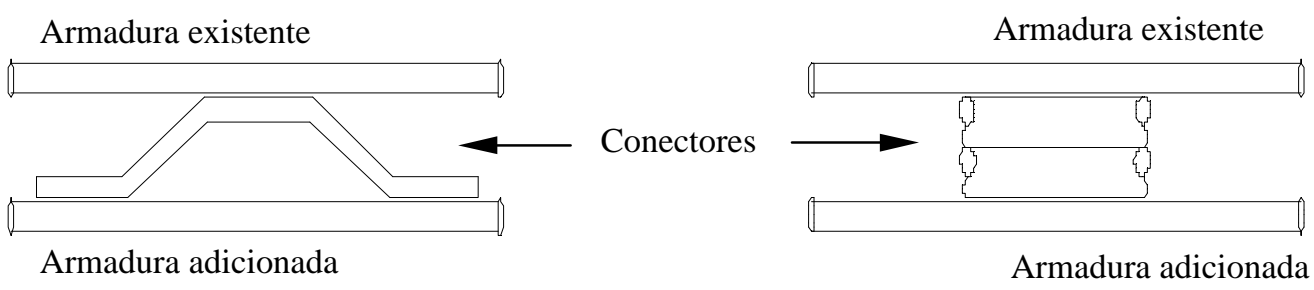

Figura 2.21 - Conectores de barras soldadas para ligar armadura-armadura (SOUZA, 1990)

Caso seja usado solda para promover a ligação entre as armaduras, deve-se observar os seguintes aspectos:

- qualificação e experiência dos soldadores;

- tipo e diâmetro dos eletrodos de acordo com a posição, camada e seção dos elementos; 
- intensidade da corrente elétrica, de forma a produzir somente a quantidade de calor necessária para realização da soldagem, especialmente durante a solda dos aços de alta resistência devido ao perigo de ocorrer recristalização;

- quando as armaduras forem constituídas de barras tratadas a frio, a solda deve ser feita a baixas temperaturas, de modo a evitar perda da resistência obtida com o tratamento.

A ancoragem das barras de aço do reforço também podem ser feitas através desses conectores. No caso de ancoragem feita introduzindo-se a armadura em furos preenchidos com material apropriado, o diâmetro desse furo irá depender do material de enchimento e do diâmetro da armadura. O CEB (1983), recomenda que o diâmetro do furo seja igual a bitola do aço mais $5 \mathrm{~mm}$. Depois de feito o furo, a cavidade deve ser limpa e seca, injetando-se posteriormente o material de enchimento de forma cuidadosa para evitar a penetração de ar. A armadura deve ser inserida levemente com movimentos giratórios garantindo que esta fique na posição correta. Alguns exemplos de ancoragens estão ilustrados na Figura 2.22.
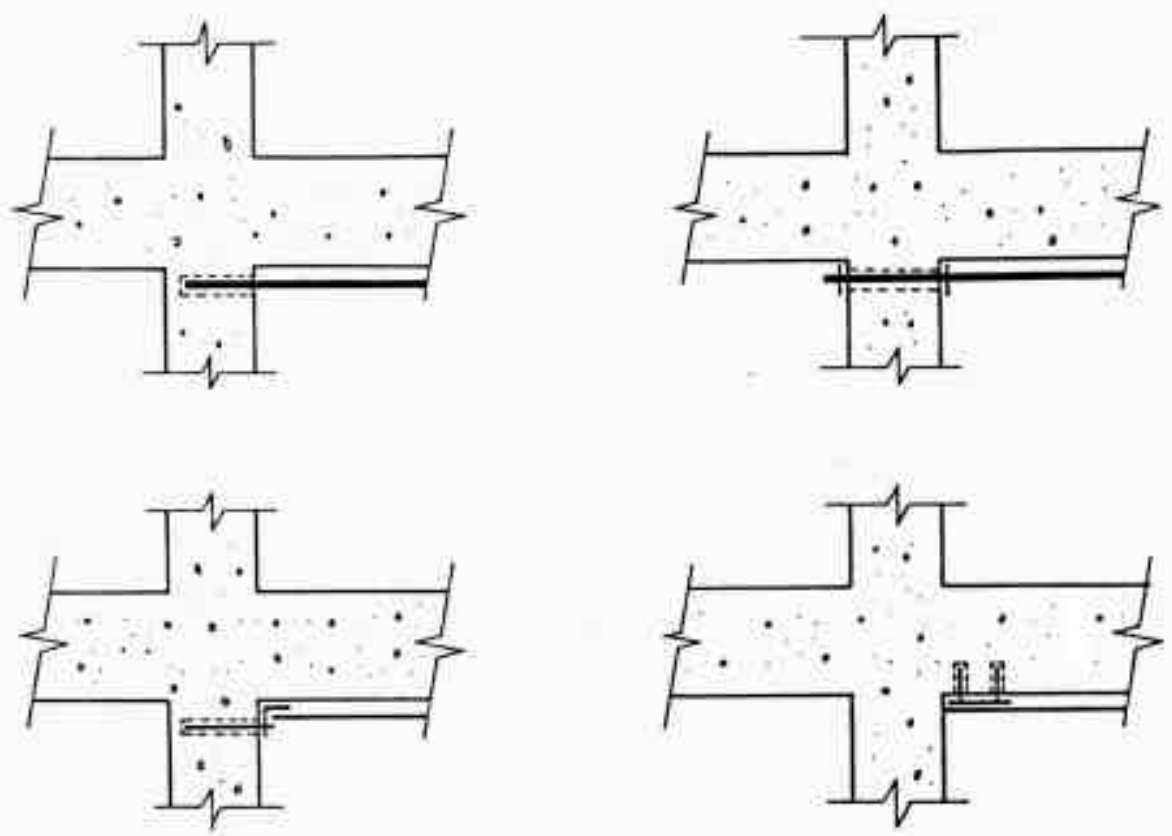

Figura 2.22 - Exemplos de ancoragem (SOUZA, 1990) 
Ao reabilitar estruturas mediante a adição de armaduras convencionais, devese sempre envolvê-la com concreto ou argamassa moldada no local ou projetada. A fim de prevenir os efeitos de corrosão, as armaduras podem ser de aço inoxidável ou sofrer tratamentos especiais como a galvanização e os revestimentos eletrostáticos poliméricos.

Fazendo uma analogia entre o comportamento de peças compostas* submetidas à flexão com as peças reabilitadas, percebe-se que suas formas de transferir os esforços são similares. Nesse caso, a parte pré-moldada corresponde ao substrato, enquanto a parte moldada no local corresponde ao concreto novo (reforço/reparo). Sendo assim, acredita-se ser possível adotar o mesmo processo de dimensionamento de conectores indicado para as peças compostas (ver Figura 2.23).

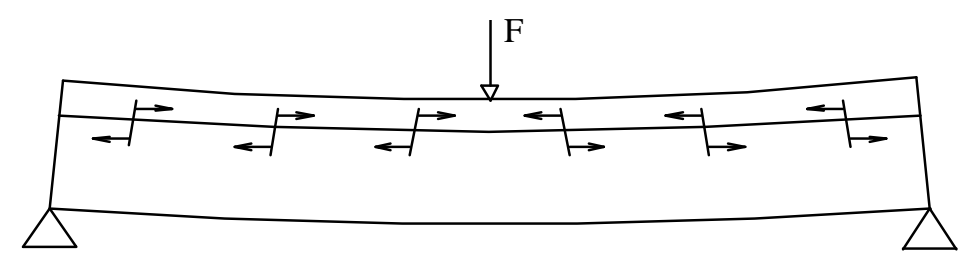

Figura 2.23 - Viga ou laje pré-moldada ligada por conector (ARAÚJO, 1997)

Para dimensionar esses conectores, é necessário obter as tensões de cisalhamento existentes na interface de ligação do reforço com o substrato (tensão solicitante de cálculo). Entretanto, esta tensão não é obtida diretamente, ou seja, é preciso medir o carregamento ou a força aplicada à viga e, só a partir daí, conseguese estimar a tensão na interface. Esta estimativa pode ser feita por três métodos:

a) Equação elástica

Uma das maneiras de avaliar essa tensão solicitante na interface é através da expressão da Resistência dos Materiais:

\footnotetext{
* As peças compostas são formadas pela associação de elementos pré-moldados com concreto moldado no local. Esta denominação pode ser aplicada também às estruturas formadas por dois materiais diferentes tais como peças reabilitadas.
} 


$$
\tau_{\mathrm{sd}}=\frac{\text { V.S }}{\mathrm{I} . \mathrm{b}}
$$

onde:

$\mathrm{V}=$ esforço cortante na seção;

$\mathrm{S}=$ momento estático da área acima da fibra em estudo com relação ao centróide da seção transversal;

I = momento de inércia da seção transversal;

$\mathrm{b}=$ largura da seção transversal na fibra em estudo.

Esta expressão é válida apenas para materiais no regime elástico linear. Entretanto, pode ser utilizada para o concreto fissurado, adotando-se as propriedades geométricas da seção fissurada e desprezando-se a região tracionada do concreto.

b) Equilíbrio de forças horizontais

Nesse caso, a tensão na interface pode ser obtida calculando a resultante de compressão, ou de tração, na seção de momento fletor máximo e promover sua transferência pela interface, através de tensões de cisalhamento horizontais, no trecho compreendido entre os pontos de momento fletor máximo e momento fletor nulo (ver Figura 2.24).

$$
\tau_{\mathrm{sd}}=\frac{\mathrm{R}_{\mathrm{d}}}{\mathrm{b} \cdot \mathrm{a}_{\mathrm{v}}} \leq \frac{\mathrm{A}_{\mathrm{s}} \cdot \mathrm{f}_{\mathrm{y}}}{\mathrm{b} \cdot \mathrm{a}_{\mathrm{v}}}
$$

onde:

$\mathrm{A}_{\mathrm{c} 2}$ =área da seção de concreto moldada no local;

$\mathrm{A}_{\mathrm{s}}$ = área de aço da armadura passiva;

$\mathrm{R}_{\mathrm{cc} 2}=$ força de compressão no concreto moldado no local $\left(\mathrm{R}_{\mathrm{cc} 2}=0,85 \cdot \mathrm{f}_{\mathrm{cd}} \cdot \mathrm{A}_{\mathrm{c} 2}\right)$;

$\mathrm{R}_{\mathrm{cc}} \quad=$ força total de compressão na seção composta;

$\mathrm{R}_{\mathrm{st}}=$ força total de tração $\left(\mathrm{R}_{\mathrm{st}}=\mathrm{A}_{\mathrm{s}} \cdot \mathrm{f}_{\mathrm{y}}\right)$;

$\mathrm{R}_{\mathrm{d}}=$ força atuante na interface;

$\mathrm{a}_{\mathrm{v}}=$ distância entre os pontos de momento máximo e momento nulo;

$\mathrm{b}$ = largura da interface; 
$\mathrm{f}_{\mathrm{cd}}=$ resistência de cálculo do concreto à compressão;

$\mathrm{f}_{\mathrm{y}}=$ Resistência característica à tração do aço.

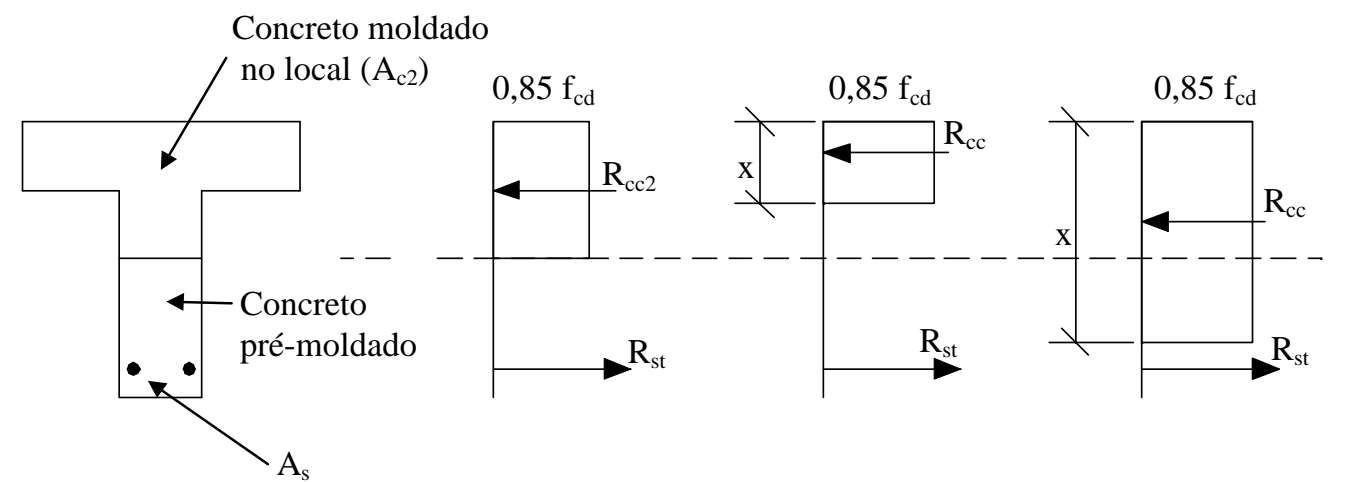

Caso 1

Caso 2

Caso $1: \mathrm{R}_{\mathrm{cc} 2}>\mathrm{R}_{\mathrm{cc}} \Rightarrow \mathrm{R}_{\mathrm{d}}=\mathrm{R}_{\mathrm{cc}}=\mathrm{R}_{\mathrm{st}}$

Caso $2: \mathrm{R}_{\mathrm{cc} 2}<\mathrm{R}_{\mathrm{cc}} \Rightarrow \mathrm{R}_{\mathrm{d}}=\mathrm{R}_{\mathrm{cc} 2}<\mathrm{R}_{\mathrm{st}}$

(a) Seção submetida a momento positivo
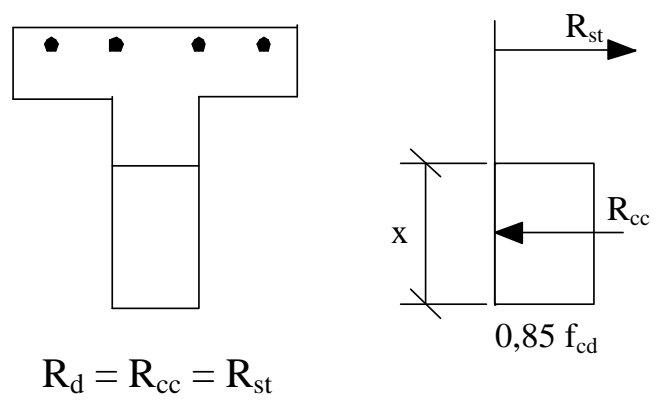

(b) Seção submetida a momento negativo

Figura 2.24 - Avaliação da tensão na interface por equilíbrio de forças (ARAÚJO, 1997) 
c) Equação aproximada

No estado limite último, a tensão de cisalhamento horizontal na interface também pode ser avaliada conforme ilustrado na Figura 2.25. Nessa figura, a interface MN é formada por uma peça pré-moldada e por outra moldada no local. Chamando de $M_{d}$ o momento de cálculo numa seção transversal e $V_{d}$ o esforço cortante de cálculo, a força transmitida pela interface entre as duas peças, por unidade de comprimento, pode ser obtida pela variação do esforço normal de compressão na peça moldada no local.

$$
\mathrm{R}_{\mathrm{d}} \cdot \mathrm{ds}=\mathrm{dR}_{\mathrm{cc}}=\frac{\mathrm{dM}_{\mathrm{d}}}{\mathrm{z}} \Rightarrow \mathrm{R}_{\mathrm{d}}=\frac{1}{z} \cdot \frac{\mathrm{dM}_{\mathrm{d}}}{\mathrm{ds}}=\frac{1}{z} \cdot \mathrm{V}_{\mathrm{d}}
$$

Sendo assim, de acordo com ARAUJO (1997), a tensão de cisalhamento horizontal na interface, para o estado limite último, pode ser obtida dividindo-se o fluxo de cisalhamento pela largura da interface.

$$
\tau_{\mathrm{sd}}=\frac{\mathrm{V}_{\mathrm{d}}}{\mathrm{b} . \mathrm{z}}
$$

Como normalmente o braço de alavanca entre as resultantes de tração e compressão na seção é tomado igual a 0,9d, obtém-se a equação 2.14.

$$
\tau_{\mathrm{sd}}=\frac{\mathrm{V}_{\mathrm{d}}}{0,9 \cdot \mathrm{b} \cdot \mathrm{d}}
$$

Esta equação é válida somente quando toda a região comprimida da seção está acima da interface, ou seja, a linha neutra está acima da interface. Quando a linha neutra está abaixo da interface, deve-se utilizar a equação 2.15 .

$$
\tau_{\mathrm{sd}}=\frac{\mathrm{V}}{0,9 . \mathrm{b} \cdot \mathrm{d}} \cdot \frac{\mathrm{R}_{\mathrm{cc} 2}}{\mathrm{R}_{\mathrm{cc}}}
$$


sendo:

$\mathrm{R}_{\mathrm{cc} 2}=$ força de compressão no concreto moldado no local;

$\mathrm{R}_{\mathrm{cc}}=$ força total de compressão da seção composta;

$\mathrm{V}$ = esforço cortante na seção;

b = largura da interface;

d = altura útil da seção.

\section{Concreto moldado}

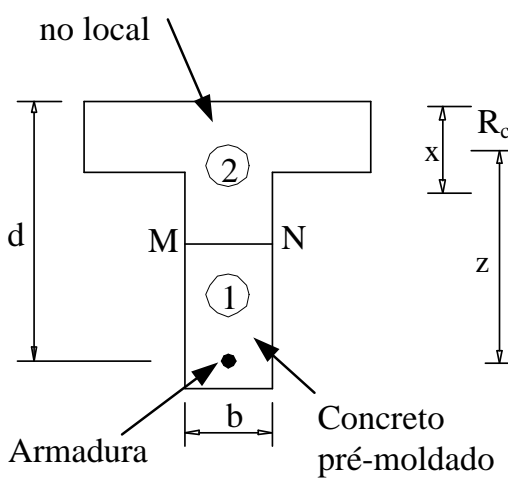

(a)

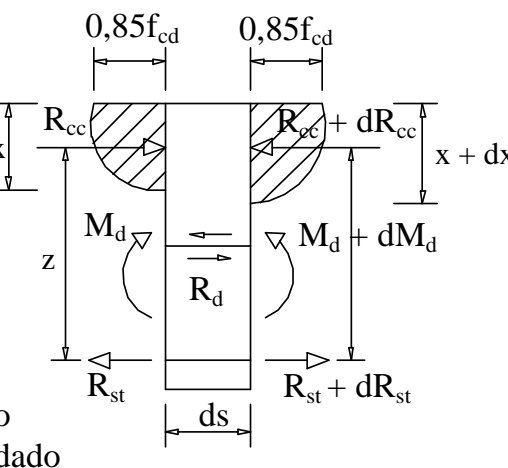

(b)

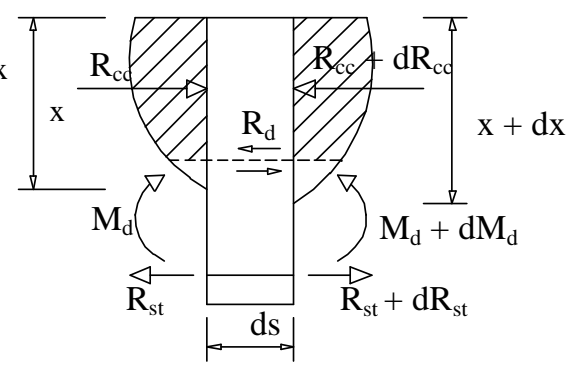

(c)

\section{Figura 2.25 - Avaliação da tensão de cisalhamento horizontal na interface}

Segundo ARAÚJO (1997), a escolha da equação a ser utilizada para estimar a tensão solicitante de cálculo, $\tau_{\mathrm{sd}}$, depende do procedimento adotado para avaliar a resistência de cálculo da interface ao cisalhamento horizontal, $\tau_{\mathrm{rd}}$.

Dentre os procedimentos usuais para avaliar $\tau_{\mathrm{rd}}$, destacam-se os indicados pela FIP 1982 (Federal Internationale de la Precontrainte), PCI 1992 (Prestressed/Precast Concrete Institute) e NBR-9062 (1985).

a) Procedimento da FIP

Este procedimento é aplicado a peças simplesmente apoiadas e as expressões utilizadas permitem o dimensionamento no estado limite último, garantindo o 
funcionamento como seção composta tanto no estado limite último quanto no estado de utilização. A tensão solicitante de cálculo $\tau_{\mathrm{sd}}$, deve ser avaliada pela equação 2.14 . No caso de vigas compostas (situações de alta solicitação, ou seja, pequena largura de contato da interface), $\tau_{\mathrm{rd}}$ deve obedecer aos limites $\tau_{\mathrm{sd}} \leq \tau_{\mathrm{rd}} \leq 0,25 \mathrm{f}_{\mathrm{ck}, \mathrm{c}}$ e pode ser estimada por:

$$
\tau_{\mathrm{rd}}=\beta_{1} \cdot \frac{\mathrm{A}_{\mathrm{sw}}}{\mathrm{s} \cdot \mathrm{b}} \cdot \mathrm{f}_{\mathrm{yd}}+\beta_{2} \cdot \mathrm{f}_{\mathrm{td}, \mathrm{c}} \leq 0,25 \mathrm{f}_{\mathrm{ck}, \mathrm{c}}
$$

onde:

$\mathrm{s}=$ espaçamento da armadura dos conectores;

$\mathrm{b}=$ largura ou comprimento transversal à interface;

$\beta_{1}$ e $\beta_{2}=$ Coeficientes multiplicadores da resistência que dependem da armadura e da superfície de contato, fornecidos pela FIP;

$\mathrm{f}_{\mathrm{yd}} \quad=$ Resistência de cálculo do aço $(\mathrm{MPa})$

$\mathrm{f}_{\mathrm{td}, \mathrm{c}}=$ Resistência de cálculo do concreto a tração indicada pela FIP (MPa)

$\mathrm{f}_{\mathrm{ck}, \mathrm{c}}=$ Resistência característica do concreto medida em corpos-de-prova cúbicos $(\mathrm{MPa})$

$\mathrm{A}_{\mathrm{sw}}=$ área de aço dos conectores $\left(\mathrm{cm}^{2}\right)$.

Como é possível calcular os valores limites entre os quais $\tau_{\mathrm{rd}}$ deve ficar, basta igualar a expressão 2.16 a cada um desses limites, encontrando dois valores para $\frac{\mathrm{A}_{\mathrm{SW}}}{\mathrm{s}}$. Adota-se, portanto, o menor valor como sendo a área de aço $\left(\mathrm{cm}^{2} / \mathrm{m}\right)$ necessária para resistir aos esforços cisalhantes existentes na junta.

b) Procedimento do PCI

Este procedimento é baseado no item 17.5.3 do ACI 318 (1989) e contempla tanto as situações de compressão quanto de tração no concreto moldado no local. Para esse caso, a verificação da resistência ao cisalhamento é feita com base na seguinte condição: 


$$
\mathrm{R}_{\mathrm{d}} \leq \mathrm{R}_{\mathrm{rd}}
$$

onde:

$\mathrm{R}_{\mathrm{d}}=$ Força horizontal solicitante de cálculo na interface;

$\mathrm{R}_{\mathrm{rd}}=$ Força horizontal resistente de cálculo na interface.

O valor da força horizontal solicitante de cálculo é determinado considerando os valores médios de tensão de cisalhamento, que são obtidos em função da variação da resultante das tensões no concreto moldado no local. Para dimensionar o conector, o PCI classifica a peça em três casos distintos em função do valor de $R_{d}$.

É importante salientar que em todas as equações utilizada no procedimento do PCI, deve-se utilizar os parâmetros com unidades em psi e não no sistema internacional de unidades.

- Caso 1

$$
\mathrm{R}_{\mathrm{d}} \leq 80 \cdot \mathrm{b} \cdot \mathrm{a}_{\mathrm{v}}
$$

Para esse caso não é necessário o uso de conectores.

$\bullet$ Caso 2

$$
80 \cdot b \cdot a_{v}<R_{d} \leq 350 \cdot b \cdot a_{v}
$$

Nesse caso, deve-se colocar uma armadura mínima de conectores, dada pela expressão 2.20 .

$$
\mathrm{A}_{\mathrm{swmin}}=\frac{50 \cdot \mathrm{b} \cdot \mathrm{a}_{\mathrm{v}}}{\mathrm{f}_{\mathrm{y}}}
$$

- Caso 3

$$
\mathrm{R}_{\mathrm{d}}>350 \cdot \mathrm{b} \cdot \mathrm{a}_{\mathrm{v}}
$$

Nesse caso, deve-se colocar uma armadura calculada de acordo com a teoria do atrito-cisalhamento. Esta a armadura é determinada pela equação 2.22. 


$$
\mathrm{A}_{\mathrm{sw}}=\frac{\mathrm{R}_{\mathrm{d}}}{\mu_{\mathrm{e}} \cdot \mathrm{f}_{\mathrm{y}}}
$$

onde:

$$
\mu_{\mathrm{e}}=\frac{1000 \cdot \lambda \cdot \mathrm{a}_{\mathrm{v}}}{\phi \cdot \mathrm{R}_{\mathrm{d}}} \leq 2,9
$$

Como para esse caso o valor de $\mathrm{R}_{\mathrm{d}}$ é elevado, deve-se verificar a condição inicial dada pela equação 2.17. Para isso calcula-se a força resistente de cálculo na interface através da equação 2.24 .

$$
\mathrm{R}_{\mathrm{rd}}=\phi 250 \cdot \lambda^{2} \cdot \mathrm{f}_{\mathrm{ck}} \cdot \mathrm{b} \mathrm{a}_{\mathrm{v}}
$$

Esta força resistente de cálculo deve obedecer ao limite: $R_{\mathrm{rd}} \leq 1000 \cdot \lambda^{2} \cdot \mathrm{b}_{\mathrm{v}} \cdot \mathrm{a}_{\mathrm{v}}$ sendo $\lambda$ e $\phi$ obtidos a partir da teoria do atrito-cisalhamento.

c) Procedimento da NBR-9062

Para o cálculo da tensão de cisalhamento solicitante na interface, é recomendada a equação 2.14 , baseada no equilíbrio de forças em um trecho da viga. A tensão resistente pode ser obtida por:

$$
\tau_{\mathrm{rd}}=\beta \mathrm{s} \cdot \frac{\mathrm{A}_{\mathrm{sw}} \cdot \mathrm{f}_{\mathrm{yd}}}{\mathrm{s} \cdot \mathrm{b}}+\beta_{\mathrm{c}} \cdot \mathrm{f}_{\mathrm{td}}
$$

onde:

$\beta$ s e $\beta c=$ Coeficientes de minoração para a armadura e o concreto respectivamente, válidos para superfícies ásperas, de acordo com a NBR-9062.

Admitindo que $\tau_{\mathrm{sd}}=\tau_{\mathrm{rd}}$, e isolando-se o termo $\frac{\mathrm{A}_{\mathrm{SW}}}{\mathrm{s}}$, determina-se a área de aço mínima necessária para que a seção composta resista aos esforços de cisalhamento na junta. 


\subsection{Ensaios para avaliar a aderência entre substrato/reparo}

Quando a reabilitação de uma estrutura de concreto envolve a adição de um novo material ao substrato, geralmente tem-se o interesse de avaliar a aderência entre esses materiais para verificar o grau de monolitismo da intervenção. A garantia da boa aderência é essencial para o sucesso do trabalho, embora sua avaliação seja complexa e difícil pois além dos fenômenos físico-químicos que ocorrem na ligação, esses elementos podem estar submetidos a uma grande variedade de tensões devido às ações mecânicas existentes na estrutura (SOUZA, 1990).

Com o aumento de produção e uso de materiais de reparo, muitas técnicas para avaliar a aderência foram desenvolvidas, mas um método normalizado e satisfatório ainda não está disponível apesar das inúmeras contribuições da literatura dentro desse campo de estudo (CLIMACO, 1990). Isto porque, apesar da indústria de produtos adesivos possuir um grande número de testes de laboratórios para avaliar a aderência, as situações existentes na prática são diferentes, uma vez que as condições de carregamento são difíceis de se simular. Além disso, deve-se levar em conta as limitações inerentes aos ensaios em relação à sua representatividade frente a um comportamento real em obra, que torna difícil reproduzir os apoios e suas condições termo-higrométricas no momento de aplicação do produto.

De acordo com CLÍMACO (1991), os ensaios usados na avaliação da aderência devem simular um estado de tensões que represente, o melhor possível, as condições de serviço, devem fornecer baixo coeficiente de variação, sendo sensível à propriedade medida e devem possuir um procedimento de teste de simples reprodução.

SOUZA (1990) afirma que a grande dificuldade está na interpretação dos resultados de tais testes uma vez que a resistência da aderência depende não só das propriedades químicas e físicas da ligação, mas também da forma como a aderência é formada, da rugosidade da superfície de concreto, da presença de água livre ou absorvida, do tipo e espessura dos adesivos eventualmente utilizados, das condições de cura, da existência de diferentes módulos de elasticidade e coeficientes de Poisson, variações térmicas, etc. Entretanto, apesar das inúmeras variáveis que 
condicionam a resistência da aderência, a realização de qualquer teste permite uma interpretação qualitativa da aderência e um valor numérico para a tensão média de aderência. Cabe então ao projetista verificar a validade do valor encontrado.

Dentre os ensaios mais comuns utilizados para avaliar a aderência, pode-se citar: testes de tração, testes de compressão direta, testes de cisalhamento, testes de flexão e testes de compressão-cisalhamento de junta inclinada.

Os ensaios de tração ou flexão modificados podem ser realizados na própria estrutura reparada, traduzindo melhor as condições reais da reabilitação. Já os demais ensaios são feitos somente em laboratório, fornecendo basicamente a resistência da mistura compactada e curada de forma padronizada, e raramente refletindo a resistência encontrada nas estruturas. Além disso, não se consegue obter, através desses testes, qualquer informação sobre uma possível deterioração do concreto com o tempo ou os efeitos de subsequentes danos à sua resistência*

a) Testes de tração

Basicamente existem testes de tração destrutivos ou não-destrutivos. Alguns desses tipos de testes estão ilustrados na Figura 2.26.

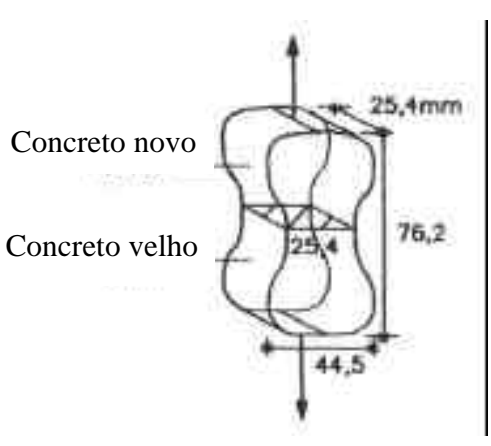

(a) Tração direta "Dogbone test"

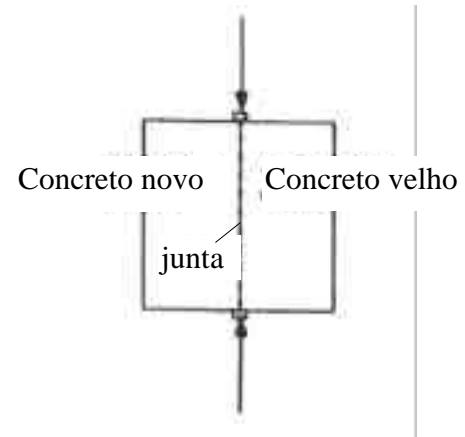

(b) Tração indireta "Splitting test"

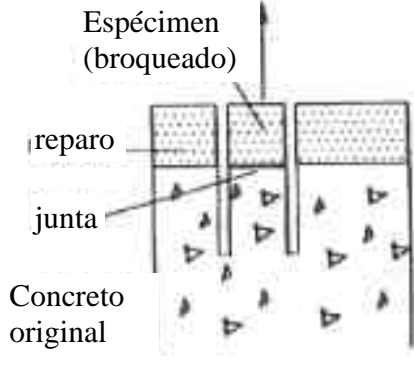

(c) Testes não destrutivos "Pull-off test"

\section{Figura 2.26 - Testes de tração para avaliação de aderência (CLÍMACO, 1991)}

\footnotetext{
* A análise das tensões atuantes na ligação é bastante complexa, necessitando de um estudo bem elaborado. Nesse trabalho não se pretende desenvolver nenhum estudo mais aprofundado sobre o assunto, mas apenas fornecer uma revisão bibliográfica enfatizando sua importância.
} 
J. R. EYRE, apud SOUZA (1990) considera que esses testes têm pouco interesse, pois indicam apenas se a resistência de aderência excede ou não a resistência à tração do concreto. Como o concreto é um material com baixa resistência à tração, essa informação é de pouca relevância, principalmente porque a resistência à tração é, em muitos casos, desprezada nos estados limites últimos. Além disso, os testes de tração podem mascarar os diferentes desempenhos de sistemas adesivos, pois apresentam uma elevada dispersão nos resultados (CLÍMACO, 1990). Outro fator a ser questionado é que, nesses testes, as dimensões das amostras são extremamente reduzidas, portanto, dificilmente representariam situações reais de reparo.

Apesar das limitações citadas, estes ensaios podem ser úteis para avaliações preliminares em determinados trabalhos de reparo.

b) Testes de compressão direta

Este tipo de teste não tem muita relevância para se determinar a aderência, já que, mesmo em situações de aderência zero consegue-se transferir tensões entre os materiais novos e antigos quando a junta está perpendicular à direção da força aplicada. Além disso, esse tipo de teste indica apenas a ruína por compressão de um dos dois materiais. Sendo assim, a ruptura na linha de aderência pode ser apenas um efeito indireto, proveniente das tensões tangenciais devido às diferenças nas respostas elásticas dos dois materiais.

c) Testes e cisalhamento

Existem diversos testes de cisalhamento realizados na prática, como ilustrado na Figura 2.27. Estes testes apresentam algumas limitações principalmente porque a distribuição irregular de tensões de cisalhamento na interface provoca uma alta concentração de tensões nas extremidades da junta, gerando distorções nos resultados obtidos. Além disso, há evidências de que a resistência da junta também depende da 
resistência à tração do concreto, o que introduz limitações adicionais ao se analisar os resultados obtidos.

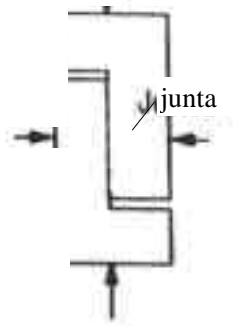

(a) cisalhamento direto

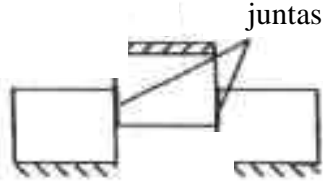

(b) cisalhamento direto

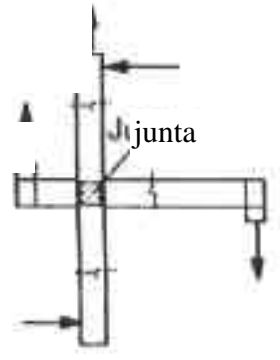

(c) cisalhamento com torção

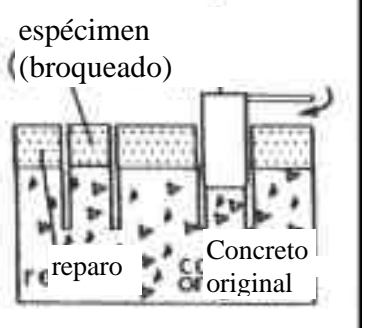

(d) "friction transfer test"

Figura 2.27 - Testes de cisalhamento

De acordo com CLÍMACO (1997), os ensaios à flexão de vigas reparadas de concreto são freqüentemente mencionados na literatura como eficientes por submeterem a junta à tensões de tração, compressão e cisalhamento. Contudo, esses testes tem problemas de sensibilidade à aderência, apresentando uma elevada variação nos resultados devido a baixa resistência à tração do concreto e devido as discrepâncias nos módulos de elasticidade dos materiais envolvidos.

A Figura 2.28 mostra dois tipos de ensaios à flexão de vigas reparadas de concreto.

Carregamento aplicado em geral nos terços do vão

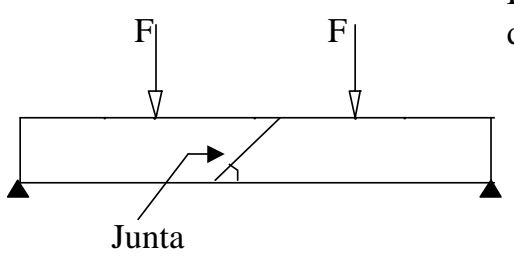

(ângulos usuais: $30^{\circ}, 45^{\circ}$ e $60^{\circ}$ )

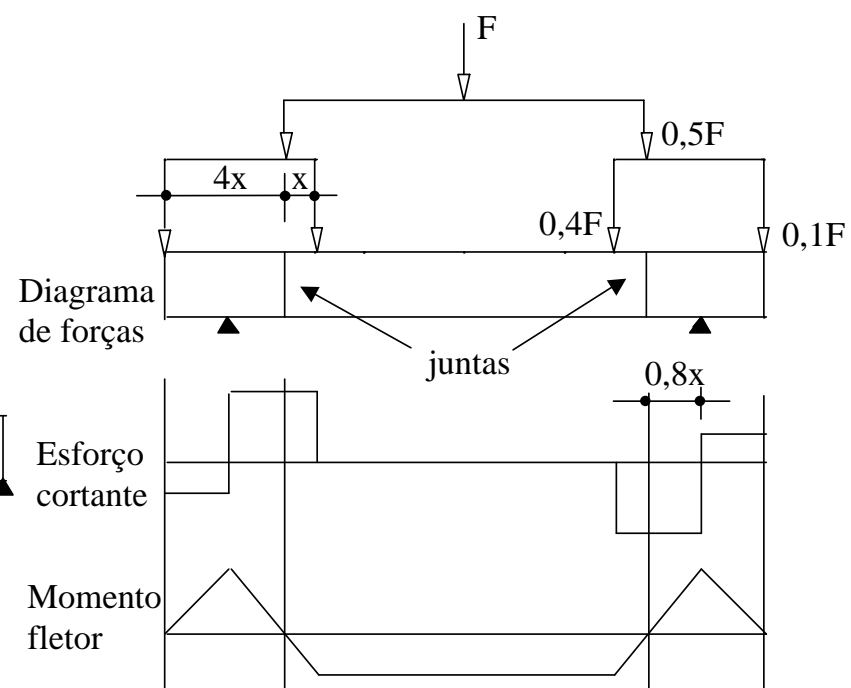

Figura 2.28 - Testes de flexão 
e) Testes de compressão-cisalhamento de junta inclinada (slant shear test)

Este teste consiste na aplicação de compressão axial em um corpo-de-prova prismático composto, com a junta fazendo determinado ângulo com a direção da ação, conforme ilustra a Figura 2.29. Este tipo de teste apresenta um estado de tensões na junta bastante representativo de situações típicas de reparo, fornece uma boa sensibilidade na medição da aderência e é um teste de realização relativamente simples.

Por outro lado, de acordo com SOUZA (1990) os "slant shear tests" normalizados têm sido muito contestados por diversos pesquisadores no que diz respeito ao tratamento da superfície de ligação, ao ângulo utilizado, ao tamanho dos prismas e até a forma de apresentação dos resultados. CLÍMACO (1990), que estudou mais a fundo esse tipo de ensaio, confirma que algumas das vantagens desse tipo de teste só são obtidas com a correta combinação dos parâmetros: ângulo da junta e preparo da superfície.
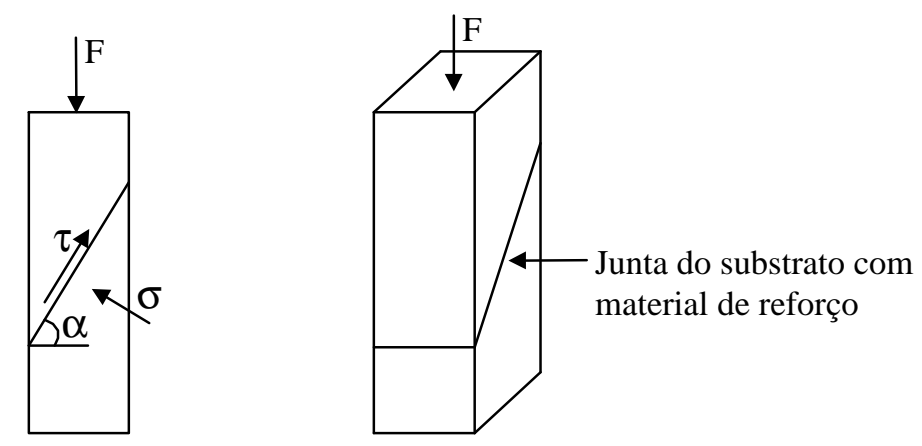

Figura 2.29 - Teste compressão-cisalhamento de junta inclinada

\subsection{Técnicas de reforço estudadas}

No caso das vigas, pode-se ter reforços/reparos destinados a solucionar tanto problemas causados por esforços devido ao momento fletor quanto por esforços devido a força cortante. O tratamento de cada um desses casos é diferente. No caso de ação do momento fletor, a falha pode ter sido produzida pela existência de uma taxa de armadura de tração insuficiente, provocando fissuras na região central da viga e podendo levar a peça à ruína; pela baixa resistência à compressão do concreto, devido à má qualidade do material, ou por insuficiência de armadura na zona 
comprimida. No caso de deficiência quanto ao esforço cortante, as falhas podem ocorrer devido à falta ou má colocação da armadura transversal e também por resistência insuficiente do concreto.

Como esse trabalho enfatiza apenas a reabilitação de estruturas devido ao momento fletor, não serão apresentados detalhes de reforços de vigas devido a ação dos esforços cortantes.

É importante ressaltar que o reforço através da adição de novas armaduras tracionadas (barras de aço ou chapas de aço), pode acarretar um deslocamento da linha neutra e aumento da região comprimida do concreto, influenciando no comportamento elástico da peça e no seu estado tensional. Outro fator que altera o comportamento da peça reabilitada é a quantidade de carga aplicada na viga durante a execução do reforço.

A peça estrutural geralmente está submetida a momentos fletores produzidos por ações permanentes $\left(\mathrm{M}_{\mathrm{g}}\right)$ e por sobrecargas de uso $\left(\mathrm{M}_{\mathrm{q}}\right)$. Por esse motivo, quando se realiza a execução da intervenção sem descarregar totalmente a peça, esta pode apresentar um estado de deformação/tensão descontínuo.

Segundo CÁNOVAS (1988), para determinar o estado de tensões na peça, faz se a superposição das deformações na viga admitindo o estado limite último após a atuação do momento $\mathrm{M}_{\mathrm{q}}$ (dimensionamento feito no estádio III) conforme ilustra a Figura 2.30.

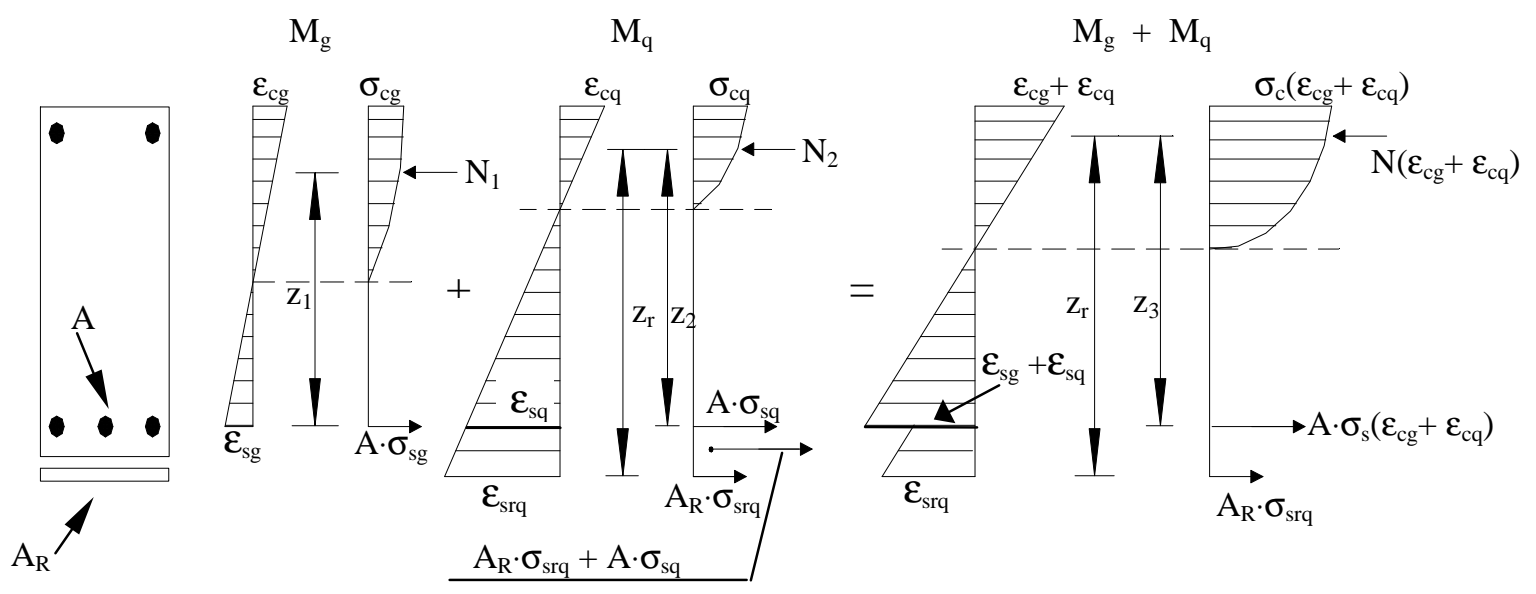

Figura 2.30 - Estados de tensão e deformação em uma viga reforçada (CANOVAS, 1988) 
onde:

A - Área de aço do substrato;

$A_{R}$ - Área de aço do reforço;

$\varepsilon_{\mathrm{cg}}$ e $\sigma_{\mathrm{cg}}$ - Deformação e tensão do concreto para cargas permanentes;

$\varepsilon_{\mathrm{sg}}$ e $\sigma_{\mathrm{sg}}$ - Deformação e tensão do aço do substrato para cargas permanentes;

$\varepsilon_{\text {srg }}$ e $\sigma_{\text {srg }}$ - Deformação e tensão do aço do reforço para cargas permanentes;

$\varepsilon_{\mathrm{cq}}$ e $\sigma_{\mathrm{cq}}$ - Deformação e tensão do concreto para cargas de uso;

$\varepsilon_{\mathrm{sq}}$ e $\sigma_{\mathrm{sq}}$ - Deformação e tensão do aço do substrato para cargas de uso;

$\varepsilon_{\text {srq }}$ e $\sigma_{\text {srq }}$ - Deformação e tensão do aço do reforço para cargas de uso;

$\sigma_{\mathrm{c}}\left(\varepsilon_{\mathrm{cg}}+\varepsilon_{\mathrm{cq}}\right)$ - Função da tensão no concreto dependente dos parâmetros $\varepsilon_{\mathrm{cg}}$ e $\varepsilon_{\mathrm{cq}}$;

$\sigma_{\mathrm{s}}\left(\varepsilon_{\mathrm{cg}}+\varepsilon_{\mathrm{cq}}\right)$ - Função da tensão no aço do substrato dependente dos parâmetros $\varepsilon_{\mathrm{cg}} \mathrm{e}$

$$
\varepsilon_{\mathrm{cq}}
$$

$\mathrm{N}\left(\varepsilon_{\mathrm{cg}}+\varepsilon_{\mathrm{cq}}\right)$ - Função da força de compressão no concreto dependente dos parâmetros

$$
\varepsilon_{\mathrm{cg}} \text { e } \varepsilon_{\mathrm{cq}}
$$

$\mathrm{Z}_{\mathrm{r}}$ - Braço de alavanca da armadura do reforço;

$\mathrm{Z}_{1}$ - Braço de alavanca da armadura do substrato devido $\mathrm{M}_{\mathrm{g}}$;

$\mathrm{Z}_{2}$ - Braço de alavanca da armadura do substrato devido $\mathrm{M}_{\mathrm{q}}$;

$\mathrm{z}_{3}$ - Braço de alavanca da armadura do substrato devido $\mathrm{M}_{\mathrm{q}}$ e $\mathrm{M}_{\mathrm{g}}$;

No caso da reabilitação de vigas, além de se determinar a área de aço do reforço analisando os possíveis estados de tensão e deformação existentes na peça, é preciso verificar também se a tensão tangencial na interface do reforço com o substrato, $\tau_{\alpha,}$ é maior que a tensão tangencial máxima, $\tau_{\alpha, \text { máx }}$, calculada de acordo com indicações do CEB (1983). Este código sugere o cálculo do valor limite da tensão tangencial máxima em função do tipo de técnica de reforço utilizada. De acordo com estudos realizados, a tensão tangencial na interface reforço/substrato existente em um trecho da viga submetida a um esforço cortante $\mathrm{V}$ é calculada pela equação 2.26 .

$$
\tau_{\alpha} \cong \frac{\mathrm{V}}{\mathrm{b} \cdot \mathrm{z}_{\mathrm{r}} \cdot\left[1+\frac{\mathrm{A} \cdot \mathrm{z}_{3} \cdot\left(\mathrm{d}_{1}-\mathrm{x}\right)}{\mathrm{A}_{\mathrm{r}} \cdot \mathrm{z}_{\mathrm{r}} \cdot\left(\mathrm{d}_{2}-\mathrm{x}\right)}\right]}
$$


onde:

b - Largura da viga;

V - Esforço cortante a ser absorvido pelo elemento depois de reforçado;

$\mathrm{d}_{1}$ - Altura útil devido à armadura inicial;

$\mathrm{d}_{2}$ - Altura útil devido à armadura de reforço;

$\mathrm{x}$ - Altura da linha neutra.

O CEB (1983) recomenda também não aumentar em mais de 50\% a capacidade resistente última existente antes do reforço.

$$
\begin{array}{ll}
\text { Momentos fletores - } & \Delta \mathrm{M}_{\mathrm{u}, \text { adicionado }} \leq 0,5 \mathrm{M}_{\mathrm{u}, \text { existente }} \\
\text { Esforços Cortantes - } & \Delta \mathrm{V}_{\mathrm{u}, \text { adicionado }} \leq 0,5 \mathrm{~V}_{\mathrm{u} \text {,existente }}
\end{array}
$$

\subsubsection{Reforço mediante encamisamento de concreto armado/argamassa}

Esta técnica consiste em acrescentar concreto/argamassa armada às peças a serem recuperadas, mediante aumento de seção transversal ou substituição do material danificado. Nesse caso, o material adicionado passará a trabalhar unido ao concreto existente através da aderência entre ambos, constituindo-se uma peça solidária. A eficiência desse reforço é garantida, desde que sejam tomados os devidos cuidados durante sua realização. Segundo CÁNOVAS (1988), essa eficiência pode ser superior à resistência dada por outras técnicas. As principais vantagens desse método de reabilitação são:

1 - maior conhecimento dos materiais empregados (concreto e o aço);

2 - domínio e conhecimento da execução;

3 - custo em geral mais baixo, se comparado com outros métodos de recuperação.

Por outro lado, tem-se como desvantagens a necessidade de fôrmas para concretagem, o aumento de seção transversal das peças na maioria dos casos, e o fato de que a peça reforçada só poderá ser solicitada após o concreto ter atingido a sua resistência de projeto. O principal problema é a mudança de volume que, devido à 
retração, prejudica a aderência e induz a fissuração, provocando a separação entre o concreto antigo e o material novo. Para melhorar a aderência e controlar a retração, o CEB (1983), recomenda que sejam tomadas as seguintes precauções:

- remover o concreto deteriorado ou desintegrado com ponteiro ou talhadeira. Por razões práticas, o tamanho mínimo da camada a ser adicionada deve ficar em torno de $75 \mathrm{~mm}$ a $100 \mathrm{~mm}$, possibilitando que a compactação do novo concreto e o posicionamento da nova armadura possam ser feitos de forma adequada;

- promover uma superfície rugosa deixando os agregados expostos, e remover, quando necessário, o concreto que envolve as armaduras, eliminando somente o concreto deteriorado;

- remover a ferrugem das armaduras e óleos do concreto;

- eliminar o pó utilizando água sob pressão;

- saturar o concreto antigo por pelo menos seis horas antes de aplicar o concreto novo. Este procedimento não é recomendado por alguns pesquisadores que acreditam que esse umedecimento pode prejudicar a adesão entre reforço/substrato ao invés de melhorá-la;

- evitar bolhas de ar aplicando concreto ou argamassa com uma maior fluidez e a partir de um mesmo lado da fôrma. Muitas vezes, é necessário abrir janelas temporárias na fôrma para lançar o concreto e permitir a passagem do vibrador de imersão;

- promover a cura com umedecimento da superfície ou cobrindo-a com materiais úmidos tais como areia, espuma, estopa e outros. Este umedecimento deve persistir por dez dias, no mínimo;

- usar concreto de melhor qualidade, com resistência característica de, no mínimo, $5 \mathrm{MPa}$ a mais do que a do concreto existente;

- reduzir a quantidade de água com o uso de superplastificante.

Recomenda-se ainda que o concreto ou a argamassa de reforço tenham resistência mecânica, módulo de elasticidade e coeficiente de dilatação compatíveis com os do concreto existente. 
Para recuperação de elementos em locais de difícil acesso, uma alternativa consiste na utilização do concreto projetado, o qual pode ser lançado em qualquer superfície e direção e necessita de uma menor quantidade de fôrmas. A desvantagem desse método é relacionada aos custos mais elevados e necessidade de mão-de-obra e equipamentos especializados.

\subsubsection{Reforço mediante aumento de seção transversal}

Este tipo de reforço pode ser utilizado quando a viga apresenta insuficiência de armadura na zona tracionada.

O reforço realizado com concreto adequadamente preparado apresenta boa eficiência, sendo em muitos casos superior à obtida por outros métodos. Contudo, esse sistema de reforço padece do inconveniente de produzir seções finais de dimensões muito superiores às iniciais de projeto, o que, em alguns casos, pode ser indesejável e problemático.

Caso a concretagem seja dificultada pela existência de lajes que não podem ser danificadas, faz-se o apicoamento da peça para retirar a camada superficial de argamassa nas faces da viga e a camada de concreto, na face inferior, até encontrar os estribos da viga original, onde serão fixadas as novas armaduras transversais. Os estribos adicionados devem ser dimensionados para suportar os esforços tangenciais que provocam uma tendência de deslizamento horizontal entre o substrato e o material de reforço. Em seguida, são colocadas as armaduras longitudinais de reforço e fixadas as fôrmas suspensas (cachimbos). Por fim, realiza-se a concretagem conforme Figura 2.31. O excesso de concreto deve ser retirado posteriormente ao endurecimento do material do reparo, utilizando talhadeiras ou marretas. Para os casos em que a laje pode ser danificada, o procedimento é o ilustrado na Figura 2.32.

De acordo com a bibliografia disponível, recomenda-se fazer furos para a passagem dos estribos com brocas de $20 \mathrm{~mm}$ e dispor as armaduras do reforço o mais próximo possível das barras existentes, a fim de diminuir as distâncias dos planos dos baricentros das duas armaduras. Uma vez introduzidos os estribos, os vazios existentes entre eles e os furos devem ser preenchidos manual ou mecanicamente, com pasta de cimento injetada com relação água-cimento (a/c) não superior a 0,40 . 

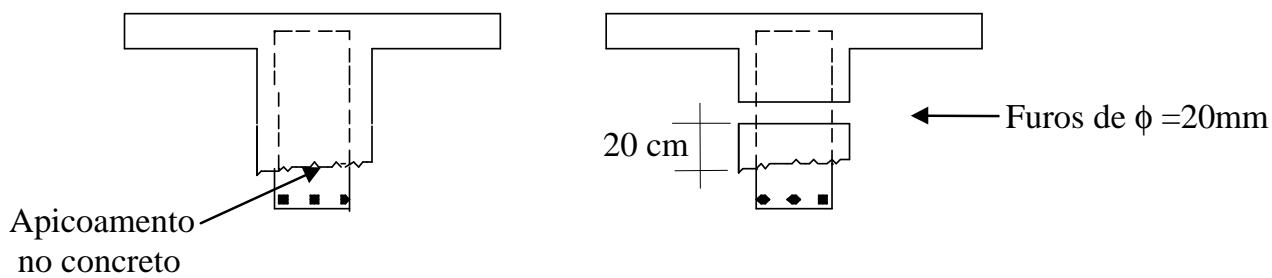

no concreto

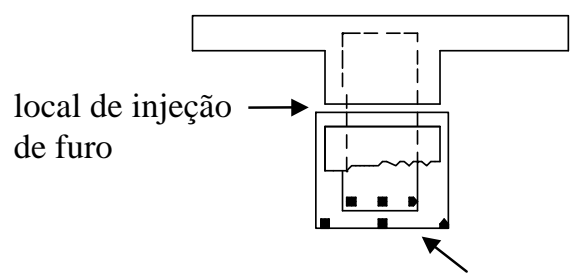

Armadura de reforço fixada por estribos

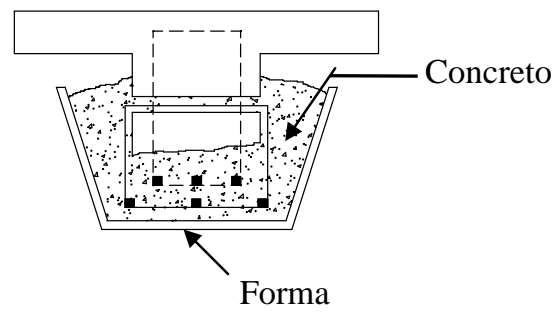

(2)

\section{Figura 2.31 - Reforço de viga com nova armadura atada à mesma}

\section{(CÁNOVAS, 1988)}

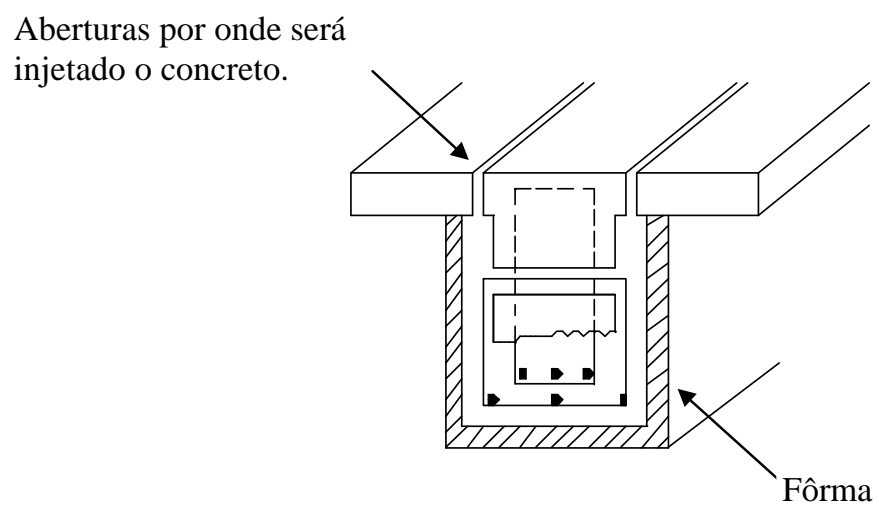

\section{Figura 2.32 - Reforço com aumento da base com danos à laje} (CÁNOVAS, 1988)

Para realizar a ancoragem das barras que chegam até os apoios, PETRUCCI, apud CÁNOVAS (1988), recomenda furar o concreto e, após a introdução das barras, preencher os vazios com argamassa epóxi ou com injeções de adesivo.

Para o dimensionamento da peça, deve-se ressaltar que as armaduras ficam em planos diferentes e, portanto, as distâncias dos baricentros das armaduras iniciais e do reforço à armadura de compressão são distintas. Apesar da viga ter sido inicialmente descarregada através de escoramento, é provável que a descarga não 
tenha sido total. Sendo assim, a armadura antiga pode estar submetida a uma tensão maior do que a do reforço. Tal fato, assim como as diferenças na posição dos baricentros das armaduras, devem ser considerados no dimensionamento.

Quando não é necessário estribos adicionais, pode-se usar chaves de cisalhamento na face inferior da viga, a fim de absorver os esforços cortantes que agem na interface entre o substrato e o concreto novo (ver Figura 2.33).
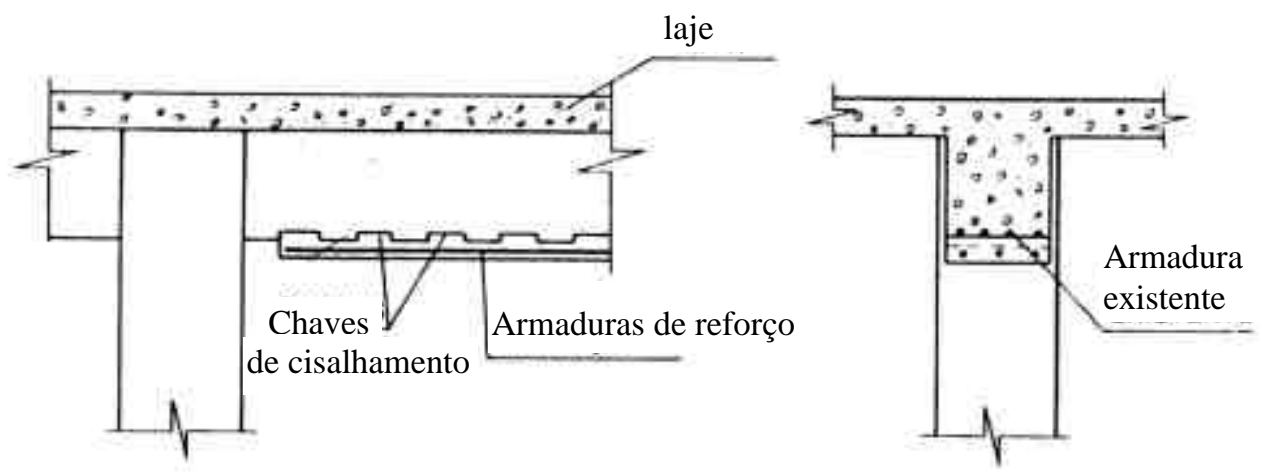

Figura 2.33 - Reforço de viga mediante “denteamento” (CÁNOVAS, 1988)

Caso não sejam utilizados aditivos e adesivos no concreto novo, o CEB (1983) recomenda que a tensão tangencial na superfície de aderência, $\tau_{\alpha}$, calculada pela expressão 2.26, seja menor que o valor limite fornecidos pela expressão 2.27 :

$$
\tau_{\alpha, \max }=\frac{1}{\gamma_{c}} \cdot \frac{2}{10} \mathrm{f}_{c k}^{2 / 3}
$$

onde:

$\tau_{\alpha, \max }$ - tensão tangencial limite na interface reforço/substrato;

$\mathrm{f}_{\mathrm{ck}} \quad$ - resistência característica do concreto antigo à compressão em MPa;

$\gamma_{c}$ - coeficiente de minoração da resistência do concreto.

Quando se aplicam adesivos na união concreto velho/concreto novo, essa mesma norma não limita a tensão tangencial na interface, permitindo considerar o elemento reforçado como monolítico. Recomenda-se ainda que o acréscimo de área na seção transversal da viga seja menor que um terço da área da seção original. 
É importante ressaltar que para qualquer que seja a técnica de reabilitação escolhida, é imprescindível tomar cuidados especiais (ver item 2.6.1) durante o preparo da superfície a receber a intervenção.

\subsubsection{Reforço mediante substituição do material danificado}

Nesse caso, o reforço é executado sem aumento de seção e deve ser realizado por meio de abertura de sulcos longitudinais na face da viga que apresenta deficiência de armaduras. Sendo assim, adiciona-se barras de aço na face superior quando faltam armaduras de compressão ou de tração (devido ao momento fletor negativo) e na face inferior quando faltam armaduras de tração (devido ao momento fletor positivo). Nesses sulcos são introduzidas as armaduras de reforço, preenchendo-se, posteriormente, os espaços vazios com argamassa epóxi ou com argamassa expansiva de alta resistência, para evitar retração (ver Figura 2.34).

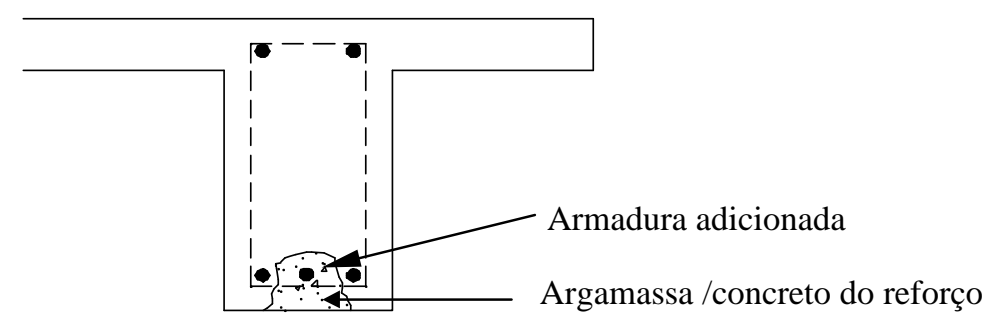

Figura 2.34 - Reforço realizado por meio de sulcos longitudinais

Este método, apesar de ser bastante trabalhoso, apresenta a vantagem de não aumentar a altura da viga. Deve-se salientar que as armaduras podem ser distintamente solicitadas, especificamente se a viga não foi totalmente descarregada antes da intervenção.

\subsubsection{Reforço mediante o uso de chapas de aço}

Esta técnica de recuperação consiste na colagem de chapas de aço, na superfície dos elementos de concreto armado, utilizando colas epóxicas. Segundo 
CÁNOVAS (1988), sua eficácia está avalizada pela quantidade de obras que foram realizadas até o momento.

Dentre as inúmeras vantagens proporcionadas pela utilização de resinas epóxi no campo das reparações e reforços, percebe-se que uma das mais importantes é a de permitir a união de aço a concreto. Mediante aplicação de resinas epóxi, a armadura suplementar introduzida na viga ou elemento danificado é incorporada em forma de chapas de aço coladas ao concreto no lugar adequado. As principais vantagens observadas na aplicação desse tipo de intervenção são:

1. rapidez na execução;

2. não utilização de materiais molhados ou úmidos;

3. ausência de vibrações e baixo nível de ruídos;

4. não há necessidade de instalações auxiliares importantes;

5. o acréscimo da seção é muito pequeno;

6. pouca interferência no uso da estrutura durante a execução da reabilitação* .

Como a armadura suplementar aparece em forma de chapas de aço, alterando muito pouco as dimensões finais da peça, não há necessidade de se fazer uma redistribuição das ações no restante da estrutura. Esta técnica, no entanto, tem sido criticada devido aos seguintes fatores:

1. a colagem das chapas impede a visualização de fissuras que podem aparecer, indicando deficiência da capacidade portante da peça, bem como a visualização de possíveis deteriorações por corrosão na face interna da viga, causadas por eventual penetração de umidade entre a chapa e a cola;

2. tanto a chapa de aço, devido à pequena espessura, quanto a resina epóxi apresentam baixa resistência a elevadas temperaturas. Isto aumenta o risco de ruína no caso de incêndio;

\footnotetext{
* No caso de carregamento preponderantemente móvel, como em pontes e viadutos, nem sempre é necessário o uso de escoramentos. Já no caso de edificações, o escoramento é necessário pois o peso próprio é bem maior proporcionalmente que a sobrecarga. Sendo assim, o simples descarregamento das sobrecargas não é suficiente para que, ao recarregar a estrutura, o reforço também entre em carga.
} 
3. tendência de descolamento das extremidades da chapa em relação ao substrato devido às elevadas concentrações de tensão nessa região;

4. exigência de não haver umidade para a utilização com resina epóxi.

Numa ligação de dois materiais mediante colagem, a adesão é a propriedade mais relevante. A intensidade dessa adesão depende da qualidade do adesivo, do estado das superfícies dos dois materiais e das propriedades dessas superfícies. No reforço de vigas ou lajes de concreto, por meio de colagem de chapas de aço com resinas epóxi, deve-se sempre garantir um valor limite mínimo de adesividade tangencial. Esta limitação tem por finalidade prevenir a ocorrência de falhas no plano da ligação, produzidas por esforços tangenciais causados pelo carregamento. Estudos sistemáticos da colagem de chapas de aço ao concreto por meio de adesivo epóxi para recuperação de estruturas tiveram início em 1964, tendo sido desenvolvido inicialmente, por L'HERMITE e, em seguida, por JAQUES BRESSON na França.

As espessuras da camada de resina epóxica e das chapas de aço devem respeitar limites máximos de 1,5 $\mathrm{mm}$ e $3,0 \mathrm{~mm}$, respectivamente. Havendo necessidade de chapa com maior espessura, deve-se utilizar sistemas especiais de ancoragem. Entretanto, mesmo utilizando esses dispositivos, a espessura da chapa não deve ser superior a $10 \mathrm{~mm}$ pois chapas mais espessas, sendo pouco flexíveis, não se adaptam às irregularidades da superfície do concreto. Por outro lado, chapas muito finas são problemáticas, pois empenam e dificultam a sua colocação. De acordo com RODRIGUES (1994), o coeficiente largura/espessura ideal da chapa varia entre 50 e 60. Coeficientes iguais ou menores do que 40 poderão causar tensões excessivas na região de colagem, resultando no levantamento das extremidades das chapas.

Para realizar o dimensionamento deste reforço, deve-se conhecer as características mecânicas do aço que compõe a chapa: resistência à tração e módulo de elasticidade. A partir desses dados, determina-se a área da seção transversal da chapa, de forma que a peça reforçada, se submetida a esforços maiores do que os previstos, atinja a ruína simultaneamente por plastificação do concreto na zona comprimida e escoamento das barras e chapa de aço, não ocorrendo ruptura na superfície de contato entre chapa/adesivo ou entre adesivo/concreto. 
Nesse tipo de reforço, é imprescindível garantir uma superfície de concreto com resistência suficiente para transmitir os esforços de cisalhamento atuantes na ligação. A resistência da chapa não deve ser totalmente explorada. Para evitar descolamento na região de ancoragem, deve-se utilizar chumbadores metálicos ou estender a chapa até regiões onde ela não seja necessária. CAMPAGNOLO (1993) indica alguns tipos de ancoragens para esses casos (ver Figura 2.35).

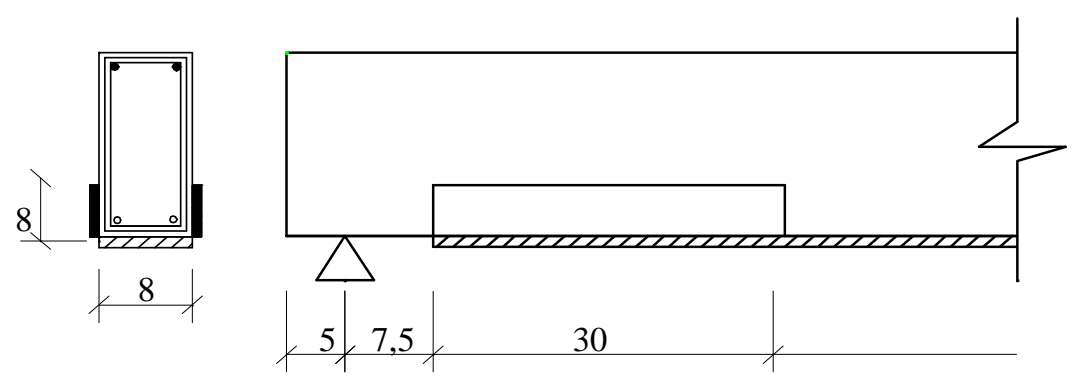

(a) Ancoragem por meio de chapa lateral

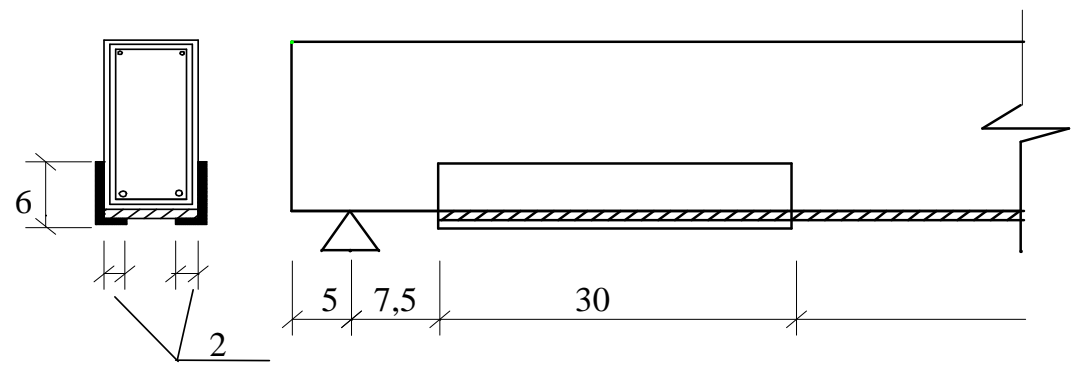

(b) Ancoragem por meio de chapa envolvente

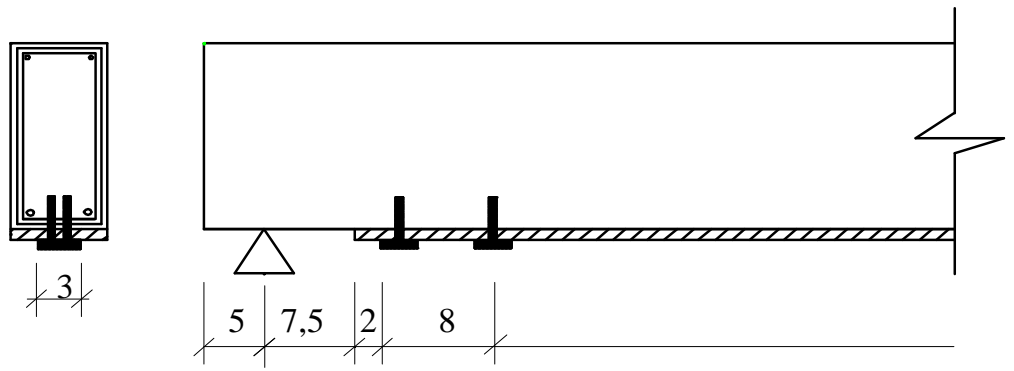

(c) Ancoragem por meio de parafusos tipo "parabolt"

Figura 2.35 -Tipos de ancoragem estudadas por CAMPAGNOLO (1993) 
Para obter uma colagem satisfatória da chapa no elemento de concreto, devese pressioná-la de forma uniforme por, no mínimo, 24 horas. Este tempo de colagem varia em função do tipo de resina empregado e da temperatura ambiente.

De acordo com o CEB (1983), também é possível fixar as chapas de aço ao elemento a ser reforçado através de chumbadores, com posterior injeção de resina entre o aço e o concreto, eliminando assim a probabilidade da formação de bolhas de ar na camada de resina.

PETRUCCI, citado por SALES et ali (1994), recomenda que, se o comprimento da chapa não for suficiente para cobrir toda extensão do reforço, devese efetuar emendas através de soldagem das chapas. Nesse caso, sobre a zona soldada deve-se fazer uma cobrejunta com chapa de aço de mesma espessura, colada com adesivo epóxi.

No caso de reforço com chapas de aço, além dos modos de ruptura convencionais que podem existir em qualquer peça de concreto armado (ruptura ocasionada por ação do momento fletor ou do esforço cortante) podem ocorrer ainda a ruptura por descolamento da chapa ou a ruptura por arrancamento do concreto de cobrimento (ver Figura 2.36).

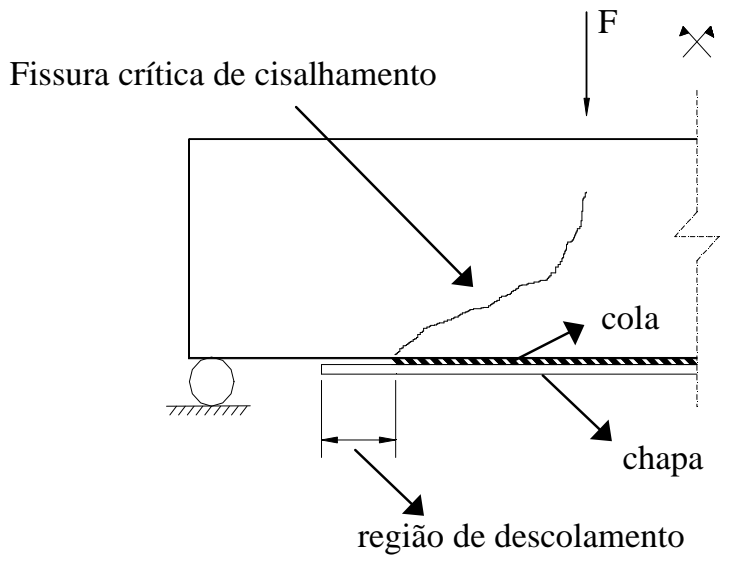

(a) ruptura por descolamento da chapa

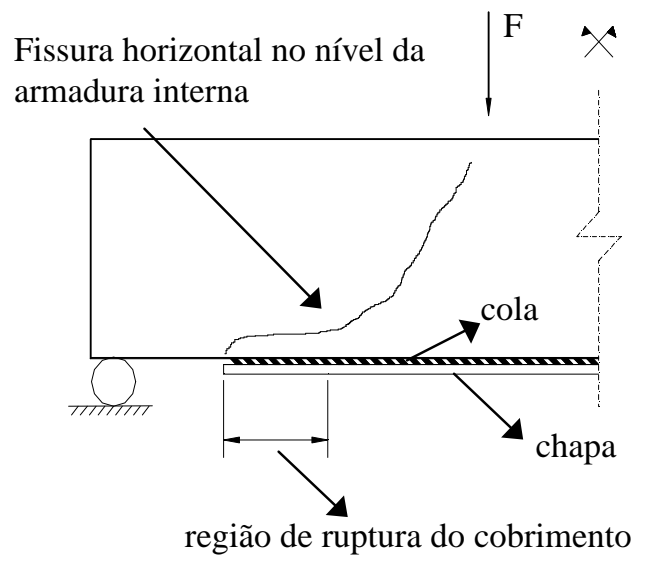

(b) ruptura por arrancamento do cobrimento

Figura 2.36 - Modos de ruptura prematura em vigas reforçadas com chapas de aço 
A ruptura por descolamento da chapa de aço ocorre devido a uma má execução da colagem ou quando a espessura da chapa começa a ficar acima dos 2 mm. Pode ocorrer ainda quando o carregamento for muito rápido ou em situações de impacto. A ruptura por arrancamento do cobrimento caracteriza-se por uma fissura, surgida na seção transversal coincidente com a extremidade da chapa, que se horizontaliza mais ou menos no nível das armaduras internas. Estas fissuras, ao ligarem-se com as fissuras de cisalhamento, levam a viga a um colapso brusco (SILVEIRA, 1997).

Para evitar a ruptura prematura da viga reforçada com chapas de aço, o CEB (1983) estabelece limites para o valor da tensão tangencial na interface reforço/substrato. Como a resistência de aderência depende mais da resistência do concreto à tração do que da resistência do adesivo ao cisalhamento, recomenda-se que, para chapas coladas continuamente, $\tau_{\alpha}$, calculada pela equação 2.26 , seja menor que a resistência média do concreto à tração dada pela expressão 2.28.

$$
\tau_{\alpha} \leq \frac{1}{\gamma_{c}} \cdot f_{c t, m}
$$

\subsection{Mecanismos de ruína em vigas}

Este item aborda os principais mecanismos de ruína em vigas de concreto armado. $\mathrm{O}$ conhecimento desses mecanismos permite que, a partir do esquema de fissuração, sejam identificadas as causas da deterioração do elemento estrutural.

As vigas de concreto armado podem atingir o estado limite último basicamente pela ação de dois tipos de esforços que são as solicitações normais (ação de momento fletor) e as tangenciais (ação de força cortante). Para cada uma dessas solicitações existem diferentes mecanismos de ruína que dependem da taxa de armadura longitudinal e transversal do elemento. A Figura 2.37 ilustra as principais configurações de ruína.

\section{- Ruína por solicitações normais}


Para esse caso, existem duas formas de atingir o estado limite último, a saber:

1. Deformação plástica excessiva da armadura longitudinal de tração;

2. Esmagamento do concreto na face comprimida.

O escoamento da armadura tracionada ocorre quando a viga é subarmada, ou seja, a taxa de armadura longitudinal é pequena, fazendo com que o processo de ruína se inicie na seção de momento máximo. Nesse caso, o limite de deformação do aço é atingido antes do concreto na zona comprimida romper por esmagamento. Dessa forma, presenciam-se fissuras com grandes aberturas e flechas com valores excessivos, indicando uma ruína dúctil. Como conseqüência do aumento de deformação do aço, ocorre uma diminuição na altura da linha neutra, podendo ocasionar, inclusive, a ruptura do concreto na região comprimida, conforme ilustra a Figura 2.37a.

Para casos extremos de peças subarmadas, pode ocorrer uma ruptura brusca quando a força de tração no concreto for maior do que a resistência da armadura longitudinal à tração. Nesse caso, o surgimento da primeira fissura de flexão pode provocar a ruína da peça. Por esse motivo são definidas as percentagens mínimas de armadura.

Quando a viga é superarmada, ou seja, com elevada taxa de armadura longitudinal, a ruptura ocorre de maneira frágil devido ao esmagamento do concreto comprimido (ver Figura 2.37b). Este caso ocorre principalmente em vigas de concreto de alta resistência e deve ser evitado por causa do perigo que oferece, já que não existe um aviso prévio de que a estrutura está atingindo o estado limite último.

\section{- Ruína por solicitações tangenciais}

Nos locais onde a viga está submetida a esforços cortantes, surgem tensões principais de tração inclinadas. Quando essas tensões são superiores à resistência do concreto, aparecem fissuras de cisalhamento e, consequientemente, uma transposição dos esforços existentes na peça para a armadura de cisalhamento e para as diagonais comprimidas de concreto. Essa redistribuição de esforços internos depende muito da 
quantidade e da direção da armadura de cisalhamento. Assim sendo, são possíveis diversos tipos de ruptura para esse tipo de solicitação, as quais podem ser classificadas em:

a) Escoamento da armadura transversal (Força Cortante - Tração)

Esta configuração de ruína corresponde a um estado limite último convencional, pois alcançá-lo não significa que simultaneamente ocorra o colapso da peça, FUSCO (1982) apud TOTTI JR e GIONGO (1994). Este tipo de ruptura provoca grandes deformações na armadura transversal e fissuração excessiva (ruína dúctil), caracterizando ruptura de peça subarmada transversalmente. O colapso pode ocorrer de quatro maneiras distintas:

1. Tração diagonal ou ruptura da armadura transversal;

2. Esmagamento prematuro das bielas;

3. Esmagamento do banzo comprimido;

4. Flexão localizada da armadura longitudinal.

A ruína por tração diagonal, ilustrada na Figura $2.37 \mathrm{c}$, é causada por deficiência na quantidade de armadura transversal destinada a absorver as tensões de tração diagonal devidas ao cisalhamento, provocando o fendilhamento da peça. É possível ocorrer, inclusive, a ruptura da armadura transversal.

Dependendo da largura da viga, é possível atingir a resistência última da peça pelo esmagamento prematuro das bielas comprimidas (ver Figura 2.37d). Nesse caso, a armadura transversal entra em escoamento sofrendo grandes deformações e fazendo com que a tensão correspondente seja praticamente constante. Dessa forma, os acréscimos de esforços passam a ser absorvidos pelas bielas comprimidas, conduzindo ao esmagamento do concreto.

O terceiro tipo de ruína ocorre como conseqüência da redução na altura do banzo comprimido devido à fissuração gerada pela deformação excessiva da armadura transversal (ver Figura 2.37e). Por esse motivo, deve-se dar atenção 
especial às regiões próximas aos apoios intermediários de vigas contínuas, já que nesses locais, tanto a força cortante quanto o momento fletor têm valores elevados.

A flexão localizada da armadura longitudinal ocorre devido ao fato das bielas comprimidas estarem "apoiadas" também nas barras dessa armadura. Sendo assim, o alongamento excessivo da armadura transversal reduz sua participação como apoio, podendo provocar esse tipo de ruína (ver Figura 2.37f).

b) Esmagamento das bielas comprimidas (Força Cortante - Compressão)

É característico de peças superarmadas transversalmente ou quando a armadura transversal é suficiente, porém a largura da viga é pequena para resistir aos esforços de compressão gerados pela força cortante. Ocorre de maneira frágil (sem aviso) pois o esmagamento do concreto das bielas se dá antes da armadura transversal atingir o escoamento. Este mecanismo difere do esmagamento prematuro das bielas, porque naquela situação o esmagamento ocorre por escoamento da armadura transversal (ver Figura $2.37 \mathrm{~g}$ ).

c) Deficiência de ancoragem

É um tipo de ruína brusca que ocorre devido ao deslizamento da armadura de flexão da viga na região do apoio, indicando que o comprimento das barras de aço não foi suficiente para resistir às forças de tração existentes no local (ver Figura 2.37h). 


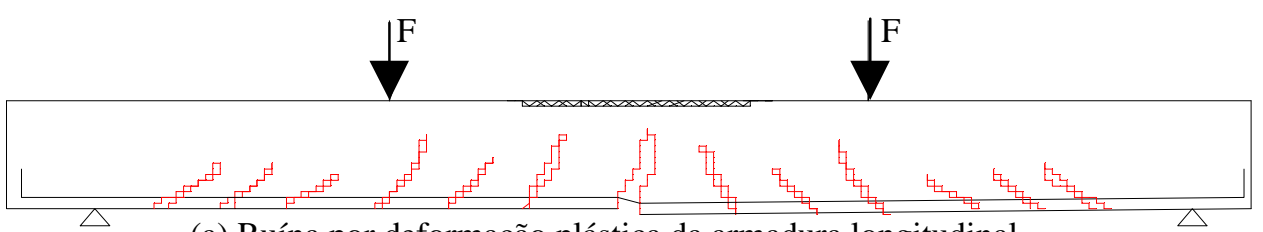

(a) Ruína por deformação plástica da armadura longitudinal

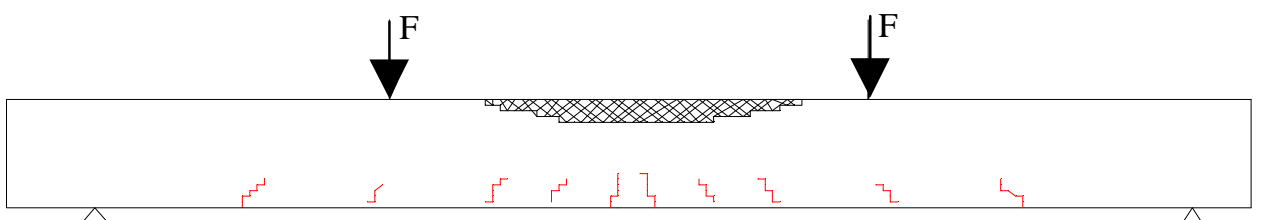

(b) Ruína por esmagamento da face comprimida do concreto

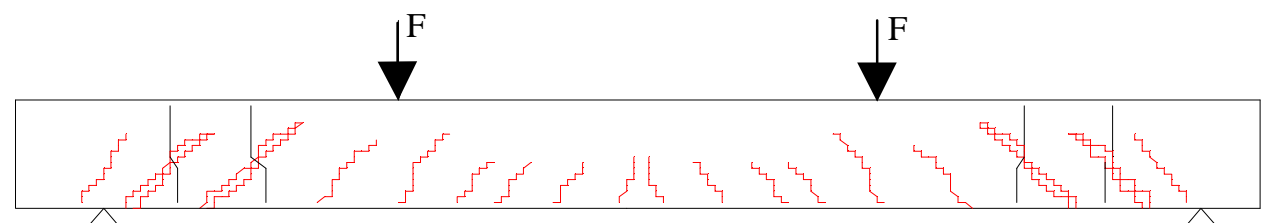

(c) Ruína por tração diagonal ou ruptura da armadura transversal

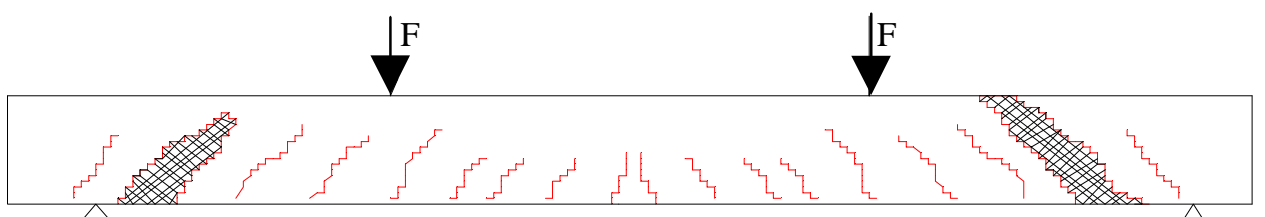

(d) Ruína por esmagamento prematuro das bielas

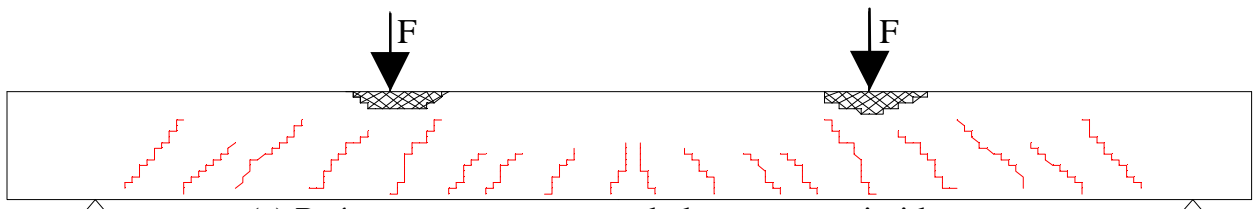

(e) Ruína por esmagamento do banzo comprimido

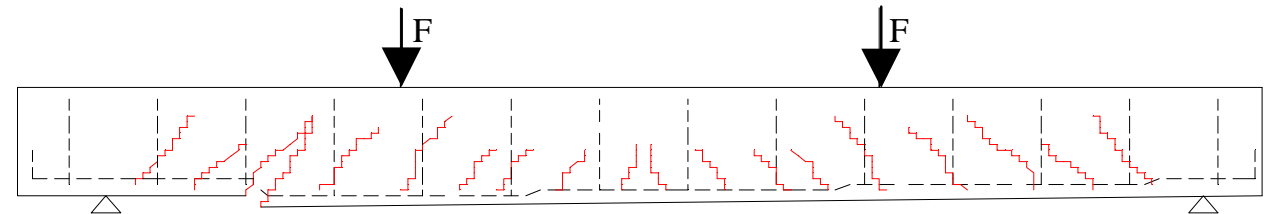

(f) Ruína por flexão localizada da armadura longitudinal

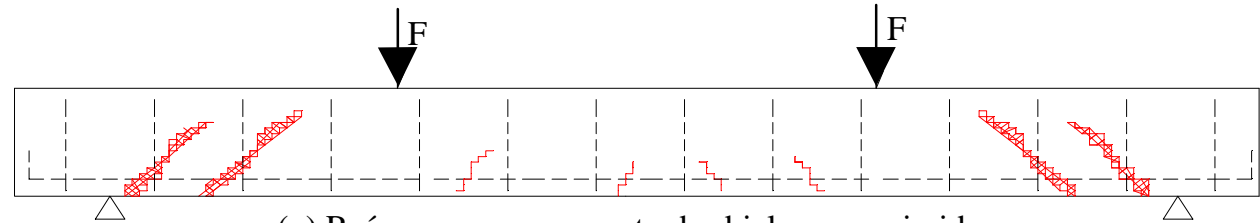

(g) Ruína por esmagamento das bielas comprimidas

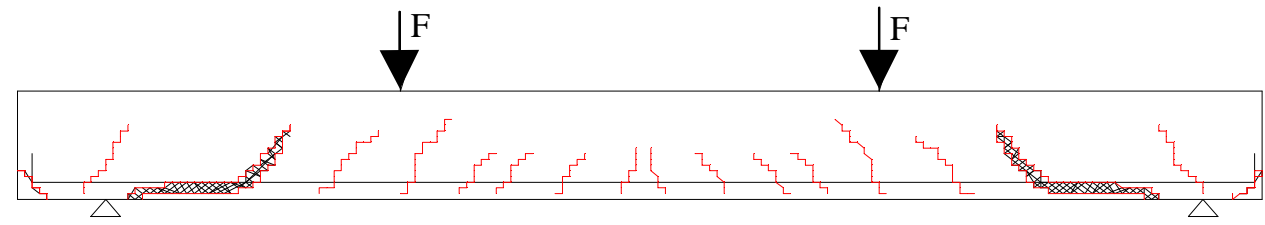

(h) Ruína por deficiência de ancoragem

Figura 2.37 - Tipos de ruptura em vigas de concreto armado 


\section{ENSAIOS REALIZADOS POR OUTROS PESQUISADORES}

\subsection{Revisão Bibliográfica}

Não se pode dizer que o interesse pelas causas e formas de solucionar a degradação de estruturas de concreto armado é recente. Já em 1856, Robert Stevenson, presidente do Instituto Britânico de Engenharia, recomendava que os acidentes ocorridos deviam ser estudados, analisados e divulgados, pois nada seria tão útil e instrutivo para os profissionais da Engenharia como o conhecimento deles e os meios empregados em sua reparação (CÁNOVAS, 1988). Apesar disso, somente após o colapso de grandes estruturas que ocorreram em todo o mundo*, percebeu-se com mais intensidade o surgimento de empresas especializadas em diagnosticar as causas da degradação e as formas de reabilitar estruturas de concreto. Entretanto, ainda existe uma grande carência de conhecimento a respeito de como se comportam as estruturas reabilitadas.

Nesse item, descreve-se, de forma sucinta, alguns trabalhos mais recentes a respeito de reabilitação de estruturas de concreto submetidas à flexão, com a finalidade

\footnotetext{
* No Brasil pode-se citar o caso do Pavilhão de Exposições da Gameleira em Belo Horizonte e do Viaduto Paulo de Frontin no Rio de Janeiro.
} 
de fornecer um panorama geral das pesquisas realizadas sobre este tema ${ }^{*}$.

No Brasil, entre os trabalhos mais importantes realizados e divulgados na área de reabilitação de vigas, pode-se citar aqueles desenvolvidos pelos pesquisadores: João Carlos T. S. Clímaco, da Universidade de Brasília; Regina Helena F. Souza e Vicente Custódio M. de Souza, da Universidade Federal Fluminense; Ibrahim Shehata, na COPPE da Universidade Federal do Rio de Janeiro; João L. Campagnolo, da Universidade Federal do Rio Grande do Sul; Élvio Piancastelli, da Universidade Federal de Minas Gerais e outros.

Em sua tese de doutorado, CLÍMACO (1990) desenvolveu um programa experimental para analisar o comportamento de vigas biapoiadas, reforçadas por adição de concreto novo, com ou sem novas armaduras de tração. Também foram estudados métodos para avaliar a resistência de aderência entre o substrato e o reparo/reforço. $\mathrm{O}$ trabalho de SOUZA (1990), desenvolvido em Portugal, seguiu essa mesma linha de pesquisa ao analisar o comportamento de vigas biapoiadas, de concreto armado, reforçadas ao momento fletor e ao esforço cortante. No caso do reforço devido as ações normais, adicionou-se barras de aço no bordo tracionado, envolvendo-as posteriormente com argamassa ou concreto projetado.

PIANCASTELLI, desde 1995, tem realizado um extenso programa experimental sobre vigas biapoiadas, reabilitadas através do aumento das seções transversais de concreto e adição de armadura longitudinal. Em seus diversos artigos publicados, o autor descreveu o comportamento e a eficiência dessas vigas quando solicitadas a baixa idade, observando a influência do nível de carregamento existente durante a execução do reforço e do número de estribos prolongados que envolveram a armadura adicionada.

Ainda no âmbito experimental, CAMPAGNOLO et al. (1996) realizaram no LEME-CPGEC/UFRGS ${ }^{\dagger}$, ensaios em vigas com trechos de armadura exposta a fim de

\footnotetext{
* Alguns dos trabalhos abordados serão melhor detalhados no item 3.2 deste capítulo a fim de possibilitar que se façam comparações entre o comportamento das peças ensaiadas na EESC - USP e os resultados experimentais obtidos por outros pesquisadores.

${ }^{\dagger}$ LEME-CPGEC/UFRGS - Laboratório de Ensaios e Modelos Estruturais do curso de pós-graduação em Engenharia Civil da Universidade Federal do Rio Grande do Sul
} 
elaborar um método que avaliasse a capacidade estrutural remanescente durante o processo de recuperação dessas peças.

RODRIGUES (1996), aproveitando os resultados experimentais de SOUZA e PIANCASTELLI, desenvolveu um programa computacional para simular o comportamento de vigas biapoiadas de concreto armado reforçadas mediante adição de armadura longitudinal envolvida por concreto.

De posse de vários resultados experimentais realizados na COPPE ao longo dos últimos anos, SHEHATA publicou, em 1997, um artigo onde se avaliava a eficiência de vigas de concreto armado reabilitadas devido as ações normais e tangenciais simultaneamente, utilizando diversas técnicas de reabilitação.

No que se refere às pesquisas realizadas no exterior, pode-se citar SAIIDI (1990). Este autor, juntamente com outros pesquisadores, desenvolveram um modelo analítico para prever o comportamento de vigas reabilitadas pela da adição de camadas de concreto na zona tracionada e/ou na zona comprimida e estudaram também a interferência do uso de resina epóxi na resistência da ligação reparo/substrato.

Além do uso do concreto, um outro material que tem se destacado como alternativa para a reabilitação de estruturas fletidas é a argamassa armada. Vários estudos têm sido desenvolvidos, principalmente no exterior, a respeito do comportamento de peças de concreto armado reforçadas utilizando esse material. Dentre os pesquisadores que mais se dedicaram ao estudo dessa nova técnica de reforço, pode-se citar: Ahmad, da Nacional Engineering Services of Pakistan; Ong e Paramasivam do Departament of Civil Engineering of National University of Singapore; Sharma da University fo West Indies na Tailândia, entre outros.

AHMAD et al. (1991) ensaiaram várias vigas utilizando telas de galinheiro hexagonais como armadura de reforço envolvidas por argamassa comum. Foram estudados parâmetros relativos à variação da taxa de armadura e à configuração geométrica da tela. Além disso, fez-se uma análise da influência do grau de descarregamento da viga durante a execução do reparo. De acordo com os autores, esta técnica é de fácil execução pois não exige mão-de-obra e equipamentos especializados. 
Além disso, o aumento da ação permanente devido ao peso próprio da intervenção é praticamente desprezível.

ONG et al. (1992) investigaram o comportamento de vigas biapoiadas reabilitadas aplicando camadas de argamassa armada no bordo tracionado. Os parâmetros observados foram: ligação entre reparo e substrato com/sem conectores de cisalhamento e com/sem pontes de aderência, taxa de armadura do reforço e nível de dano nas vigas antes da reabilitação. A maioria das vigas apresentou resistência última maior do que as das vigas de controle, indicando que o uso de resina epóxi e de conectores de cisalhamento conseguiram garantir o monolitismo das peças.

O trabalho desenvolvido por SHARMA (1992) forneceu dados sobre o comportamento de vigas contínuas de concreto armado fletidas e reabilitadas por encamisamento da armadura longitudinal utilizando concreto normal ou um material composto denominado fibro-ferroconcrete, que correspondia a uma argamassa armada com adição de fibras de aço. O comportamento estrutural das vigas reabilitadas foi similar ao das vigas originais, sendo que as peças que utilizaram o fibro-ferroconcrete resistiram melhor ao início de fissuração e tiveram capacidade portante maior do que as vigas originais e do que as peças reforçadas com concreto convencional.

PARAMASIVAM et al. (1993) analisaram o comportamento de vigas de seção transversal T, simplesmente apoiadas e reabilitadas com camadas de argamassa armada. A tela soldada foi fixada ao substrato por conectores de cisalhamento feitos com barras de aço CA-25 dobradas em L. Os autores concluíram que a adição de camadas de argamassa armada na face tracionada da viga usando conectores em L para fixar a tela de aço foi eficiente. $\mathrm{O}$ aparecimento da primeira fissura foi retardado pela presença da argamassa armada, sendo este fator influenciado pela taxa de armadura de tela soldada. A rigidez à flexão nas peças reabilitadas foi maior do que a das vigas de controle. Entretanto, o acréscimo de rigidez dependeu do surgimento de fissuras horizontais e eventuais descolamentos na interface de ligação entre o reparo e o substrato.

Uma outra técnica muito utilizada na reabilitação de peças fletidas é a introdução de chapas de aço como armadura de reforço adicional coladas com resina epóxi no bordo 
tracionado. Dentro desta área de pesquisa, os primeiros ensaios foram realizados por Jacques Bresson e Robert L'Hermite no final da década de 60. Nessa mesma época, também surgiram na África do Sul, vários estudos sobre esse tipo de reforço.

BRESSON (1971), apud TEIXEIRA JR. (1994), realizou no ITBTP (Institut Technique du Batiment et des Travaus Publics) estudos teórico-experimentais sobre a união chapas de aço, resina epóxi e concreto. Nos ensaios foram medidas as tensões de cisalhamento nas ligações entre o aço e a resina e entre o concreto e a resina, variando-se a espessura da chapa. Entre os três materiais, constatou-se que o concreto é o elo mais fraco e, portanto, é este material que determina o valor da tensão máxima cisalhante que pode atuar na ligação reforço/substrato. A espessura da chapa também merece atenção especial, pois interfere na transmissão das tensões de cisalhamento para o elemento estrutural, sendo necessário prever uma espessura ótima. Em outro trabalho, BRESSON (1971) apud SILVEIRA (1997), analisou o comportamento de vigas reforçadas à flexão com chapas de aço coladas e propôs fórmulas para o cálculo da espessura da chapa de aço do reforço, das tensões limites e das tensões existentes na interface substrato/reforço.

Nas décadas de 70 e 80, na Inglaterra, vários pesquisadores tais como R.N. Swamy, R. Jones e G.C.Mays realizaram pesquisas fazendo com que essa técnica de reforço se tornasse mais confiável, viabilizando sua utilização em toda a Europa.

A dissertação de ALFAIATE (1986), desenvolvida em Lisboa, apresenta um estudo experimental de vigas de concreto armado fletidas reabilitadas por adição de chapas de aço no bordo tracionado. Em algumas peças a ligação entre o reforço e a estrutura original foi feita apenas com resina epóxi e em outras utilizou-se resinas epóxi e buchas metálicas.

No artigo publicado por ZIBARA et al. (1994), descreve-se procedimentos para dimensionar vigas de concreto armado reforçadas por chapas de aço baseado nos estados limites últimos. Estes procedimentos foram baseados na observação do comportamento experimental de peças reabilitadas por esta técnica e na simulação do comportamento da peça através de modelagens numéricas não-lineares, utilizando elementos finitos. 
Em um artigo publicado por CAMPAGNOLO nas XXVIII Jornadas SulAmericanas de Engenharia Estrutural, em 1997, descreveu-se um estudo teóricoexperimental de vigas reforçadas por chapas de aço fixadas no bordo tracionado através de resina epóxi e/ou parafusos. Outro aspecto observado foi a importância de realizar uma ancoragem adequada da chapa de aço do reforço, pois caso contrário poderia ocorrer uma ruína prematura devida à separação entre a chapa e o substrato. Um estudo mais aprofundado sobre a ancoragem das chapas de aço em vigas reabilitadas foi abordado por CAMPAGNOLO (1994).

Outros trabalhos que contribuíram para melhorar o conhecimento do comportamento de peças recuperadas foram os desenvolvidos na UFF* por SILVEIRA (1997) e na COPPE/UFRJ por MORAIS (1997).

SILVEIRA (1997), em sua dissertação de mestrado, descreveu diversos métodos de dimensionamento de vigas reforçadas por chapas de aço existentes na literatura. $\mathrm{O}$ autor desenvolveu ainda um novo método de cálculo para determinar a área de aço do reforço e comparou os resultados dos diversos processos de cálculo entre si e com os resultados fornecidos pelo método proposto.

MORAIS (1997) desenvolveu um programa experimental bastante genérico onde se estudou a eficiência de vários métodos de reforço concomitantemente ao momento fletor e ao esforço cortante, aplicados em vigas de concreto armado. As técnicas de reforço utilizadas foram: uso de tirantes externos pré-tracionados, colagem de chapas de aço com resina epóxi, uso de estribos externos pré-tracionados e uso de estribos em forma de "U" feitos a partir de tiras de chapas de aço.

A seguir, apresenta-se um levantamento de várias vigas ensaiadas através de técnicas de reabilitação semelhantes às empregadas neste trabalho (adição de armadura longitudinal ou fixação de chapa de aço no bordo tracionado). A análise destes dados permitirá verificar se há diferenças entre o comportamento das vigas reabilitadas por REIS (1998) e o comportamento observado nos programas experimentais desenvolvidos por outros pesquisadores.

\footnotetext{
*UFF - Universidade Federal Fluminense
} 


\subsection{Reabilitação por adição de armadura longitudinal convencional}

Em relação à reabilitação de vigas por adição de armadura longitudinal no bordo tracionado da peça, analisou-se os trabalhos realizados por SOUZA, CLÍMACO e PIANCASTELLI.

\subsubsection{Ensaios realizados por SOUZA (1990)}

O trabalho de SOUZA (1990) mostra os resultados dos ensaios de várias vigas biapoiadas de concreto armado, reforçadas ao momento fletor. Os modelos ensaiados apresentavam escala reduzida de aproximadamente 1:2,5 e simulavam erros de projeto referentes a deficiência das armaduras. Esses modelos foram inicialmente ensaiados até um determinado nível de carregamento, suficiente para provocar a fissuração da peça correspondente aos danos que se pretendia simular. Depois, dava-se início aos trabalhos de reforço com adição de armaduras envolvidas por concreto projetado ou argamassa especial à base de resinas acrílicas. Feito isso, a viga era reensaiada até a ruína. Para facilitar a identificação das vigas ensaiadas, foi utilizada a nomenclatura da Tabela 3.1.

Os detalhes das fôrmas e armaduras das vigas ensaiadas estão ilustrados nas Figuras 3.1 a 3.4 .

Tabela 3.1 - Características das vigas ensaiadas por SOUZA (1990)

\begin{tabular}{|c|c|c|c|c|c|c|c|c|}
\hline \multirow[b]{2}{*}{ Viga } & \multirow[b]{2}{*}{$\begin{array}{l}\text { Tipo de } \\
\text { ensaio }\end{array}$} & \multirow[b]{2}{*}{$\begin{array}{l}\text { Tipo de } \\
\text { reforço } \\
\end{array}$} & \multicolumn{3}{|c|}{ Substrato } & \multicolumn{3}{|c|}{ Reforço } \\
\hline & & & $\begin{array}{c}\mathrm{f}_{\mathrm{cm}} \\
\mathrm{MPa}\end{array}$ & $\begin{array}{c}\mathrm{f}_{\mathrm{tm}} \\
\mathrm{Mpa}\end{array}$ & $\begin{array}{l}\mathrm{E}_{\mathrm{cm}} \\
\mathrm{Gpa} \\
\end{array}$ & $\begin{array}{c}\mathrm{f}_{\mathrm{cm}} \\
\mathrm{MPa}\end{array}$ & $\begin{array}{r}\mathrm{f}_{\mathrm{tm}} \\
\mathrm{MPa} \\
\end{array}$ & $\begin{array}{l}\mathrm{E}_{\mathrm{cm}} \\
\mathrm{Gpa} \\
\end{array}$ \\
\hline $\begin{array}{l}\mathrm{FC} 1 \\
\mathrm{FC} 2\end{array}$ & $\begin{array}{l}\text { ensaiadas antes do } \\
\text { reforço }\end{array}$ & argamassa & 40 & 3,8 & 35 & - & - & - \\
\hline $\begin{array}{l}\text { FP1 } \\
\text { FP2 }\end{array}$ & $\begin{array}{l}\text { ensaiadas antes do } \\
\text { reforço } \\
\end{array}$ & $\begin{array}{l}\text { concreto } \\
\text { projetado }\end{array}$ & 40 & 3,8 & 35 & - & - & - \\
\hline $\begin{array}{l}\text { FC1R } \\
\text { FC2R }\end{array}$ & ensaiadas após o reforço & argamassa & 42 & 4,1 & 37 & 60 & 6,7 & 27 \\
\hline $\begin{array}{l}\text { FP1R } \\
\text { FP2R }\end{array}$ & ensaiadas após o reforço & $\begin{array}{l}\text { concreto } \\
\text { projetado }\end{array}$ & 42 & 4,1 & 37 & 39 & 3,7 & 27 \\
\hline $\mathrm{DF}$ & $\begin{array}{c}\text { referência antes do } \\
\text { reforço }\end{array}$ & - & 42 & 4,1 & 37 & - & - & - \\
\hline RF & referência após o reforço & - & 42 & 4,1 & 37 & - & - & - \\
\hline
\end{tabular}




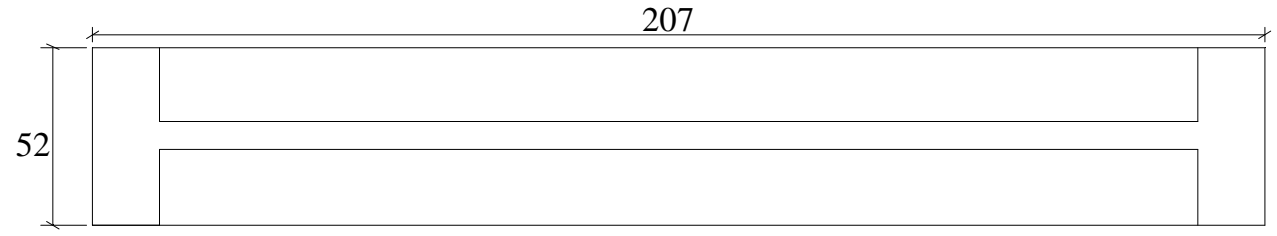

Vista superior

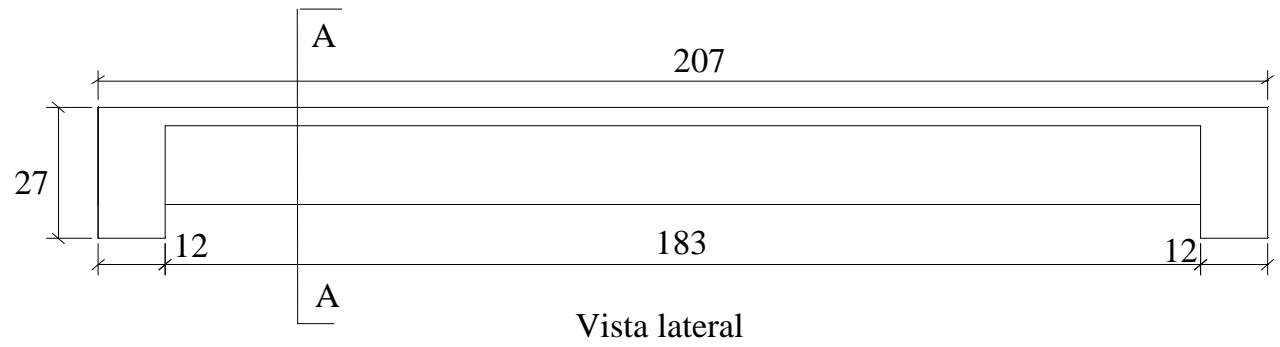

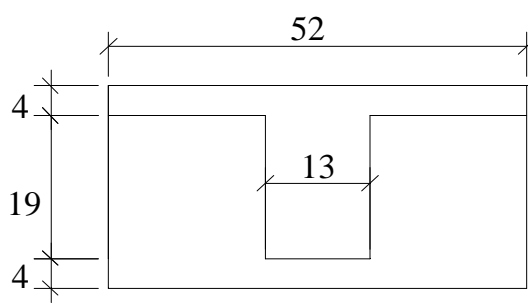

Corte AA

(RF)

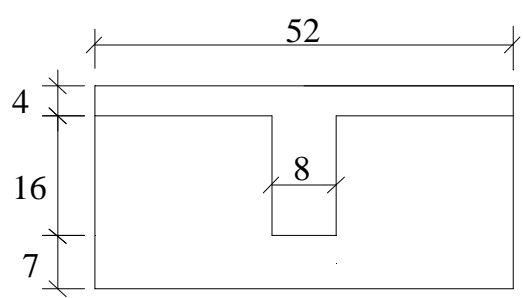

Corte AA (FC1, FC2, FP1,FP2 e DF)

Figura 3.1 - Fôrmas das vigas a serem ensaiadas antes do reforço FC1, FC2, FP1, FP2 e DF) e da viga de referência após o reforço (RF)
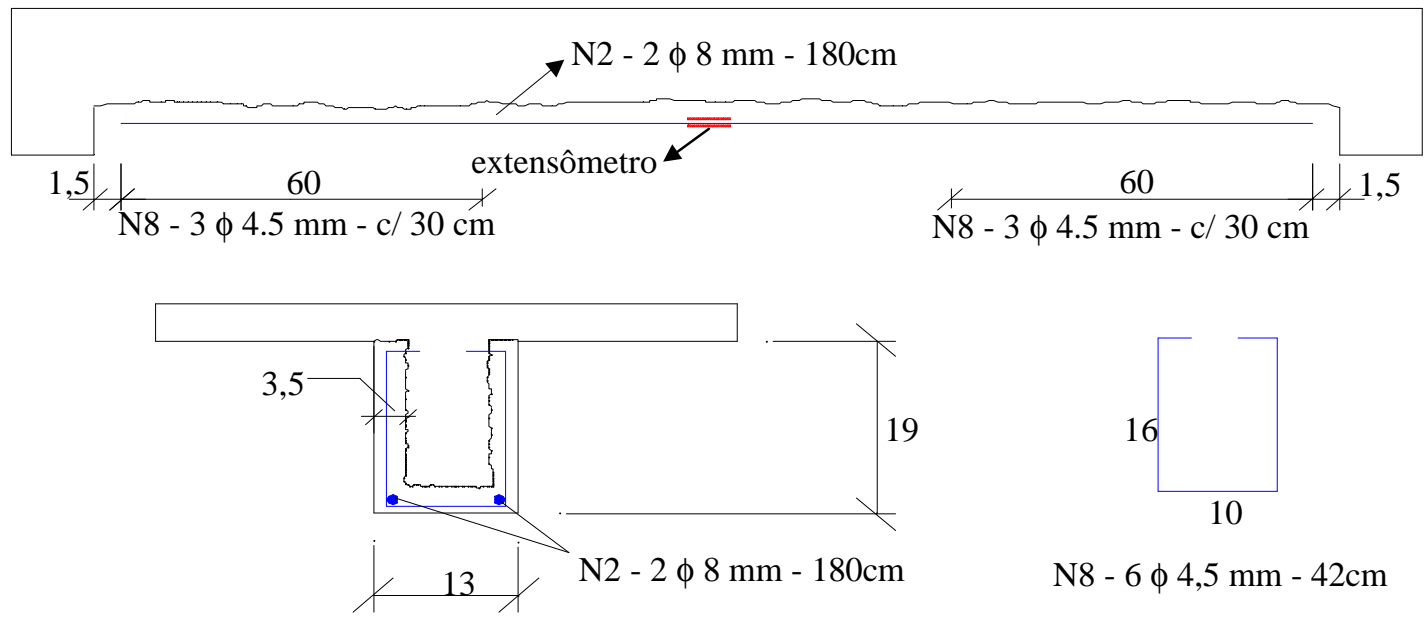

Figura 3.2 - Armadura de reforço das vigas FC1R, FC2R, FP1R e FP2R 

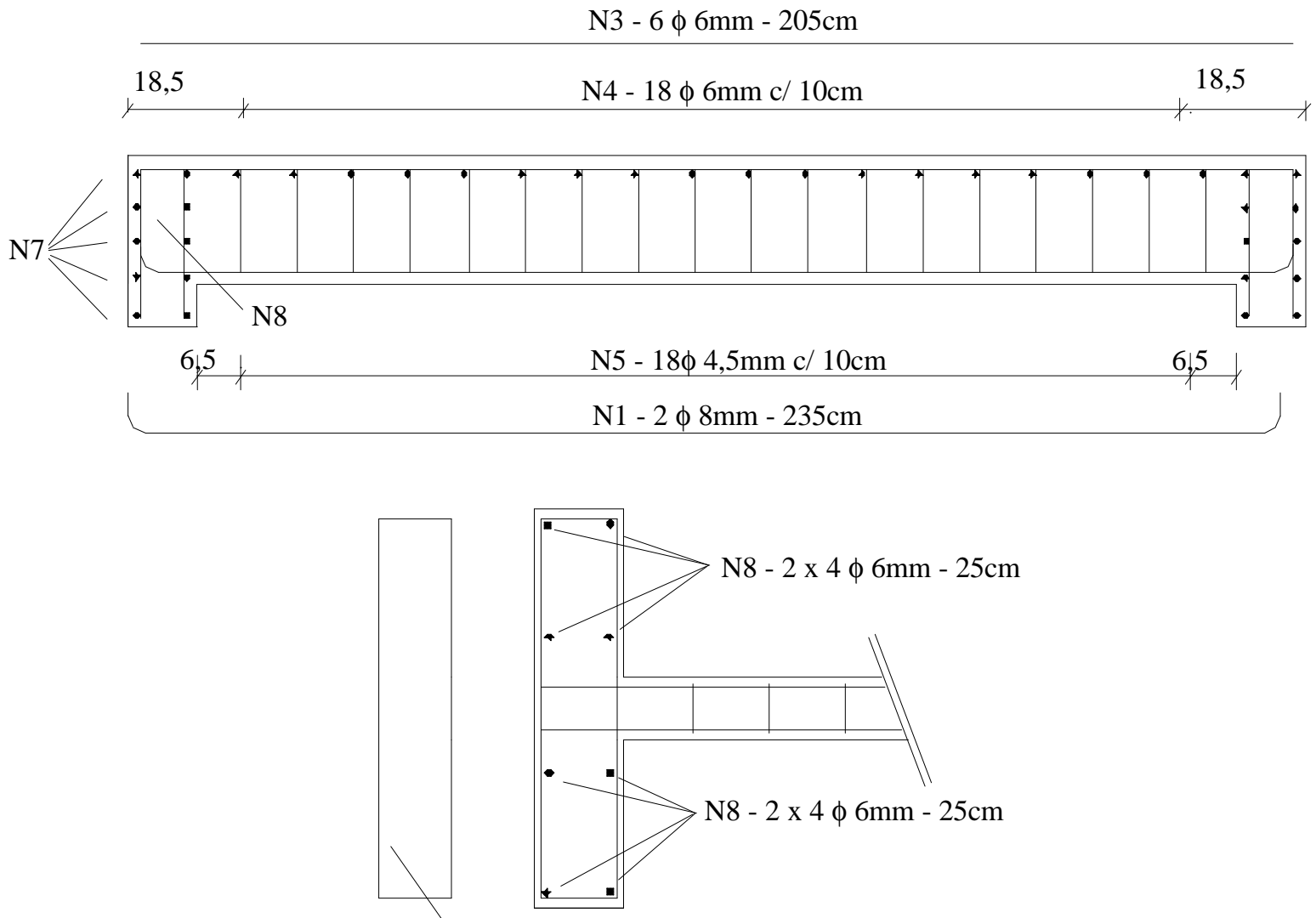

N7 - 2 x $5 \phi 5 \mathrm{~mm}-127 \mathrm{~cm}$ cada $5 \mathrm{~cm}$

Região do apoio (vista superior)

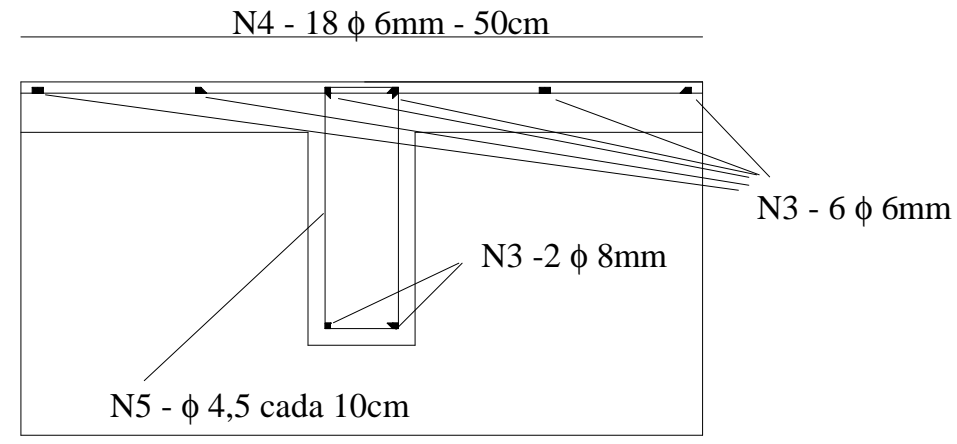

Corte na seção transversal

Figura 3.3 - Armadura das vigas ensaiadas antes do reforço (FC1, FC2, FP1, FP2 e DF) 

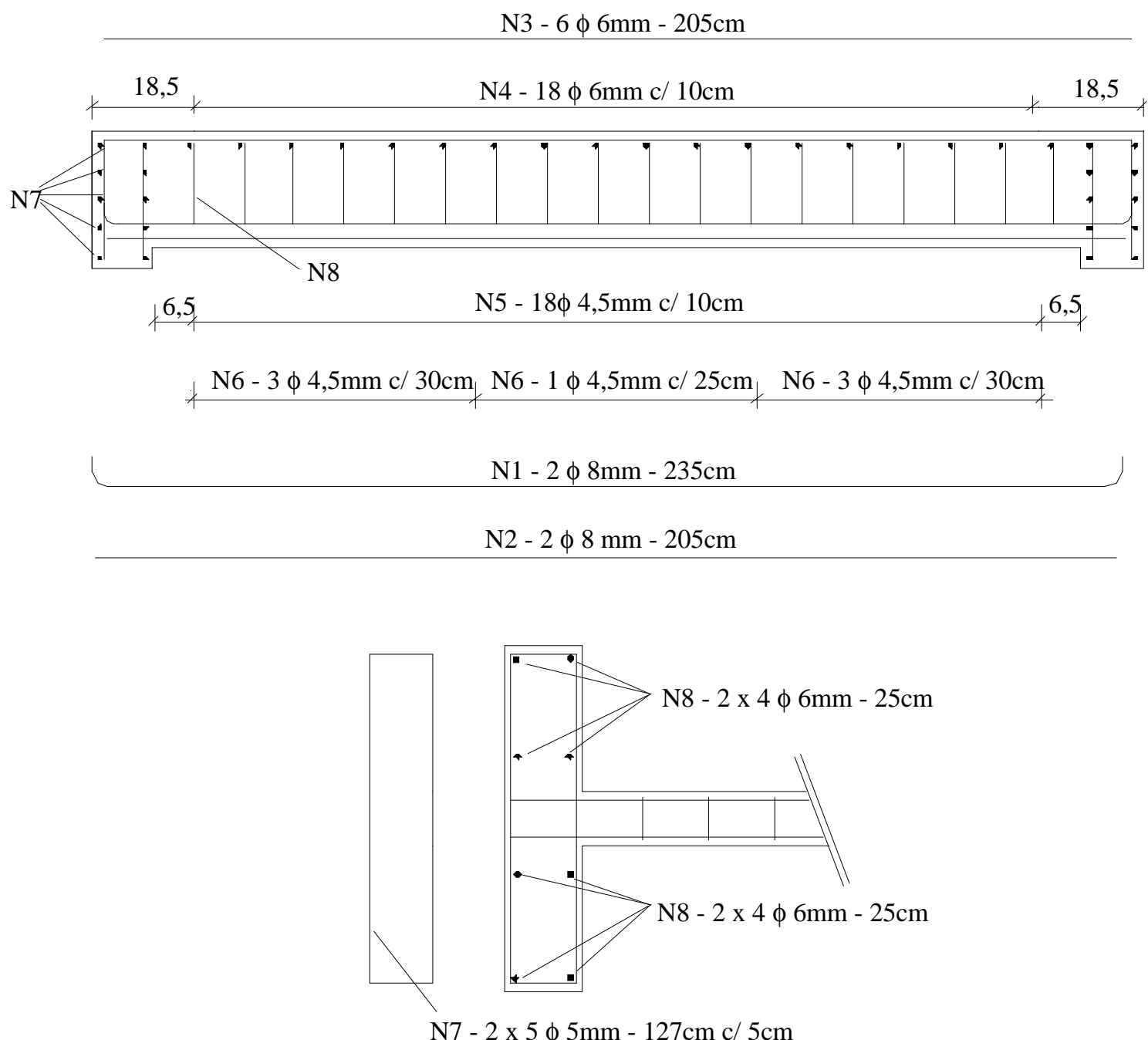

$\mathrm{N} 7-2 \times 5 \phi 5 \mathrm{~mm}-127 \mathrm{~cm} \mathrm{c} / 5 \mathrm{~cm}$

Região do apoio (vista superior)

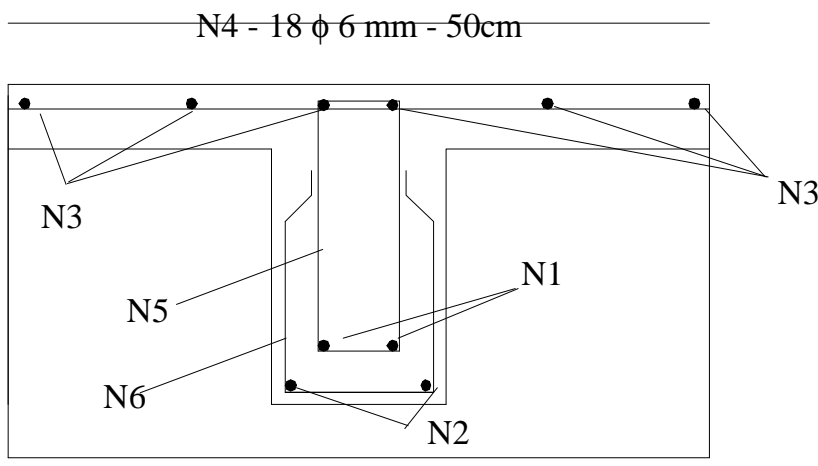

Corte na seção transversal

Figura 3.4 - Armadura da viga de referência após o reforço (RF) 
O reforço consistiu na adição de uma armadura longitudinal constituída por duas barras de $8 \mathrm{~mm}$ de diâmetro, representando um acréscimo de $100 \%$ na área de aço. Como só interessava estudar o comportamento da peça reabilitada em relação às solicitações normais, a viga foi armada ao esforço cortante adotando as dimensões finais após a realização da intervenção. Assim, não foi necessário reforçar a armadura transversal, mas apenas introduzir alguns estribos construtivos, com a finalidade única de fixar as novas armaduras longitudinais.

Para realizar os serviços de reforço, as vigas foram colocadas na sua posição usual, retirou-se o concreto superficial numa espessura de $0,5 \mathrm{~cm}$ a $1,0 \mathrm{~cm}$ ao longo das faces inferiores das vigas, sendo executados pequenos furos para fixar os estribos construtivos através de resina epóxi. Após essa etapa, limpou-se toda a superfície com escova de aço e, antes de aplicar o material de reforço, umedeceu-se toda a superfície, sem contudo permitir o acúmulo de água.

Em relação ao ensaio, quando o nível de carregamento atingia a carga de serviço, aplicavam-se ciclos de carga e descarga. A duração dos ensaios foi de aproximadamente três horas, em geral com uma parada de duas horas após a execução dos ciclos de carregamento. Os resultados das vigas reforçadas estão apresentados na Tabela 3.2.

Tabela 3.2 - Momentos de fissuração e de ruína das vigas ensaiadas por SOUZA (1990)

\begin{tabular}{||c|c|c|c|c||}
\hline \hline Viga & $\mathrm{M}_{\mathrm{r} \text { experimental }}$ & $\mathrm{M}_{\mathrm{r} \text { teórico }}$ & $\mathrm{M}_{\mathrm{u} \text { experimental }}$ & $\mathrm{M}_{\mathrm{u} \text { teórico }}$ \\
\hline $\mathrm{FC} 1$ & 3,2 & 3,2 & - & - \\
\hline FC2 & 3,3 & 3,2 & - & - \\
\hline FP1 & 3,0 & 3,2 & - & - \\
\hline FP2 & 3,3 & 3,2 & - & - \\
\hline FC1R & 3,6 & 9,4 & 24,2 & 27 \\
\hline FC2R & 3,7 & 9,4 & 25,9 & 27 \\
\hline FP1R & 4,6 & 5,4 & 24,5 & 27 \\
\hline FP2R & 4,6 & 5,4 & 25,8 & 27 \\
\hline RF & 6,9 & 6,7 & 25 & 27 \\
\hline $\begin{array}{l}\text { M } \\
\text { M }\end{array}$ memto de fissuração em kN/m; \\
\hline
\end{tabular}


Os resultados dos ensaios de SOUZA (1990) devem ser analisados com cuidado pois, como se utilizaram modelos reduzidos, deve-se levar em consideração o efeito escala, uma vez que as estruturas de pequenas dimensões tendem a apresentar uma resistência maior que as estruturas de tamanho usual. Outro fator que pode interferir nos resultados é o uso do microconcreto (material teoricamente mais homogêneo que o concreto comum) na moldagem destas vigas.

Analisando o comportamento das vigas reabilitadas, concluiu-se que o aumento da percentagem mecânica das armaduras tracionadas não correspondeu à mesma elevação da sua capacidade resistente. Isso ocorreu apesar de todos os modelos ensaiados apresentarem o comportamento para o qual foram projetados, atingindo a ruína por escoamento da armadura longitudinal com o surgimento de grandes flechas e esmagamento do banzo comprimido no ponto de aplicação da força. Após a intervenção, as vigas apresentam praticamente a mesma rigidez entre si, sendo que a perda de rigidez no início da fissuração, tão nítida nas vigas antes do reforço e em RF, tornou-se bem mais suave nas peças reforçadas. Tal fato pode ter ocorrido devido à não injeção das fissuras do concreto antes do reforço.

Após descarregar as peças, depois de produzir um determinado nível de dano antes de reforçá-las, constatou-se a existência de deformações residuais nas armaduras longitudinais que correspondiam 30\% da deformação de escoamento das barras na seção de meio do vão. Observando ainda o desenvolvimento das deformações das armaduras longitudinais do substrato e do reforço, foi possível verificar que ambas funcionaram como a primeira e a segunda camada de uma viga comum de concreto armado, já que as tensões existentes nas armaduras foram proporcionais aos respectivos braços de alavanca. As vigas reforçadas, independentemente do material de reforço, apresentaram um comportamento monolítico, com deformações na armadura longitudinal do reforço praticamente coincidentes com os valores teóricos previstos.

Como não se realizou a injeção das fissuras, a inércia das vigas reforçadas, a grosso modo, só poderia contar com o banzo comprimido de concreto, com a espessura do encamisamento e com as armaduras. Assim calculou-se, de forma simplificada, a 
rigidez para determinar o momento de fissuração das vigas reforçadas. Comparando os valores teóricos com os experimentais notou-se, para a viga monolítica, que o momento de fissuração experimental foi ligeiramente maior que o teórico. Entretanto, para as vigas reforçadas, ao contrário do que se esperava, o momento de fissuração teórico foi bem superior ao experimental. Além disso, esperava-se obter uma resistência à físsuração mais elevada nas vigas encamisadas com argamassa, por possuírem maior resistência à tração. Todavia, essas foram as primeiras a fissurar. Diante desse comportamento, percebe-se que para vigas reforçadas, o valor da resistência à tração do material de reparo deixa de ser o parâmetro mais relevante, passando a qualidade da aderência da ligação a comandar o processo de fissuração. Nos ensaios, apenas as vigas encamisadas com argamassa apresentaram fissuração na junta, confirmando a melhor aderência apresentada pelo concreto projetado. Foi por isso que o concreto projetado, apesar de possuir uma menor resistência à tração em relação à argamassa, forneceu maior resistência à fissuração. Sendo assim, ao escolher o material de reparo, deve-se buscar aquele que promova uma boa aderência, garantindo o monolitismo da peça, não sendo necessário altos valores de resistências. Apesar das diferenças verificadas no início da fissuração, os reforços realizados não reduziram a capacidade resistente última das vigas, ou seja, a qualidade da aderência afetou mais o início da fissuração e o comportamento em serviço do que a capacidade última das peças.

As flechas e abertura de fissuras das vigas reforçadas foram maiores do que as das vigas monolíticas e de referência, mas acredita-se que a injeção prévia das fissuras com resina epóxi poderia ter melhorado esse comportamento. Comparando as vigas reforçadas entre si, as encamisadas com argamassa apresentaram fissuras de flexão no meio do vão mais abertas e mais afastadas do que aquelas reabilitadas com concreto projetado. Isso confirma novamente que o concreto projetado ofereceu melhor aderência na ligação entre os materiais envolvidos, apesar do comportamento no estado limite último ter sido o mesmo para as duas técnicas de reforço.

Em relação ao dimensionamento do reforço, percebeu-se que foi possível determinar a área de aço a ser adicionada no bordo tracionado seguindo os princípios 
válidos para estruturas novas, garantindo a segurança nos estados limites últimos e de utilização através do uso de coeficientes parciais de segurança específicos.

Quando o nível de danos levou as armaduras a alcançar uma tensão próxima ao valor do escoamento do aço, presumiu-se a necessidade de injetar as fissuras para permitir maior controle das deformações em serviço, porém quando existe uma deficiência das armaduras, somente a injeção das fissuras não é suficiente, sendo necessário a introdução de novas armaduras. Além disso, dependendo do nível de danos, as tensões residuais instaladas nas armaduras devem ser consideradas no cálculo do reforço.

Diante de todas estas observações, SOUZA (1990) concluiu que os materiais e as técnicas utilizadas nos trabalhos de reforço são bastante variados e ainda não se dispõe da mesma segurança e do mesmo número de regulamentações que existem para a construção e supervisão das construções novas. Isso aumenta as possibilidades de falhas na construção, exigindo um controle de qualidade mais rigoroso para garantir a eficiência das intervenções.

\subsubsection{Ensaios realizados por CLíMACO (1990)}

CLÍMACO realizou em Londres, um programa experimental para investigar o comportamento de vigas reabilitadas de concreto armado mediante remoldagem da seção transversal. Para isso foram ensaiadas oito vigas biapoiadas, reforçadas através de adição de armadura convencional no bordo tracionado envolvidas com concreto novo. As Figuras 3.5 e 3.6 ilustram as dimensões e detalhes das vigas ensaiadas e as Tabelas 3.3 e 3.4 apresentam as características destas peça.

As vigas recuperadas foram ensaiadas à ruptura e o desempenho comparado ao de uma viga monolítica de controle. O dimensionamento foi feito de acordo com a norma inglesa BS-8110 (1985) supondo seção sub-armada no estado limite último, sem aplicar os coeficientes de segurança parciais e admitindo as seções monolíticas após o 
reforço. Os estribos foram dimensionados para evitar ruptura por cisalhamento, para as dimensões finais da viga $150 \mathrm{~mm}$ x $300 \mathrm{~mm}$.

A viga original (sem armadura de reforço) foi inicialmente concretada invertida com a armadura de flexão para cima. Após a cura por três dias, a junta foi escarificada com martelete pneumático de agulha para remover parte do concreto do substrato e expor o agregado graúdo. Depois de fixar as barras adicionais de tração à armadura original, a peça foi recolocada na fôrma para a moldagem do reforço, não sendo aplicado nenhum tipo de adesivo na junta para servir como ponte de aderência.

A intervenção em todas as peças, com exceção da V3, foi feita na posição normal, isto é, com a face tracionada da viga voltada para baixo. Na viga V1 não se tomou providências para evitar o aprisionamento de ar durante a remoldagem, o que ocasionou falhas de concretagem que foram corrigidas através de um remendo de argamassa. Nas vigas seguintes este tipo de problema foi evitado executando-se furos laterais uniformemente espaçados na fôrma, ao nível da junta.

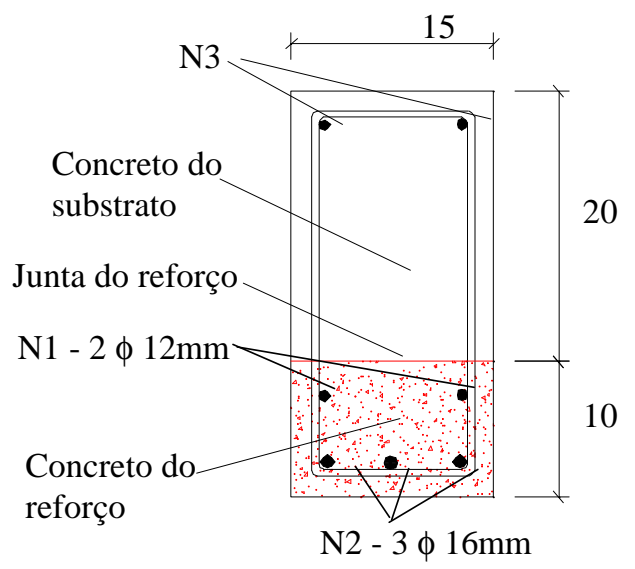

OBS. Unidades em $\mathrm{cm}$ $\mathrm{N} 3=2 \phi 8 \mathrm{~mm}$ para V1 a V4, V7 e V8;

$2 \phi 6 \mathrm{~mm}$ para V5;

$2 \phi 10 \mathrm{~mm}$ para V6.

Figura 3.5 - Modo de recuperação nas vigas ensaiadas por

CLÍMACO (1990) 
Tabela 3.3 - Características das vigas ensaiadas por CLIMACO (1990)

\begin{tabular}{|c|c|c|c|c|c|c|c|}
\hline \multirow[t]{2}{*}{ Viga } & \multirow{2}{*}{$\begin{array}{l}\text { Método de } \\
\text { remoldagem }\end{array}$} & \multirow[t]{2}{*}{ carregamento } & \multirow[t]{2}{*}{$\mathrm{a} / \mathrm{d}$} & \multicolumn{2}{|c|}{ substrato } & \multicolumn{2}{|c|}{ reforço } \\
\hline & & & & $\mathrm{f}_{\mathrm{cc}}$ & $f_{t}$ & $\mathrm{f}_{\mathrm{cc}}$ & $\mathrm{f}_{\mathrm{t}}$ \\
\hline V1 & $\begin{array}{l}\text { reparo posição normal } \\
\text { + reparo superficial }\end{array}$ & estático & 4 & 43,4 & 3,36 & 38,5 & 3,2 \\
\hline $\mathrm{V} 2$ & monolítica & estático & 4 & 49,0 & 3,03 & - & - \\
\hline V3 & $\begin{array}{l}\text { reparo posição } \\
\text { invertida }\end{array}$ & estático & 4 & 40,3 & 2,97 & 38,4 & 2,99 \\
\hline V4 & reparo posição normal & estático & 4 & 49,1 & 3,51 & 39,1 & 3,00 \\
\hline V5 & reparo posição normal & estático & 5 & 50,3 & 3,40 & 46,8 & 3,00 \\
\hline V6 & reparo posição normal & estático & 2 & 45,0 & 2,57 & 41,1 & 2,71 \\
\hline V7 & reparo posição normal & estático & 3 & 56,2 & 2,83 & 36,7 & 2,42 \\
\hline V8 & reparo posição normal & cíclico & 4 & 43,5 & 2,66 & 59,5 & 3,95 \\
\hline
\end{tabular}

Tabela 3.4 - Resultados dos ensaios de CLÍMACO (1990)

\begin{tabular}{|c|c|c|c|c|c|c|c|c|}
\hline \multirow[t]{2}{*}{ Viga } & \multicolumn{3}{|c|}{ Força de fissuração } & \multirow{2}{*}{$\begin{array}{l}\text { Força de } \\
\text { ruína } \\
\text { experimental }\end{array}$} & \multicolumn{2}{|c|}{$\begin{array}{l}\text { Força teórica } \\
\qquad(\mathrm{kN})\end{array}$} & \multicolumn{2}{|c|}{$\mathrm{F}_{\text {real }} / \mathrm{F}_{\text {teórica }}$} \\
\hline & flexão & $\begin{array}{c}\text { cisalhament } \\
\mathrm{o}\end{array}$ & $\begin{array}{c}\text { junt } \\
\text { a }\end{array}$ & & Ruína & serviço & ruína & $\begin{array}{c}\text { serviç } \\
\text { o }\end{array}$ \\
\hline V1 & 50 & 85 & 100 & 146 & 162 & 82 & 0,90 & 1,77 \\
\hline V2 & 50 & 90 & - & 165 & 166 & 85 & 0,99 & 1,93 \\
\hline V3 & 45 & 90 & - & 180 & 160 & 81 & 1,13 & 2,23 \\
\hline V4 & 45 & 90 & 100 & 180 & 166 & 85 & 1,08 & 2,11 \\
\hline V5 & 40 & 70 & 70 & 147 & 134 & 69 & 1,10 & 2,14 \\
\hline V6 & 75 & 120 & 220 & 365 & 328 & 167 & 1,11 & 2,18 \\
\hline $\mathrm{V7}$ & 65 & 90 & 110 & 238 & 227 & 118 & 1,05 & 2,02 \\
\hline V8 & 60 & 80 & 100 & 170 & 162 & 83 & 1,05 & 2,06 \\
\hline
\end{tabular}


$\underline{\mathrm{V} 1, \mathrm{~V} 2, \mathrm{~V} 3, \mathrm{~V} 4 \text { e V8 - a/d }=4}$

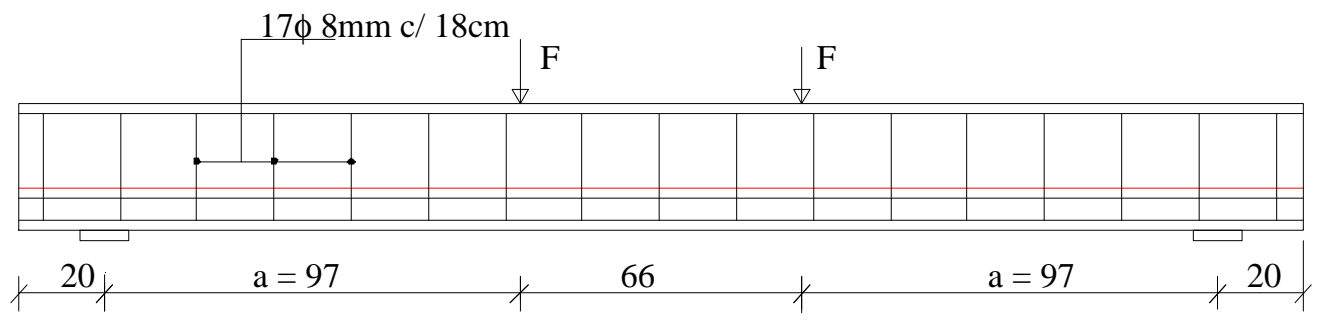

$\underline{\mathrm{V} 5-\mathrm{a} / \mathrm{d}=5}$

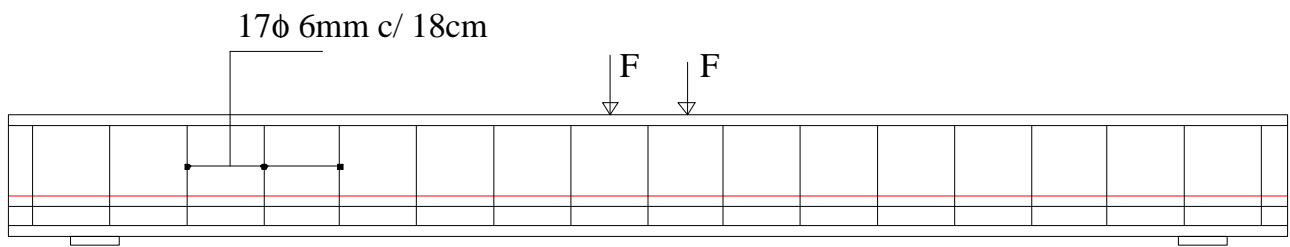
20
$\mathrm{a}=121$
$18+a=121$
$\nmid 20 \mid$

$\underline{V 6-a / d=2}$

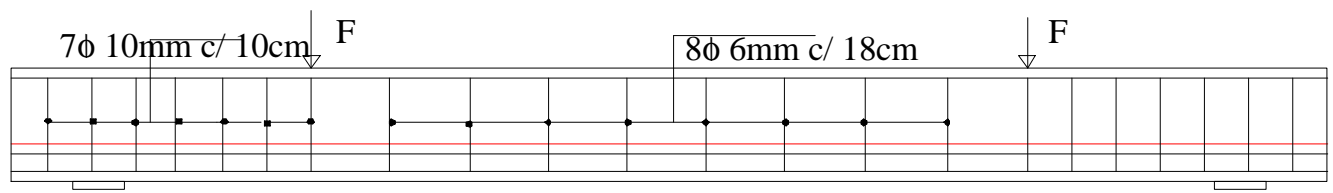

$\nmid 20 \nmid \quad \mathrm{a}=48,4 \nmid \quad 163,2 \quad \mathrm{a}=48,4 \quad 20 \nmid \nmid$

$\underline{\mathrm{V} 7-\mathrm{a} / \mathrm{d}=3}$

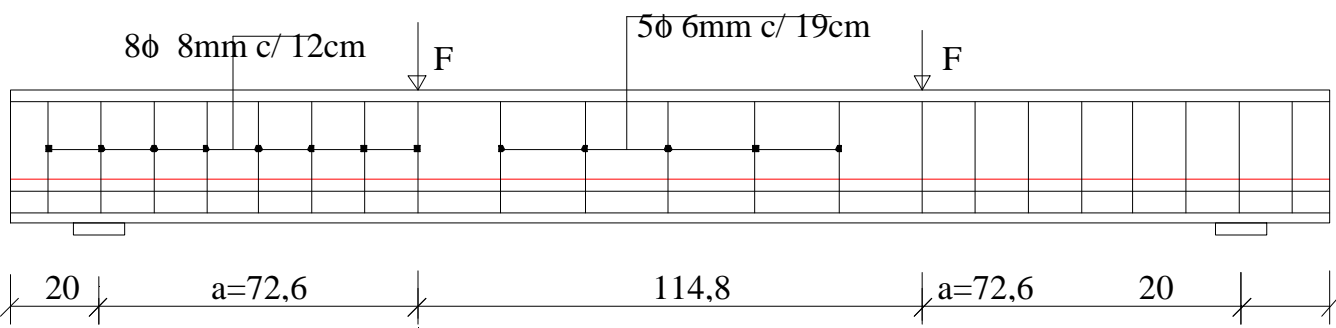

Figura 3.6 - Características das vigas reforçadas por CLÍMACO (1990)

Após todos os ensaios, CLÍMACO observou que todas as rupturas ocorreram por esmagamento do concreto após o escoamento da armadura de flexão, e que todas as vigas apresentaram fissuras na região da junta, dentro do vão de corte " $a$ ”. Entretanto, essa perda parcial de aderência não reduziu, com exceção da V1, a capacidade portante 
das vigas reabilitadas. Notou-se menos fissuras de flexão e de cisalhamento nas vigas reforçadas do que na viga sólida de controle V2. Isso ocorreu provavelmente por causa da perda parcial de aderência na junta das peças reforçadas.

O reparo superficial feito na V1 resolveu apenas parcialmente o problema das falhas de concretagem, já que a perda de aderência na junta foi mais severa nesta peça. Esta viga apresentou ruptura por esmagamento do concreto do substrato na região imediatamente superior à junta, para uma seção transversal localizada no meio do vão de cisalhamento. Esse tipo de ruptura indicou que o substrato, após a fissuração da junta, passou a trabalhar como um elemento de concreto sem armadura, apoiado de forma contínua na parte inferior da viga (camada do reforço). Apesar disso, essa viga apresentou uma carga de ruptura elevada correspondente a $90 \%$ da força de ruína teórica.

As vigas V3 e V4 tiveram desempenho semelhantes ao da viga sólida V2, em relação à fissuração e modo de ruptura. A V8, mesmo estando submetida a um carregamento cíclico, obteve uma resistência última 5\% superior à prevista. As vigas V5, V6 e V7 também apresentaram valores de resistência última próximas aos valores previstos de acordo com a norma BS-8110.

As flechas teóricas foram calculadas a partir da curvatura da viga, admitindo a hipótese das seções planas. Para todas as vigas, com exceção da V1 (com reparo superficial) a razão dos valores experimentais e teóricos foi próxima da unidade, indicando que as flechas das vigas reparadas sob carga de serviço podem ser previstas pelo método clássico de viga sólida.

O acompanhamento das deformações do concreto ao longo da altura da viga possibilitou verificar o comportamento pós-reforço da peça com relação à hipótese das seções planas. A partir destas deformações, obteve-se a altura da linha neutra para a solicitação mais alta antes da ruptura. Este parâmetro foi comparado ao valor teórico calculado no estado limite último, observando-se uma correlação satisfatória entre os valores experimentais e teórico. Os valores das alturas da linha neutra teóricas e experimentais estão apresentados na Tabela 3.5. 
As deformações na armadura de tração foram medidas para todas as vigas em três seções diferentes: no meio do vão, a $100 \mathrm{~mm}$ do apoio e no centro do vão de corte. A Tabela 3.6 apresenta as deformações na seção central das vigas para a força de serviço* . A previsão das deformações da armadura longitudinal no meio do vão foram relativamente satisfatórias, sendo os valores experimentais ligeiramente superiores aos previstos para a maioria das vigas, com uma diferença máxima na V6 $(\mathrm{a} / \mathrm{d}=2)$.

Tabela 3.5 - Altura da linha neutra no meio do vão (mm)

\begin{tabular}{||c|c|c|c|c|c|c|c|c||}
\hline Viga & V1 & V2 & V3 & V4 & V5 & V6 & V7 & V8 \\
\hline \hline Força $(\mathrm{kN})$ & 140 & 140 & 170 & 170 & 140 & 360 & 220 & 160 \\
\hline $\mathrm{h}_{\text {exp }}$ & 99 & 90 & 99 & 91 & 74 & 92 & 94 & 111 \\
\hline $\mathrm{h}_{\text {teo }}$ & 97 & 86 & 105 & 86 & 84 & 94 & 75 & 97 \\
\hline $\mathrm{h}_{\text {exp }} / \mathrm{h}_{\text {teo }}$ & 1,02 & 1,05 & 0,94 & 1,06 & 0,88 & 0,98 & 1,25 & 1,14 \\
\hline $\mathrm{h}=$ altura da linha neutra da viga em relação ao topo da viga \\
\hline
\end{tabular}

Tabela 3.6 - Deformações da armadura de tração no meio do vão (mm/m)

\begin{tabular}{||c|c|c|c|c|c|c|c|c||}
\hline Viga & V1 & V2 & V3 & V4 & V5 & V6 & V7 & V8 \\
\hline \hline Força $(\mathrm{kN})$ & 80 & 80 & 80 & 80 & 70 & 160 & 120 & 80 \\
\hline$\varepsilon_{\exp }$ & 1,13 & 1,04 & 1,01 & 1,02 & 1,09 & 0,85 & 1,13 & 0,95 \\
\hline$\varepsilon_{\text {teo }}$ & 1,09 & 1,09 & 1,09 & 1,09 & 1,19 & 1,09 & 1,22 & 1,09 \\
\hline$\varepsilon_{\text {exp }} / \varepsilon_{\text {teo }}$ & 1,04 & 0,95 & 0,93 & 0,94 & 0,91 & 0,78 & 0,93 & 0,87 \\
\hline$\varepsilon=$ deformação da armadura longitudinal da viga \\
\hline
\end{tabular}

Quanto ao deslocamento relativo entre o substrato e o reforço na região da junta, constatou-se um aumento significativo ao surgir a primeira fissura visível de cisalhamento, indicando o início da perda de aderência na junta. Os movimentos da junta próximos à ruína são altos, alcançando valores da ordem de $1 \mathrm{~mm}$, apesar das vigas

\footnotetext{
* As deformações experimentais foram determinadas como sendo a média entre as deformações das barras de $12 \mathrm{~mm}$ e $16 \mathrm{~mm}$.

As deformações teóricas foram calculadas com a inércia da seção fissurada.
} 
romperem nitidamente por escoamento da armadura longitudinal seguida de esmagamento do concreto comprimido.

A partir desses resultados, pode-se dizer que este método de reforço foi eficiente para carregamento estático, uma vez que se obteve, para as vigas reabilitadas, um desempenho estrutural equivalente ao da viga sólida de controle. As vigas reabilitadas demonstraram ainda que obedecem aos princípios estruturais simples válidos para vigas monolíticas, apresentando uma boa margem de segurança para as cargas de serviço, com relação à previsão das flechas e das deformações da armadura e do concreto.

Embora a fissuração na junta não tenha prejudicado o desempenho estrutural sob cargas de serviço e última, esse é um problema a ser enfrentado no que se refere à durabilidade da peça reparada.

\subsubsection{Ensaios realizados por PIANCASTELLI (1997)}

PIANCASTELLI ensaiou na Universidade Federal de Minas Gerais várias vigas reabilitadas à flexão. Neste item descreve-se basicamente os resultados encontrados por este pesquisador e publicados nos Anais da XXVIII Jornadas SulAmericanas de Engenharia Estrutural e nos Anais do IV Congresso Ibero-Americano de Patologia das Construções CONPAT 1997.

Reunindo os dados disponíveis nestes dois artigos, pode-se dizer que PIANCASTELLI ensaiou dez vigas de concreto armado, divididas em cinco séries de duas peças cada uma. As peças foram reforçadas aumentando as seções de concreto e de aço conforme ilustra a Figura 3.8c.

Oito dessas vigas foram concretadas originalmente com as mesmas características, tendo sido denominadas de vigas originais (ver Figura 3.7). Essas vigas foram posteriormente reforçadas constituindo as séries 1 a 4 . As séries 1 e 2, ambas com apenas dez estribos na posição N3 (ver Figura 3.8b), diferenciavam entre si apenas pela ação atuante no instante do reforço. As vigas da série 1 (vigas reforçadas sem carga) foram reforçadas apenas sob a ação do seu peso próprio e do peso do reforço. As da série 2 (vigas reforçadas sob carga) estavam submetidas a um carregamento correspondente a 
91\% da carga de serviço, além do seu peso próprio e do peso do reforço, uma vez que foram utilizadas fôrmas suspensas.

As vigas da série 3 e 4, que também estavam submetidas à ação do peso próprio e do peso do reforço, diferenciavam entre si apenas pela quantidade de estribos que envolviam a armadura de reforço. Para a série 3 foram usados trinta estribos, enquanto para a série 4 usou-se apenas dez.

As vigas da série 5 (vigas monolíticas de referência) foram moldadas em uma só etapa e apresentavam as mesmas características das peças da série 3 depois de reforçadas, inclusive com relação ao número de estribos prolongados (ver Figura 3.8a).

Nas peças armadas com dez estribos envolvendo a armadura do reforço, colocou-se três estribos em cada extremidade da viga, para trabalhar como armadura de suspensão, e quatro estribos distribuídos ao longo do eixo longitudinal, para possibilitar a fixação da armadura adicionada. Os estribos utilizados nas vigas originais (posição N3) foram maiores que a seção transversal da peça para evitar operações de prolongamento destas armaduras durante a execução do reforço. Nas posições onde não se desejava tal armadura, estes estribos foram simplesmente cortados. Para permitir deslocamento relativo entre o reforço e o substrato (ver Figura 3.7) foram utilizadas chapas de poliestireno expandido entre estes materiais.

O reforço consistiu no acréscimo de seções de concreto e aço na zona tracionada e tentou-se tirar partido de tudo que pudesse tornar a execução da reabilitação mais simples. Por isso optou-se por uma concretagem convencional, não sendo utilizado nenhum adesivo estrutural na ligação substrato/concreto novo nem umedecendo-se o substrato antes da execução do reforço. O reforço das vigas da série 2 foi realizado sob carga por ser essa a condição real quando não se quer ou não se pode erguer e escorar a peça estrutural antes de sua execução. As peças reforçadas foram ensaiadas para baixa idade do concreto do reforço, porque em situações reais é freqüente a necessidade de se colocar rapidamente em uso as estruturas reforçadas. 
As vigas reabilitadas foram ensaiadas em duas etapas. Na primeira etapa (antes da execução do reforço), as vigas originais utilizadas na confecção das séries 1 e 2 foram pré-carregadas até atingir 97\% da carga de ruína prevista. Já para as vigas originais que constituiriam as vigas das séries 3 e 4, o pré-carregamento chegou a $70 \%$ da capacidade portante da peça. Esse procedimento foi adotado para simular os danos estruturais existentes em um elemento que necessita ser reforçado. Após esses ensaios preliminares, as faces inferiores das vigas originais foram apicoadas e lavadas, posicionando-se posteriormente as armaduras de reforço nas fôrmas suspensas. É importante salientar que no momento da concretagem do reforço, o substrato estava total e propositadamente seco. A segunda etapa, ocorreu quatro dias após a execução do reforço, quando as vigas foram levadas à ruptura. As vigas da série 5 (monolíticas) foram ensaiadas em uma única etapa. Os resultados dos ensaios estão apresentados na Tabela 3.7.

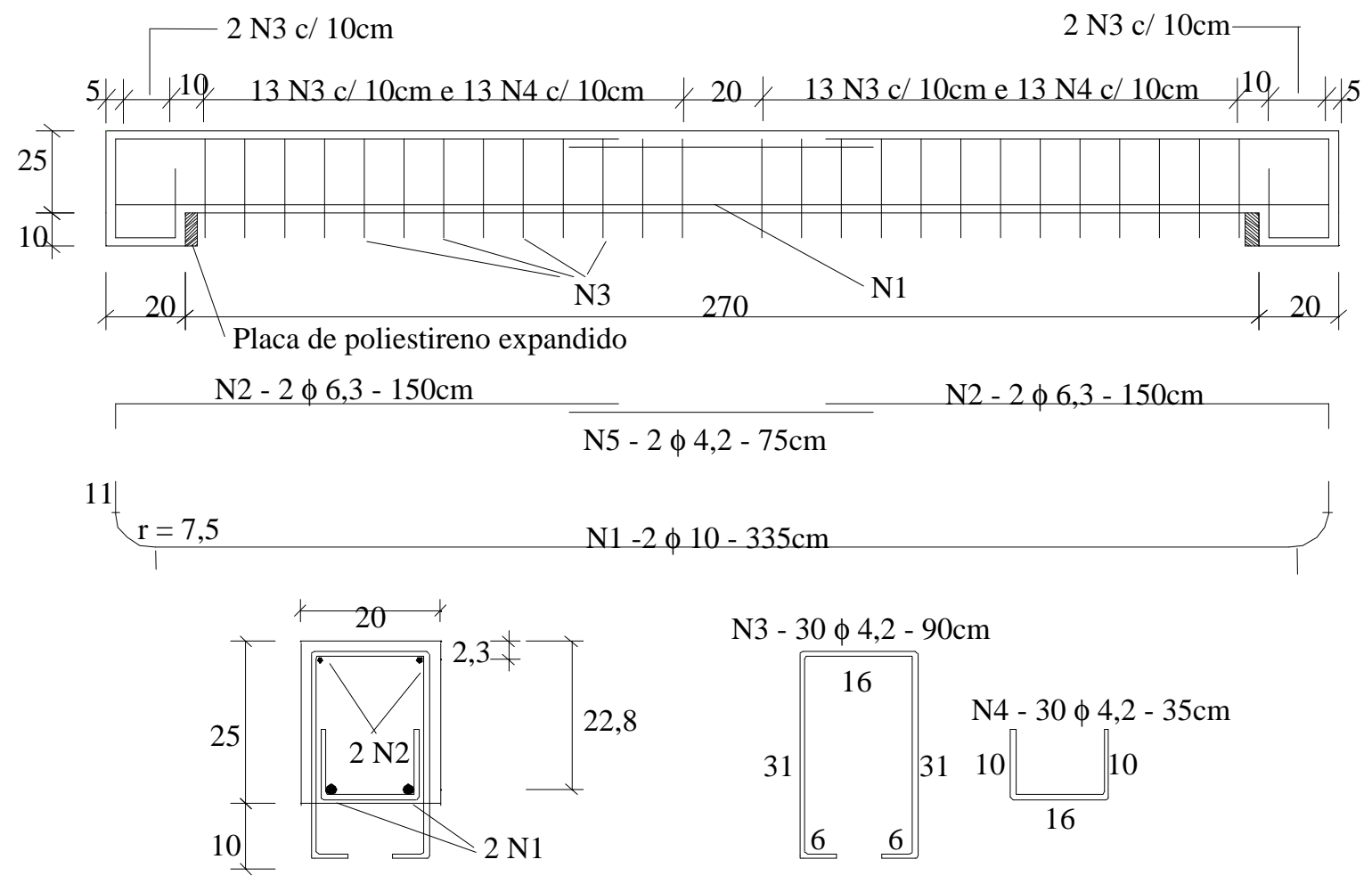

Figura 3.7 - Características das vigas originais de PIANCASTELLI 


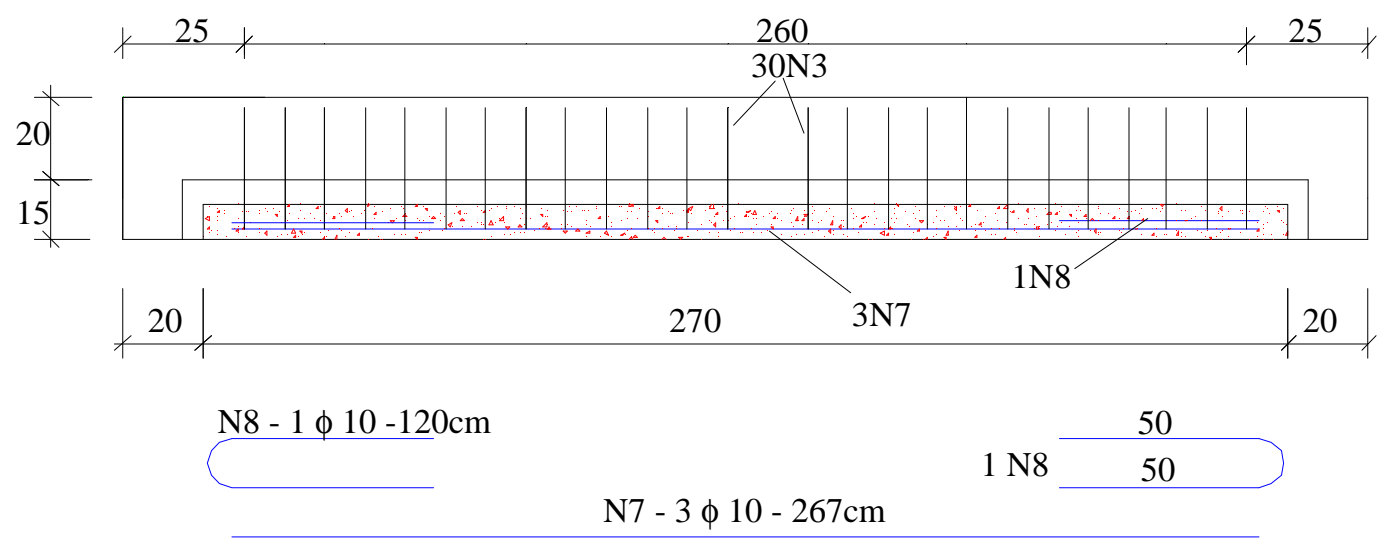

(a) Vigas reforçadas da série 3 e 5

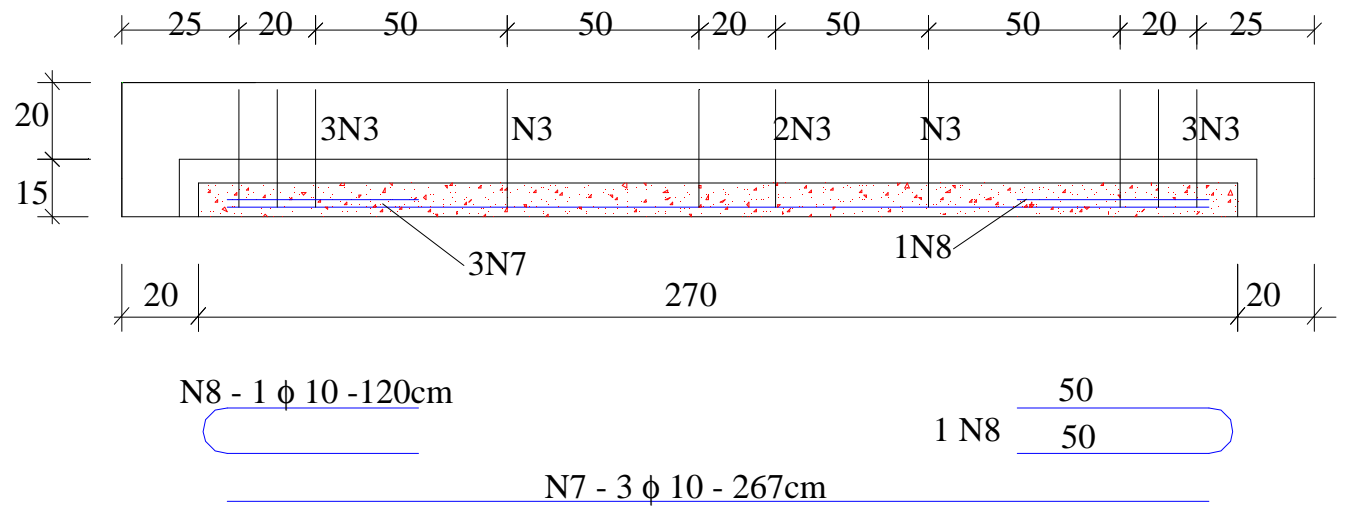

(b) Vigas reforçadas da série 1, 2 e 4

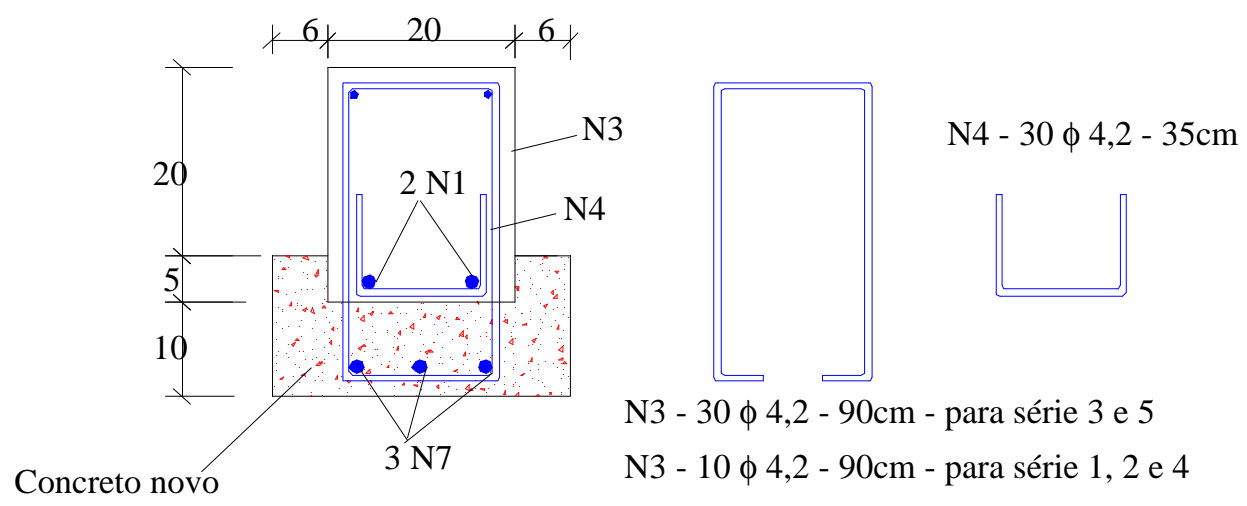

(c) Seções transversais das vigas ensaiadas

Figura 3.8 - Características das vigas reforçadas por PIANCASTELLI 
Tabela 3.7 - Resultados experimentais e resultados teóricos segundo a NBR-6118

\begin{tabular}{||c|c|c|c|c|c|c||}
\hline \hline Série & \multicolumn{3}{|c|}{ Força de fissuração } & \multicolumn{3}{c||}{ Força de ruína } \\
\hline & experimental & teórica & teo/exp & experimental & teórica & teo/exp \\
\hline \hline 1 & 43,9 & 46,6 & 1,06 & 100,2 & 71,6 & 0,71 \\
\hline 2 & 59,6 & 65,8 & 1,10 & 109,2 & 71,6 & 0,66 \\
\hline $3^{*}$ & 43,0 & - & - & 105,6 & - & - \\
\hline $4^{*}$ & 43,9 & - & - & 100,2 & - & - \\
\hline 5 & 28,6 & 34,7 & 1,21 & 108,3 & 71,6 & 0,66 \\
\hline $\begin{array}{l}* \\
\text { publicados nalores previstos para a força de fissuração e ruína das séries 3 e 4 não foram }\end{array}$ \\
\hline
\end{tabular}

Observando os resultados, pode-se concluir que o material empregado e a metodologia de recuperação utilizada foram eficientes, mesmo ao solicitar as peças reabilitadas quando o material do reforço ainda está “jovem”. Isso é possível desde que o traço do concreto seja bem estudado, apresentando características mecânicas de resistência, módulo de elasticidade e aderência compatíveis, na idade de solicitação, com a peça a ser recuperada.

Ao analisar os valores das forças de fissuração e ruína das séries 3 e 4, pode-se dizer que não houve influência da quantidade de estribos prolongados no comportamento e desempenho destas peças. Esse fato revela, segundo PIANCASTELLI, uma boa aderência entre os diferentes concretos, assegurando ainda mais o bom desempenho do material e do processo de recuperação utilizado.

Pela Tabela 3.7 percebe-se que em relação à força de fissuração, as vigas recuperadas apresentaram valores experimentais maiores que os das vigas da série 5 (vigas monolíticas). Isto se deu em função da maior resistência à tração do concreto do reparo. Com relação à força de ruína, ocorreram pequenas diferenças que não chegaram a caracterizar uma melhora de desempenho de uma série para outra. 
A previsão da fissuração, feita com base nos critérios da NBR-6118, superestimou a força de fissuração das vigas reforçadas e das vigas monolíticas. No caso da força de ruína, obteve-se valores teóricos, em média, 67\% inferiores aos experimentais, devido ao uso dos coeficientes de minoração aplicado sobre os valores característicos das resistências dos materiais e à limitação da deformação das armaduras.

Em relação à abertura de fissuras, as formulações da NBR-6118 forneceram valores próximos dos experimentais para as vigas reforçadas. Entretanto, para as vigas monolíticas, estes valores foram menores que os reais. $\mathrm{O}$ autor acredita que isto pode ter ocorrido devido às diferentes condições de concretagem e cura dos dois tipos de viga. Quanto à estimativa das flechas, encontrou-se valores teóricos bem maiores que os experimentais, indicando que esta norma foi bastante conservativa.

Diante destes resultados, percebe-se que o comportamento das vigas reforçadas foram estimados com segurança pela norma NBR-6118, estando a peça solicitada ou não no momento da execução do reforço. Em qualquer caso, a consideração das deformações e deslocamentos já existentes no momento do reforço é de fundamental importância.

As premissas de não levar em consideração, nos cálculos, o fato das vigas já estarem fissuradas, bem como de considerar o funcionamento conjunto dos dois concretos envolvidos (em função da boa aderência observada entre eles), foram confirmadas.

O autor concluiu ainda que nem sempre é necessário utilizar adesivos estruturais nas ligações entre concreto velho e concreto novo e nem umedecer o substrato para obter resultados satisfatórios nos trabalhos de recuperação.

\subsection{Reabilitação através de chapas de aço}

Em relação à reabilitação de vigas de concreto através do uso de chapas de aço fixados no bordo tracionado da peça, analisou-se os trabalhos de ALFAIATE e CAMPAGNOLO. 


\subsubsection{Ensaios realizados por ALFAIATE (1986)}

ALFAIATE estudou o comportamento de vigas de concreto armado de seção retangular de $8 \mathrm{~cm}$ x $20 \mathrm{~cm}$ e vão livre de 1,80 m. Essas peças foram carregadas nos terços de vão sendo reforçadas pela adição de chapas de aço coladas no bordo tracionado. Nestes ensaios foram analisados os seguintes parâmetros:

-Variação da relação entre as áreas de aço da armadura de reforço e da armadura longitudinal original $\left(\mathrm{A}_{\mathrm{sr}} / \mathrm{A}_{\mathrm{sl}}\right)$;

-Variação no nível de dano $\varepsilon_{\mathrm{sl}, \mathrm{i}}$, (pequeno, intermediário ou grande) existente nas vigas antes de realizar a intervenção;

-Influência da colagem da chapa de aço com resina epóxi isoladamente ou combinada com buchas metálicas.

Em relação ao nível de dano introduzido antes da aplicação do reforço, foi aplicada uma carga que produzisse respectivamente deformações ${ }^{*}$ de:

a) $\varepsilon_{\mathrm{sl}, \mathrm{i}}=2 \times 10^{-3}$

Corresponde ao limite aceitável de deformação e fissuração especificado pelo estado limite de utilização. Não foi feita a reparação nas fissuras da estrutura antes de realizar o reforço;

b) $\varepsilon_{\mathrm{sl}, \mathrm{i}}=3 \times 10^{-3}$

Corresponde ao início do escoamento das armaduras longitudinais. Neste caso, tentou-se reparar algumas fissuras antes de realizar a intervenção;

c) $\varepsilon_{\text {sl,i }}$ variando entre $5 \times 10^{-3}$ e $8 \times 10^{-3}$

Corresponde a fase de pré-ruína da peça. Fez-se a reparação de praticamente todas as fissuras usando resina epóxi antes de realizar o reforço;

\footnotetext{
* $\varepsilon_{\mathrm{sl}, \mathrm{i}}$ é a deformação inicial na armadura longitudinal antes da realização do reforço.
} 
Além dos ensaios das vigas previamente danificadas e reforçadas, foram feitos testes em vigas que não foram reforçadas, mas que tiveram suas fissuras reparadas. Desta forma, pretendia-se obter dados sobre o comportamento de uma estrutura reparada e comparar os resultados com os dados de uma estrutura reparada e reforçada. No total foram ensaiadas 16 vigas com as características apresentadas na Tabela 3.8.

Após aplicar determinado nível de carregamento, para gerar danos no elemento, e de escarificar sua superfície usando um martelete de agulhas para aumentar a rugosidade das mesmas, posicionou-se a chapa de aço sobre a face preparada (face superior pois os modelo foi moldado na posição invertida para facilitar os trabalhos de remoldagem). Foram colocados tubos de plástico sob a chapa para possibilitar a injeção da resina, vedou-se o exterior da ligação chapa/concreto aplicando-se um betume de ferro espalhado em volta da chapa e fez-se a injeção propriamente dita. O processo do reforço das vigas que possuíam buchas metálicas foi idêntico ao descrito anteriormente, exceto na furação da superfície de concreto nos pontos marcados pelos orifícios preexistentes na chapa. As buchas são introduzidas logo após a colocação da chapa no bordo tracionado, só se introduzindo a resina depois. Quando as fissuras tinham aberturas muito pequenas, não era possível injetar a resina de forma eficiente, o que gerou três situações distintas: vigas não reparadas; vigas deficientemente reparadas e vigas bem reparadas.

A Figura 3.9 apresenta um esquema representativo das diferentes etapas relativas à passagem das vigas de referência (tipo A) para as vigas reabilitadas (tipo B e tipo C). A nomenclatura das vigas segue a ordem T-N Série-S onde:

$\mathrm{T}=$ representa o tipo em relação ao valor de $\mathrm{A}_{\mathrm{sl}} ;$
$\mathrm{N}=$ número de ensaios correspondente ao tipo e a série;

Série - S = Indica o modo de reforço realizado;

Série 0 - Sem reforço e sem reparo;

Série 1 - Ligação reforço/concreto com resina epóxi;

Série 2 - Ligação reforço/concreto com resina epóxi e buchas metálicas;

Série 3 - Reparadas mas não reforçadas. 
Tabela 3.8 - Características das vigas ensaiadas por ALFAIATE (1986)

\begin{tabular}{|c|c|c|c|c|}
\hline \multicolumn{3}{|c|}{ Vigas ensaiadas } & \multirow{2}{*}{$\begin{array}{c}\text { Nível de } \\
\text { danos }\end{array}$} & \multirow{2}{*}{$\begin{array}{l}\mathrm{n}^{\mathrm{o}} \mathrm{de} \\
\text { ensaios }\end{array}$} \\
\hline $\mathrm{A}_{\mathrm{sr}} / \mathrm{A}_{\mathrm{sl}}$ & nome das vigas & $\mathrm{A}_{\mathrm{sl}}$ & & \\
\hline 0,00 & A-1 série 0 e $A-2$ série 0 & $2 \phi 10$ & - & 2 \\
\hline 0,68 & B-1 série 1 e $B-2$ série 1 & $2 \phi 8$ & $2 \times 10^{-3}$ & 2 \\
\hline 0,68 & B-3 série 1 e B-4 série 1 & $2 \phi 8$ & $3 \times 10^{-3}$ & 2 \\
\hline 0,68 & B-1 série 2 & $2 \phi 8$ & $2 \times 10^{-3}$ & 1 \\
\hline 0,68 & $\mathrm{~B}-2$ série 2 & $2 \phi 8$ & $3 \times 10^{-3}$ & 1 \\
\hline 0,68 & B-3 série 2 e B-4 série 2 & $2 \phi 8$ & $>5 \times 10^{-3}$ & 2 \\
\hline 1,00 & $\mathrm{C}-1$ série 1 & $3 \phi 6$ & $2 \times 10^{-3}$ & 1 \\
\hline 1,00 & C-2 série 1 & $3 \phi 6$ & $3 \times 10^{-3}$ & 1 \\
\hline 1,00 & C-3 série 1 e C-4 série 1 & $3 \phi 6$ & $>5 \times 10^{-3}$ & 2 \\
\hline 0,00 & C-1 série 3 e C-2 série 3 & $3 \phi 6$ & $>5 \times 10^{-3}$ & 2 \\
\hline \multicolumn{5}{|c|}{$\begin{array}{l}\mathrm{A}_{\mathrm{sr}}=\text { armadura do reforço correspondente a } 68 \mathrm{~mm}^{2} \text { ou } 86,4 \mathrm{~mm}^{2} \text { com chapa de } 2 \mathrm{~mm} \mathrm{de} \\
\quad \text { espessura; } \\
\mathrm{A}_{\mathrm{s} \mathrm{l}}=\text { armadura longitudinal do substrato. }\end{array}$} \\
\hline
\end{tabular}

Tabela 3.9 - Momentos de ruína das vigas ensaiadas por ALFAIATE

\begin{tabular}{|c|c|c|c|c|c|c|}
\hline $\begin{array}{c}\text { Tipos } \\
\text { de viga }\end{array}$ & $\begin{array}{c}\mathrm{M}_{\mathrm{exp}} \\
\text { (kN.m) }\end{array}$ & $\begin{array}{c}\mathrm{M}_{\mathrm{CEB}} \\
(\mathrm{kN} . \mathrm{m})\end{array}$ & $\begin{array}{l}\mathrm{M}_{\mathrm{REBAP}} \\
(\mathrm{kN} . \mathrm{m})\end{array}$ & $\mathrm{M}_{\mathrm{exp}} / \mathrm{M}_{\mathrm{CEB}}$ & $\mathrm{M}_{\text {exp }} / \mathrm{M}_{\mathrm{REBAP}}$ & $\mathrm{M}_{\mathrm{CEB}} / \mathrm{M}_{\mathrm{REBAP}}$ \\
\hline " A & 1013,76 & 12,60 & 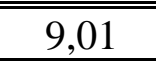 & $\begin{array}{ll}1,09 \\
\end{array}$ & 1,52 & 1,40 \\
\hline B & 14,00 & 11,38 & 8,39 & 1,23 & 1,67 & 1,36 \\
\hline C & 12,00 & 10,97 & 8,16 & 1,09 & 1,50 & 1,34 \\
\hline $\begin{array}{l}\mathrm{M}_{\text {exp }}= \\
\mathrm{M}_{\text {CEB }}= \\
\mathrm{M}_{\text {REBAP }}=\end{array}$ & $\begin{array}{l}\text { ento de } \\
\text { ento teó } \\
\text { ento tec }\end{array}$ & $\begin{array}{l}\text { obtido ex } \\
\text { btido atr } \\
\text { btido atr }\end{array}$ & $\begin{array}{l}\text { mentalr } \\
\text { das rec }\end{array}$ & daç & & \\
\hline
\end{tabular}




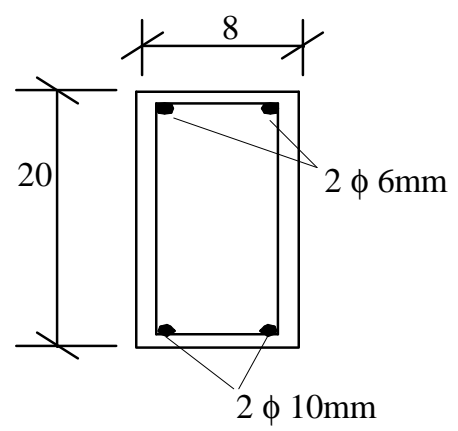

Viga de referência (tipo A )

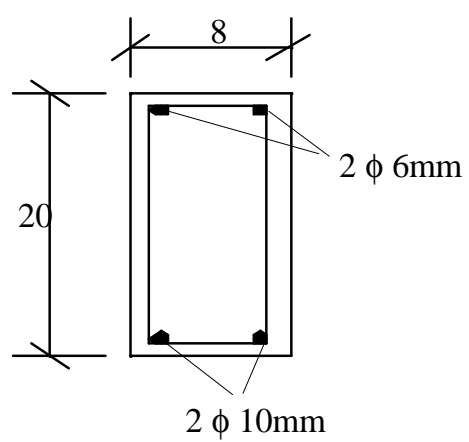

Viga de referência (tipo A )

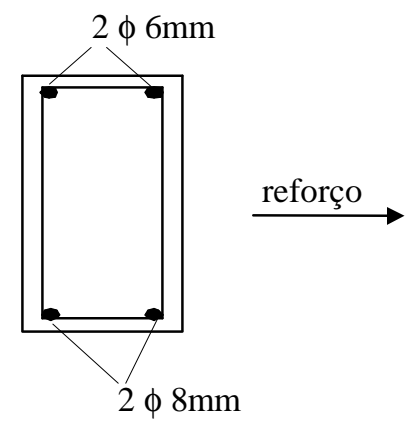

Viga inicial (tipo B sem reforço)

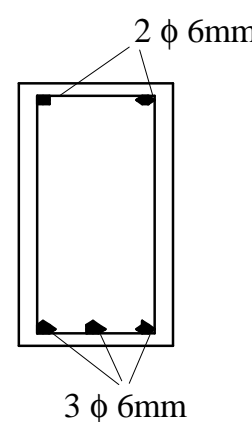

Viga inicial (tipo C sem reforço)

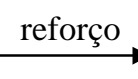

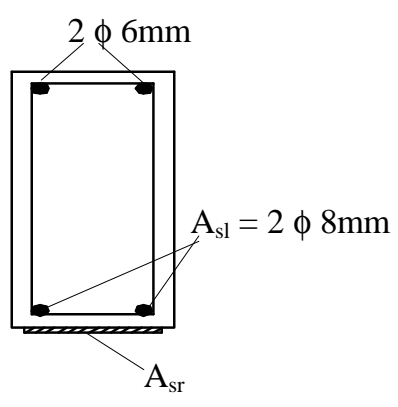

Viga inicial reforçada (tipo B com reforço)

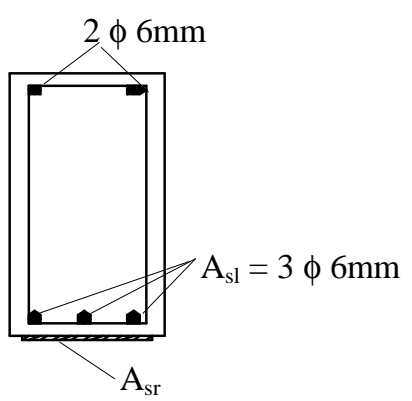

Viga inicial reforçada (tipo C com reforço)

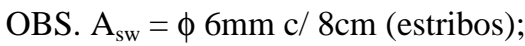

Figura 3.9 - Detalhes das vigas ensaiadas por ALFAIATE (1986)

Em função dos parâmetros observados $\left(\mathrm{A}_{\mathrm{sr}} / \mathrm{A}_{\mathrm{sl}}\right.$; nível de dano; ligação reforçoconcreto com/sem buchas metálicas), ALFAIATE observou, para o estado limite último, forças de ruína idênticas para vigas da série 0,1 e 2 (de referência e reforçadas), exceto em três vigas tipo $\mathrm{C}$ que tiveram capacidade portante menores por apresentarem menores resistências à compressão do concreto utilizado na moldagem das peças. Observou também mecanismos de ruína idênticos (esmagamento do concreto nos pontos de aplicação da força concentrada), exceto na viga C-3 série 1 , onde ocorreu o descolamento da chapa. 
Em relação ao estado limite de utilização, verificou-se que os valores de rigidez à flexão EI, antes da intervenção, foram idênticos aos valores após a introdução do reforço. No caso da reabertura das fissuras pré-existentes antes do reforço devido o précarregamento aplicado na viga, notou-se a influência da forma de reparo neste processo. Sendo assim, a reabertura das fissuras foi mais intensa para as peças que apresentaram os menores níveis de dano antes da execução do reforço. Isto porque, neste caso, as fissuras que surgiram nas peças antes do reforço possuíam aberturas extremamente finas, não permitindo a injeção de resina epóxi da maneira adequada. Durante o ensaio da viga reabilitada, as fissuras reparadas com resina epóxi de forma eficiente não voltaram a abrir, provocando o aparecimento de novas fissuras entre as pré-existentes. De qualquer forma só se constatou uma fissuração elevada (aberturas maiores que $1 \mathrm{~mm}$ ) quando a viga reabilitada estava próxima ao escoamento das armaduras longitudinais.

Para analisar os dados experimentais, foram feitas previsões analíticas conforme os códigos CEB e REBAP*. Os momentos fletores de fissuração experimentais foram idênticos aos previstos por estas duas normas, sendo que o mesmo não aconteceu para a previsão dos momentos fletores de ruína, que estão indicados na Tabela 3.10. Os momentos de ruptura previstos pelo REBAP foram mais conservativos, estando os valores fornecidos pelo $\mathrm{CEB}$ mais compatíveis com o comportamento real das peças reabilitadas, apesar de também fornecer valores teóricos inferiores aos experimentais.

ALFAIATE também observou que a qualidade da colagem da chapa com o substrato é fundamental, pois descontinuidades nesta ligação geram elevadas concentrações de tensão na região da junta, que são críticas junto às ancoragens. Isto pode provocar o descolamento da extremidade da chapa de aço, resultando em uma ruptura precoce da peça, como aconteceu com a viga C-3 série 1.

As buchas metálicas reduzem o risco de descolamento da chapa nas regiões de ancoragem, mas devem ser introduzidas o mais próximo possível das extremidades da viga, sob pena de não originarem qualquer benefício. Inclusive em um dos ensaios

\footnotetext{
* REBAP - Regulamento de Estruturas de Betão Armado e Pré-Esforçado
} 
ocorreu o descolamento da chapa junto ao apoio em virtude de se colocarem buchas metálicas a $20 \mathrm{~cm}$ do apoio, concluindo que esta distância já foi demasiadamente grande.

Dois dos ensaios efetuados (B-4 série-1 e C-3 série-1 com níveis de danos mínimos) revelaram a invalidade da hipótese de Bernoulli após o escoamento das armaduras de reforço, porém este comportamento precisa ser melhor estudado.

\subsubsection{Ensaios realizados por CAMPAGNOLO (1997)}

No artigo apresentado por CAMPAGNOLO na XXVIII Jornadas Sul-Americanas de Engenharia Estrutural, descreve-se o reforço de vigas por meio de chapas de aço fixadas com parafusos, utilizando ou não resina epóxi.

No total foram ensaiadas 4 vigas (ver Tabela 3.10) com seção transversal retangular de $12 \mathrm{~cm}$ x $25 \mathrm{~cm}$, comprimento total de 2,50 m e vão livre de 2,35 $\mathrm{m}$. As vigas foram submetidas a duas forças concentradas aplicadas a 78,5 cm a partir do apoio. A armadura longitudinal foi composta por duas barras de aço CA-50A, de $10 \mathrm{~mm}$ de diâmetro, posicionadas no banzo tracionado e por duas barras de $6,3 \mathrm{~mm}$, aço CA-50B, colocadas no bordo comprimido. A armadura transversal consistia de estribos de $6,3 \mathrm{~mm}$ espaçados a cada $11 \mathrm{~cm}$. As resistências ao escoamento para barras de $10 \mathrm{~mm}$ e 6,3 mm foram respectivamente $549 \mathrm{MPa}$ e $657 \mathrm{MPa}$. As chapas de aço utilizadas no reforço tinham 2,20 m de comprimento, $12 \mathrm{~cm}$ de largura e 2,8 $\mathrm{mm}$ de espessura, com tensão média de escoamento de $326 \mathrm{MPa}$. Os parafusos auto-fixantes utilizados tinham $8 \mathrm{~mm}$ de diâmetro e $80 \mathrm{~mm}$ de comprimento, com resistência ao cisalhamento de 13,5 kN e ao arrancamento de $14,3 \mathrm{kN}$.

O uso de parafusos neste tipo de reforço foi introduzido por uma questão operacional, sendo responsáveis por manter a chapa na posição correta e sob pressão até o endurecimento da formulação epóxi e não sendo mais necessários após o endurecimento da resina. Entretanto, como o adesivo epóxi pode se deteriorar se exposto a elevadas temperaturas, os parafusos devem ser mantidos para minimizar o risco de colapso da estrutura no caso de incêndios. Inclusive, de acordo com algumas referências, recomenda-se o dimensionamento do número e do diâmetro dos parafusos para resistir à 
carga total do reforço, desprezando a colaboração da resina, delegando a estes elementos uma função estrutural. Por este motivo, CAMPAGNOLO levantou dúvidas a respeito da real necessidade da resina no reforço, uma vez que a reabilitação fica com resistência superior à necessária, e se propôs a investigar esta questão.

O detalhamento das vigas ensaiadas e a posição dos parafusos usados nas chapas de aço estão ilustrados na Figura 3.10.

Tabela 3.10 - Características das vigas ensaiadas por CAMPAGNOLO (1997)

\begin{tabular}{||c|l||}
\hline Vigas & \multicolumn{1}{|c||}{ Características } \\
\hline \hline V1 & vigas testemunho, sem reforço \\
\hline V2 & reforçada com chapa de aço colada com resina epóxi \\
\hline V3 & reforçada com chapa de aço com parafusos auto-fixantes \\
\hline V4 & $\begin{array}{l}\text { reforçada com chapa de aço coladas com resina epóxi e fixada com } \\
\text { parafusos auto-fixantes }\end{array}$ \\
\hline
\end{tabular}

Os resultados experimentais foram comparados com previsões teóricas obtidas a partir da utilização de diferentes modelos. Para calibrar estes modelos foram usados os valores de $\mathrm{f}_{\mathrm{t}}$ e $\mathrm{E}_{\mathrm{co}}$ determinados a partir do valor experimental de $\mathrm{f}_{\mathrm{c}}$, utilizando as fórmulas 3.1 e 3.2 respectivamente. A força limite a partir da qual pode ocorrer o descolamento da chapa de aço foi prevista através da fórmula 3.3.

$$
\begin{array}{r}
\mathrm{f}_{\mathrm{t}}=0,30 \cdot \mathrm{f}_{\mathrm{c}}^{2 / 3}(\mathrm{MPa}) \\
\mathrm{E}_{\mathrm{co}}=1,25 \cdot 9500 \cdot \mathrm{f}_{\mathrm{c}}{ }^{1 / 3}(\mathrm{MPa}) \\
\mathrm{F}=2 \frac{\mathrm{E}_{\mathrm{c}}}{\mathrm{E}_{\mathrm{sch}}} \frac{\mathrm{f}_{\mathrm{ych}} \cdot \mathrm{I}_{\mathrm{x}}}{\left(\mathrm{l}_{\mathrm{b}}+\mathrm{a}\right) \cdot\left(\mathrm{d}_{\mathrm{ch}}-\mathrm{x}\right)}
\end{array}
$$

onde:

$\mathrm{f}_{\mathrm{t}}=$ Resistência média do concreto à tração;

$\mathrm{f}_{\mathrm{c}}$ = Resistência média do concreto à compressão;

$\mathrm{E}_{\mathrm{co}}=$ Módulo de deformação longitudinal inicial do concreto;

$\mathrm{E}_{\mathrm{c}}$ = Módulo de deformação longitudinal secante do concreto; 
$\mathrm{E}_{\mathrm{sch}}=$ Módulo de deformação longitudinal do aço da chapa;

$\mathrm{f}_{\mathrm{ych}}=$ Tensão de escoamento da chapa;

$\mathrm{I}_{\mathrm{x}}=$ Momento de inércia da seção homogeneizada de concreto;

$l_{b}=$ Comprimento de ancoragem da chapa;

$\mathrm{a}=$ Distância do final da chapa até o eixo do apoio;

$\mathrm{d}_{\mathrm{ch}}=$ Altura útil da chapa;

$\mathrm{x}=$ Altura da zona comprimida.

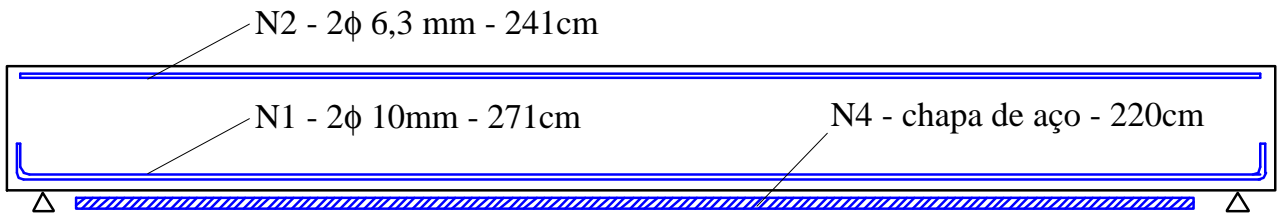

(a) armaduras longitudinais

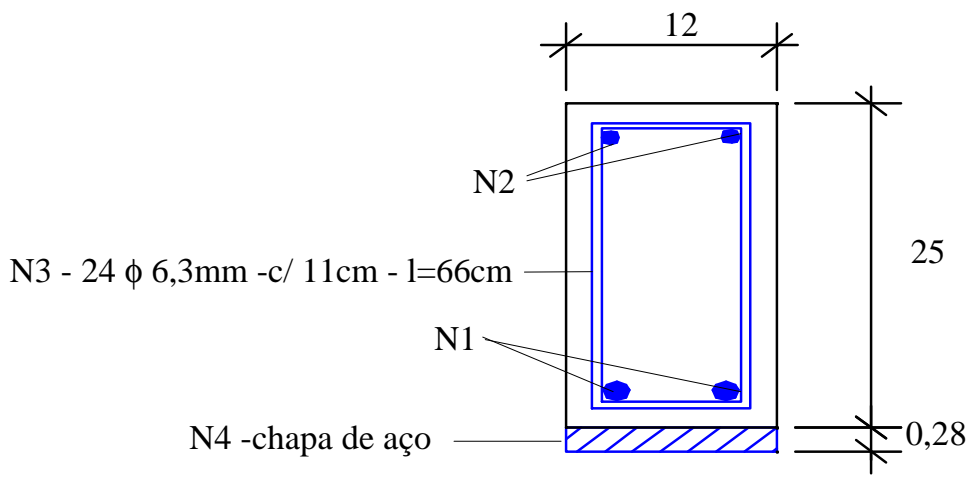

(b) seção transversal
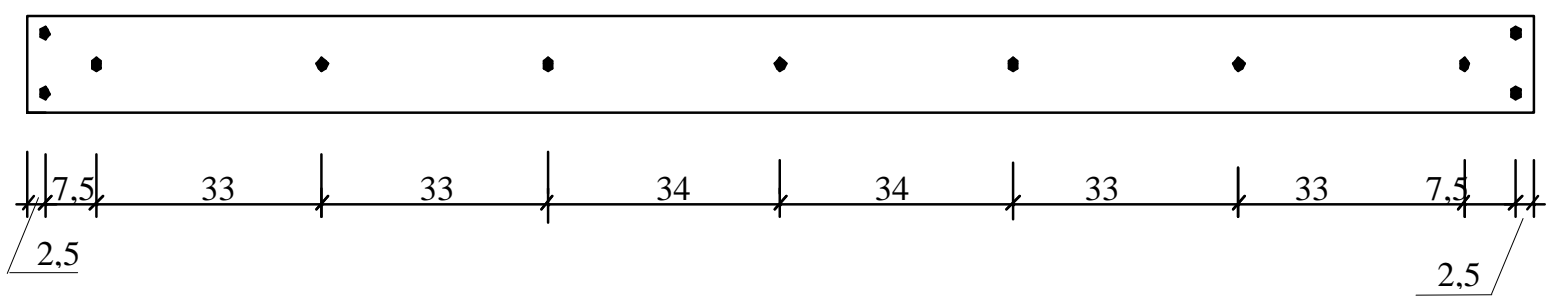

Posição dos parafusos nas chapas das vigas V3 e V4

Figura 3.10 - Detalhamento das vigas ensaiadas por CAMPAGNALO (1997) 

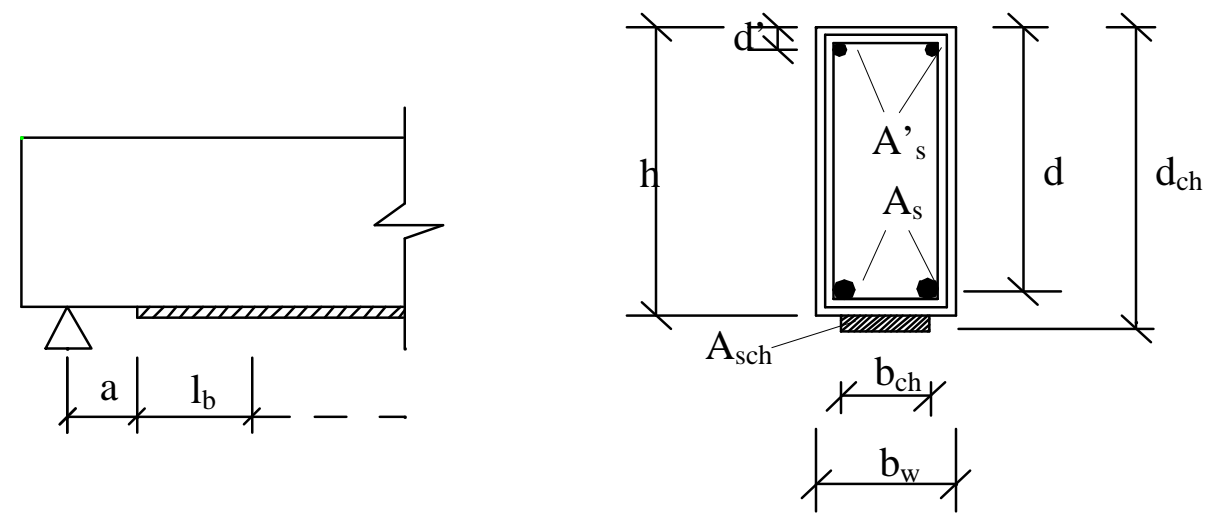

Figura 3.11 - Nomenclatura dos parâmetros utilizados nas vigas

$\mathrm{Na}$ Tabela 3.11 compara-se as forças de ruína das vigas com valores determinados teoricamente a partir de hipóteses de cálculo recomendadas pela norma NBR-6118. Nesta previsão foram utilizados os valores experimentais das características mecânicas dos materiais e todos os coeficientes de segurança foram tomados como unitários. Nesta tabela se encontram também as propriedades do concreto das vigas ensaiadas.

Tabela 3.11 - Propriedades do concreto e força de ruína das vigas reabilitadas por CAMPAGNOLO (1997)

\begin{tabular}{||c|c|c|c|c|c|c||}
\hline Vigas & $\begin{array}{c}\mathrm{f}_{\mathrm{c}} \\
\mathrm{MPa}\end{array}$ & $\begin{array}{c}\mathrm{f}_{\mathrm{t}} \\
\mathrm{MPa}\end{array}$ & $\begin{array}{c}\mathrm{E}_{\mathrm{co}} \\
\mathrm{MPa}\end{array}$ & $\begin{array}{c}\mathrm{F}_{\mathrm{r} \text {-exp }} \\
\mathrm{kN}\end{array}$ & $\begin{array}{c}\mathrm{F}_{\text {r-teo }} \\
\mathrm{kN}\end{array}$ & $\mathrm{F}_{\text {r-exp }} / \mathrm{F}_{\text {r-teo }}$ \\
\hline \hline $\mathrm{V} 1$ & 33,11 & 3,09 & 38150 & 53 & 48,5 & 1,09 \\
\hline $\mathrm{V} 2$ & 33,26 & 3,10 & 38200 & 113 & 109,7 & 1,03 \\
\hline $\mathrm{V} 3$ & 36,23 & 3,28 & 39400 & 88 & 110,4 & 0,80 \\
\hline $\mathrm{V} 4$ & 31,26 & 2,98 & 37400 & 114 & 109,2 & 1,04 \\
\hline
\end{tabular}

Observando os resultados obtidos percebe-se que os valores teóricos ficaram próximos dos experimentais, com exceção da viga V3. Isto porque nesta viga, a ruptura ocorreu por cisalhamento dos parafusos antes de se atingir o escoamento da armadura tracionada. Para as demais vigas, a ruína ocorreu por deformação plástica excessiva da armadura longitudinal do substrato e do reforço (chapa). 
É interessante observar que a força de ruína da viga V2 foi muito próxima do valor previsto para o descolamento da chapa de aço através da equação 3.3, correspondente a 103,6 kN. Neste caso, a separação da chapa simultaneamente ao rompimento da viga. A diferença básica entre o comportamento das vigas V2 e V4 foi que, para esta última, não houve descolamento da chapa de aço no instante da ruína, indicando que os parafusos auto-fixantes, apesar de não aumentarem a capacidade última da peça reabilitada, conseguem melhorar as condições de ancoragem da chapa de aço evitando o destacamento de suas extremidades.

Observando a evolução das flechas, CAMPAGNOLO verificou uma boa aproximação entre os valores previstos e os experimentais. Observou ainda que este tipo de reforço, além de incrementar a máxima capacidade portante das vigas, também aumenta significativamente a rigidez das mesmas. No caso da viga $\mathrm{V} 3$, reforçada com chapa fixada apenas por parafusos, obteve-se a menor rigidez, sendo as flechas experimentais maiores que as determinadas teoricamente. Isto ocorreu porque a chapa não estava perfeitamente aderida ao concreto do substrato, uma vez que sua fixação foi feita apenas através de parafusos, permitindo o deslizamento relativo da chapa em relação à viga. Este comportamento também fica confirmado ao se comparar os valores experimentais e teóricos das deformações na armadura longitudinal tracionada no meio do vão.

Diante destas observações, o autor concluiu que a resina é realmente necessária para garantir um bom desempenho do elemento reforçado, pois a fixação da chapa apenas com parafusos não proporciona o mesmo incremento de rigidez para a viga reabilitada. Além disso, a resina proporciona um comportamento solidário da peça devido à aderência, distribuindo melhor os esforços na estrutura.

Outro aspecto a ser ressaltado é a importância de uma ancoragem adequada da chapa de reforço para garantir que os esforços na extremidade deste elemento sejam transmitidos ao corpo da viga. Esta ancoragem pode ser feita pela colocação de chapas coladas nas laterais da viga ou por parafusos (conforme constatado na viga V4) . A não utilização destes dispositivos pode conduzir a uma separação prematura da chapa. 


\section{ESTUDO EXPERIMENTAL}

\subsection{Considerações Iniciais}

O estudo experimental realizado consistiu no ensaio de sete vigas de concreto armado com seção transversal em forma de T. Três dessas peças foram reforçadas por barras de aço convencionais adicionadas ao banzo tracionado e envolvidas por argamassa de alto desempenho. Outras três foram reforçadas pela fixação de uma chapa de aço com conectores metálicos na região tracionada, também utilizando argamassa de alto desempenho. Foi ensaiada ainda uma viga monolítica com área de aço e arranjo de armadura semelhante ao das estruturas reforçadas por adição de barras de aço. Este ensaio tinha o objetivo de verificar o grau de monolitismo das peças reabilitadas e a semelhança entre as formas de ruptura. A viga monolítica constituiu um modelo de referência, uma vez que não possuía junta de concretagem. Todavia, não correspondia à viga de resistência ideal, pois os estribos não foram prolongados de modo a envolver a armadura mais tracionada. Para determinar a capacidade portante da peça ideal, calculou-se a resistência teórica de uma viga de mesmas dimensões do elemento reforçado, porém armada de maneira convencional.

As vigas reforçadas com armadura convencional foram denominadas VA, as reabilitadas com chapa de aço VC e a viga monolítica VM. Nos casos das vigas VA e VC, foram realizadas três séries de ensaio com duas vigas cada (uma para cada tipo de reforço estudado) e no caso da viga VM foi feito um único ensaio.

Nas séries 1 e 2, o reforço foi feito antes de se aplicar qualquer tipo de carregamento nas peças. As vigas VA-1 e VA-2 se diferenciavam apenas pelo fato de, nessa última, ter sido incorporado $1 \%$ de fibras curtas de aço na argamassa de alto desempenho. $\mathrm{O}$ interesse de se analisar o efeito de fibras de aço surgiu 
em decorrência do trabalho de FURLAN JR. \& HANAI (1995), pelo qual se observou a capacidade das fibras de contribuir na resistência ao cisalhamento e na transferência de forças transversais. Em relação às diferenças entre as vigas VC, para a VC-1, utilizou-se o conector metálico tipo 1 soldado na chapa. Já para a VC-2, foi usado um segundo tipo de conector de aço associado ao conector tipo 1 (ver Figura 4.1).

Como na prática da Engenharia, geralmente, as peças que necessitam de reforço já sofreram algum tipo de dano, optou-se, na série 3, por recuperar e reensaiar as vigas rompidas na série 1 . Nesse caso, foram utilizados fibras e conectores de aço similares aos empregados na série 2 .

Todas essas vigas foram dimensionadas para ruir por deformação plástica excessiva da armadura longitudinal.

A preparação da superfície para receber o reforço foi realizada fazendo-se a escarificação da face inferior da viga, retirando-se todo o material solto e umedecendose a superfície antes da aplicação da argamassa de alto desempenho.

Optou-se por estudar vigas fletidas com seção transversal $\mathrm{T}$ porque as peças de seção retangular, que compreendem a maior parte das vigas de pavimentos de edifícios, funcionam como vigas $\mathrm{T}$ nas regiões de momento positivo, quando se utiliza o sistema de laje maciça. Além disso, esse tipo de estrutura é usual nas construções de pontes e passarelas. As dimensões das vigas ensaiadas foram escolhidas de forma a representar o tamanho real de peças dessa natureza. Quanto as ações, optou-se por aplicar duas forças concentradas, eqüidistantes dos apoios, possibilitando estudar o reforço em regiões submetidas à flexão pura e em regiões onde há esforços de cisalhamento (flexão simples).

\subsection{Dimensões e armaduras}

As vigas ensaiadas possuíam $320 \mathrm{~cm}$ de comprimento total, correspondendo a um vão livre de 300 cm e seção transversal tipo T. A Figura 4.2 indica as dimensões das peças e os dados essenciais sobre as armaduras. As vigas do tipo VC tiveram altura total menor para que a posição do centro de gravidade da chapa, em relação à mesa de concreto, fosse a mesma da armadura longitudinal do reforço usada nas vigas VA.

A armadura calculada foi disposta em 2 camadas sendo a primeira $\left(\mathrm{A}_{\mathrm{sl}}\right)$ colocada na região do substrato e a segunda $\left(\mathrm{A}_{\text {slr }}\right)$, não envolvida por estribos, colocada na região 
do reforço. Em relação à viga $\mathrm{VC}-1$, foram utilizados conectores de aço tipo 1 (segmentos de barras de aço soldados à chapa) para melhorar as condições de aderência da chapa com a camada de argamassa. Este conector foi confeccionado a partir do corte de uma barra de aço de $12 \mathrm{~mm}$ de diâmetro, do tipo CA-50, em vários pedaços de $12 \mathrm{~cm}$ de comprimento, sendo posteriormente soldados ao longo da chapa metálica a cada 20 cm (ver Figura 4.1).

Nas vigas VC-2 e VC-3 utilizou-se um segundo tipo de conector, em forma de gancho, visando melhorar a ligação entre a chapa, a camada de argamassa e o substrato. Este conector foi confeccionado dobrando-se trechos de barras de aço CA-50 de $8 \mathrm{~mm}$ de diâmetro, conforme ilustra a Figura 4.1. Estes elementos foram soldados ao longo da chapa de aço a cada $20 \mathrm{~cm}$ para a região localizada dentro do vão de cisalhamento (trecho que vai desde o apoio até o ponto de aplicação da força concentrada). Para determinar a área de aço desses conectores seguiu-se as recomendações de cálculo de conectores utilizados em peças pré-moldadas, indicadas pelo PCI (1992). De acordo com esse método, seriam necessários conectores de $8 \mathrm{~mm}$ de diâmetro a cada $15 \mathrm{~cm}$, mas por facilidade construtiva, optou-se por utilizar conectores de $8 \mathrm{~mm}$ a cada $20 \mathrm{~cm}$.

Ao utilizar o conector tipo 2 (gancho), idealizou-se um modelo de treliça modificado para a peça reabilitada conforme ilustrado na Figura 4.3a. Dessa forma, tentou-se testar o conceito de união entre a chapa de reforço ao banzo tracionado por meio de barras localizadas, ou seja, os conectores fariam a transferência de esforços através de "ligações discretas" entre o banzo existente e o reforço. Com a utilização de fibras de aço na camada de argamassa do reforço, pensou-se em analisar o mecanismo de transferência de esforços como se fossem "ligações contínuas" existentes entre as barras adicionadas e o banzo tracionado, proporcionadas pelo "efeito de costura" gerado pelas fibras (ver Figura 4.3b).

Na série 2, reduziu-se o comprimento de ancoragem da armadura de reforço para simular a existência de um pilar na região do apoio, que impedisse o prolongamento das barras de reforço além da face desse pilar. Com isso, o comprimento dos elementos de reforço foi reduzido de $317 \mathrm{~cm}$ para $280 \mathrm{~cm}$.

O cobrimento adotado foi de $1,5 \mathrm{~cm}$ tanto para a armadura do substrato quanto para o reforço. 
$\mathrm{Na}$ Tabela 4.1 encontram-se resumidas as características gerais das vigas e da condição inicial de cada ensaio.

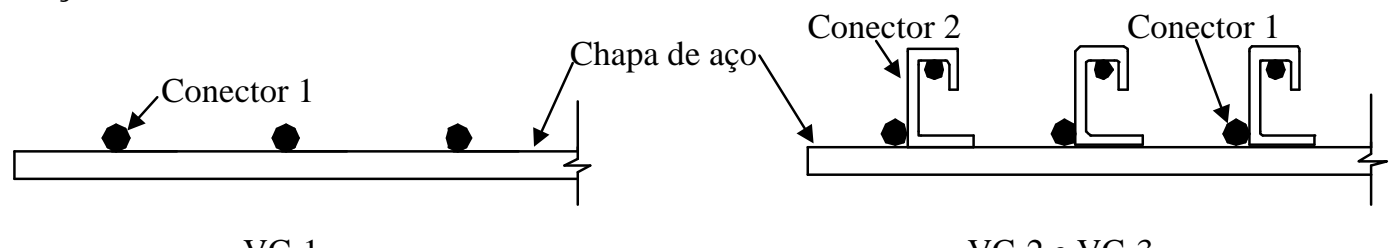

VC-1

VC-2 e VC-3

(a) Detalhe da fixação dos conectores na chapa de aço

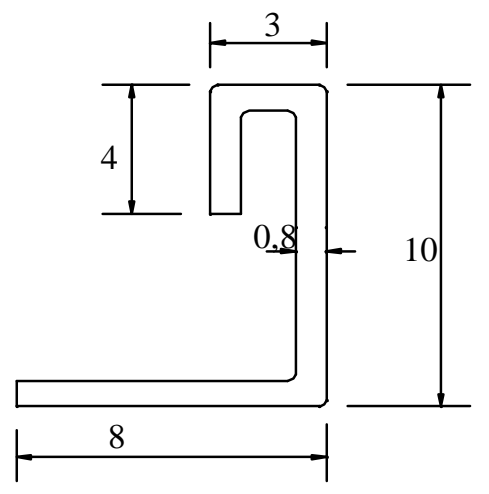

(b) Dimensões do conector tipo 2

Figura 4.1 - Conectores tipo 1 e 2

Tabela 4.1 - Características gerais das vigas e condição inicial de ensaio

\begin{tabular}{|c|c|c|c|c|}
\hline Viga & $\mathbf{A}_{\text {slr }}$ & $\mathbf{A}_{\text {sw }}$ & Reforço da ligação & Condição de ensaio \\
\hline VM & $\begin{array}{c}3 \text { barras } \\
\phi 16-\mid=317\end{array}$ & $\phi 8 \mathrm{c} / 9 \mathrm{~cm}$ & nenhum & monolítica, sem dano \\
\hline VA-1 & $\begin{array}{c}3 \text { barras } \\
\phi 16-\mid=317\end{array}$ & $\phi 8 \mathrm{c} / 9 \mathrm{~cm}$ & nenhum & sem dano \\
\hline VA-2 & $\begin{array}{c}3 \text { barras } \\
\phi 16-\mid=280\end{array}$ & $\phi 10 \mathrm{c} / 9 \mathrm{~cm}$ & $\begin{array}{l}1 \% \text { em volume } \\
\text { de fibras de aço }\end{array}$ & sem dano \\
\hline VA-3 & $\begin{array}{c}3 \text { barras } \\
\phi 16-\mid=317\end{array}$ & $\phi 8 \mathrm{c} / 9 \mathrm{~cm}$ & $\begin{array}{l}1 \% \text { em volume } \\
\text { de fibras de aço }\end{array}$ & $\begin{array}{l}\text { viga VA-1 } \\
\text { reabilitada }\end{array}$ \\
\hline VC-1 & $\begin{array}{c}\text { Chapa } \\
\mathrm{e}=95-\mid=317\end{array}$ & $\phi 8 \mathrm{c} / 9 \mathrm{~cm}$ & $\begin{array}{l}\text { conector } \\
\text { tipo } 1\end{array}$ & sem dano \\
\hline VC-2 & $\begin{array}{c}\text { Chapa } \\
\mathrm{e}=95-\mid=280\end{array}$ & $\phi 10 \mathrm{c} / 9 \mathrm{~cm}$ & $\begin{array}{l}\text { conector } \\
\text { tipo } 1 \text { e } 2\end{array}$ & sem dano \\
\hline VC-3 & $\begin{array}{c}\text { Chapa } \\
\mathrm{e}=95-\mid=317\end{array}$ & $\phi 8 \mathrm{c} / 9 \mathrm{~cm}$ & $\begin{array}{l}\text { conector } \\
\text { tipo } 1 \text { e } 2\end{array}$ & $\begin{array}{l}\text { viga } \mathrm{VC}-1 \\
\text { reabilitada }\end{array}$ \\
\hline \multicolumn{5}{|c|}{$\begin{array}{l}\text { OBS. Unidades: } \phi ; \mathrm{e}-\text { diâmetro e espessura da chapa dados em mm; } \\
\begin{aligned} \mid \quad-\text { comprimento dado em } \mathrm{cm} ; \\
\mathrm{A}_{\mathrm{sw}}=\text { Armadura dos estribos } \\
\mathrm{A}_{\mathrm{slr}}=\text { Armadura longitudinal do reforço; } \\
\mathrm{A}_{\mathrm{sl}}=\text { Armadura longitudinal do substrato }(3 \phi 16-\mid-357 \mathrm{~cm}) ; \\
\mathrm{A}_{\mathrm{s}}^{\prime}=\text { Armadura de compressão }(4 \phi 8-\mid-317 \mathrm{~cm}) ;\end{aligned}\end{array}$} \\
\hline
\end{tabular}


$\mathrm{A}_{\mathrm{S}}^{\prime}-4 \phi 8 \mathrm{~mm}-\mathrm{I}=317$

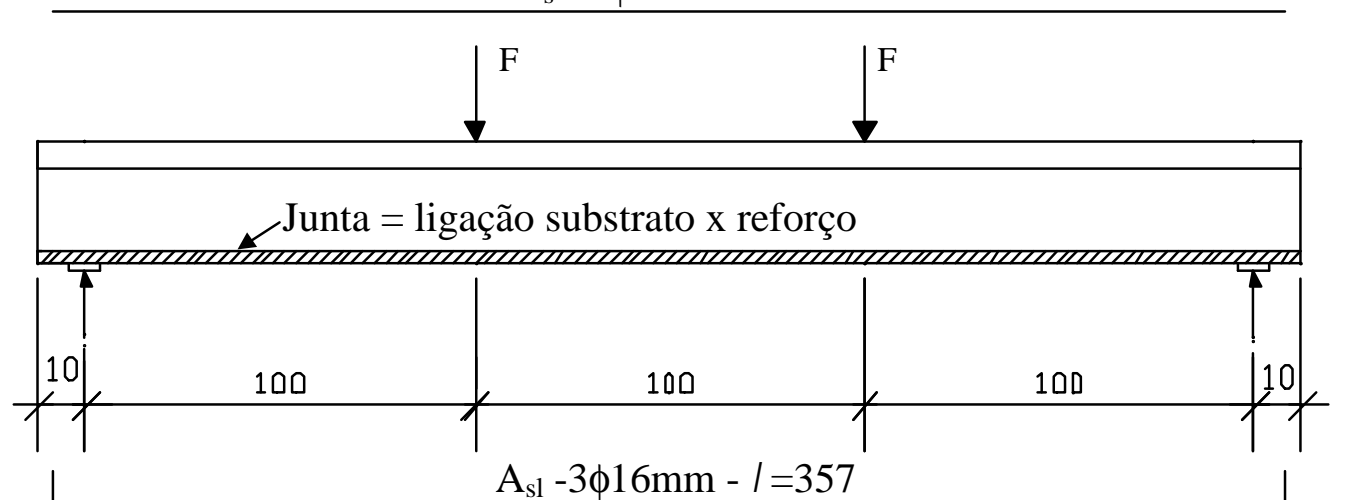

ver Tabela $4.1-\mathrm{A}_{\mathrm{slr}}$

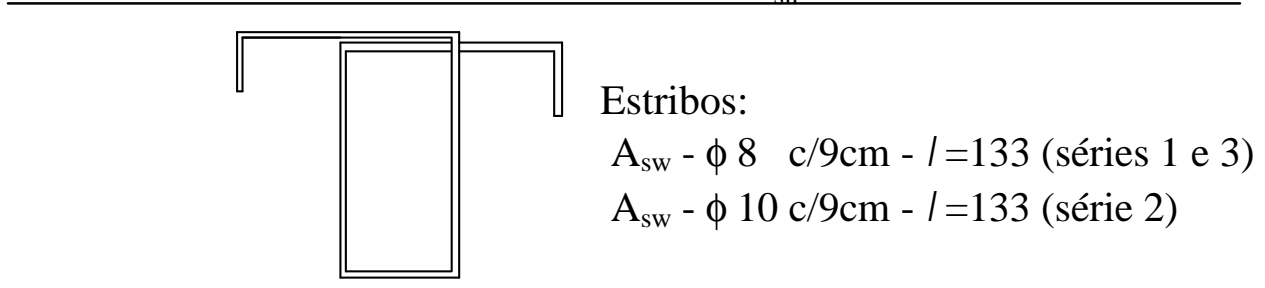

(a) Armaduras longitudinais e transversais

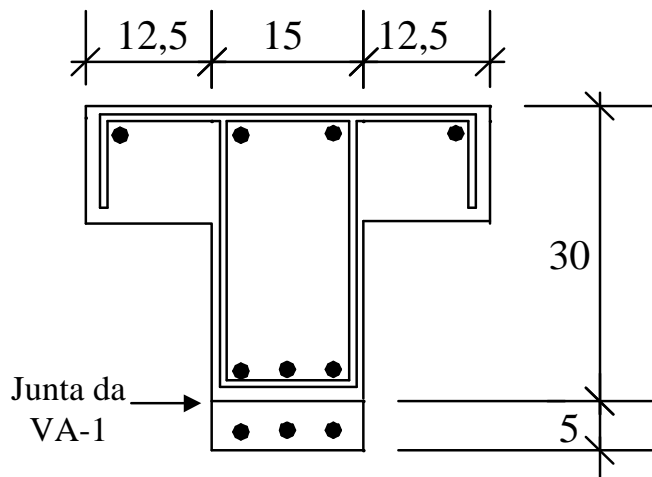

VA-1 e VM

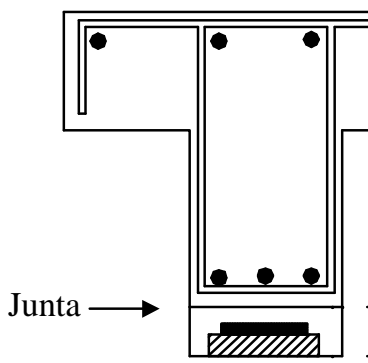

VC-1

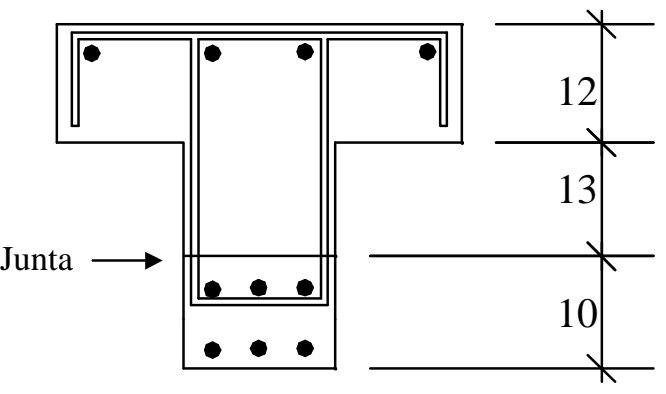

VA-2 e VA-3

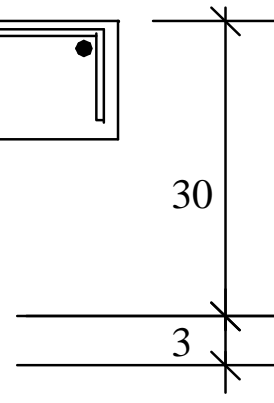

(b) Seções transversais

OBS. A viga VM não apresenta junta pois foi moldada em uma única etapa

Figura 4.2 - Dimensões da seção transversal e detalhamento das armaduras 


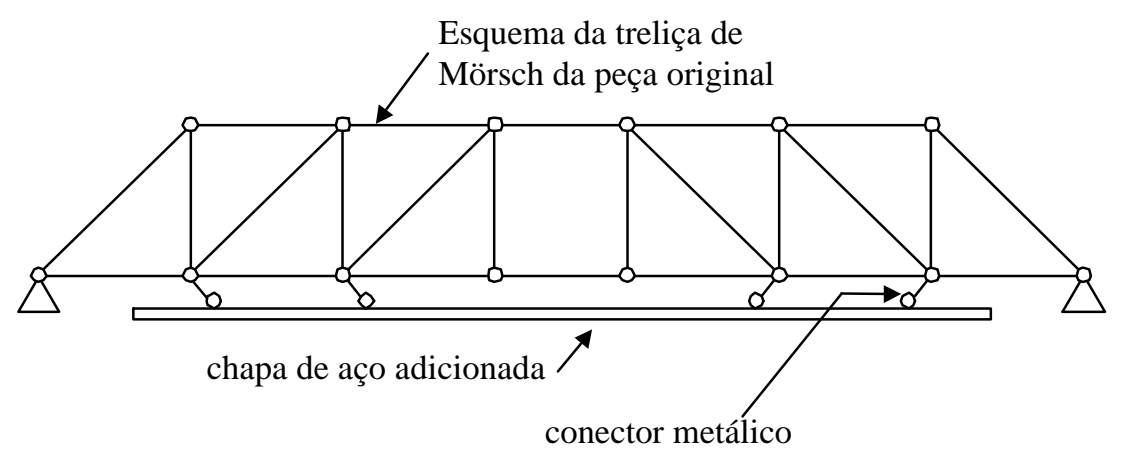

(a) Ligação discreta - conectores metálicos

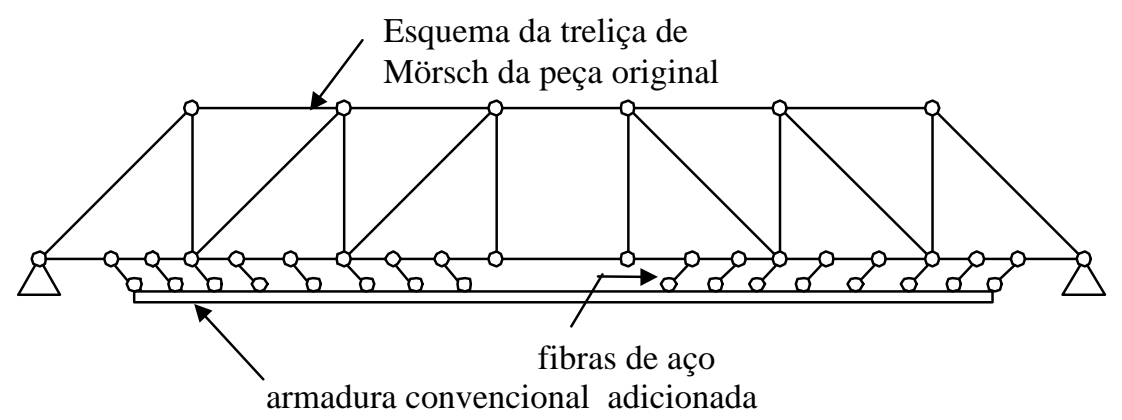

(b) Ligação contínua - fibras de aço

\section{Figura 4.3 - Esquema de treliça modificada após a reabilitação da peça}

\subsection{Esquema de Ensaio}

Para realizar os ensaios, montou-se um pórtico de reação onde foi fixado o atuador hidráulico (ver Figura 4.4). Através desse dispositivo aplicou-se a força sobre um perfil metálico biapoiado em cima da mesa da viga. O carregamento da viga, composto pelas reações do perfil metálico, consistiu de duas forças concentradas, de mesmo valor, distantes entre si de $100 \mathrm{~cm}$, conforme ilustra a Figura 4.2. É importante ressaltar que as deformações e deslocamentos na peça, gerados pelo carregamento devido ao peso próprio da viga, foram descontados durante a leitura dos instrumentos de medição instalados.

Para evitar o aparecimento de reações horizontais, utilizaram-se apoios móveis garantindo o esquema estático idealizado de viga biapoiada. A Figura 4.5 mostra o aparelho de apoio utilizado no ensaio. 

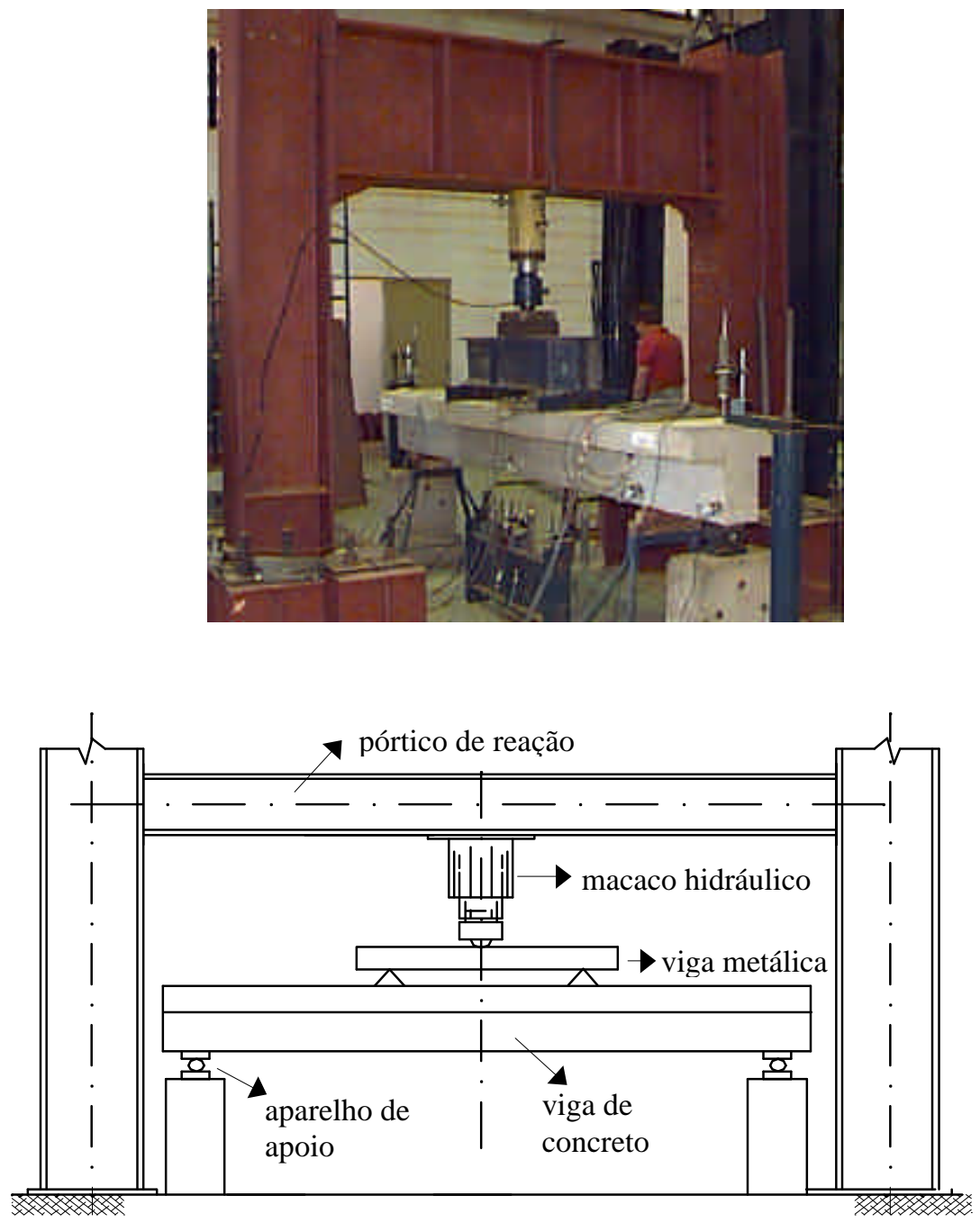

Figura 4.4 - Esquema de ensaio

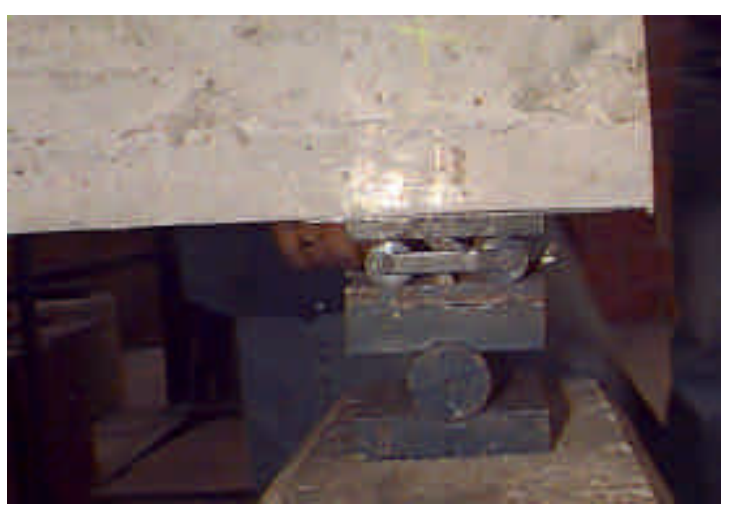

Figura 4.5 - Aparelho de apoio 


\subsection{Materiais}

\subsubsection{Concreto e argamassa}

Foram utilizados dois tipos de traço na confecção do concreto do substrato (traço $1 \mathrm{~S}$ e $2 \mathrm{~S}$ ). Esses traços foram escolhidos de forma que o substrato apresentasse uma resistência à compressão superior a $20 \mathrm{MPa}$ aos 7 dias. No caso da argamassa de reforço, foram utilizados três tipos de traço (traço $1 \mathrm{R}, 2 \mathrm{R}$ e $3 \mathrm{R}$ ). $\mathrm{O}$ primeiro continha pedriscos, o segundo foi feito apenas com cimento e areia e no último, adicionaram-se fibras de aço. Esses traços apresentavam resistência à compressão superior ao do substrato no dia do ensaio.

As proporções dos materiais utilizados na confecção de cada um desses traços, bem como em quais vigas foram utilizados, estão apresentadas nas Tabelas 4.2 e 4.3.

Tabela 4.2 - Traços usados na confecção do concreto do substrato

\begin{tabular}{|c|c|c|}
\hline Material & Traço 1S & Traço 2S \\
\hline cimento comum CP-II F-32 & 1,00 & 1,00 \\
\hline areia & 2,70 & 2,52 \\
\hline pedra britada $\mathrm{n}^{\mathbf{0}} 1$ & 3,70 & 3,38 \\
\hline $\mathrm{a} / \mathrm{c}$ & 0,55 & 0,58 \\
\hline Consumo de cimento $\left(\mathrm{kg} / \mathrm{m}^{3}\right)$ & 315 & 330 \\
\hline Vigas utilizadas & VA-1 e VA-3 & $\begin{array}{c}\text { VA-2, VM, VC-1, } \\
\text { VC-2 e VC-3 }\end{array}$ \\
\hline
\end{tabular}

Tabela 4.2 - Traços usados na confecção da argamassa de reforço

\begin{tabular}{|c|c|c|c|c|}
\hline \multicolumn{2}{|c|}{ Material } & Traço 1R & Traço 2R & Traço 3R \\
\hline \multirow{4}{*}{$\begin{array}{c}\text { proporção } \\
\text { em } \\
\text { massa }\end{array}$} & cimento ARI Plus & 1,00 & 1,00 & 1,00 \\
\hline & areia & 1,33 & 2,00 & 2,00 \\
\hline & pedrisco & 2,33 & - & - \\
\hline & $\mathrm{a} / \mathrm{c}$ & 0,49 & 0,42 & 0,46 \\
\hline \multirow{3}{*}{$\begin{array}{c}\% \\
\text { em relação } \\
\text { ao volume } \\
\text { de concreto }\end{array}$} & $\begin{array}{l}\text { superplastificante } \\
\text { REAX SP 1000A }\end{array}$ & $1,2 \%$ & $1,2 \%$ & $1,2 \%$ \\
\hline & sílica ativa & $12 \%$ & $12 \%$ & $12 \%$ \\
\hline & fibra de aço & - & - & $1 \%$ \\
\hline \multicolumn{2}{|c|}{ Consumo de cimento $\left(\mathrm{kg} / \mathrm{m}^{3}\right)$} & 576 & 670 & 670 \\
\hline \multicolumn{2}{|c|}{ Vigas utilizadas } & VA-1 & $\mathrm{VC}-1, \mathrm{VC}-2$ e $\mathrm{VC}-3$ & $\mathrm{VA}-2$ e VC-3 \\
\hline
\end{tabular}


Os traços $2 \mathrm{R}$ e $3 \mathrm{R}$ são semelhantes sendo que neste último foi incorporado $1 \%$ de fibras curtas de aço. Como a adição de tais fibras prejudicam a trabalhabilidade, aumentou-se consequentemente a relação a/c para 0,46. As fibras utilizadas foram da marca HAREX, tipo HSCF 25 com ganchos nas extremidades e apresentam as seguintes características:

a) Denominação conforme ASTM - A820/90 Tipo II : "cut sheet”; “deformed”

Comprimento nominal: $1_{\mathrm{n}}=25 \mathrm{~mm}$

Diâmetro nominal equivalente: $\mathrm{d}_{\mathrm{c}}=0,667$

Razão nominal de aspecto: $\lambda_{\mathrm{n}}=37,45$

Peso específico: $\gamma_{\mathrm{e}}=7850 \mathrm{~kg} / \mathrm{m}^{3}$

b) Dados dimensionais:

$$
\begin{aligned}
& \mathrm{L}_{\text {ges }}=(25 \pm 1,0) \mathrm{mm} \\
& \mathrm{L}_{\mathrm{m}}=(20 \pm 1,6) \mathrm{mm} \\
& \mathrm{L}_{\mathrm{e}}+\mathrm{L}_{\mathrm{k}}=(2,5 \pm 0,8) \mathrm{mm} \\
& \mathrm{b}=(0,70 \pm 0,07) \mathrm{mm} \\
& \mathrm{d}=(0,70 \pm 0,07) \mathrm{mm}
\end{aligned}
$$

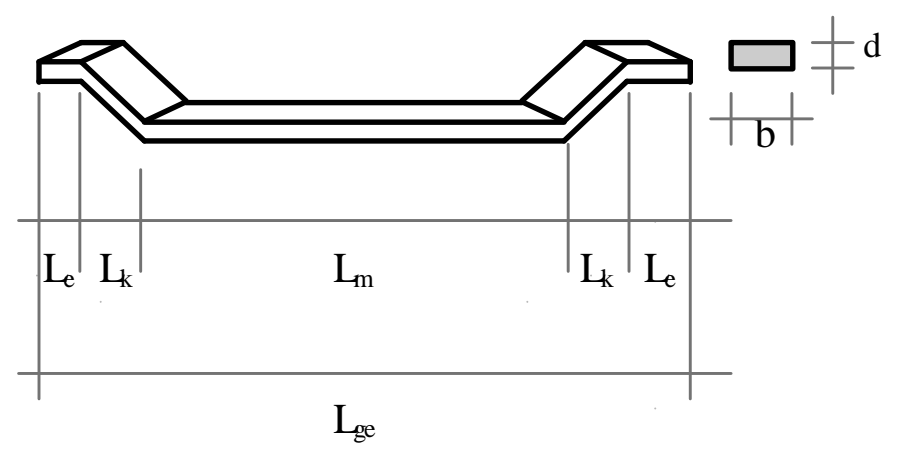

Figura 4.6 - Dados sobre a fibra de aço

As propriedades mecânicas do material foram determinadas no dia do ensaio pela ruptura de 6 corpos-de-prova cilíndricos de $10 \mathrm{~cm}$ de diâmetro por $20 \mathrm{~cm}$ de altura. Para cada traço foram ensaiados três corpos-de-prova à compressão simples e três à 
tração por compressão diametral, na máquina de compressão ELE Auto-test com capacidade de $3000 \mathrm{kN}$ e velocidade de deformação controlada.

O adensamento foi feito por meio de vibrador de imersão, com exceção dos corpos-de-prova que possuíam fibras de aço. Nesse caso, se utilizou o adensamento através de mesa vibratória.

Como a resistência utilizada nos cálculos teóricos refere-se a corpos-de-prova cilíndricos de $15 \mathrm{~cm}$ x $30 \mathrm{~cm}$, minorou-se em $5 \%$ os valores experimentais de resistência, a fim de considerar o efeito de escala dos corpos-de-prova ensaiados. A Tabela 4.4 apresenta, já corrigidas, as resistências à compressão e à tração do concreto e da argamassa, indicando a idade desses materiais no dia do ensaio.

Simultaneamente ao ensaio de compressão axial, fez-se o acompanhamento das deformações dos corpos-de-prova, de forma que fosse possível traçar o diagrama tensãodeformação do concreto. Através desse gráfico, determinou-se os módulos de elasticidade tangente e secante que também estão indicados na Tabela 4.4.

Os módulos de elasticidade do concreto do substrato e da argamassa de alto desempenho foram próximos, apesar das resistências serem sensivelmente diferentes. Este fato pode ser justificado porque, segundo MEHTA (1994), o módulo de elasticidade não depende somente da resistência do concreto, mas também dos materiais usados na confecção de cada traço.

Tabela 4.4 - Características do concreto e argamassa e idade no dia do ensaio

\begin{tabular}{|c|c|c|c|c|c|c|c|c|c|c|}
\hline \multirow{2}{*}{ Viga } & \multicolumn{2}{|c|}{ Idade (dias) } & \multicolumn{6}{|c|}{ Substrato } & \multicolumn{4}{|c|}{ Reforco } \\
\cline { 2 - 12 } & sub & ref & $\begin{array}{c}\mathrm{E}_{\mathrm{co}} \\
\mathrm{MPa}\end{array}$ & $\begin{array}{c}\mathrm{E}_{\mathrm{c}} \\
\mathrm{MPa}\end{array}$ & $\begin{array}{c}\mathrm{f}_{\mathrm{cj}} \\
\mathrm{MPa}\end{array}$ & $\begin{array}{c}\mathrm{f}_{\mathrm{tj}} \\
\mathrm{MPa}\end{array}$ & $\begin{array}{c}\mathrm{E}_{\mathrm{co}} \\
\mathrm{MPa}\end{array}$ & $\begin{array}{c}\mathrm{E}_{\mathrm{c}} \\
\mathrm{MPa}\end{array}$ & $\begin{array}{c}\mathrm{f}_{\mathrm{cj}} \\
\mathrm{MPa}\end{array}$ & $\begin{array}{c}\mathrm{f}_{\mathrm{tj}} \\
\mathrm{MPa}\end{array}$ \\
\hline VM & 14 & - & 25.996 & 22.139 & 24,76 & 2,39 & - & - & - & - \\
\hline VA-1 & 12 & 8 & 26.834 & 20.457 & 34,03 & 2,75 & 27.837 & 19.473 & 46,02 & 3,87 \\
\hline VC-1 & 10 & 7 & 27.187 & 24.239 & 22,70 & 1,91 & 34.498 & 29.924 & 66,57 & 3,10 \\
\hline VA-2 & 13 & 8 & 35.468 & 30.218 & 26,32 & 2,76 & 28.808 & 26.483 & 58,70 & 4,95 \\
\hline VC-2 & 10 & 7 & 27.273 & 24.440 & 28,94 & 2,86 & 28.239 & 25.934 & 52,85 & 3,47 \\
\hline VA-3 & 175 & 7 & 36.454 & 32719 & 46,04 & 3,46 & 30.215 & 28.335 & 60,23 & 4,87 \\
\hline VC-3 & 75 & 8 & 39.780 & 33.486 & 30,00 & 2,50 & 32.961 & 28.620 & 54,69 & 3,66 \\
\hline $\begin{array}{l}\mathrm{E}_{\mathrm{co}}=\text { módulo de elasticidade tangente na origem; } \\
\mathrm{E}_{\mathrm{c}}=\text { módulo de elasticidade secante a 40\% da resistência de ruptura. }\end{array}$ \\
\hline
\end{tabular}




\subsubsection{Aço}

O aço utilizado pelas barras de aço tracionadas foi do tipo CA-50, sendo suas características mecânicas obtidas por ensaios de tração, conforme recomenda a norma NBR-6152 (1980). O módulo de elasticidade $E_{c}$, a resistência de escoamento, $f_{y}$, e a deformação $\varepsilon_{\mathrm{y}}$, a partir da qual a armadura atinge o escoamento, estão indicados na Tabela 4.5. Para as barras de aço com diâmetro menor ou igual a $10 \mathrm{~mm}$, os ensaios foram realizados na Máquina Universal DARTEC com capacidade de $100 \mathrm{kN}$. Para diâmetros superiores a $10 \mathrm{~mm}$, utilizou-se a Máquina Universal ALSRED J. AMSLER, com capacidade de $250 \mathrm{kN}$.

As chapas de aço foram do tipo SAC-41 de 9,5 mm de espessura. Suas características mecânicas foram obtidas por ensaios de tração em corpos-de-prova usinados, conforme indicações da norma ASTM A 370-92, utilizando a Máquina Universal INSTRON, com capacidade de $100 \mathrm{kN}$.

Tabela 4.5 - Características das armaduras usadas nas vigas

\begin{tabular}{|c|c|c|c|}
\hline$\phi(\mathrm{mm})$ & $\mathrm{E}(\mathrm{GPa})$ & $\mathrm{f}_{\mathrm{y}}(\mathrm{MPa})$ & $\varepsilon_{\mathrm{y}}(\%)$ \\
\hline $8 \quad($ lote 1$)$ & 210,000 & 630 & 3,00 \\
\hline $8 \quad($ lote 2$)$ & 210,178 & 574 & 2,73 \\
\hline $10 \quad($ lote 1$)$ & 204,782 & 594 & 2,90 \\
\hline $16 \quad($ lote 2$)$ & 196,093 & 612 & 3,12 \\
\hline 16 & 203,922 & 565 & 2,77 \\
\hline chapa (lote 1) & 197,902 & 305 & 1,54 \\
\hline chapa (lote 2) & 209,212 & 342 & 1,63 \\
\hline - o módulo de elasticidade da barra de 8 mm do lote 1, foi adotado conforme o \\
valor convencional prescrito pela norma NBR-6152 (1980). \\
- as armaduras do lote 1 foram usadas na confecção das vigas das série 1 e da viga \\
monolítica. As do lote 2 foram utilizadas nas demais vigas. \\
\hline
\end{tabular}

\subsection{Execução das vigas}

\subsubsection{Fôrma}

A fôrma utilizada na moldagem das vigas foi confeccionada em madeira compensada de $15 \mathrm{~mm}$ reforçada com caibros de madeira, sendo as peças ligadas por 
parafusos. A Figura 4.7 ilustra as dimensões da fôrma usada para moldagem das vigas ensaiadas.

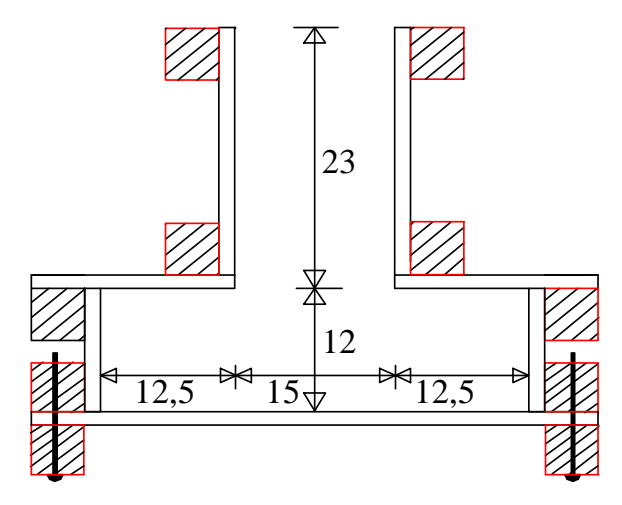

Figura 4.7 - Dimensões da Fôrma

\subsubsection{Preparação do substrato, moldagem e cura}

Com exceção da viga VM (viga monolítica), todas as outras peças foram moldadas em duas etapas para simular a realização de um reforço. Na primeira etapa, moldava-se a mesa da viga juntamente com parte da alma. Depois de certo período de tempo, moldava-se o restante da alma que correspondia a camada de reforço. Devido à dificuldade em se fabricar fôrmas suspensas, essas vigas foram moldadas na posição invertida. Apesar dessa situação não ocorrer na prática, acreditou-se que isto não deveria influenciar, de forma significativa, no comportamento da peça reabilitada.

$\mathrm{O}$ concreto do substrato e a argamassa de reforço foram preparados em uma betoneira com capacidade de $0,16 \mathrm{~m}^{3}$, sendo colocados na fôrma com o auxílio de pás e adensados em mesa vibratória. Em função do volume de concreto e argamassa gastos nas vigas, estas ficaram com um peso total de aproximadamente $6,6 \mathrm{kN}$.

Em geral, depois de 3 dias da moldagem do substrato, iniciava-se a preparação da superfície para receber o reforço através de sua escarificação. Este processo está ilustrado na Figura 4.8a. O aspecto final da superfície escarificada está ilustrado na Figura 4.8b. O reforço foi moldado no dia seguinte à escarificação, sendo que, antes de realizá-lo, limpou-se a superfície com ar comprimido para retirar todo o material solto, umedecendo-a em seguida.

No caso da moldagem das vigas tipo VC, a chapa de aço tinha $12 \mathrm{~cm}$ de largura enquanto a alma da peça tinha $15 \mathrm{~cm}$ de largura. Existia, portanto, uma folga de 1,5 cm 
de cada lado, possibilitando introduzir a argamassa de reforço por essas lacunas. Tomou-se os devidos cuidados para retirar todo o ar que poderia eventualmente ficar preso entre a chapa e a argamassa de reforço durante a remoldagem da peça (ver Figura 4.10).

O posicionamento da armadura do reforço, tanto para as vigas tipo VA quanto para as tipo VC, está ilustrado na Figura 4.9.

Para a cura do substrato e do reforço, colocou-se espuma umedecida na superfície exposta ao ar por 3 dias após a moldagem. Os corpos-de-prova destes materiais foram desformados após 24 horas e mantidos nas mesmas condições de cura da viga a ser ensaiada. As Figuras 4.10 e 4.11 ilustram o processo de moldagem e de cura do reforço.

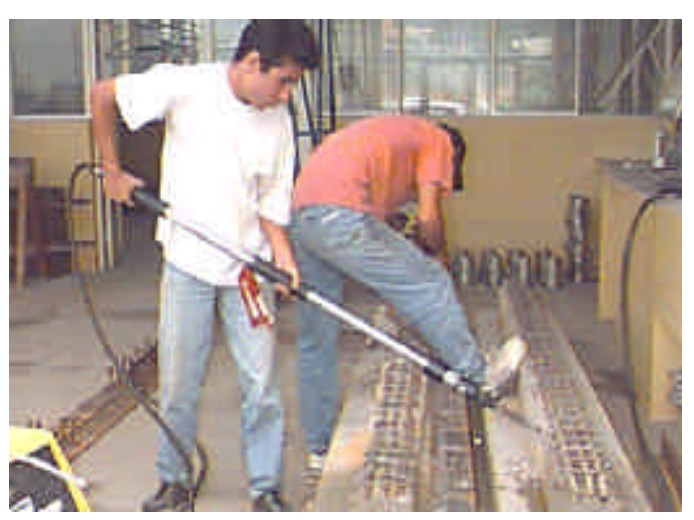

(a) escarificação da superfície com martelete pneumático

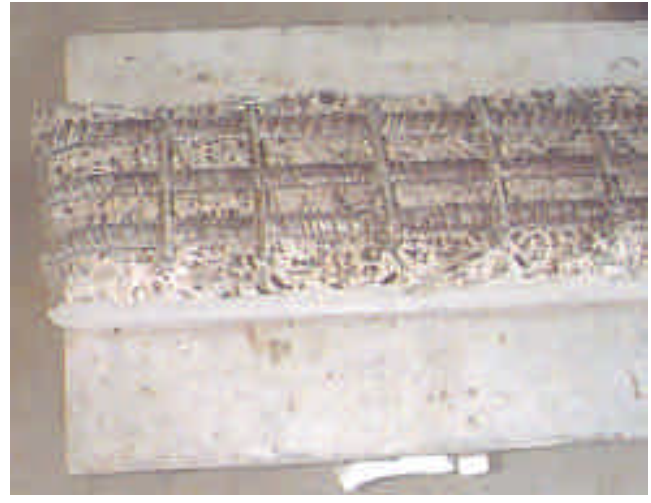

(b) superfície final escarificada

Figura 4.8 - Preparação da superfície à ser reforçada
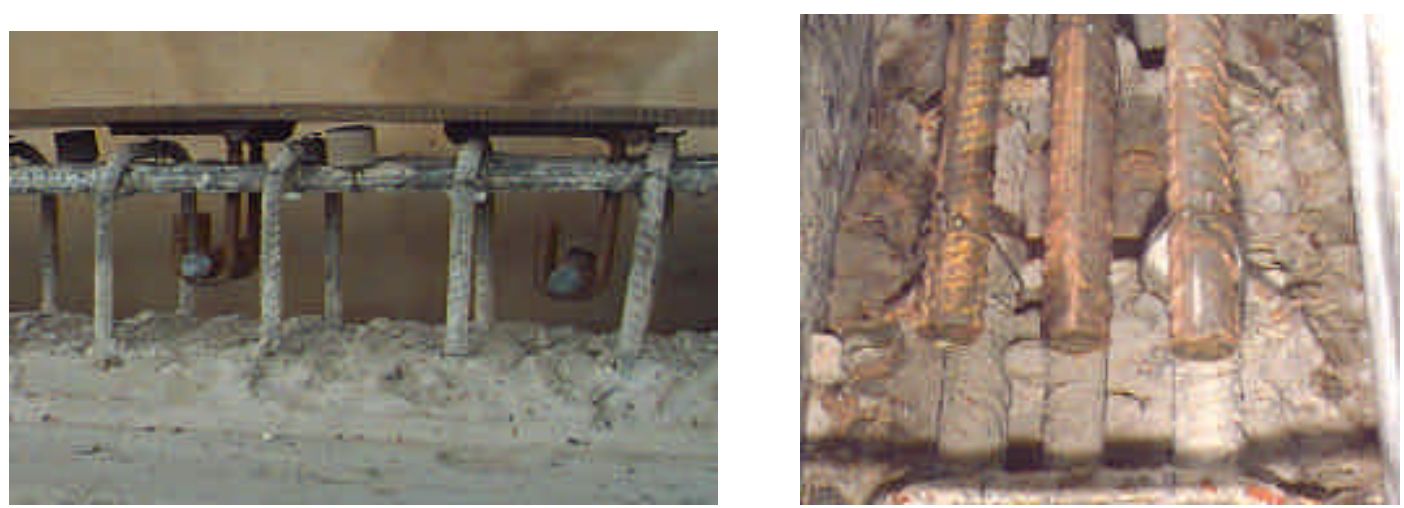

(a) armadura de reforço da VC-2

(b) armadura de reforço da VA-3

Figura 4.9 - Posicionamento da armadura do reforço 


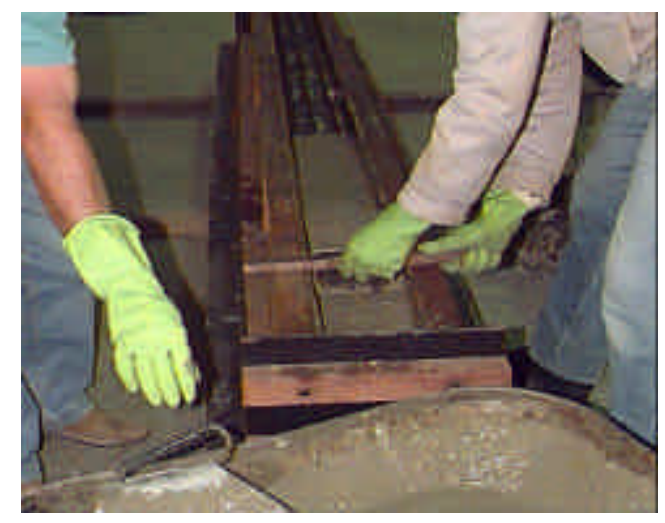

(a) moldagem da viga VA-1

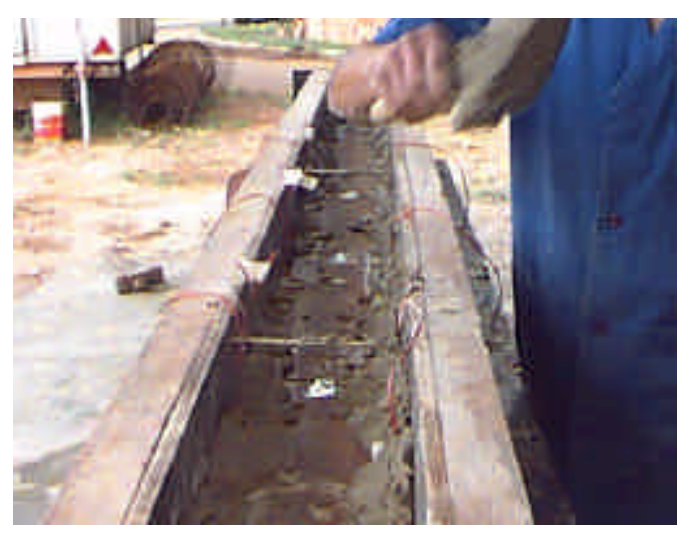

(b) moldagem da viga VC-1

Figura 4.10 - Moldagem do reforço

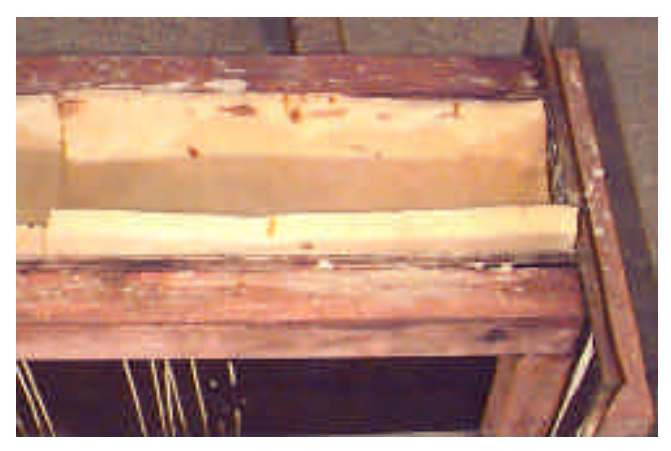

Figura 4.11 - Cura com espuma umedecida

\subsection{Instrumentação}

Os equipamentos e instrumentos de medição utilizados nos ensaios estão discriminados na Tabela 4.6. As vigas foram instrumentadas em várias seções para acompanhar as deformações e deslocamentos. As Figuras 4.12 à 4.14 ilustram as posições dos instrumentos. A Figura 4.15 mostra detalhes dessa instrumentação.

Para posicionar os transdutores usados na medição dos deslocamentos verticais, definiu-se na viga, sete pontos específicos. Dois localizavam-se exatamente sob os apoios, outros dois sob os pontos de aplicação da força vertical e os três restantes foram posicionados no meio vão. Para o meio do vão foram medidas as flechas na alma e nos dois pontos extremos da mesa (ver Figura 4.12, seção A). Os transdutores colocados na região dos apoios tinham a finalidade de adequar os resultados experimentais ao modelo teórico adotado, pois apesar dos apoios serem teoricamente indeslocáveis verticalmente, 
na prática podem ocorrer deslocamentos nessas regiões devido à deformação dos calços de apoio. Portanto, mede-se a movimentação dos apoios e desconta-se este valor dos deslocamentos verticais obtidos para o meio e para os terços do vão.

Os extensômetros elétricos colados nas armaduras longitudinais para medir as deformações, foram distribuídos em três seções distintas ao longo do eixo da viga (ver Figura 4.12 e 4.13). Através dessas leituras foi possível comparar as diferenças no grau de solicitação entre as barras de aço do reforço e do substrato e verificar se o comportamento da peça reabilitada se assemelhava ao de uma viga monolítica.

Os extensômetros elétricos colados no estribo posicionado no meio do vão de cisalhamento ${ }^{*}$ tinham a finalidade de monitorar as deformações dessa armadura, possibilitando identificar eventuais diferenças em seu comportamento, uma vez que os estribos não envolviam toda a armadura longitudinal tracionada.

Para medir as deformações do concreto foram usados extensômetros elétricos uniaxiais colados na mesa da viga para o meio do vão. Por meio desses instrumentos foi possível saber se o concreto comprimido estava ou não próximo da plastificação no instante da ruína da peça. Utilizaram-se ainda rosetas coladas na alma da viga para avaliar as tensões de cisalhamento em uma seção situada a $50 \mathrm{~cm}$ do apoio.

Os relógios comparadores foram fixados em vários pontos da viga (ver Figura 4.12 e 4.13) na região da junta para permitir o acompanhamento de eventuais deslocamentos horizontais existentes entre o substrato e o reforço.

\footnotetext{
* O vão de cisalhamento corresponde ao trecho de $100 \mathrm{~cm}$ de comprimento situado entre o apoio e ponto de aplicação da força vertical.
} 

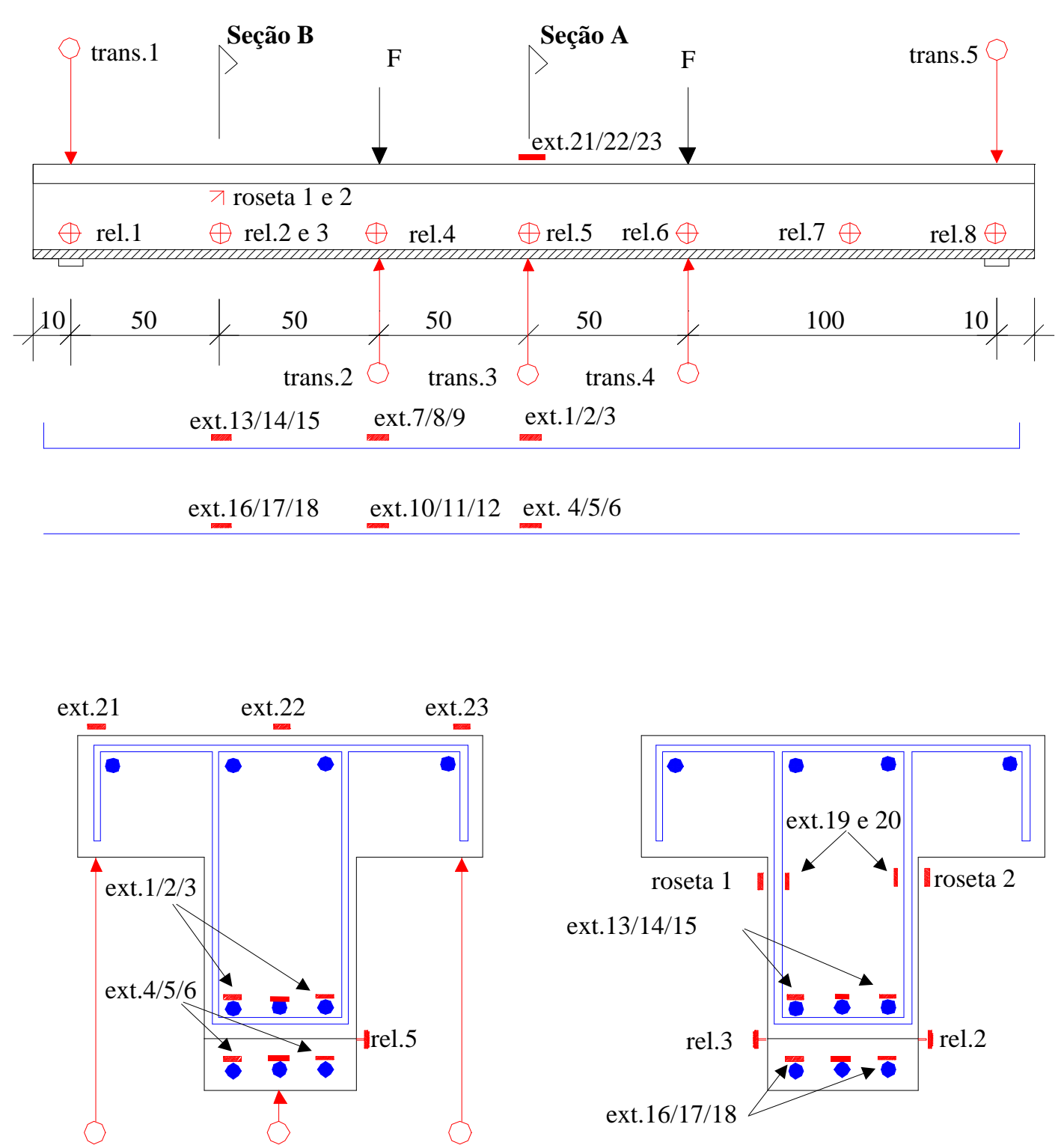

trans.7

trans.3

trans.6

seção A

seção B

Legenda: rel. - relógios comparadores

trans. - transdutores de deslocamento

ext. - extensômetros elétricos

OBS. VA-1 não foram utilizados: rel. 4, 6, 7 e 8; roseta 2; ext. 2, 5, 7 a 12, 14 e 17. VA-3 não foram utilizados: rosetas 1 e 2; ext. 2, 5, 8, 11, 14, 17.

VM não foram utilizados: rel. 7; ext. 2, 5, 8, 11, 14, 17.

Figura 4.12 - Posição dos instrumentos de leitura nas vigas tipo VA e VM 

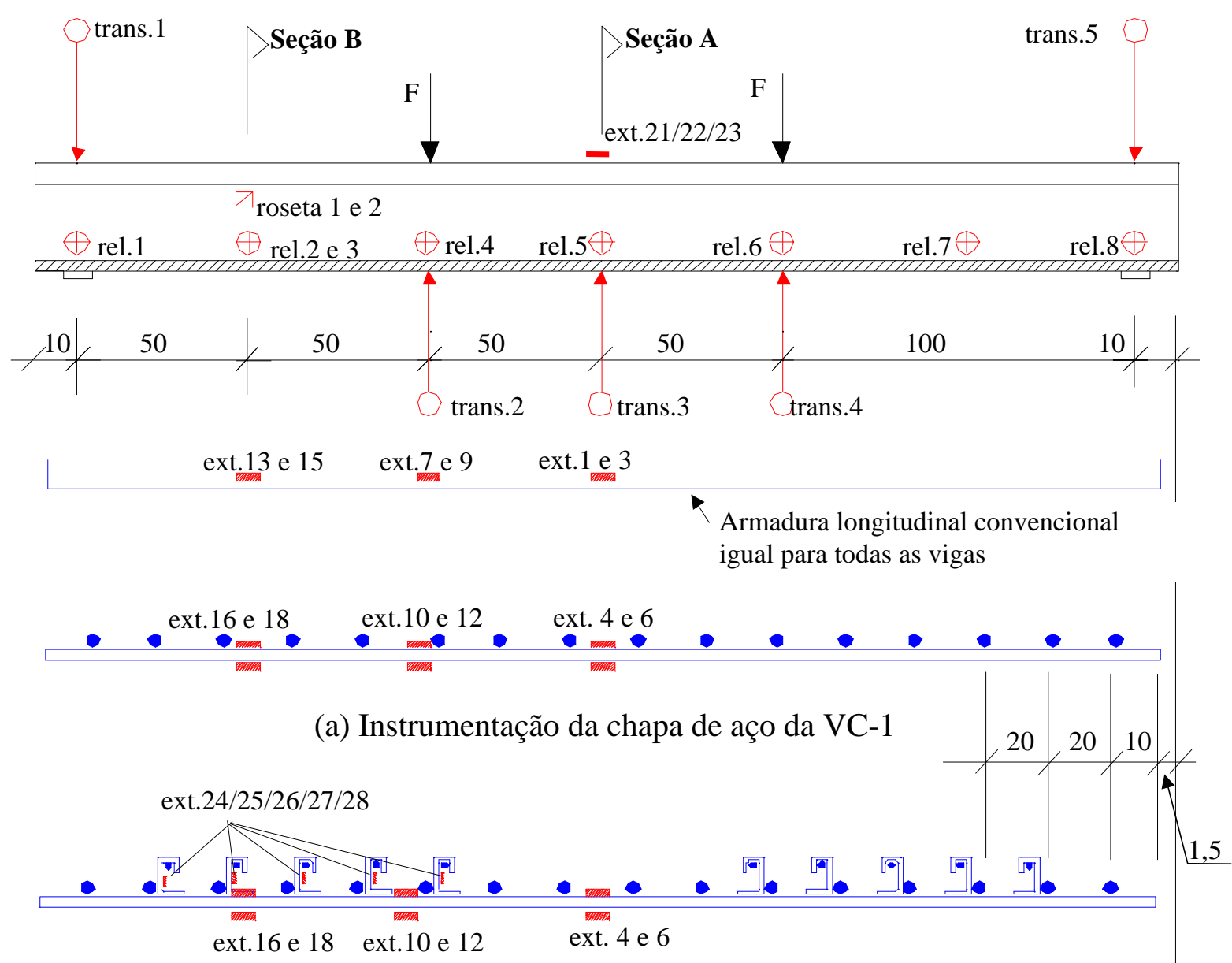

(b) Instrumentação da chapa de aço da VC-3

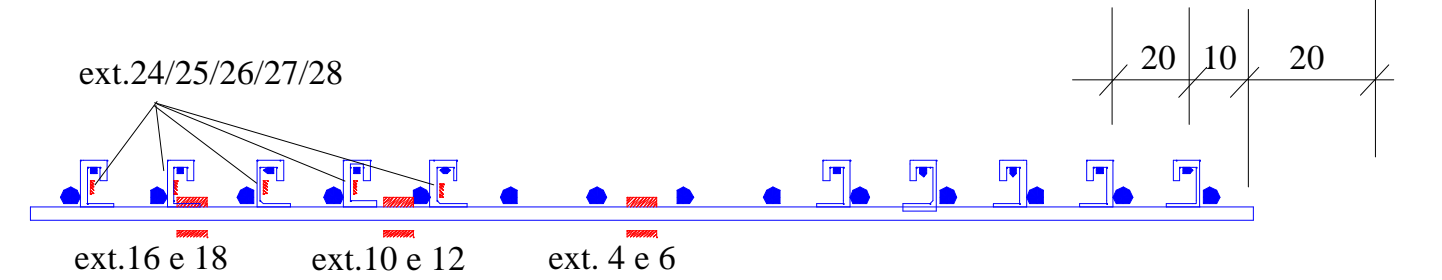

(c) Instrumentação da chapa de aço da VC-2

Figura 4.13 - Posição dos instrumentos de leitura nas vigas tipo VC 


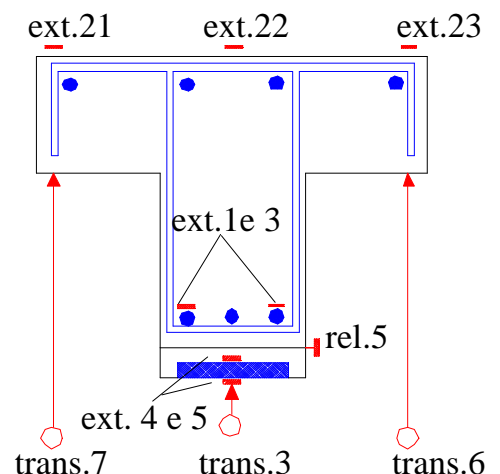

seção A

VC-1, VC-2 e VC-3

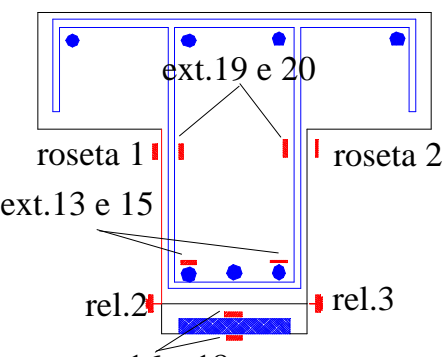

ext.16 e 18

seção B

VC-1

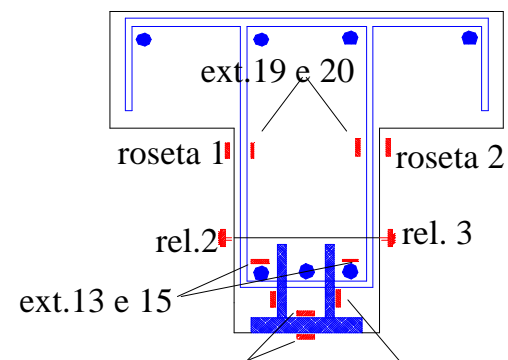

ext.16 e $18 \quad$ ext. 24

VC-2 e VC-3

Figura 4.14 - Posição dos instrumentos nas seções transversais das vigas tipo VC

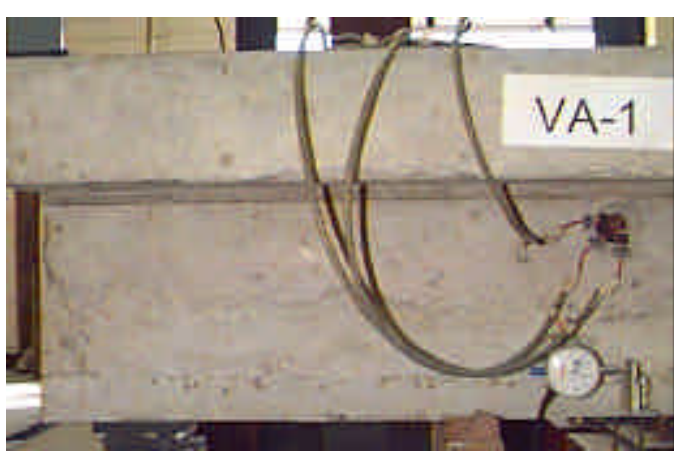

(a) relógio comparador a $50 \mathrm{~cm}$ do apoio e roseta no concreto

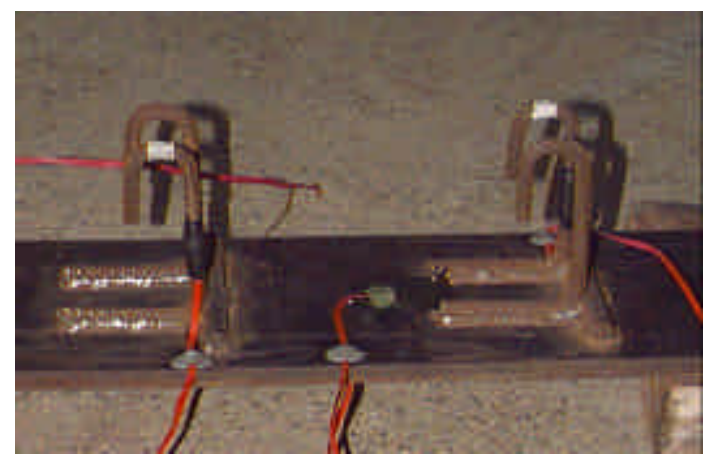

(c) extensômetros na chapa/conectores

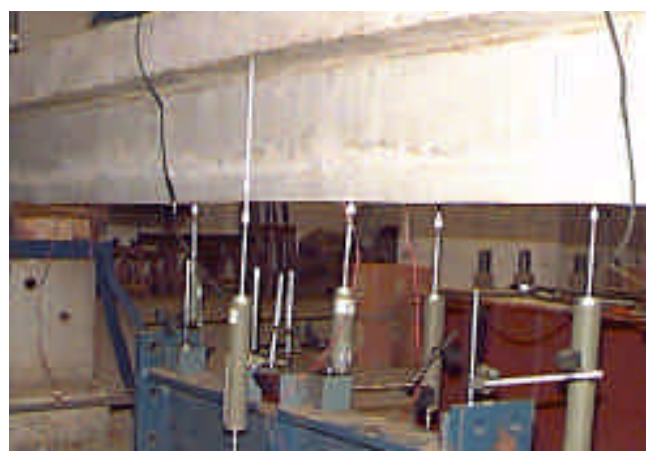

(b) posição dos transdutores para o meio do vão e a $1 / 3$ do vão

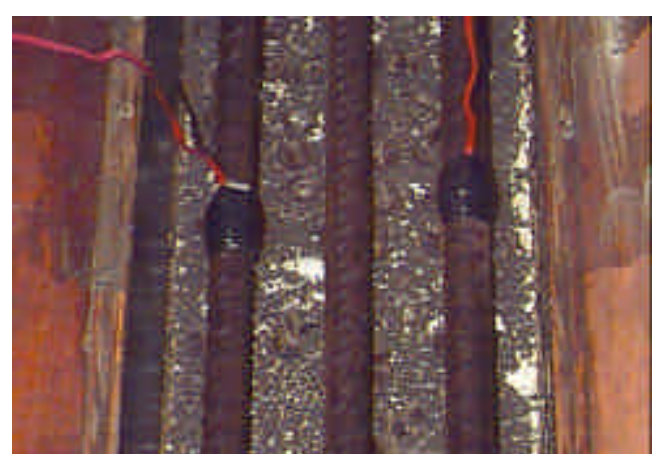

(d) extensômetros nas armaduras

Figura 4.15 - Detalhes da instrumentação 
Tabela 4.6 - Equipamentos e instrumentos de medição

\begin{tabular}{|c|c|c|c|c|}
\hline Instrumento & Tipo & Finalidade & Marca & Características \\
\hline $\begin{array}{l}\text { transdutores } \\
\text { de } \\
\text { deslocamento }\end{array}$ & - & $\begin{array}{c}\text { medição de } \\
\text { deslocamentos } \\
\text { verticais }\end{array}$ & KYOWA & $\begin{array}{l}\text { sensibilidade }=0,10 \mathrm{~mm} \\
\text { curso }=100 \mathrm{~mm}\end{array}$ \\
\hline \multirow{2}{*}{$\begin{array}{l}\text { extensômetros } \\
\text { elétricos de } \\
\text { resistência }\end{array}$} & $\begin{array}{l}\text { rosetas } \\
\text { retangulares }\end{array}$ & $\begin{array}{c}\text { medição de } \\
\text { deformações na } \\
\text { superfície da alma }\end{array}$ & KYOWA & $\begin{array}{l}\mathrm{GF}=2,16(\text { concreto }) \\
\text { base }=10 \mathrm{~mm}\end{array}$ \\
\hline & uniaxiais & $\begin{array}{l}\text { medição de } \\
\text { deformações }\end{array}$ & KYOWA & $\begin{array}{l}\text { GF }=2,15 \text { (concreto) } \\
\text { base }=10 \mathrm{~mm} \\
\mathrm{GF}=2,11(\text { aço }) \\
\text { base }=5 \mathrm{~mm}\end{array}$ \\
\hline $\begin{array}{c}\text { relógios } \\
\text { comparadores } \\
\end{array}$ & - & $\begin{array}{c}\text { medição de } \\
\text { deslocamentos }\end{array}$ & KYOWA & $\begin{array}{l}\text { curso }=10 \mathrm{~mm} \\
\text { sensibilidade }=0,01 \mathrm{~mm}\end{array}$ \\
\hline $\begin{array}{c}\text { células de } \\
\text { carga }\end{array}$ & coluna & $\begin{array}{l}\text { medição do } \\
\text { carregamento } \\
\text { aplicado }\end{array}$ & - & $\begin{array}{c}\text { capacidade nominal de } \\
500 \mathrm{kN}\end{array}$ \\
\hline $\begin{array}{c}\text { cilindro } \\
\text { hidráulico }\end{array}$ & $\begin{array}{l}\text { bomba } \\
\text { manual }\end{array}$ & $\begin{array}{l}\text { aplicação do } \\
\text { carregamento }\end{array}$ & - & $\begin{array}{c}\text { capacidade nominal de } \\
1000 \mathrm{kN}\end{array}$ \\
\hline $\begin{array}{c}\text { Sistema de } \\
\text { Aquisição de } \\
\text { Dados }\end{array}$ & $\begin{array}{l}\text { SYSTEM } \\
4000\end{array}$ & $\begin{array}{l}\text { coleta e gravação } \\
\text { automática de dados }\end{array}$ & $\begin{array}{c}\text { measurements } \\
\text { group instruments }\end{array}$ & $\begin{array}{l}200 \text { canais } \\
\text { sensibilidade } 1 \text { micro- } \\
\text { strain }\end{array}$ \\
\hline
\end{tabular}

Todos os dados coletados através do Sistema de Aquisição de Dados estão apresentados nas Tabelas do Apêndice II desse trabalho.

\subsection{Procedimentos de Ensaio}

Foram empregadas duas etapas de carregamento sendo a primeira com incremento de força de $10 \mathrm{kN}$ até atingir a força de início de fissuração da peça. Logo após, aplicou-se a segunda etapa de carregamento com incrementos de $20 \mathrm{kN}$ até atingir a força máxima de ruína. $\mathrm{O}$ uso de incrementos menores na primeira etapa permitiu observar o instante em que surgia a primeira fissura devido à flexão.

As leituras dos deslocamentos e das deformações foram realizadas para cada incremento de força, através do Sistema de Aquisição de Dados. A duração dos ensaios foram de aproximadamente 90 minutos e cada estágio de carregamento consumiu, em média, 2 minutos para marcar e observar as aberturas das fissuras.

Após realizar todos os ensaios previstos, os resultados foram sintetizados, apresentados e analisados no Capítulo 5 desse trabalho. 


\section{APRESENTAÇÃO E ANÁLISE DOS RESULTADOS}

Este capítulo apresenta os resultados dos ensaios realizados no programa experimental desenvolvido e também descreve algumas comparações com os resultados de vigas reabilitadas à flexão por outros pesquisadores. A previsão teórica do comportamento destas vigas foi feita com base nas hipóteses de cálculo descritas no Anexo I.

As comparações do comportamento da viga foram feitas em relação à força total aplicada pelo macaco hidráulico, sendo que esta força correspondia ao dobro do valor da força concentrada aplicada em cada ponto de carregamento da viga.

É importante observar também que para traçar os gráficos, utilizou-se a nomenclatura da instrumentação indicada nas Figuras 4.12 e 4.13.

\subsection{Modo de ruína e forças de fissuração e de ruína}

Ao analisar os dados da Tabela 5.1, que mostra as forças de fissuração reais e previstas, observou-se que para a todas as vigas ensaiadas (com exceção da VA-1), a primeira fissura de flexão surgiu para um carregamento de $40 \mathrm{kN}$. A força de fissuração prevista de acordo com as indicações da NBR-6118, usando a resistência do substrato, foi menor que a real, com exceção da viga VC-2.

No caso da previsão da fissuração utilizando a resistência da argamassa de reforço, as forças previstas foram maiores que as observadas, com exceção da VA-1. Este fato pode ter sido ocasionado por se usar, nesta viga, traços diferentes daqueles utilizados na confecção das demais peças.

Acredita-se, portanto, que a resistência à fissuração é influenciada tanto pela 
resistência do material de reforço quanto pela resistência do substrato, variando também em função da qualidade de aderência existente entre estes dois materiais e do traço utilizado na confecção da peça.

Tabela 5.1 - Força de fissuração real e prevista das vigas ensaiadas

\begin{tabular}{|c|c|c|c|c|c|c|}
\hline \multirow{3}{*}{ Série } & \multirow{3}{*}{ Viga } & \multicolumn{3}{|c|}{$\begin{array}{l}\text { Força de físsuração à flexão } \\
\qquad(k N)\end{array}$} & \multicolumn{2}{|c|}{$\mathbf{F}_{\text {real }} / \mathbf{F}_{\text {prev }}$} \\
\hline & & \multirow[t]{2}{*}{$\mathbf{F}_{\text {real }}$} & \multicolumn{2}{|c|}{$\mathbf{F}_{\text {prevista }}$} & \multirow[b]{2}{*}{ substrato } & \multirow[b]{2}{*}{ reforço } \\
\hline & & & substrato & reforço & & \\
\hline 0 & $\mathrm{VM}$ & 40 & 31 & - & 1,29 & - \\
\hline \multirow[t]{2}{*}{1} & VA-1 & 60 & 35 & 49 & 1,71 & 1,22 \\
\hline & VC-1 & 40 & 29 & 47 & 1,38 & 0,85 \\
\hline \multirow[t]{2}{*}{2} & VA-2 & 40 & 32 & 57 & 1,25 & 0,70 \\
\hline & VC-2 & 40 & 43 & 52 & 0,93 & 0,77 \\
\hline \multirow[t]{2}{*}{3} & VA-3 & 40 & 40 & 56 & 1,00 & 0,71 \\
\hline & VC-3 & 40 & 31 & 46 & 1,29 & 0,87 \\
\hline
\end{tabular}

O esquema de fissuração das vigas ensaiadas está ilustrado na Figura 5.1. Apesar de todas as vigas terem apresentado intensa fissuração devido aos esforços de momento fletor e esforço cortante, as peças VA-1, VA-2, VM e VC-1 tiveram uma fissuração diferenciada daquela referente a uma viga monolítica ideal* .

Nas vigas VA-1 e VC-1, para o trecho onde havia esforço cortante, as fissuras iniciaram-se praticamente na vertical e somente passaram a apresentar inclinação de $45^{0}$ após cruzar a interface com o substrato. As fissuras se desenvolveram gradualmente até ocorrer problemas de aderência na junta, que geraram fissuras horizontais na interface reforço/substrato. A partir deste instante, as aberturas das fissuras de cisalhamento e flexão passaram a aumentar de forma bem mais acentuada para um mesmo incremento de força.

No caso das vigas VM e VA-2, apareceram pequenas fissuras inclinadas na região da armadura longitudinal do reforço devido ao escorregamento desta em relação ao concreto/argamassa que a envolvia.

\footnotetext{
* Observar que a viga VM não corresponde à viga monolítica ideal por não ter estribos envolvendo a armadura do reforço.
} 
Para as vigas VA-2 e VA-3, que continham fibras de aço na argamassa do reforço, observou-se aberturas de fissuras menores que as da viga VA-1 para um mesmo nível de carregamento. Além disso, o espaçamento entre as fissuras foi menor, ou seja, a fissuração foi mais intensa. Acredita-se que esta mudança na configuração da fissuração tenha sido causada pela influência das fibras de aço no material do reparo.

As vigas VA-3 e VC-3, por serem pré-danificadas, apresentaram uma fissuração mais intensa que as demais devido o surgimento de novas fissuras entre as já existentes e aumento das aberturas das fissuras antigas. Estas vigas, juntamente com a VC-2, apresentaram um modelo de fissuração semelhante ao de uma viga monolítica ideal, pois surgiram várias fissuras de flexão e cisalhamento além de fissuras na mesa comprimida, indicando o início do esmagamento do concreto no meio do vão.

A Tabela 5.2 apresenta as principais características das vigas ensaiadas, as forças de ruína previstas e reais e o modo de ruína. A Figura 5.2 mostra, com mais detalhes, a seção onde ocorreu a ruína para cada uma das peças ensaiadas.

De acordo com os resultados experimentais, pode-se notar que as vigas VA-1 e VC-1 sofreram colapso prematuro. Em ambos os casos, a ruína ocorreu por falha de aderência na ligação do substrato com o reforço. No caso da viga VA-2, houve também colapso prematuro com capacidade portante inclusive inferior à da VA-1. Este fato não era esperado, porém tudo indica que a causa da ruína foi a redução do comprimento de ancoragem que provocou o escorregamento da armadura de reforço.

Na viga VC-2, a redução deste comprimento de ancoragem não foi tão prejudicial, pois os conectores metálicos soldados na chapa, além de ajudarem na transmissão de esforços entre o reforço e o substrato, funcionaram como elementos de ancoragem. Apesar desta peça apresentar menor capacidade portante que as vigas da série 3, seu comportamento indica que a ruína ocorreu por flexão.

As vigas da série 3, mesmo possuindo um certo nível de dano prévio, apresentaram resistências superiores à da série 1, indicando que a introdução de fibras de aço ou de conectores de cisalhamento tipo 2 foram eficientes. Estas peças 
Tabela 5.2 - Características das vigas ensaiadas

\begin{tabular}{|c|c|c|c|c|c|c|c|c|}
\hline \multirow[t]{2}{*}{ Viga } & \multirow{2}{*}{$\begin{array}{l}\text { Características } \\
\text { gerais }\end{array}$} & \multicolumn{3}{|c|}{ Força de ruína $(\mathrm{kN})$} & \multicolumn{2}{|c|}{$\mathbf{F}_{\text {real }} / \mathbf{F}_{\text {prev }}$} & \multirow{2}{*}{$\begin{array}{l}\mathbf{F}_{\text {serv }} \\
(\mathrm{kN})\end{array}$} & \multirow[t]{2}{*}{ Modo de ruína } \\
\hline & & $\mathbf{F}_{\text {real }}$ & $\mathbf{F}_{\text {prev1 }}$ & $\mathbf{F}_{\text {prev2 }}$ & $\begin{array}{c}\mathbf{F}_{\text {prev }} \\
1 \\
\end{array}$ & $\begin{array}{c}\text { Frev } \\
2 \\
\end{array}$ & & \\
\hline VM & $\begin{array}{l}\text { monolítica, } \\
\text { sem dano }\end{array}$ & 320 & 305 & 273 & 1,05 & 1,17 & 195 & $\begin{array}{l}\text { Fissura horizontal na interface substrato/reforço, por falta } \\
\text { de ligação com estribos e início do escoamento de } \mathrm{A}_{\text {slr }}\end{array}$ \\
\hline VA-1 & sem dano & 320 & 408 & 286 & 0,78 & 1,12 & 204 & Perda de aderência entre as camadas substrato/reforço \\
\hline $\mathrm{VC}-1$ & $\begin{array}{c}\text { sem dano, } \\
\text { conector tipo } 1\end{array}$ & 230 & 382 & 269 & 0,60 & 0,86 & 192 & Perda de aderência entre as camadas substrato/reforço \\
\hline VA-2 & $\begin{array}{l}\text { sem dano, } \\
\text { com fibras }\end{array}$ & 260 & 369 & 273 & 0,70 & 0,95 & 195 & Deficiência de ancoragem da armadura principal \\
\hline $\mathrm{VC}-2$ & $\begin{array}{c}\text { sem dano, } \\
\text { conector tipo } 1 \text { e } 2\end{array}$ & 390 & 402 & 280 & 0,97 & 1,39 & 200 & $\begin{array}{c}\text { Escoamento da armadura de flexão seguida de } \\
\text { descolamento parcial da chapa de aço }\end{array}$ \\
\hline VA-3 & $\begin{array}{l}\text { com dano, } \\
\text { com fibras }\end{array}$ & 404 & 388 & 293 & 1,04 & 1,38 & 209 & $\begin{array}{l}\text { Escoamento da armadura de flexão e esmagamento do } \\
\text { concreto comprimido }\end{array}$ \\
\hline VC-3 & $\begin{array}{c}\text { com dano, } \\
\text { conector tipo } 1 \text { e } 2\end{array}$ & 407 & 404 & 277 & 1,01 & 1,47 & 198 & $\begin{array}{l}\text { Escoamento da armadura de flexão e esmagamento do } \\
\text { concreto comprimido }\end{array}$ \\
\hline \multicolumn{9}{|c|}{$\begin{aligned} \mathrm{F}_{\text {real }}= & \text { força de ruína observada experimentalmente; } \\
\mathrm{F}_{\text {prev1 }}= & \text { força de ruína calculada pela NBR-6118 utilizando os valores reais obtidos experimentalmente para as resistências dos materiais; } \\
\mathrm{F}_{\text {prev2 }}= & \text { força de ruína calculada de acordo com a NBR-6118 utilizando os valores característicos para as resistências dos materiais e os } \\
& \text { respectivos coeficientes de segurança }\left(\gamma_{\mathrm{s}}=1,15 ; \gamma_{\mathrm{c}}=1,40 \mathrm{e} \phi=0,85 \text { - efeito Rüsch); }\right. \\
\mathrm{F}_{\text {serv }}= & \text { força de serviço obtida dividindo-se } \mathrm{F}_{\text {prev2 }} \text { por } 1,4 ;\end{aligned}$} \\
\hline
\end{tabular}




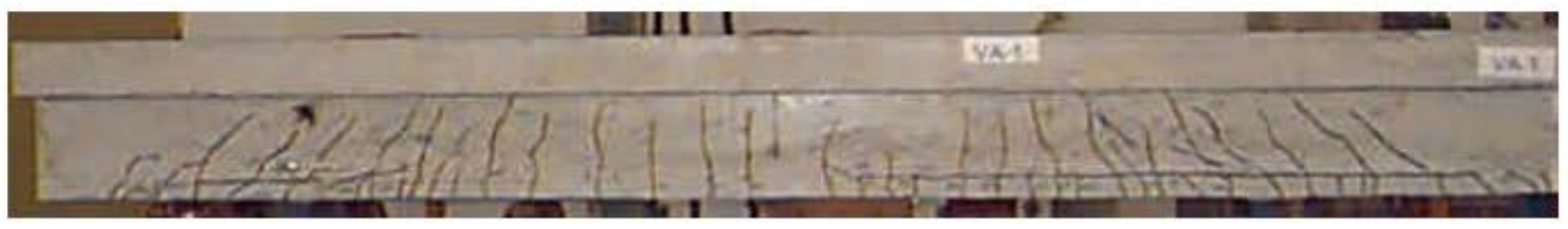

VA-1

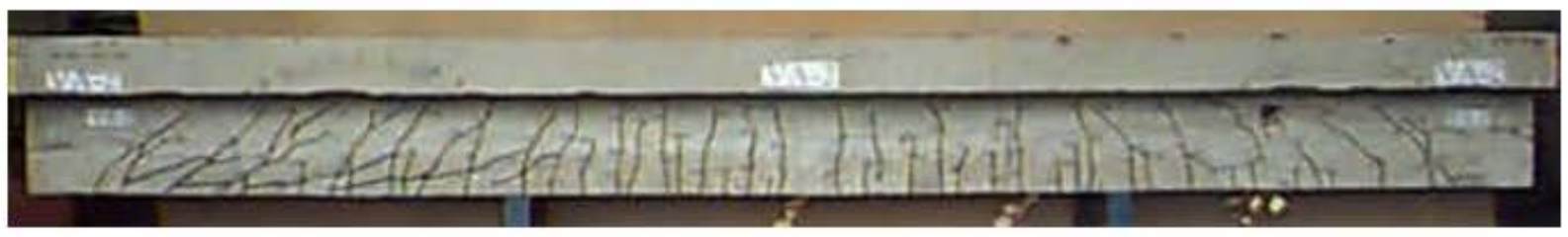

VA-2

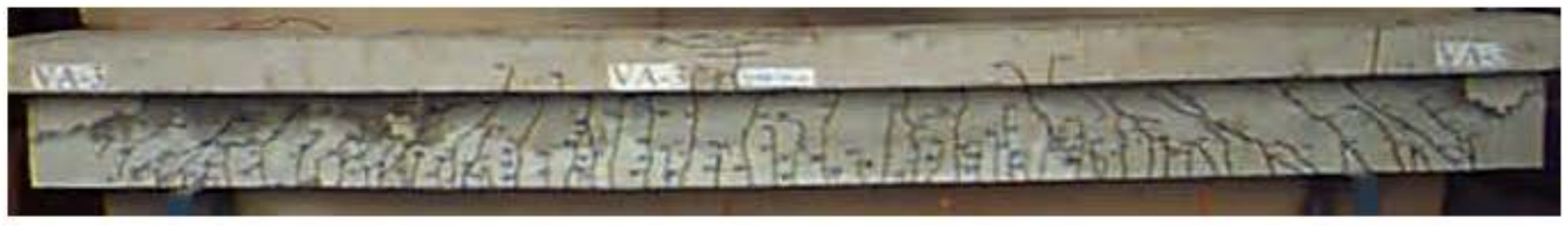

VA-3

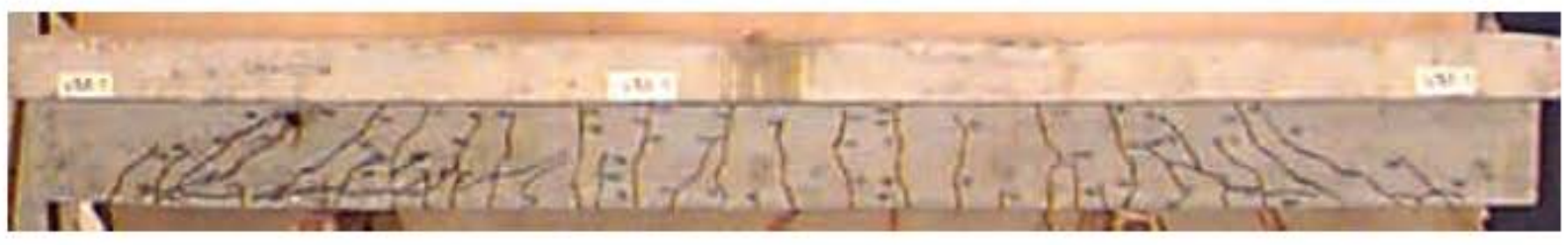

VM

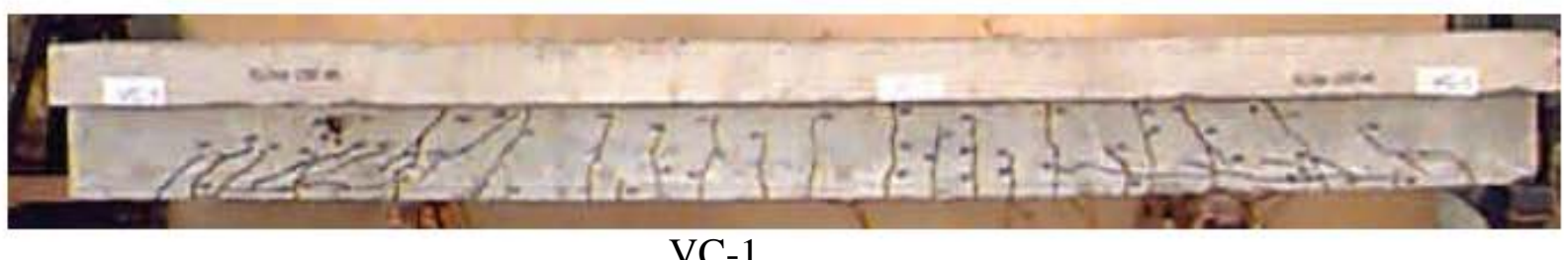

VC-1

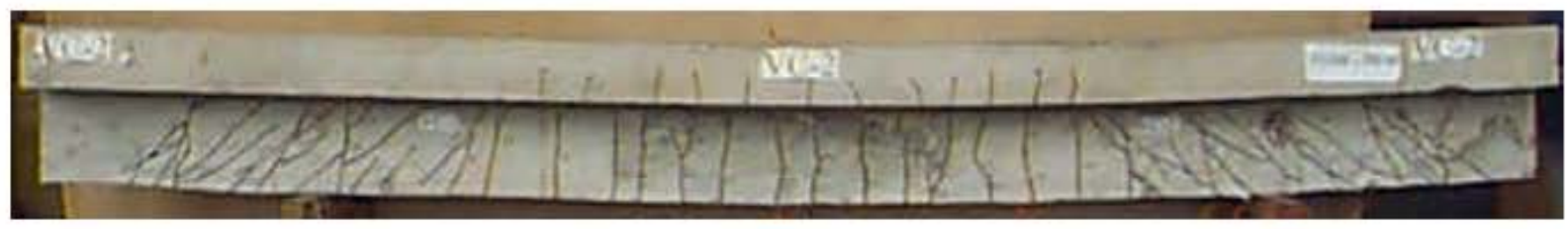

VC-2

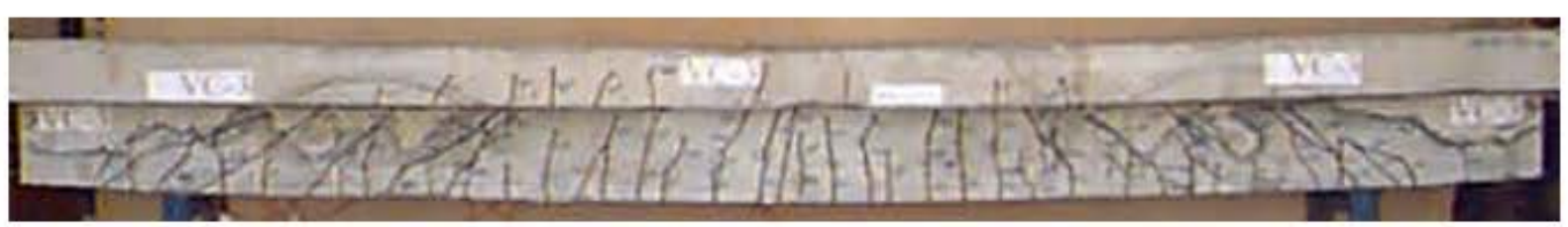

VC-3

Figura 5.1 - Esquema de fissuração 


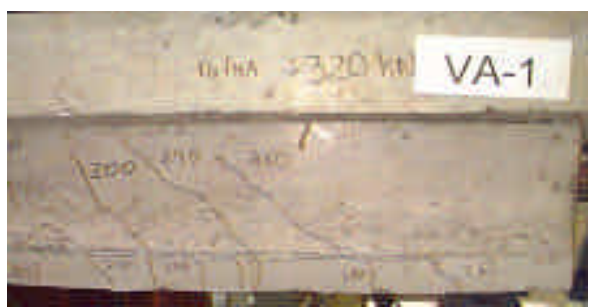

VA-1

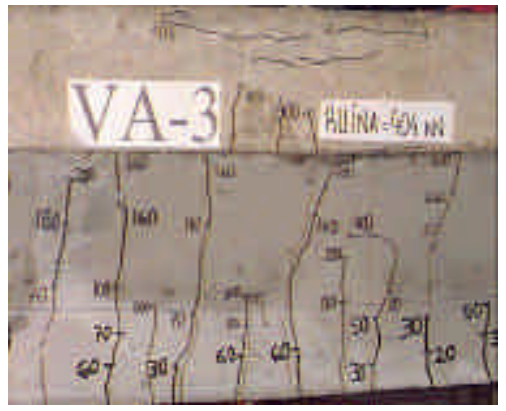

VA-3

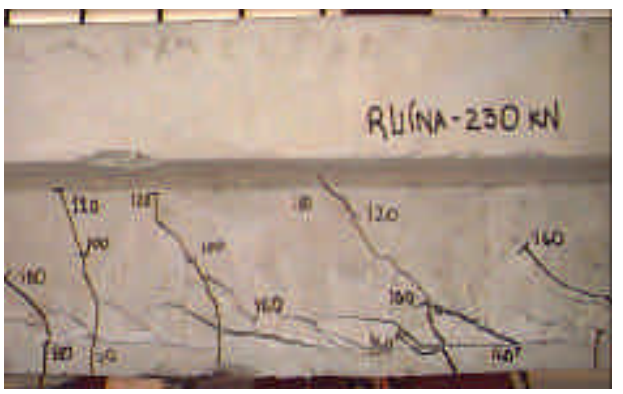

VC-1

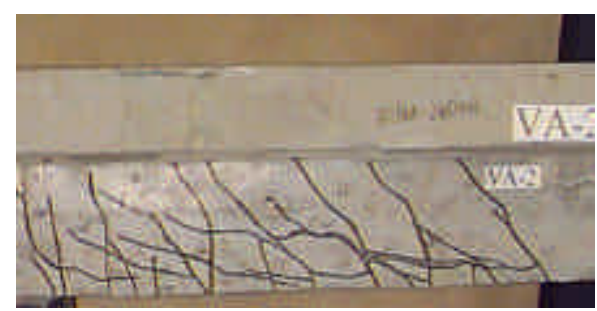

VA-2

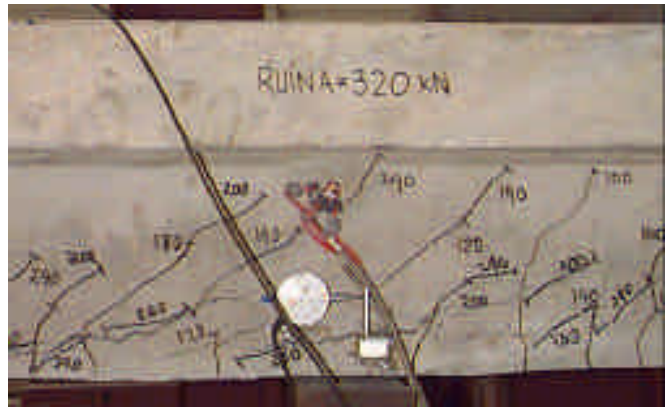

VM

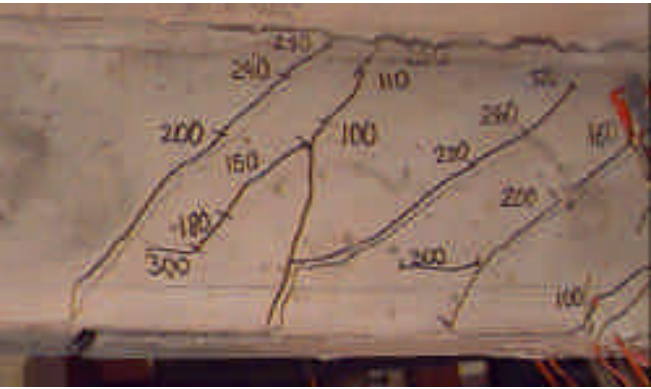

VC-2

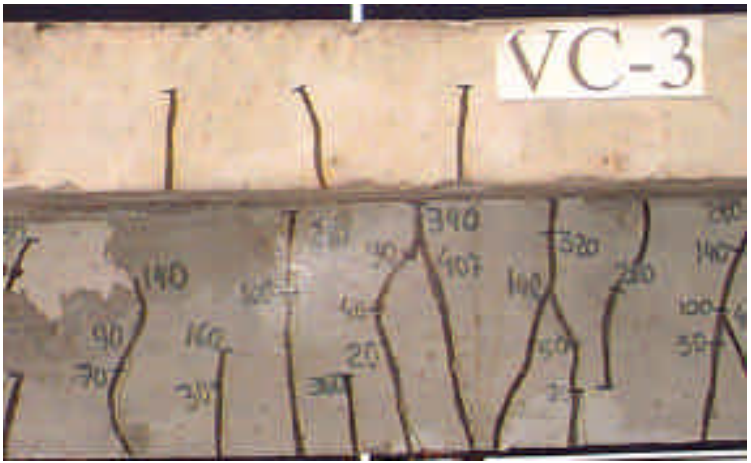

VC-3

Figura 5.2 - Detalhe da região em que ocorreu a ruína da peça 
atingiram o colapso por escoamento da armadura longitudinal seguido de um esmagamento na mesa de concreto.

A viga VM rompeu devido ao surgimento de fissuras horizontais entre as barras de aço do substrato e do reforço, indicando realmente a necessidade de se colocar algum tipo de armadura complementar (fibras de aço ou estribos) envolvendo as barras de aço do reforço e que resista aos esforços horizontais provenientes do cisalhamento. Analisando o comportamento desta viga em relação às demais, percebe-se que o reforço realizado nas vigas da série 3 foi eficiente pois, mesmo não possuindo estribos envolvendo a armadura do reforço, estas peças tiveram resistências superiores à da viga monolítica. Pode-se dizer ainda que o comportamento da viga VA-1, mesmo não sendo reforçada usando fibras, também foi satisfatório pois apresentou resistência final igual a da VM.

Ao comparar os valores das forças de ruína reais com as previstas, $\mathrm{F}_{\text {prev1 }}$, para as vigas que apresentaram escoamento da armadura tracionada (VM, VC-2, VA-3 e VC-3), percebe-se que as diferenças foram praticamente desprezíveis (menores que $5 \%$ ). Isto indica que estas peças apresentaram um comportamento bastante satisfatório, já que a força de ruína prevista correspondia à resistência calculada de acordo com a NBR-6118, para uma viga monolítica ideal utilizando os valores reais das resistências dos materiais sem aplicar nenhum coeficiente de segurança. Para as demais vigas, observou-se um subaproveitamento da capacidade portante devido à ocorrência de ruptura prematura.

Ao analisar os valores da força de ruína prevista, $\mathrm{F}_{\text {prev2}}$, calculada utilizando os valores característicos das resistências dos materiais e dos coeficientes de segurança indicados pela NBR-6118, percebe-se que até mesmo para as peças em que ocorreu ruína prematura, a relação $\mathrm{F}_{\text {real }} / \mathrm{F}_{\text {prev2 }}$ apresentou valores próximos da unidade. A diferença máxima encontrada entre os valores experimentais e previstos para tais vigas foi de 14\%, no caso da viga VC-1. Para as vigas que atingiram o escoamento da armadura tracionada, pode-se dizer que a capacidade portante foi estimada com bastante segurança, pois as forças de ruína previstas ficaram, em média, $40 \%$ menores que as forças de ruína reais. Para a viga VM, esta porcentagem foi de apenas $17 \%$, porque apesar de ter ocorrido o escoamento da armadura 
tracionada do reforço, o mesmo não ocorreu com a armadura tracionada do substrato, indicando o subaproveitamento da capacidade resistente das armaduras tracionadas.

É importante ressaltar que apesar de ter ocorrido ruína prematura em algumas peças ensaiadas, foi observada uma intensa fissuração do concreto e grandes deformações, ou seja, todas as peças apresentaram ruína com aviso prévio.

\subsection{Deslocamentos horizontais na junta}

Em relação aos deslocamentos relativos que surgiram na ligação do substrato com o material do reforço, observou-se um comportamento semelhante para as vigas que romperam por falha de aderência (VA-1 e VC-1). Nesses casos, percebeu-se que quase não houve deslizamento relativo entre os materiais para a região do apoio, o mesmo ocorrendo no meio do vão. Os maiores deslocamentos horizontais surgiram na seção situada a $50 \mathrm{~cm}$ do apoio, conforme pode ser observado na Figura 5.3.

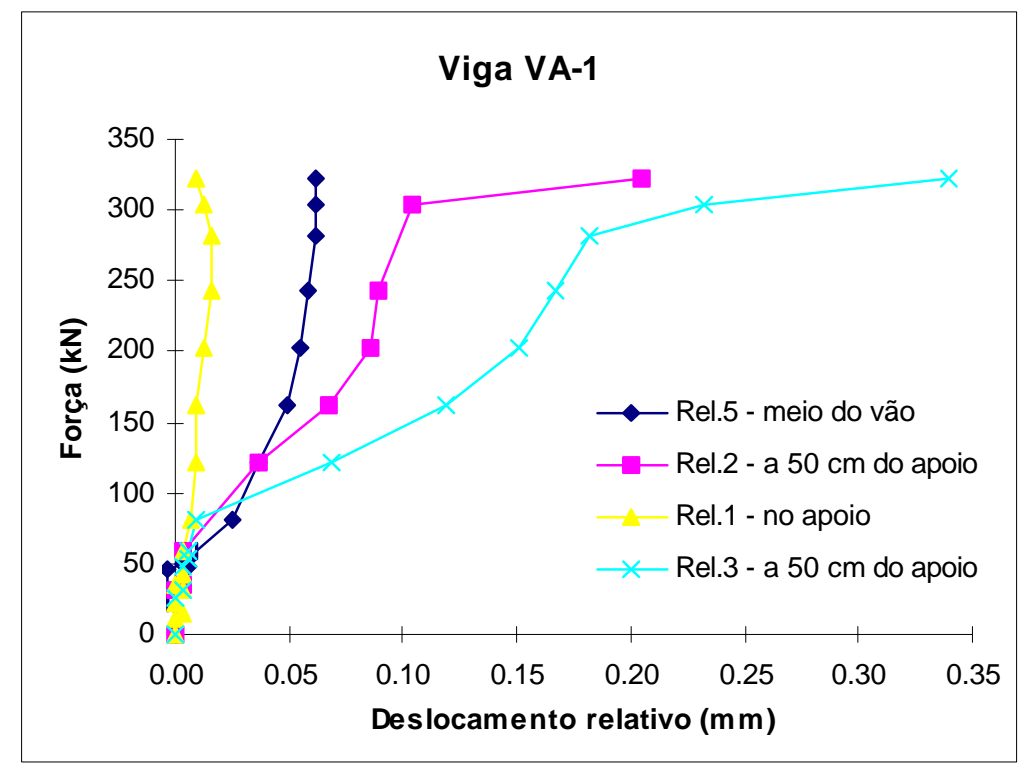

Figura 5.3 - Gráfico da força $x$ deslocamento relativo entre reforço e substrato para VA-1

O fato do deslizamento relativo da junta, na região do apoio, ser menor do que o deslocamento ocorrido na seção situada a $50 \mathrm{~cm}$ deste, talvez possa ser explicado pela ocorrência de fissuras de cisalhamento mais acentuadas nesta seção. 
Desta forma, é possível que as leituras destes deslocamentos tenham sido influenciadas pelas aberturas destas fissuras.

Para as demais vigas, os deslocamentos horizontais medidos sofreram grande influência da fissuração, não fornecendo valores representativos, pois não correspondiam aos deslocamentos horizontais na junta, e sim aos deslocamentos gerados por fissuras de cisalhamento ou de flexão que passavam entre os relógios comparadores (fixados no substrato) e as cantoneiras, que serviam de base para medição (fixadas no material de reforço). Sendo assim, acredita-se que nessas vigas, os deslocamentos horizontais foram desprezíveis, já que não foi notada nenhuma perda de aderência entre o material do reforço e o substrato.

\subsection{Deslocamentos verticais}

Ao comparar os resultados experimentais e teóricos para a seção no meio do vão e para a seção a 1/3 do vão, percebeu-se que no regime elástico (anterior à fissuração do concreto), os deslocamentos verticais foram bastante próximos dos previstos, conforme ilustram as Figuras 5.4 a 5.6. Todavia, os deslocamentos experimentais para forças próximas da ruína foram bem maiores que os previstos, principalmente para as vigas VA-3, VC-2 e VC-3, que romperam por deformação plástica excessiva da armadura longitudinal. Apesar disso, essas discrepâncias já eram esperadas pois o modelo de cálculo usado na previsão dos resultados não levava em consideração a não-linearidade física dos modelos.

Em relação aos gráficos das Figuras 5.4 a 5.6, pode-se dizer que as curvas experimentais foram traçadas utilizando as leituras dos transdutores 2 e 4 , localizados a $100 \mathrm{~cm}$ do apoio, e dos transdutores 3,6 e 7, posicionados no meio do vão $(150 \mathrm{~cm}$ do apoio).

Observando a Figura 5.7, pode-se analisar a rigidez de cada uma das vigas. As flechas iniciais (no início do carregamento) foram praticamente iguais para todas as vigas, notando-se uma rigidez ligeiramente maior para as peças reforçadas com chapas de aço. Entretanto, para forças superiores a $150 \mathrm{kN}$, a evolução dos deslocamentos verticais no meio do vão começou a apresentar maiores discrepâncias entre si. 

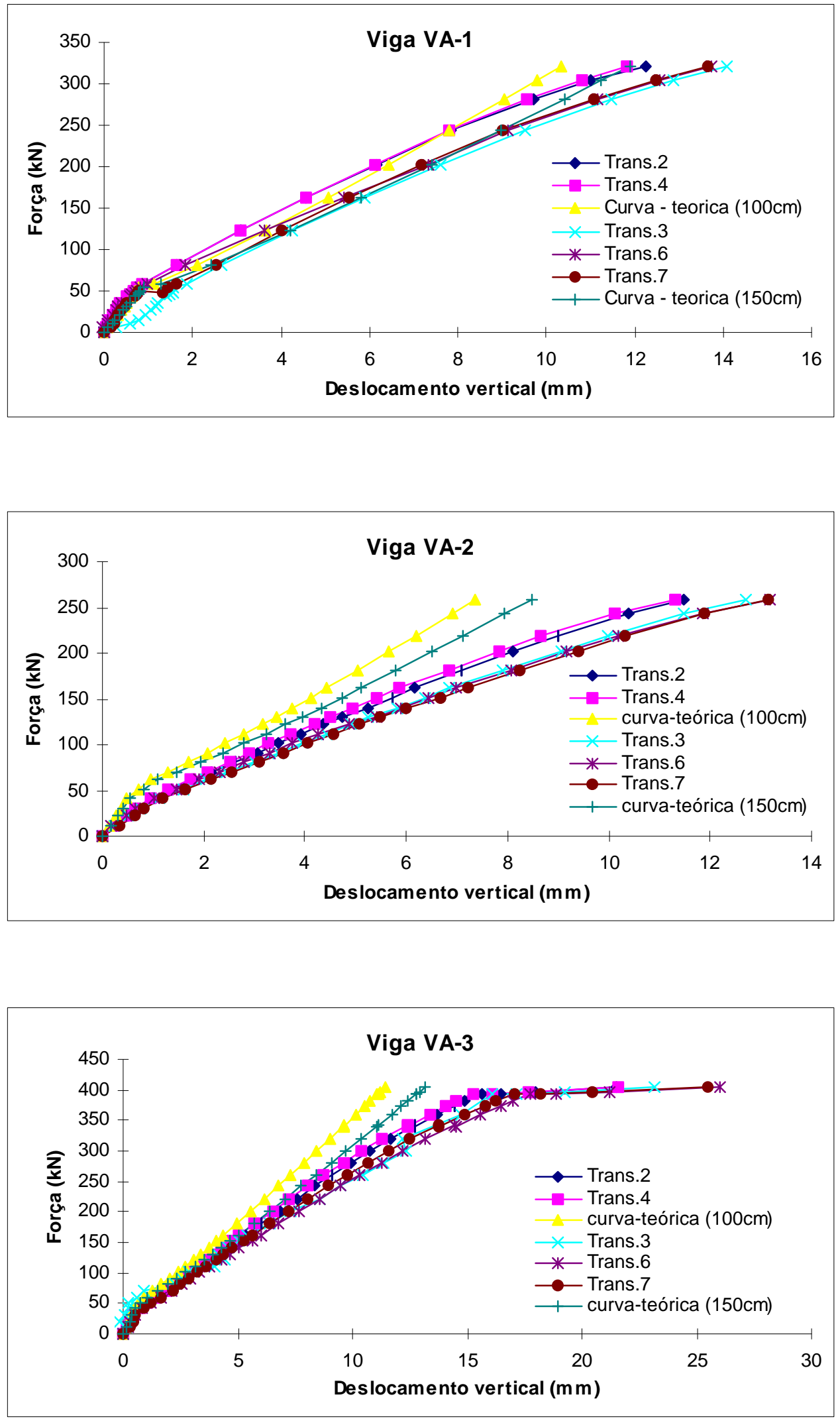

Figura 5.4 - Gráficos da força $x$ deslocamento vertical para vigas tipo VA 

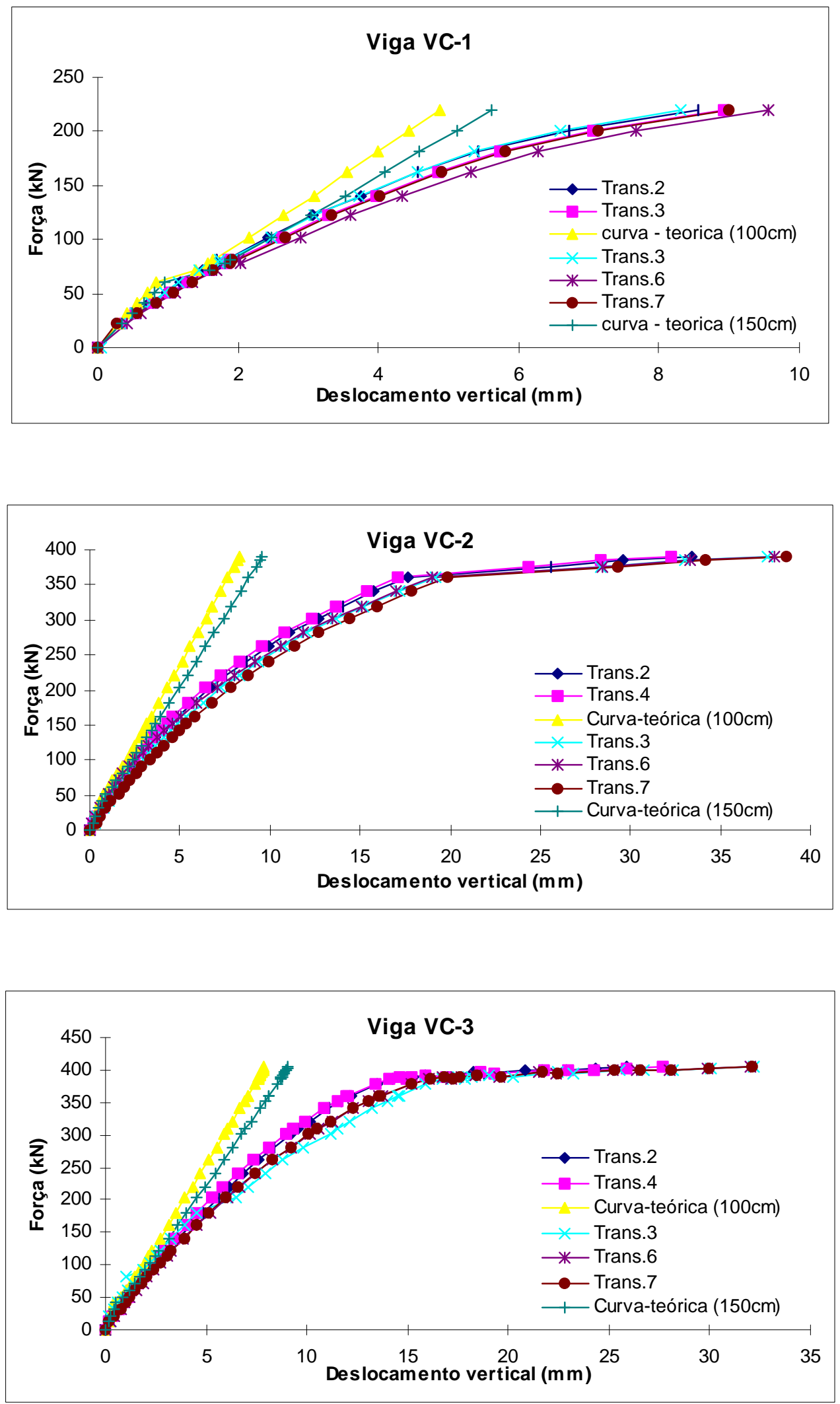

Figura 5.5 - Gráficos da força x deslocamento vertical para vigas tipo VC 


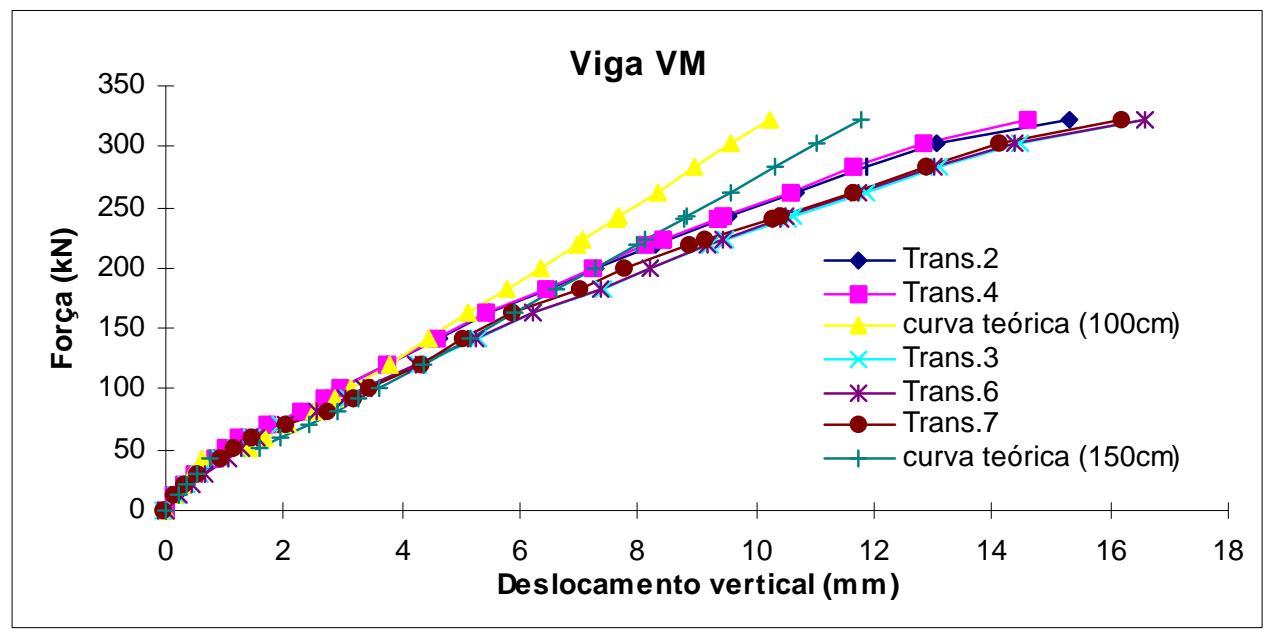

Figura 5.6 - Gráfico da força x deslocamento vertical para viga VM

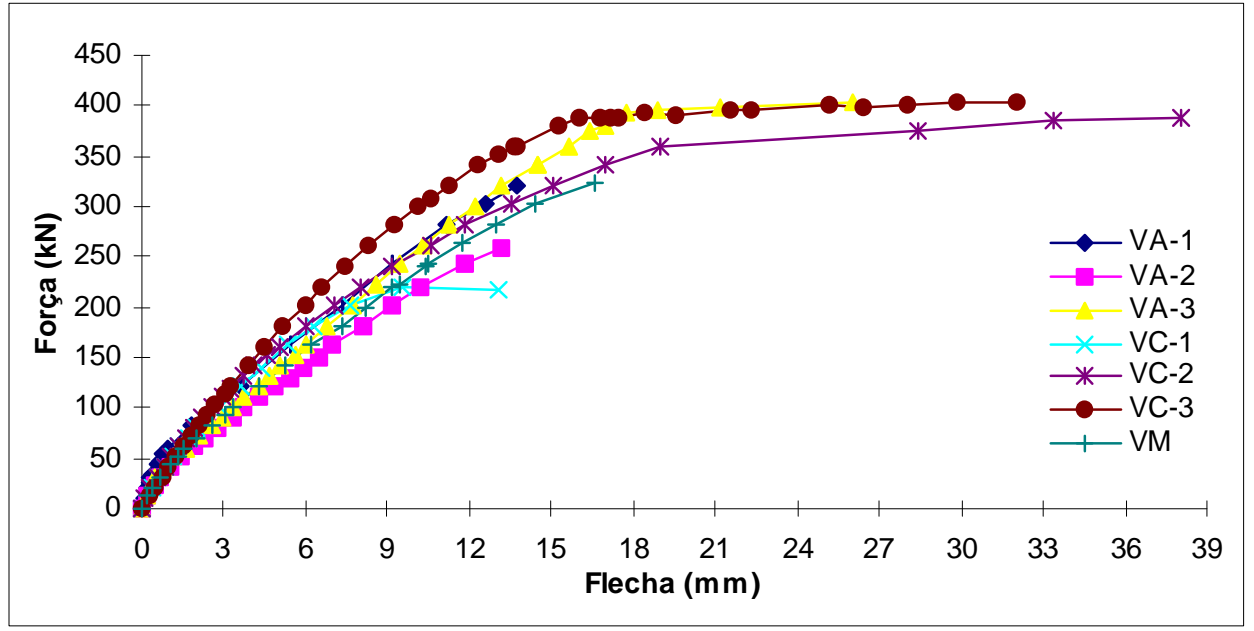

Figura 5.7 - Gráfico da força $\mathrm{x}$ flecha para todas as vigas

A viga $\mathrm{VC}-1$ teve valores de flecha semelhantes aos das outras vigas reforçadas com chapas até o instante em que rompeu de forma brusca devido o descolamento da chapa de aço.

A viga $\mathrm{VC}-3$ apresentou os menores deslocamentos, para um mesmo nível de força, que as demais peças reforçadas com chapa de aço. Isso pode ter ocorrido em função do uso de conectores metálicos tipo 2. Apesar da VC-2 também utilizar esse mesmo tipo de elemento, suas deformações foram menores que as da VC-3, 
provavelmente pelo fato da resistência do seu substrato ser inferior a do correspondente da VC-3. Além disso, na VC-2 ocorreu uma perda parcial da aderência entre a chapa e a argamassa de reforço, o que pode ter contribuído também para reduzir sua rigidez. Entre as vigas reforçadas com chapa de aço, a que mais se deformou foi a VC-1, que não possuía conectores metálicos tipo 2, indicando uma tendência de que esses conectores interferem na rigidez da peça reabilitada.

Para ações mais elevadas, ao contrário do que se esperava, as flechas da VA-3 praticamente se igualaram às encontradas para a VC-3, que foi a peça que apresentou maior rigidez. Na realidade, acreditava-se que as vigas da série 3 fossem as que possuíssem menor rigidez, já que estavam previamente fissuradas. Talvez isso tenha ocorrido porque a resistência do substrato dessas vigas eram maiores que das demais peças reabilitadas. Além disso, o fato da viga ser reforçada na posição invertida pode ter permitido a penetração da argamassa de reforço ou calda de cimento nas fissuras já existentes, possibilitando sua colmatação. Outro fator que pode ter provocado esse fenômeno é a não consideração de possíveis flechas residuais devidas à deformação gerada no ensaio anterior. Entretanto, são necessários estudos mais aprofundados para se ter certeza do que provocou o aparente aumento de rigidez dessas peças.

Desde o início do carregamento, a viga VA-1 apresentou maior rigidez que as peças do tipo VA e VM, indicando comportamento semelhante ao de uma viga monolítica ideal, mesmo rompendo prematuramente.

As vigas menos rígidas foram a VA-2 seguida da VM. No caso da viga monolítica, isso pode ter ocorrido por esse elemento não possuir, na região do bordo tracionado, uma resistência superior à gerada pelo uso de argamassa de alto desempenho na área do reforço. Entretanto, para a VA-2, não se conseguiu identificar a causa de tal comportamento, mesmo porque essa viga foi reforçada utilizando fibras de aço na argamassa de reforço, o que teoricamente deveria controlar melhor a fissuração e consequentemente aumentar sua rigidez. Sendo assim, percebe-se a necessidade de estudos mais específicos sobre a influência de fibras de aço na rigidez da estrutura reabilitada. 


\subsection{Deformações nas Armaduras}

\subsubsection{Armadura Longitudinal}

Foram feitas leituras das deformações nas armaduras longitudinais do substrato e do reforço para três seções distintas (50, 100 e $150 \mathrm{~cm}$ a partir do apoio). Comparando os resultados teóricos com os experimentais, percebeu-se que as deformações para o trecho da viga onde ocorria flexão pura foram bastante próximas, até o instante em que o comportamento não-linear da estrutura passava a ficar mais evidente. Esse fato já era esperado, pois nos cálculos teóricos não se levou em consideração o comportamento não-linear da peça, mas apenas uma redução da sua rigidez em função do grau de fissuração.

Para o trecho da viga submetida a esforços cortantes (seção a $50 \mathrm{~cm}$ do apoio) e carregamento superior a $50 \mathrm{kN}$, os valores experimentais se distanciaram dos previstos. Além disso, observou-se que as curvas experimentais das deformações apresentavam várias alterações na sua concavidade para valores de força entre $50 \mathrm{kN}$ a $150 \mathrm{kN}$. Esse comportamento ocorreu praticamente em todas as vigas, porém ficou mais evidente para aquelas reforçadas com chapa de aço. Acredita-se que essas alterações de concavidade das curvas experimentais tenham ocorrido em função da evolução da fissuração da peça, já que foi para esse intervalo de carregamento que surgiram as primeiras fissuras de flexão e de cisalhamento. No caso, antes da fissuração, a armadura longitudinal se deformava juntamente com o concreto, pois ainda não havia ocorrido nenhuma perda de aderência localizada. Após o início da fissuração, a armadura passava a se deformar mais para um mesmo incremento de força, pois não contava mais com a contribuição do concreto. Entretanto, a partir de determinado valor de força, a fissuração praticamente se estabilizava, ou seja, aumentava somente as aberturas das fissuras existentes, não surgindo nenhuma nova fissura. Conseqüentemente a armadura longitudinal voltava a se deformar menos. Uma outra possível justificativa para a alteração na concavidade das curvas experimentais é a interferência dos esforços cisalhantes na armadura tracionada, já que o efeito de flexão nessa seção não é tão intenso quanto para as seções situadas a $150 \mathrm{~cm}$ e $100 \mathrm{~cm}$ do apoio. 
A evolução das deformações na armadura longitudinal do substrato e do reforço para as diversas seções observadas está ilustrada nas Figuras 5.8 a 5.14.

Nas vigas VC, as deformações medidas na face interna ${ }^{*}$ da chapa (ext. 4, 10 e 16) foram próximas ou até menores que as deformações da armadura do substrato. Já as deformações lidas pelos extensômetros colados na face externa ${ }^{*}$ da chapa (ext. 6, 12 e 18) foram maiores que as encontradas na armadura do substrato. As diferenças entre as deformações das faces interna e externa da chapa podem ter sido causadas pelo efeito de flexão da chapa, gerado por pequenos deslocamentos relativos entre esse elemento e a argamassa de reforço. Dessa forma, supõe-se que a face interna da chapa realmente esteja menos tracionada que a face externa, podendo inclusive apresentar deformações menores que as da armadura longitudinal do substrato, em função do seu grau de interação com a estrutura propriamente dita. Este fato é semelhante ao observado em peças mistas com interação parcial, onde o diagrama de deformação apresenta uma certa descontinuidade na região de ligação chapa/estrutura. Entretanto, acredita-se que nas vigas ensaiadas, os deslocamentos relativos tenham sido tão pequenos que a descontinuidade no diagrama de deformação seja desprezível, possibilitando admitir a compatibilidade de deformações entre as armaduras do reforço e do substrato.

Para todas as vigas ensaiadas, a armadura do reforço apresentou deformações superiores às do substrato, indicando que, mesmo quando ocorre ruptura prematura, o comportamento das vigas reabilitadas é similar ao de uma estrutura monolítica. Isso porque as barras de aço do substrato e do reforço funcionaram como se fossem a primeira e a segunda camada de uma viga armada convencionalmente, apresentando deformações proporcionais aos respectivos braços de alavanca.

Nas vigas VA-1 e VA-2 não se identificou escoamento de nenhuma das barras de aço tracionadas. Já para a viga VM, apenas a armadura longitudinal do reforço escoou para a seção no meio do vão e no caso da VA-3 ocorreu o escoamento das armaduras longitudinais, tanto do reforço quanto do substrato.

No caso da VC-1, as deformações lidas pelos extensômetros colados na face externa da chapa de aço foram maiores que da armadura do substrato, até antes de

\footnotetext{
* Face interna: Corresponde à face em contato com a argamassa de reforço;
} 
ocorrer a perda de aderência entre a argamassa de reforço e o concreto antigo. Neste instante, a armadura longitudinal inicial atingiu o escoamento e as deformações na chapa de aço se reduziram, indicando que esta não estava mais resistindo aos esforços de flexão atuantes na peça.

Tanto a armadura do substrato quanto a chapa de aço das vigas VC-2 e VC-3 atingiram o escoamento. Como nessas vigas não houve perda de aderência na junta, a chapa continuou a resistir aos esforços de flexão até as peças atingirem a ruína por deformação plástica excessiva. Mesmo no caso da $\mathrm{VC}-2$, em que se verificou o destacamento da chapa em um pequeno trecho da viga, esse fato não chegou a provocar uma ruína brusca como no caso da $\mathrm{VC}-1$, pois o restante da chapa permaneceu preso ao substrato devido à presença dos conectores do tipo 2 .

Ainda em relação às vigas tipo $\mathrm{VC}$, os gráficos das Figuras 5.12 a 5.14 parecem indicar que o escoamento da armadura longitudinal do substrato foi simultâneo ao escoamento da armadura do substrato, mesmo sendo a deformação de escoamento, $\varepsilon_{\mathrm{y}}$, da chapa, bem menor que a deformação da armadura longitudinal de $16 \mathrm{~mm}$. Na realidade, o que ocorre é que, estando a chapa aderida à viga, suas deformações dependem obrigatoriamente das deformações da estrutura reabilitada como um todo. Sendo assim, apesar da chapa já ter entrado em escoamento após atingir valores de deformação maiores que $\varepsilon_{\mathrm{y}}$, nota-se que a curva da deformação em função da força aplicada na estrutura continua aumentando pois a viga ainda conta com a armadura do substrato para resistir aos acréscimos de ação aplicados na estrutura. Nesse caso, quando a tensão atuante na chapa atinge a tensão de escoamento, a força na chapa permanece constante e os incrementos de força passam a ser totalmente absorvidos pela armadura do substrato.

\footnotetext{
* Face externa: corresponde à face em contato com o meio ambiente externo.
} 

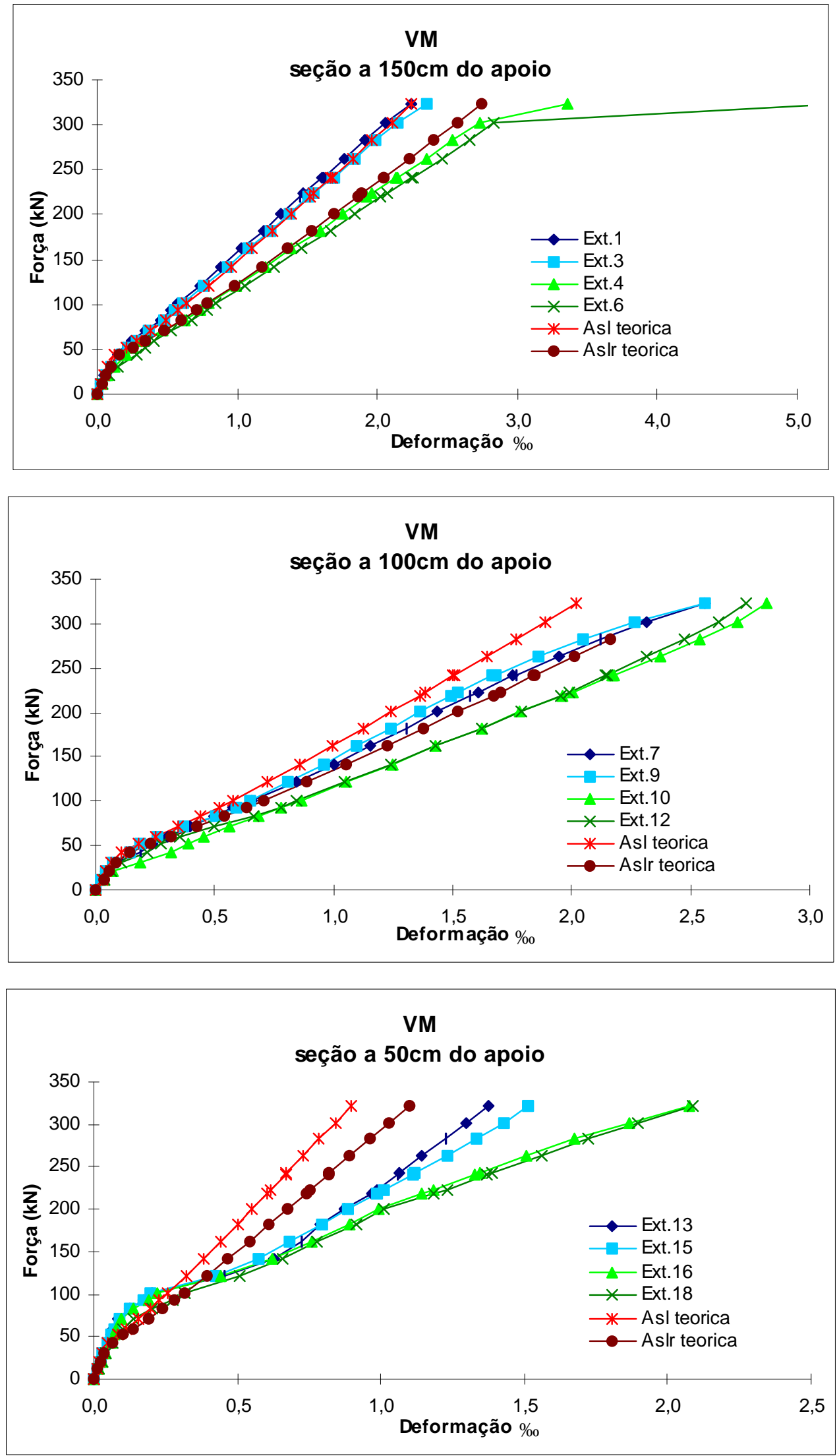

Figura 5.8 - Gráficos força x deformação na armadura longitudinal para VM 

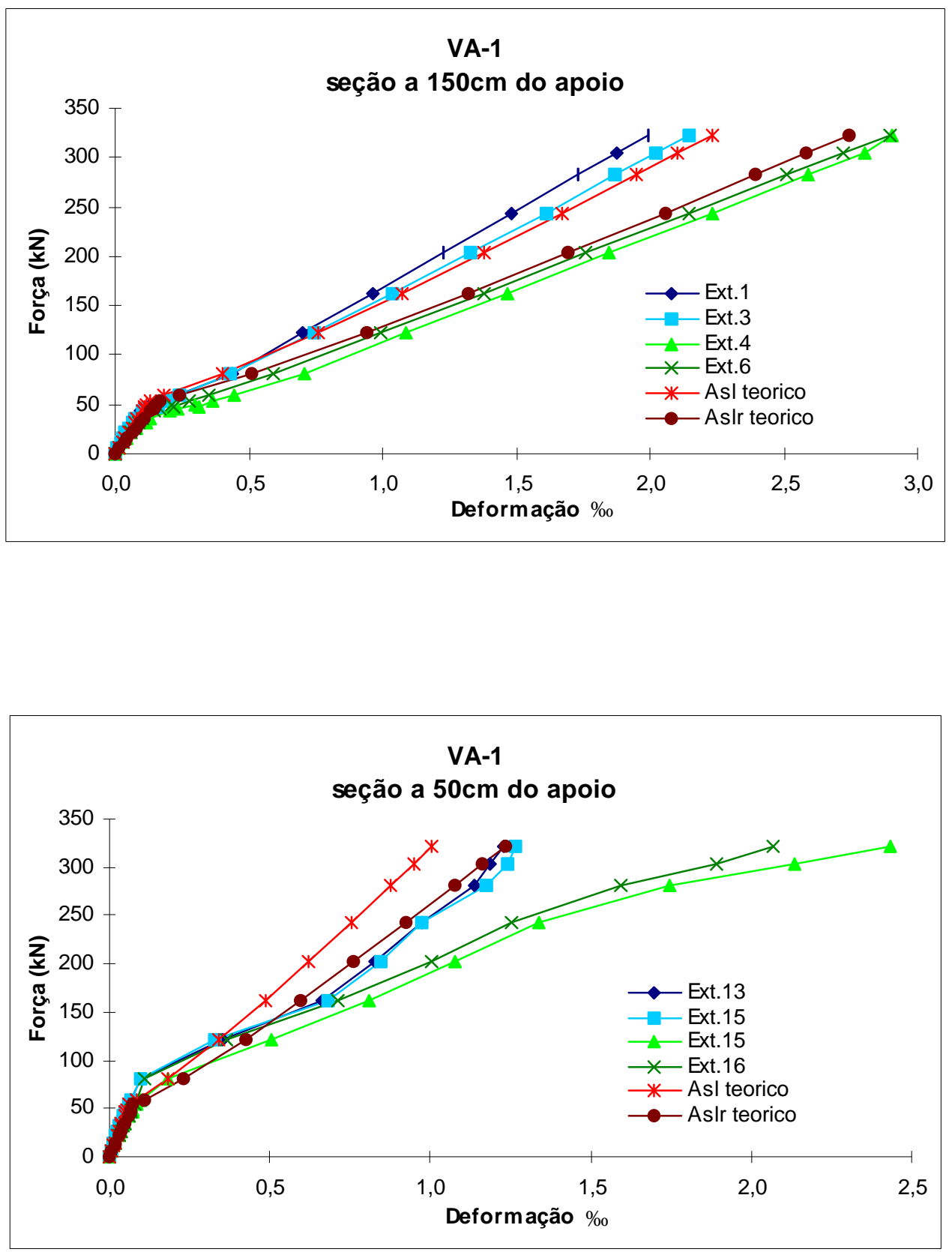

Figura 5.9 - Gráficos força x deformação na armadura longitudinal para VA-1 

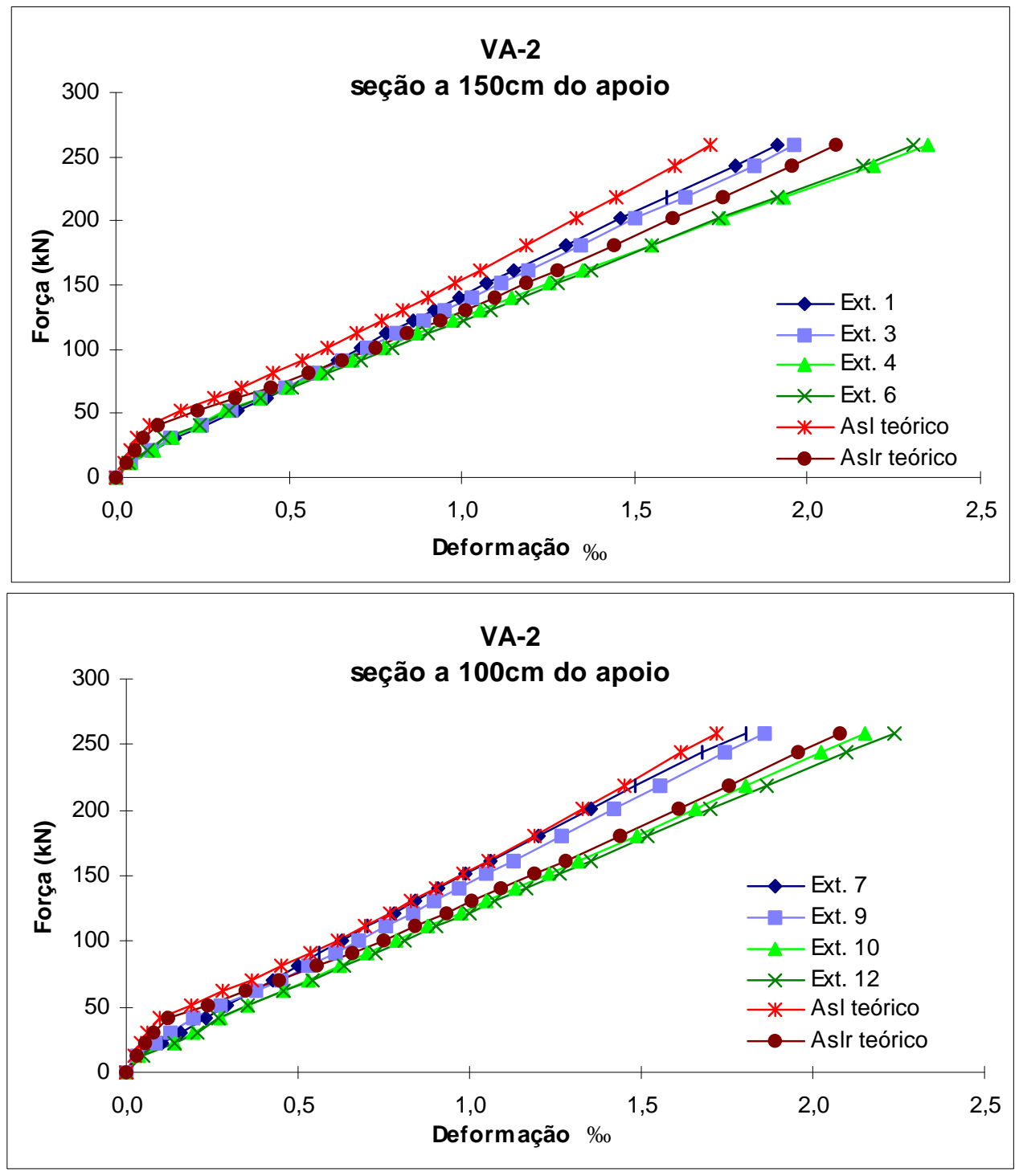

VA-2

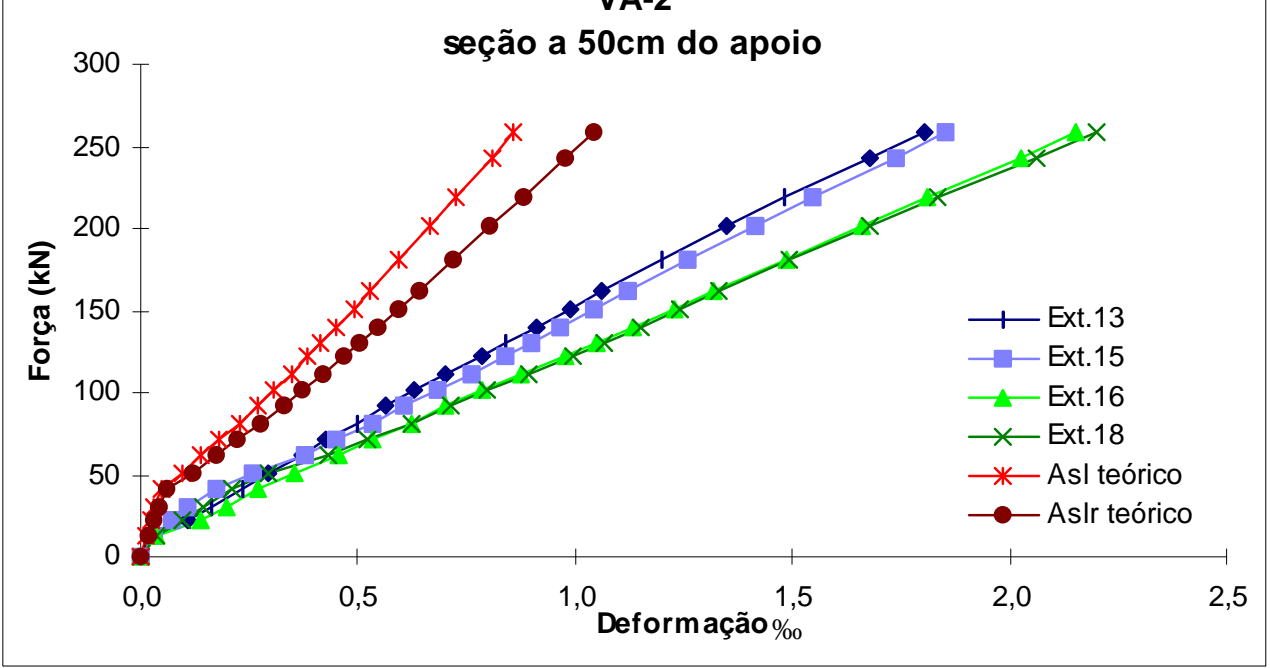

Figura 5.10 - Gráficos força x deformação na armadura longitudinal para VA-2 

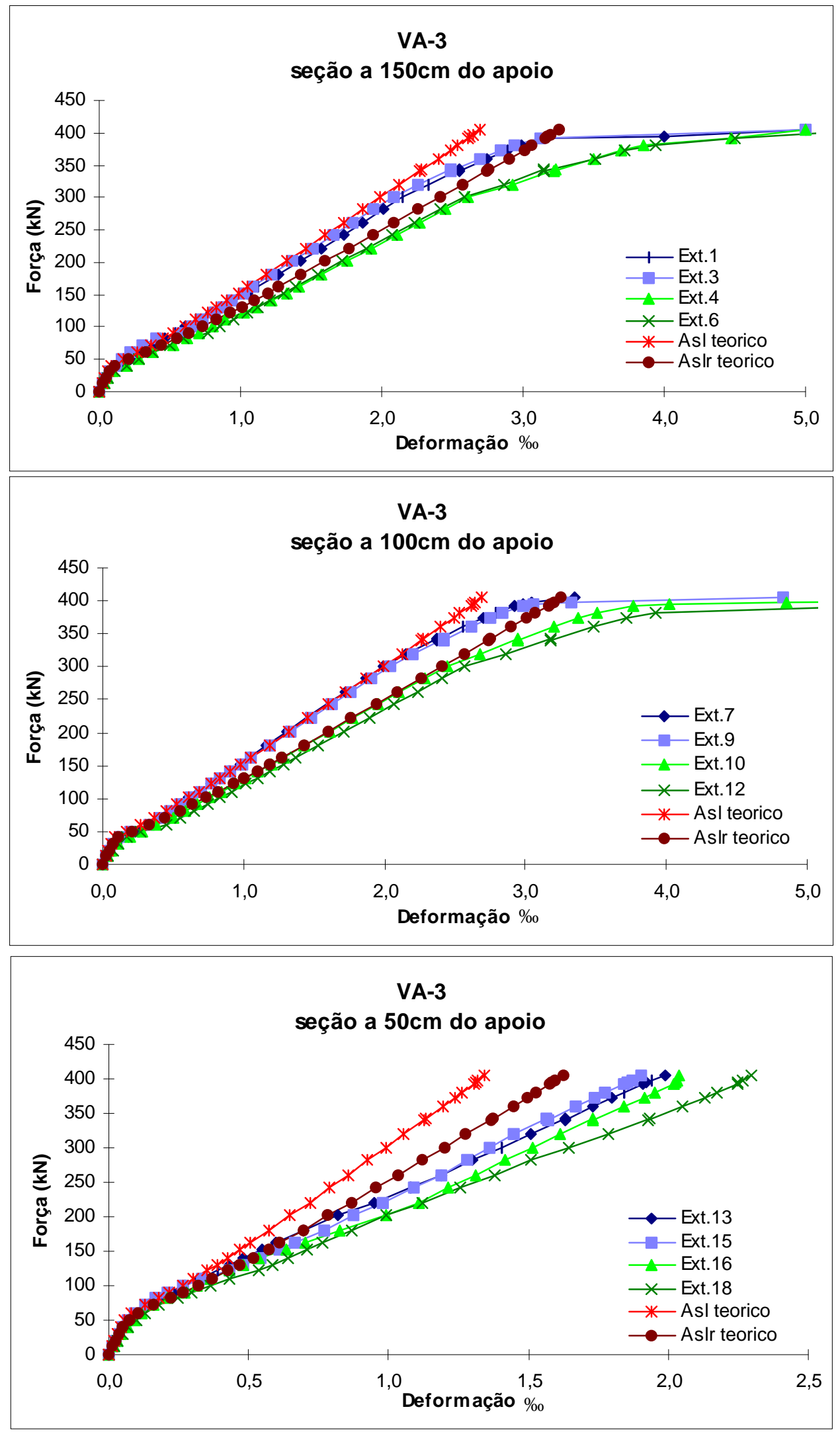

Figura 5.11 - Gráficos força x deformação na armadura longitudinal para VA-3 

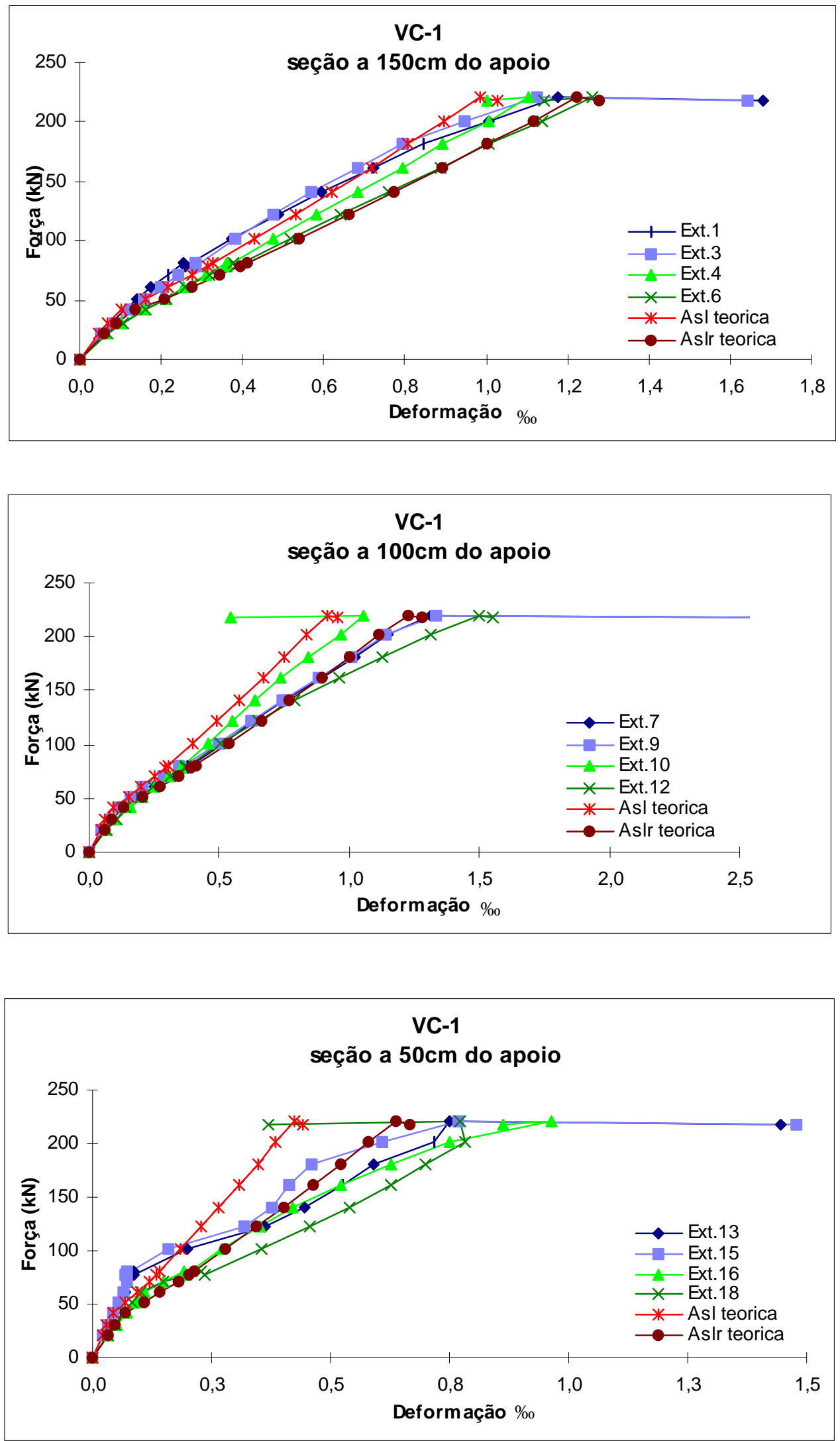

Figura 5.12 - Gráficos força x deformação na armadura longitudinal para VC-1 

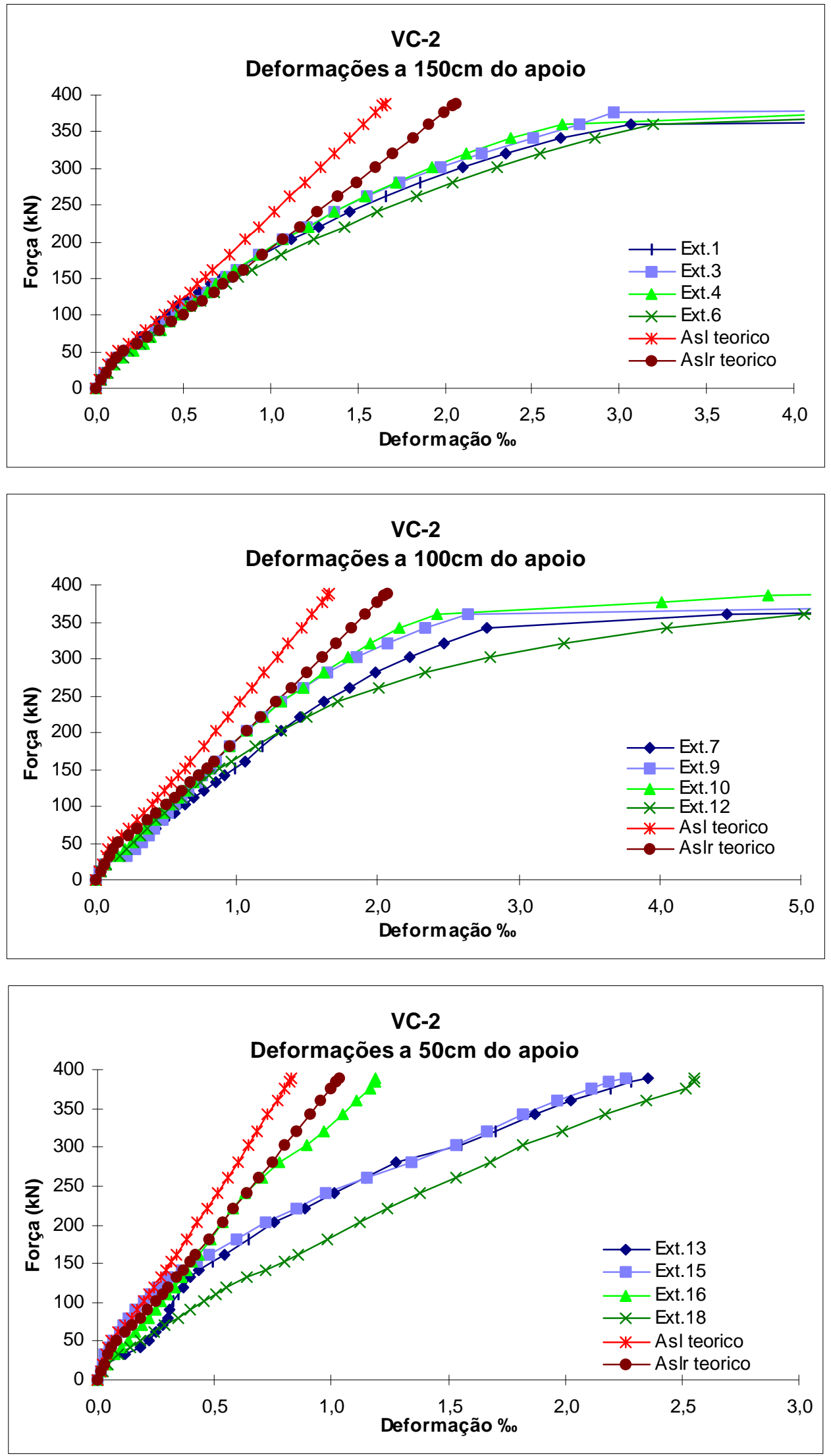

Figura 5.13 - Gráficos força x deformação na armadura longitudinal para VC-2 

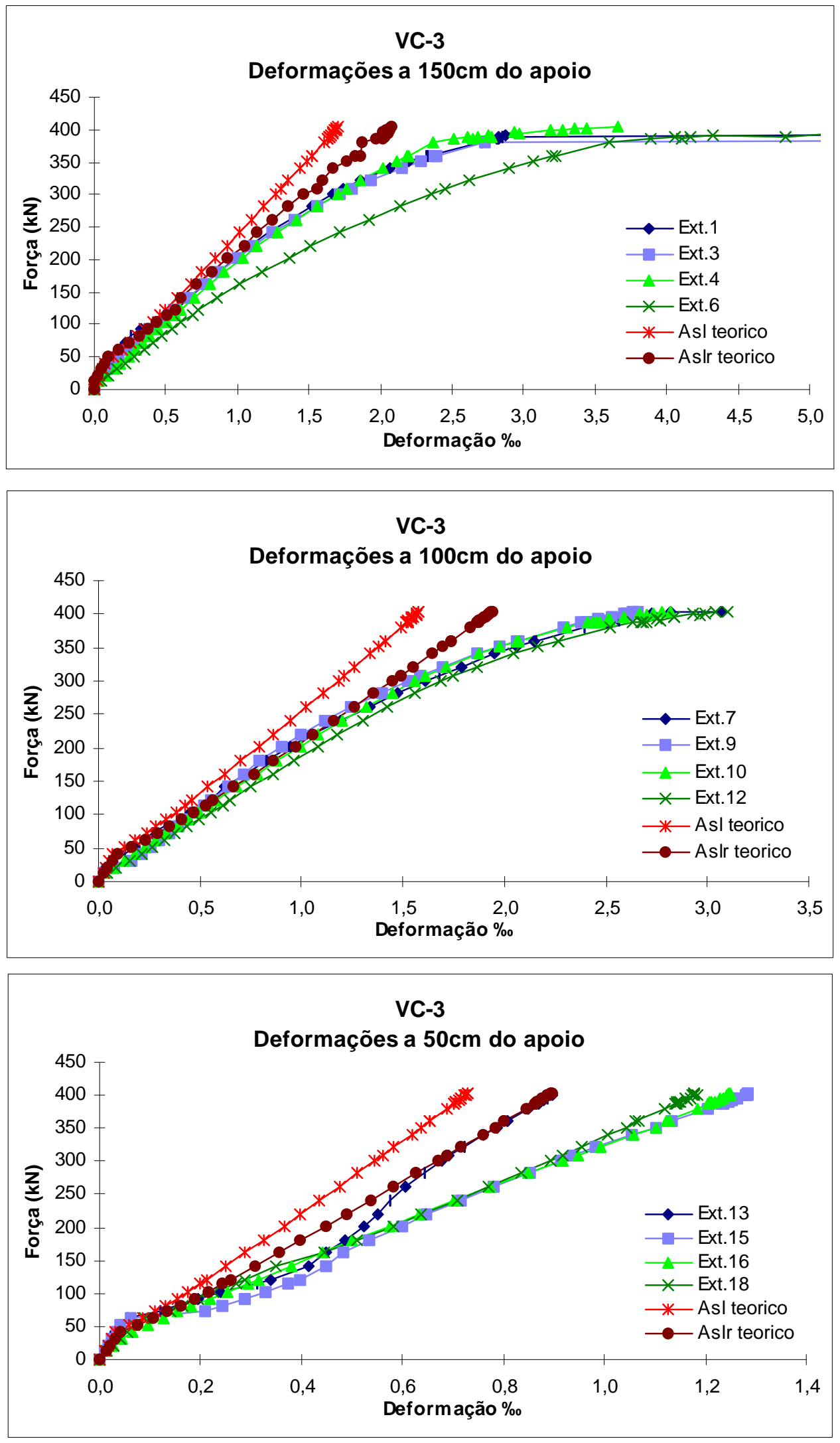

Figura 5.14 - Gráficos força x deformação na armadura longitudinal para VC-3 


\subsubsection{Armadura Transversal}

Não se observou o escoamento dos estribos para nenhuma das vigas ensaiadas, indicando que estas peças não romperam por cisalhamento da alma. Além disso, na maioria dos caso, foi observada uma concordância entre os valores previstos e os reais (com exceção das vigas VA-1 e VC-3) para o carregamento próximo da ruína. Entretanto, são necessários estudos mais aprofundados para verificar se o fato da armadura longitudinal no reforço não ter sido envolvida com estribos interfere no posicionamento do banzo tracionado e na alteração da inclinação das bielas comprimidas.

Para as vigas que não foram submetidas a nenhum tipo de dano estrutural antes do reforço, conseguia-se definir exatamente o ponto a partir do qual os estribos começavam a ser solicitados. Já para as vigas VA-3 e VC-3, que foram reensaiadas, este ponto não era tão evidente (ver Figura 5.18).

Os estribos só começaram a ser solicitados para um carregamento ligeiramente superior ao que provocou o início da fissuração por ação do momento fletor. Este fato já era esperado pois o que gera deformação nesta armadura é o aparecimento das fissuras de cisalhamento.

$\mathrm{Na}$ viga $\mathrm{VC}-1$, quando ocorreu o destacamento da camada do reforço com o substrato, os estribos apresentaram uma redução das deformações. Em contrapartida, a armadura tracionada passou a ser mais solicitada, entrando imediatamente em escoamento, pois a peça não contava mais com a resistência da chapa de aço.

Em relação a VA-1, não se conseguiu identificar porque as deformações experimentais foram menores que os valores teóricos. Para a viga VC-3, acredita-se que as discrepâncias possam ter sido causadas por eventuais diferenças entre os valores estimados e os valores reais da resistência à compressão do concreto do substrato e do módulo de elasticidade. Essas estimativas foram feitas através de regressões numéricas baseadas na evolução da resistência dos materiais e do módulo de elasticidade em função do tempo, uma vez que não se possuíam corpos-de-prova para avaliar esses parâmetros no dia do ensaio da viga. 
Acredita-se que as eventuais diferenças entre os valores experimentais lidos pelos dois extensômetros colados no estribo foram causadas pela própria variabilidade dos ensaios, imperfeições na simetria da seção transversal, do carregamento, etc.

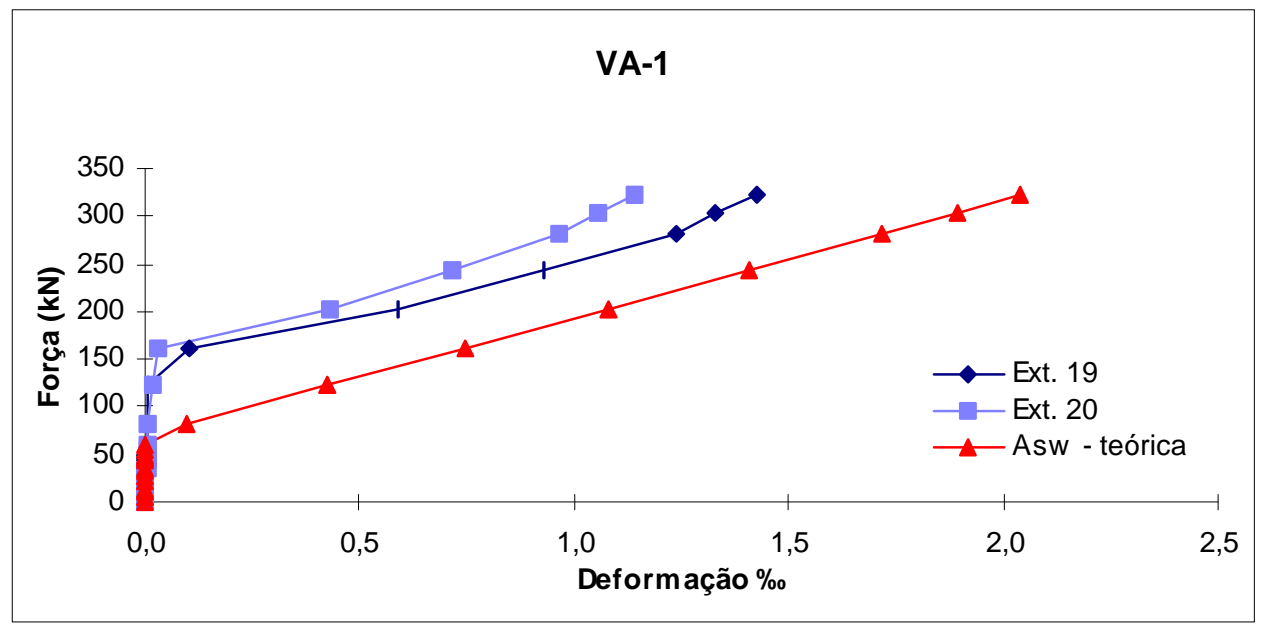

VA-2

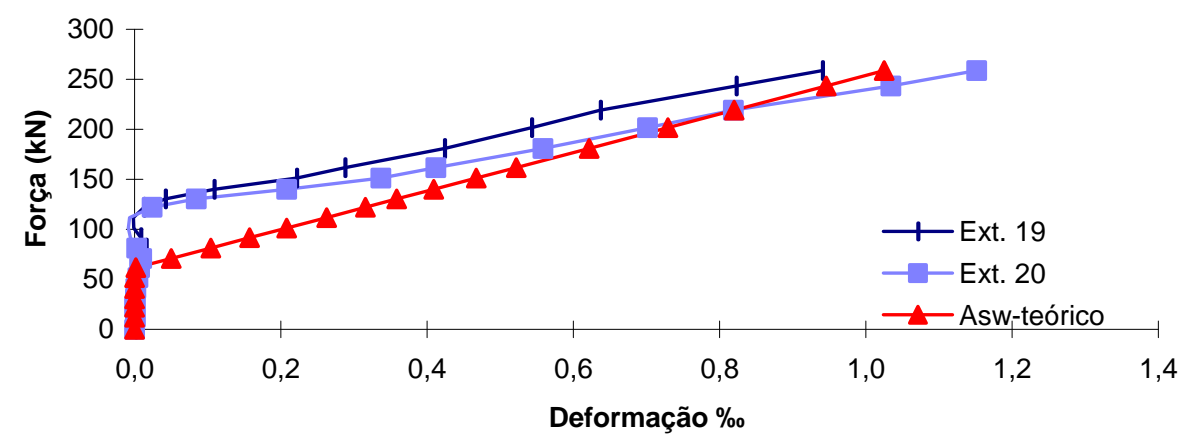

VA-3

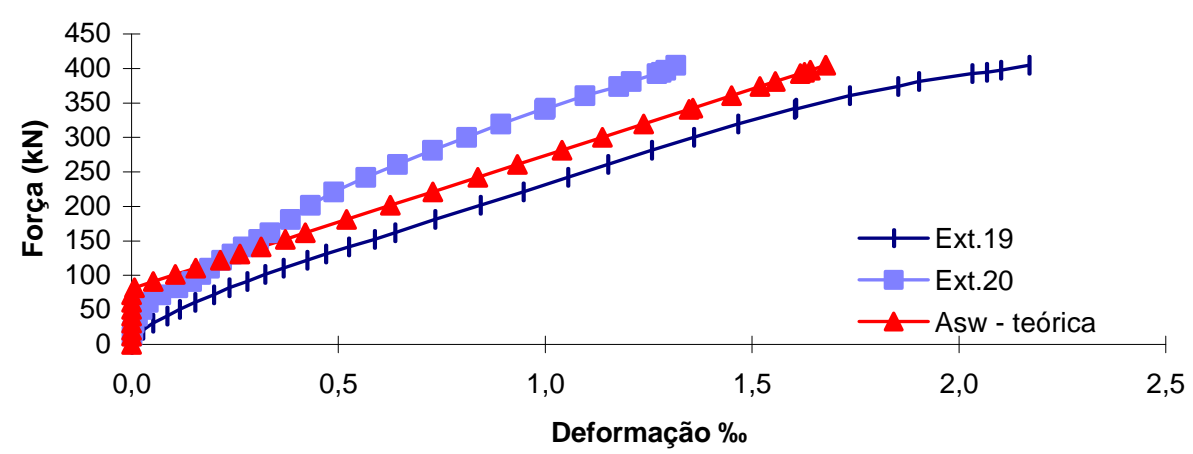

Figura 5.15 - Gráficos força x deformação dos estribos para vigas tipo VA 

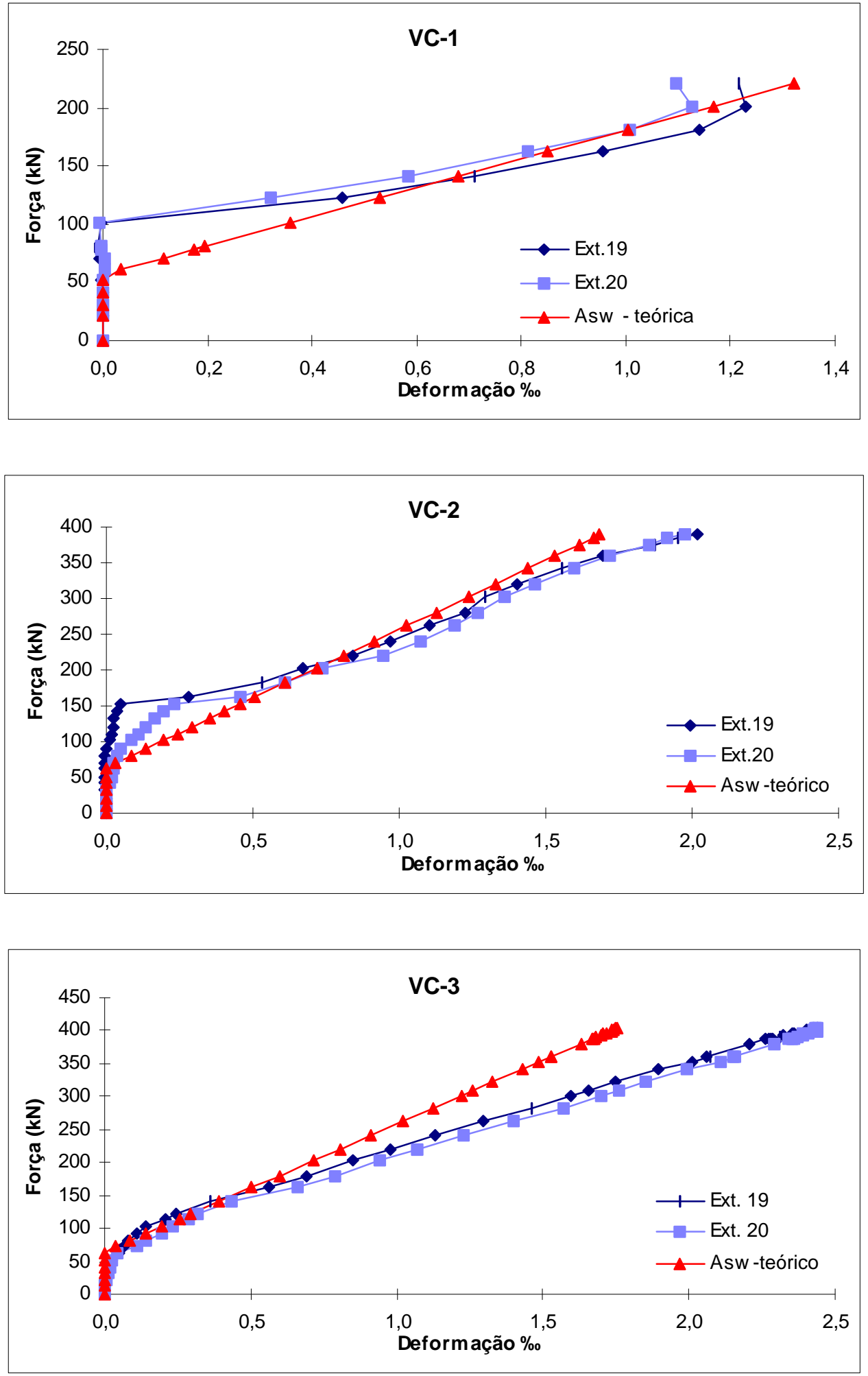

Figura 5.16 - Gráficos força x deformação dos estribos para vigas tipo VC 


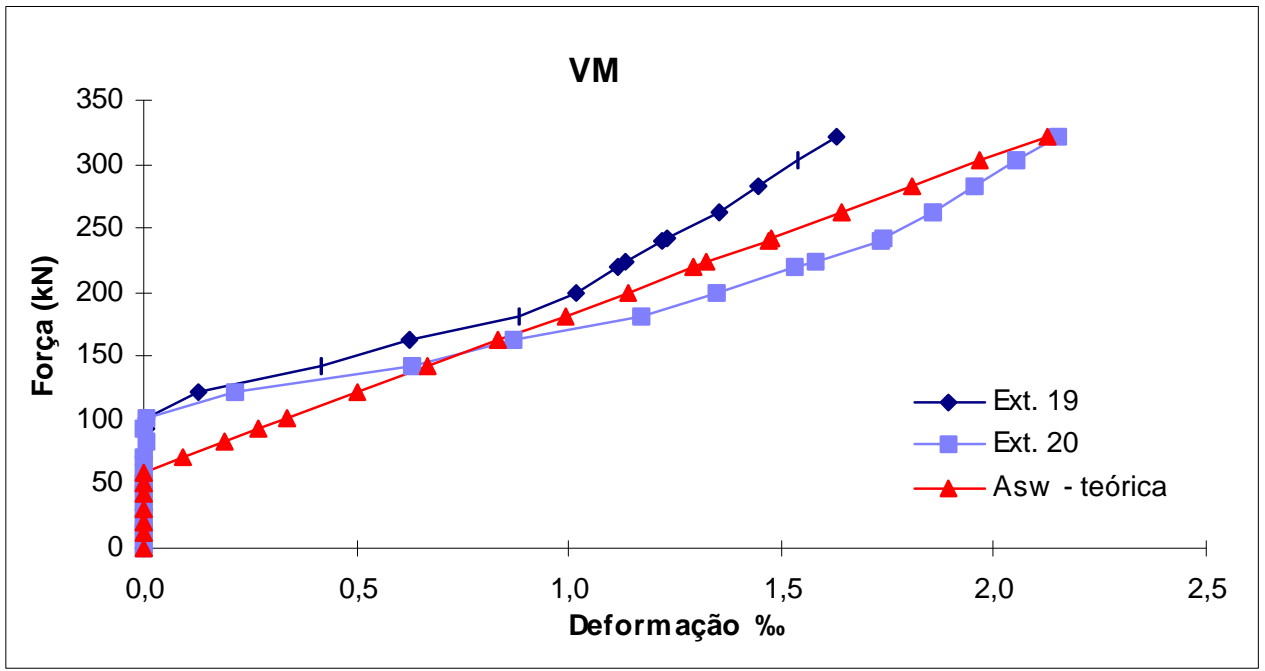

Figura 5.17 - Gráfico força x deformação dos estribos para viga VM
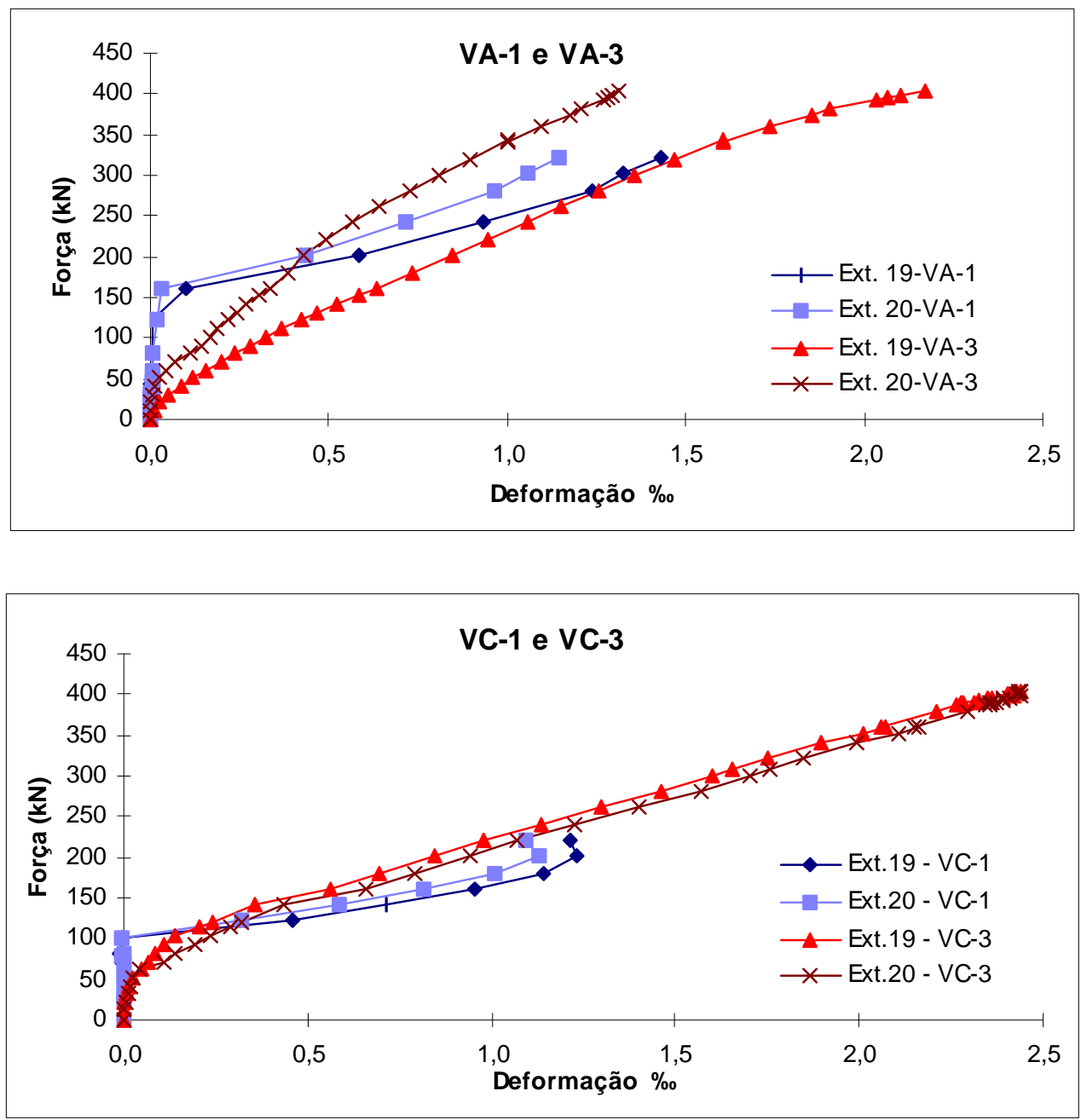

Figura 5.18 - Comparação entre as deformações dos estribos nas séries 1 e 3 


\subsection{Deformações no Concreto}

\subsubsection{Mesa Comprimida}

Não houve esmagamento da mesa comprimida no meio do vão para as vigas VA-1, VA-2 e VM, pois romperam prematuramente sem explorar toda a capacidade resistente das armaduras longitudinais. Já para a viga VA-3, que rompeu por escoamento da armadura longitudinal, os esforços de compressão na mesa da viga foram bem maiores, ocasionando a plastificação do concreto comprimido para a seção central da viga.

Todas as vigas reforçadas com chapa de aço apresentaram fissuras na mesa de concreto no meio do vão. No caso da VC-2 e VC-3, esse fato já era esperado porque as vigas atingiram o colapso por escoamento da armadura longitudinal. Entretanto, para a VC-1, que rompeu prematuramente, a plastificação do concreto ocorreu porque, no instante em que houve a perda de aderência entre substrato e argamassa de reforço, a chapa de aço não conseguiu continuar trabalhando como segunda camada de uma armadura longitudinal. Com isso, as barras de aço localizadas no substrato passaram a resistir aos esforços solicitantes sozinhas, atingindo imediatamente o escoamento e conseqüientemente, provocando o esmagamento do concreto no meio do vão.

De acordo com estes gráficos, percebe-se que a curva teórica, determinada conforme as hipóteses descritas no Anexo I, representa de forma bastante eficiente as deformações obtidas no bordo comprimido da viga. Apenas a viga VA-1 não apresentou deformações previstas compatíveis com as reais.

As Figuras 5.19 a 5.21 ilustram a evolução das deformações na mesa de concreto em função do carregamento aplicado para as vigas ensaiadas. 

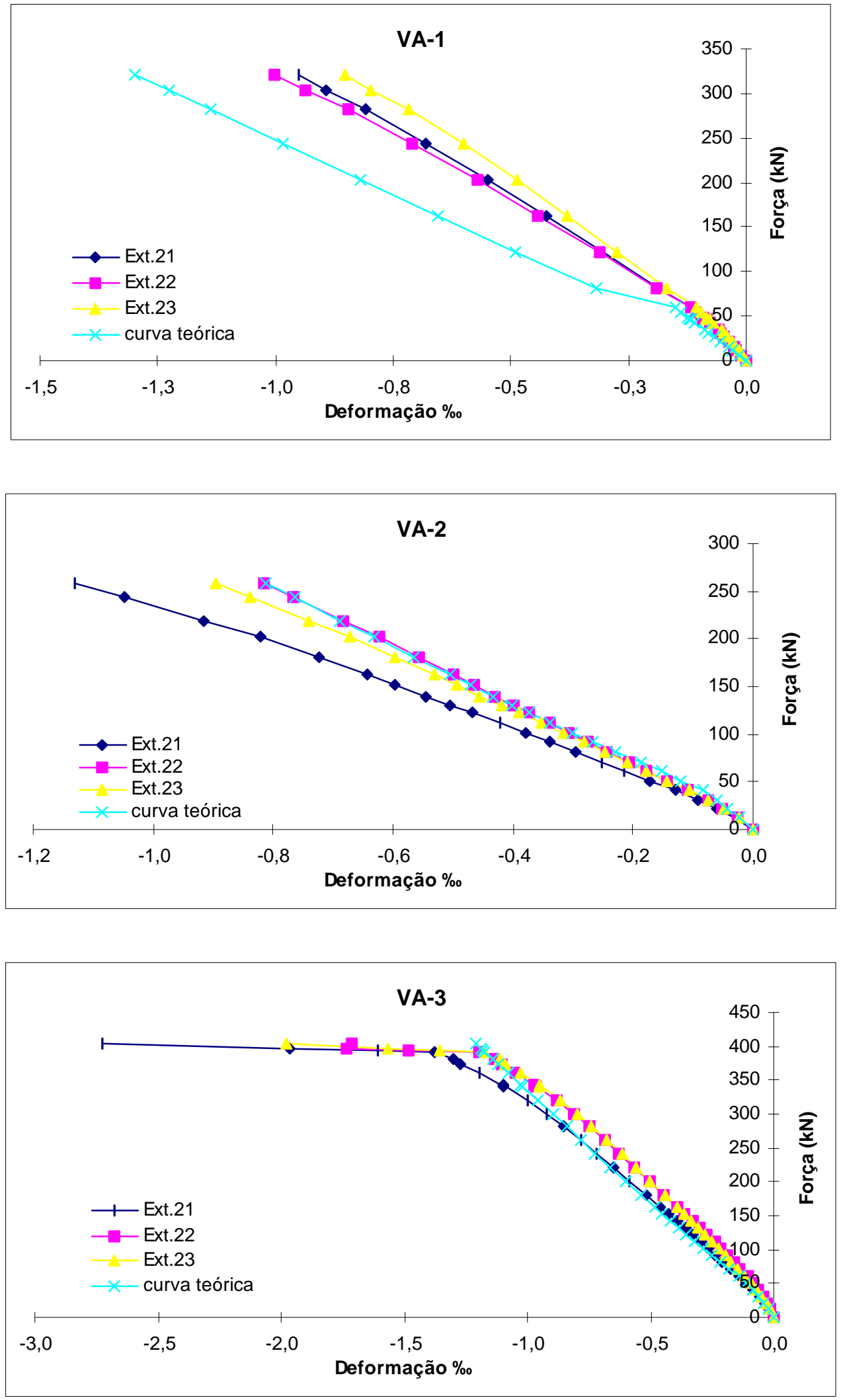

Figura 5.19 - Gráficos da força x deformação no concreto para vigas tipo VA 

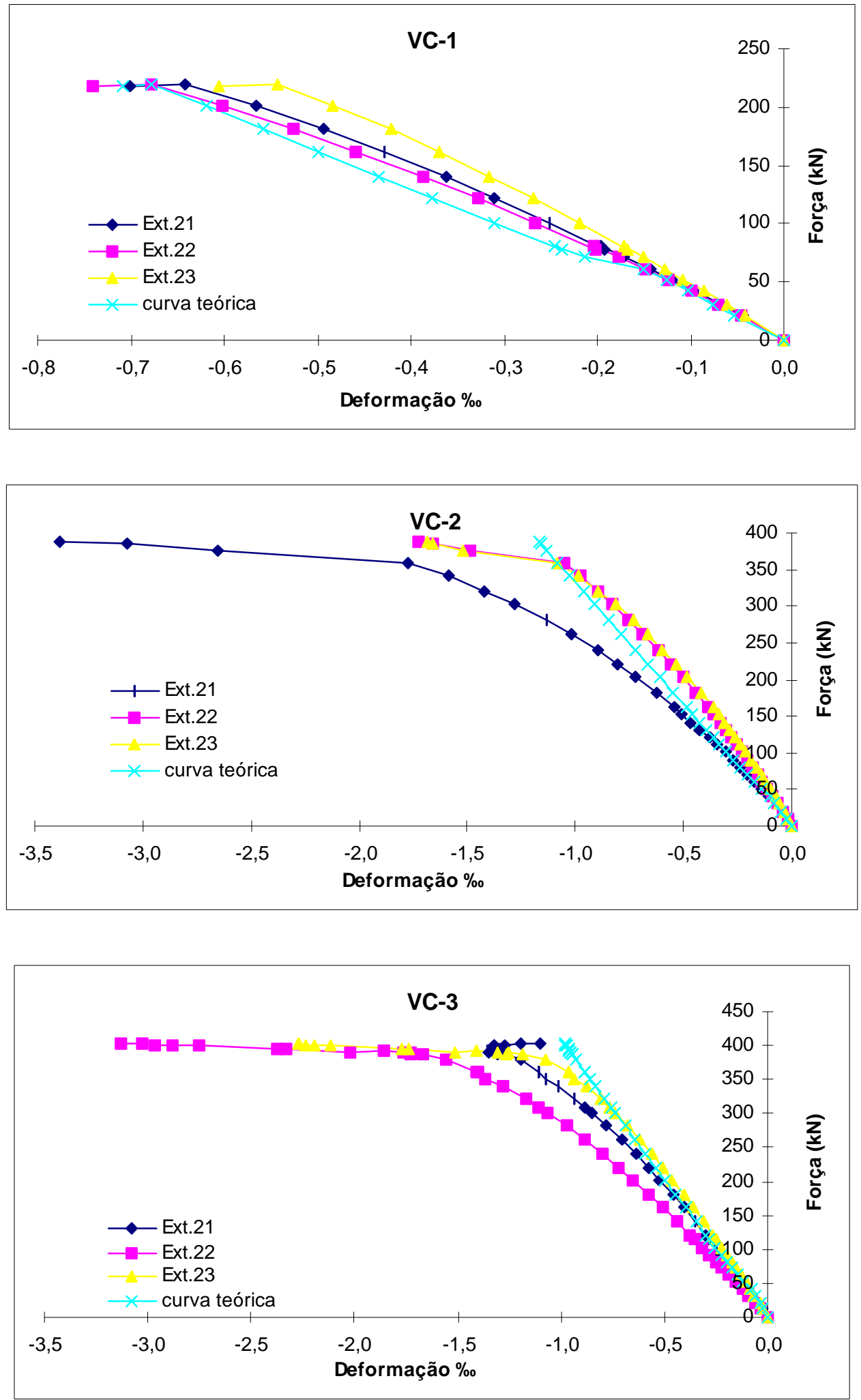

Figura 5.20 - Gráficos da força x deformação no concreto para vigas tipo VC 


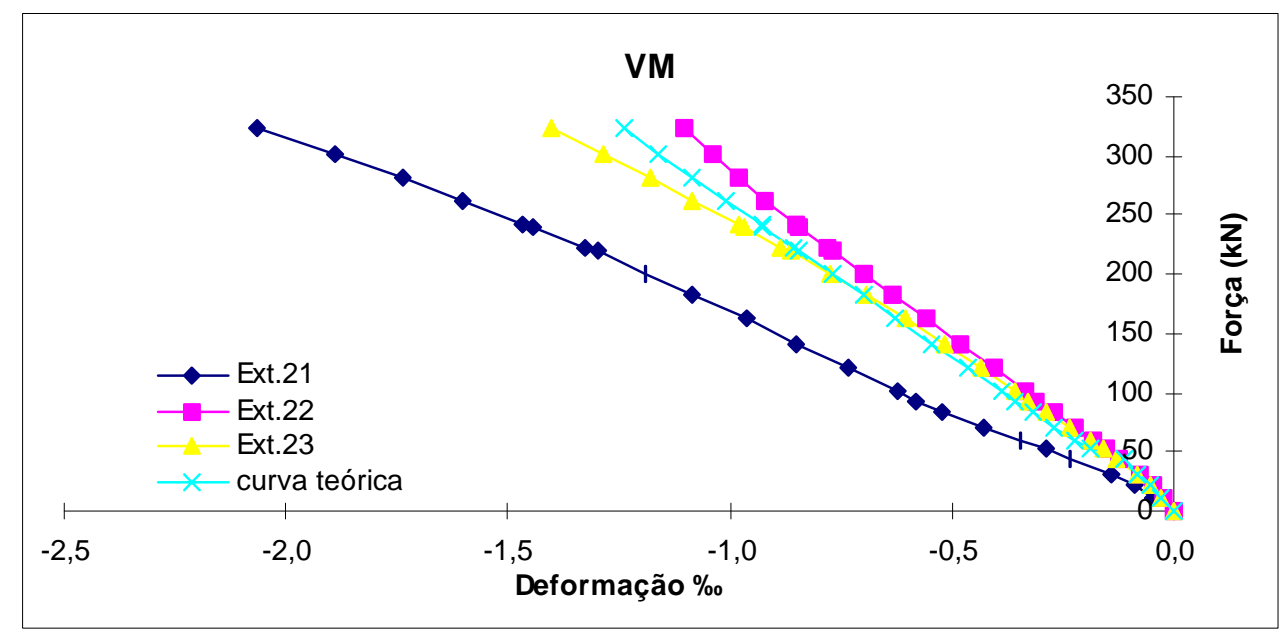

Figura 5.21 - Gráfico da força x deformação no concreto para a viga VM

\subsubsection{Alma da Viga}

Teoricamente, os resultados das tensões principais máximas e mínimas na alma da viga deveriam ser iguais em módulo, mas isso não foi observado para nenhuma das peças ensaiadas. Pela análise da Figura 5.22, percebe-se que isto não ocorreu, provavelmente porque as rosetas não foram posicionadas exatamente no local correspondente à linha neutra da peça ou pela extrema sensibilidade que esse instrumento apresenta em relação à fissuração.

As leituras fornecidas pelas rosetas só são confiáveis enquanto o concreto próximo a este instrumento não se encontra fissurado, pois a existência de fissuras compromete as leituras. Como as vigas apresentaram grande quantidade de fissuras, as leituras desse instrumento não trouxeram informações relevantes a respeito do comportamento da viga reabilitada. 

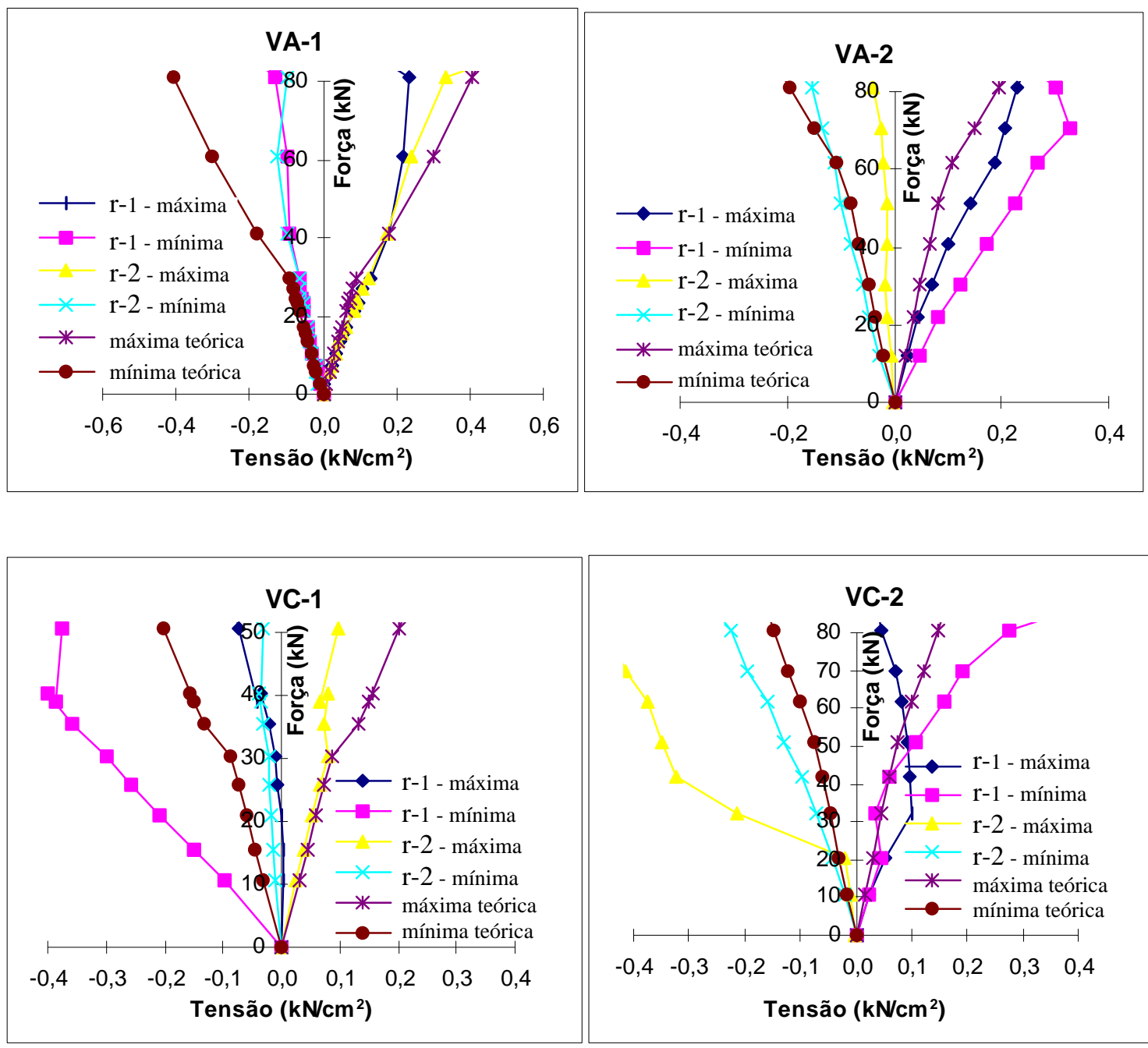

\section{LEGENDA:}

r-1 - máxima = Tensão máxima na roseta 1;

r-1 - mínima = Tensão mínima na roseta 1 ;

r-2 - máxima $=$ Tensão máxima na roseta 2 ;

r-2 - mínima $=$ Tensão mínima na roseta 2 .

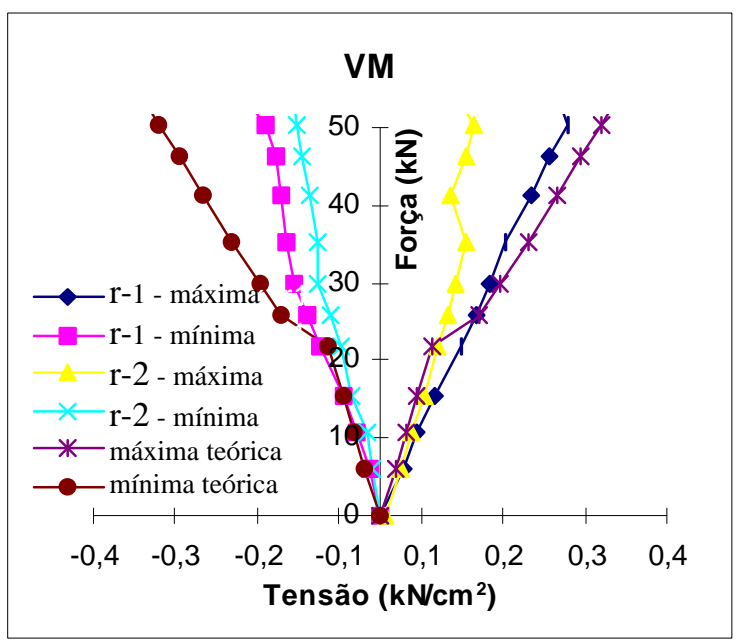

Figura 5.22 -Gráficos força x tensões máximas e mínimas 


\subsection{Conectores de cisalhamento}

No caso dos conectores do tipo 1, não se fez nenhum dimensionamento para determinar a quantidade que seria colocada na viga VC-1. Já para os conectores do tipo 2, foram seguidas as recomendações indicadas no PCI - Precast Concrete Institute, para peças compostas. Esses conectores metálicos tinham a finalidade de impedir os deslocamentos verticais e horizontais que podem surgir nas juntas, formadas por concretos com idades diferentes, em decorrência dos esforços de cisalhamento, além de colaborarem na ancoragem da chapa de aço da viga reforçada.

Através dos extensômetros elétricos colados nestes conectores, percebeu-se que na viga $\mathrm{VC}-2$ estes elementos trabalharam de forma bastante satisfatória. Os conectores soldados mais próximos das extremidades da chapa foram os mais solicitados, indicando ser esta uma seção crítica. As solicitações diminuíam conforme o conector se situava mais próximo da seção central da viga (ver Figura $5.23)$.

Na viga VC-3, o extensômetro 31, responsável pela leitura da deformação do conector situado a $30 \mathrm{~cm}$ da extremidade da chapa de aço, apresentou defeito durante o ensaio e suas leituras devem ser desprezadas. Analisando as leituras dos extensômetos 32 e 33, percebeu-se que o conector situado a $70 \mathrm{~cm}$ da extremidade da chapa foi menos solicitado (apresentou menor deformação) do que aquele situado a $90 \mathrm{~cm}$, contrariando o comportamento observado na viga VC-2. Este fato pode ter sido provocado pela ocorrência de fissuras mais intensas na seção próxima do extensômetro 33. Todavia, o conector menos solicitado foi o que estava situado mais longe da extremidade da chapa $(110 \mathrm{~cm})$.

Apesar dessas vigas apresentarem resistências últimas próximas, os conectores da VC-2 foram mais solicitados porque esta viga tinha um comprimento de ancoragem da chapa menor. Portanto, constata-se que os conectores de aço realmente exerceram a função de ancorar e não apenas evitar os deslocamentos relativos entre o substrato e o material de reforço. 
Mesmo diante das diferenças encontradas nas vigas VC-2 e VC-3, e da pouca quantidade de ensaios feitos utilizando conectores, acredita-se que o comportamento destes elementos deva estar mais de acordo com o observado para a viga VC-2. Entretanto, são necessários estudos mais aprofundados para se determinar com segurança o comportamento e a influência destes conectores na viga reabilitada.
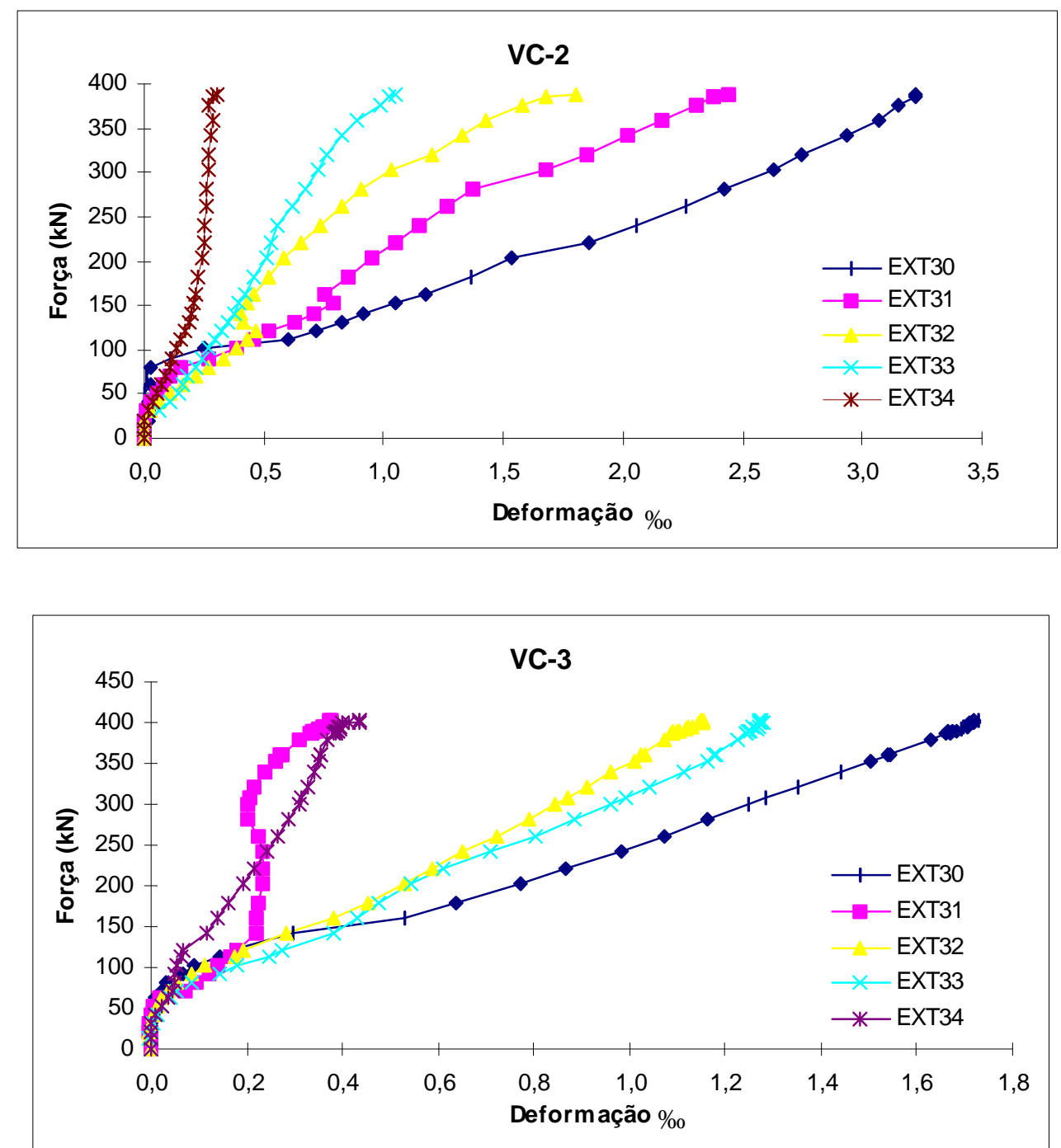

Figura 5.23 - Gráficos força x deformação nos conectores para VC-2 e VC-3 


\subsection{Comparação com os resultados encontrados na literatura}

Neste item faz-se comparações do comportamento de vigas ensaiadas por outros pesquisadores com o comportamento das vigas ensaiadas por REIS (1998).

1. Reforço por adição de armadura tracionada envolvida por concreto ou argamassa

Em relação aos modelos ensaiados por SOUZA (1990), observa-se que as forças de ruptura teóricas foram maiores que as experimentais, mesmo ocorrendo a ruína por ação do momento fletor, conforme previsto no dimensionamento. Este mesmo fato não foi observado nas vigas ensaiadas por REIS (1998) pois as peças que romperam por flexão (VA-3, VC-3 e VC-2) apresentaram resistências teóricas, calculadas de acordo com a NBR-6118, inferiores às reais. Apenas as vigas que romperam prematuramente tiveram forças teóricas de ruína maiores que as experimentais. Em relação às vigas de CLÍMACO (1990), apesar de utilizar outra norma para prever o comportamento teórico, as resistências teóricas e experimentais ficaram bastante próximas, indicando a possibilidade de se utilizar as normas existentes para prever o comportamento da peça reabilitada.

CLÍMACO (1990), SOUZA (1990) e PIANCASTELLI (1997) constataram que seus métodos de reforço foram eficientes. No caso dos ensaios de REIS (1998), os métodos de reabilitação também foram eficazes desde que sejam utilizados fibras de aço ou chapas de aço com conectores metálicos na reabilitação, não se esquecendo de observar se o comprimento de ancoragem da armadura do reforço é suficiente.

Em relação ao dimensionamento, acredita-se que o reforço das vigas ensaiadas por REIS (1998), tal qual observado por SOUZA (1990), pode ser calculado com relativa segurança adotando os princípios válidos para estruturas novas e introduzindo coeficientes de segurança parciais específicos para cada caso.

Analisando o valor da força de ruína prevista, calculada usando os valores característicos das resistências dos materiais e os coeficientes de segurança indicados pela NBR-6118, percebe-se que para vigas que romperam por flexão, a capacidade portante foi subestimada em aproximadamente $40 \%$ e $60 \%$, por REIS (1998) e por PIANCASTELLI (1997) respectivamente. Isso confirma que esta norma pode ser 
utilizada na previsão das resistências finais das vigas reabilitadas com relativa segurança.

SOUZA (1990), observou a existência de deformações residuais nas armaduras tracionadas após a peça ter sido submetida a certo nível de dano e levou em consideração essas deformações ao prever o comportamento das vigas ensaiadas. Esse parâmetro não foi observado por REIS (1998) nos ensaios das vigas da série 3 (vigas pré-fissuradas), mas tal como PIANCASTELLI (1997), acredita-se que a observação das deformações residuais seja importante para prever o real comportamento da viga reabilitada.

Igualmente aos resultados de SOUZA (1990), as armaduras do substrato e do reforço das vigas de REIS (1998) trabalharam como se fossem a primeira e a segunda camada de armadura de uma viga monolítica, ou seja, as tensões nas barras tracionadas foram proporcionais aos respectivos braços de alavanca.

No que se refere aos deslocamentos horizontais na junta, ao contrário do observado por SOUZA (1990) e por CLÍMACO (1990), a fissuração nessa interface afetou a resistência última das peças ensaiadas por REIS (1998), provavelmente porque nesses ensaios não se utilizou estribos envolvendo a armadura do reforço.

Tal qual nas vigas ensaiadas por SOUZA (1990) e PIANCASTELLI (1997), com exceção da viga VA-1, os momentos fletores de fissuração teóricos calculados a partir da resistência do reforço foram maiores que os experimentais, o que parece confirmar a hipótese de que a resistência à tração não é mais o fator determinante para o início da fissuração, mas sim a qualidade de aderência. Esse fato fica ainda mais evidente ao observar que a viga VA-1 apresentou uma força de fissuração real maior que a teórica mesmo apresentando a menor resistência à compressão para a argamassa do reforço. No caso das vigas que tiveram fibras de aço adicionadas à argamassa, não se observou nenhuma influência desse material no início da fissuração, mas apenas uma modificação na configuração das fissuras, que se mostraram mais finas e em maior quantidade do que nas demais peças.

Apesar de não se ter acompanhado as deformações do concreto ao longo das vigas reabilitadas, como fez CLÍMACO (1990), acredita-se ser razoável admitir que 
as seções planas permanecem planas após a reabilitação, em função da evolução das deformações nas armaduras e no concreto comprimido.

Analisando a viga recuperada na posição invertida, ensaiada por CLÍMACO (1990), percebe-se um comportamento semelhante ao das peças reabilitadas na posição normal. Isso indica que não deve haver grandes diferenças de comportamento entre as vigas ensaiadas por REIS (1998) e possíveis peças similares reabilitadas na posição real.

PIANCASTELLI (1997) afirmou que, para suas vigas, foi razoável admitir um comportamento conjunto entre os concretos do substrato e do reforço e não considerar, nos cálculos, o fato das vigas já estarem pré-fissuradas. Isso parece se confirma ao observar o comportamento das vigas da série 3 ensaiadas por REIS (1998).

2. Reforço através de chapa de aço fixada no bordo tracionado

A técnica de reabilitação por meio de chapa de aço colada com resina epóxi é, sem dúvida, muito mais simples de ser executada do que a fixação da chapa através de uma camada de argamassa. Entretanto, a aplicação da resina exige mão-de-obra altamente especializada para que se tenha resultados satisfatórios. Esse material também deve apresentar uma formulação específica para cada caso, já que sua resistência varia conforme as condições ambientais do local onde será aplicado, fatores que não existem quando se fixa a chapa utilizando argamassa.

Fazendo uma analogia entre os conectores de aço tipo 2 e as buchas metálicas usadas por REIS (1998) e por ALFAIATE (1986) respectivamente, pode-se dizer que, foi observado um comportamento mais satisfatório para as vigas em que foram empregados esses elementos. Isso porque esses dispositivos melhoram a ancoragem da chapa e a qualidade de aderência entre chapa/substrato.

De acordo com ALFAIATE (1986), as resistências previstas pelo CEB e pelo REBAP foram inferiores às observadas durante os ensaios das peças, indicando que tais códigos podem ser utilizados com segurança na previsão do comportamento das vigas reabilitadas com chapa de aço. 
Para as vigas ensaiadas por CAMPAGNOLO (1997), verificou-se que os parafusos auto-fixantes melhoraram a ancoragem da chapa de aço nas vigas reabilitadas, tal qual os conectores metálicos tipo 2 utilizados por REIS (1998). Além disso, tanto REIS (1998) quanto CAMPAGNOLO (1997) verificaram um aumento na rigidez das vigas reforçadas com chapa de aço em relação à peças similares sem chapa.

Observando os dados da literatura e os resultados dos testes realizados por REIS (1997) pode-se dizer que as vigas reabilitadas com chapas de aço fixadas por argamassa de alto desempenho e conectores metálicos funcionaram de forma tão eficientes quanto as vigas reabilitadas com chapas de aço coladas através de resina epóxi. Percebeu-se ainda que, para ambas as técnicas de reforço, é preciso tomar os mesmos cuidados em relação à ancoragem da chapa, para evitar ruína prematura gerada por problemas de aderência. Frente a semelhança de comportamento entre as peças reabilitadas por essas duas técnicas, acredita-se que os métodos de cálculo utilizados para dimensionar vigas reabilitadas com chapas de aço coladas com resina epóxi também possam ser aplicados para as vigas reabilitadas através de chapas de aço fixadas com argamassa. 


\section{CONCLUSÕES E PROPOSTAS DE TRABALHOS FUTUROS}

Tendo em vista as informações obtidas durante a elaboração desse trabalho pode-se chegar às seguintes conclusões:

- O modelo utilizado para prever os resultados experimentais utilizou uma redução da rigidez para tentar simular o comportamento da peça em função do aumento da fissuração. Esse modelo, que se baseava nas indicações da NBR-6118 e do ACI-318, não forneceu valores experimentais compatíveis com os teóricos para carregamentos elevados. Entretanto, isso já era esperado pois não se considerou, nos cálculos, o comportamento não-linear dos materiais e da estrutura.

- As vigas reforçadas por adição de armadura longitudinal envolvida por argamassa de alto desempenho sem adição de fibras de aço, apresentaram resistências últimas inferiores à de uma peça monolítica semelhante, armada de maneira convencional. Essa redução na capacidade portante ocorreu porque a adesão substrato/argamassa de reforço não foi suficiente para resistir às tensões tangenciais que apareceram na junta. $\mathrm{O}$ mesmo ocorreu nas vigas reabilitadas com chapas de aço fixadas só com conectores metálicos tipo 1 e argamassa de alto desempenho. Para as vigas das séries 2 e 3 não se observou esse tipo de problema, evidenciando que o uso de fibras de aço e dos conectores metálicos tipo 2 foram eficientes.

- Ao analisar o comportamento da VA-3, que atingiu a resistência estimada para uma peça monolítica similar, percebeu-se que o reforço por adição de armadura convencional encamisadas usando argamassa de alto desempenho com fibras de aço, pode ser uma boa alternativa. Isso porque as fibras de aço 
conseguiram, em parte, substituir a função das armaduras ou conectores transversais e promoveram uma melhor ligação entre a armadura adicionada e o banzo a ser reforçado. No caso da viga VA-2, também reabilitada utilizando argamassa com fibras de aço, observou-se uma resistência última baixa, que se justifica pelas falhas no comprimento de ancoragem da armadura do reforço.

- O reforço por meio de chapas de aço se mostrou eficiente quando foram soldados conectores metálicos tipo 2 na região da chapa solicitada aos esforços cortantes. O inconveniente desse tipo de conector reside na dificuldade, ainda não resolvida de modo plenamente satisfatório, de preparação dos nichos de ancoragem onde serão introduzidos esses elementos. $\mathrm{O}$ conector tipo 1 , mais simples, mostrou também uma certa eficiência, pois evitou o destacamento da chapa de aço da argamassa de reforço. Inicialmente, acreditava-se ser essa uma ligação mais crítica do que a ligação entre argamassa e substrato.

- Nas vigas onde se utilizou fibras de aço incorporadas na argamassa, ocorreu uma fissuração mais intensa, porém com aberturas menores mas não houve uma melhora aparente quanto à resistência à fissuração da peça. Além disso, a previsão da força de fissuração, tomando-se como base a resistência do material de reforço, ficou superestimada para todas as vigas ensaiadas, com exceção da VA-1. Diante desses fatores, acredita-se que o início da fissuração seja influenciado não só pela resistência do reforço mas também pela resistência do substrato, pela qualidade de aderência entre esses materiais e pelo tipo de traço utilizado na confecção de cada peça. Comportamento semelhante, em relação ao início da fissuração, também foi observado por outros pesquisadores.

- É extremamente importante garantir um comprimento de ancoragem mínimo nas vigas reabilitadas para evitar rupturas prematuras. Em relação às vigas reabilitadas através de chapas de aço, uma opção é usar dispositivos de aço semelhantes aos usados nas vigas da série 2 e 3 . Diante dos resultados experimentais, percebe-se que os conectores tipo 2, além de resistirem aos esforços tangenciais na junta, conseguem melhorar as condições de ancoragem da armadura do reforço. 
- As vigas da série 3, apesar de estarem pré-fissuradas antes da execução do reforço, apresentaram capacidade portante maiores que as demais. De acordo com outros pesquisadores, nem sempre a existência de uma pré-fissuração afeta, de maneira significativa, a resistência final da peça reabilitada. Todavia, o reparo de tais fissuras deve ser efetuado para não prejudicar a durabilidade final da estrutura.

- Apesar das vigas terem sido moldadas invertidas (bordo tracionado para cima), acredita-se que esse fator não interfere de maneira considerável no comportamento da estrutura reabilitada. CLÍMACO (1990) inclusive realizou ensaios de vigas moldadas tanto na posição invertida quanto na posição normal e não constatou diferenças relevantes entre o desempenho destas peças.

- Os conectores de aço tipo 2 mais solicitados foram os situados mais próximos do apoio. As deformações dos conectores na viga VC-2, que possuíam um comprimento de ancoragem deficiente, foram maiores que na VC-3. Sendo assim, percebe-se que estes elementos exerceram a função de transmitir esforços entre o reforço e o substrato e a função de ancorar a chapa na estrutura. Contudo, percebe-se a necessidade de estudos mais aprofundados para determinar a quantidade ideal de conectores metálicos, e as posições a partir das quais esses elementos não ajudam mais na transferência de esforços entre os diferentes materiais que constituem a peça composta.

- A comparação entre as flechas das vigas ensaiadas indicou uma maior rigidez para as peças reforçadas com chapas de aço, o que está de acordo com o observado por outros pesquisadores.

- As vigas mais rígidas foram justamente as pré-fissuradas. Acredita-se que esse comportamento tenha sido causado pela não consideração de eventuais flechas residuais e pela possível colmatação das fissuras antigas durante a execução do reforço.

- As armaduras longitudinais do reforço e do substrato trabalharam de forma satisfatória para todas as vigas já que as tensões existentes nessas armaduras foram proporcionais aos respectivos braços de alavanca. Esse fato também foi 
observado nos ensaios de SOUZA (1990), PIANCASTELLI (1997) e CLÍMACO (1990).

- De acordo com REIS (1998) e com outros pesquisadores, acredita-se ser possível obter uma aderência razoável entre concreto antigo e argamassa de reforço sem utilizar pontes de aderência nessa ligação.

- Através dos ensaios de PIANCASTELLI (1997) e REIS (1998), percebe-se que é possível solicitar vigas reabilitadas quando o material de reforço (argamassa ou concreto) ainda está "jovem".

- Analisando os ensaios de outros pesquisadores e de REIS (1998), constata-se que as regras vigentes utilizadas no dimensionamento de estruturas novas também podem ser aplicadas para se dimensionar peças reabilitadas mediante as técnicas de reforço estudadas. Contudo, deve-se usar coeficientes de segurança específicos, além dos já utilizados em construções novas, sempre observando os estados limites último e de utilização.

- A reabilitação de estruturas fletidas por meio de aumento da armadura tracionada envolvida por argamassa de alto desempenho ou por meio de fixação de chapas de aço é viável*, sendo necessário tomar as devidas providências para evitar a ruptura prematura.

- O reforço através de chapas de aço coladas com resina epóxi são, sem dúvida, mais simples de serem executados. Todavia, a possibilidade de substituir a resina pela argamassa, eliminaria muitos problemas gerados pela dificuldade em se determinar qual a formulação adequada da resina em função das características ambientais. Além disso, CAMPAGNOLO (1997) e ALFAIATE (1986) indicaram que mesmo as peças reforçadas com chapas de aço coladas com resina epóxi necessitam de dispositivos específicos de ancoragem. Isso acarretaria também trabalhos mais pesados de preparação de nichos de ancoragem em alguns trechos da viga. Outro inconveniente que seria eliminado ao substituir a resina pela argamassa é a preocupação com elevadas temperaturas que pode provocar a

\footnotetext{
* Neste trabalho não foi feito nenhum estudo da relação custo/benefício para os métodos de reabilitação propostos, indicando-se a viabilidade de tais técnicas com base apenas no comportamento estrutural da peça após a execução da intervenção.
} 
deterioração da resina e conseqüentemente a separação da chapa de aço do substrato.

- Observando os ensaios de outros pesquisadores constata-se uma certa semelhança entre o comportamento de vigas reforçadas com chapas de aço usando resina epóxi e usando argamassa e conectores metálicos. Portanto, acredita-se que os modelos de dimensionamento existentes para o primeiro tipo de reforço também possam ser aplicados para essa nova técnica estudada.

- Deve-se ressaltar que o estudo realizado por REIS (1998) indica apenas tendências de comportamento devido à pequena quantidade de ensaios realizados. Conseqüentemente, percebe-se a necessidade de se realizar ensaios e estudos mais específicos para se chegar ao conhecimento mais preciso do desempenho das vigas reforçadas por essas técnicas. Cabe salientar que, mesmo supondo um comportamento semelhante para outros tipos de vigas, os resultados aqui apresentados são específicos para vigas " $T$ ”, biapoiadas, submetidas a ação de curta duração com forças aplicadas nos terços do vão.

Diante da amplitude do tema sobre reforço de vigas, percebe-se a necessidade de estudos mais aprofundados para se estabelecer diretrizes mais precisas sobre o reprojeto de peças reabilitadas. A seguir são apresentadas algumas sugestões para pesquisas futuras que podem contribuir para o melhor conhecimento do comportamento destas peças.

- Análise dos efeitos de ações cíclicas e do processo de fadiga no comportamento da região recuperada e da estrutura de maneira geral.

- Estudo dos efeitos de ações já atuantes na peça (pré-carregamento) antes e durante a intervenção e das descontinuidades provocadas pela reabilitação nos estados de tensão e deformação da estrutura.

- Análise do desempenho de peças reabilitadas através de simulações numéricas baseadas no Método dos Elementos Finitos. Isto já tem sido feito por alguns pesquisadores apresentando resultados bastante satisfatórios quando se compara os resultados com dados experimentais. 
- Realização de ensaios específicos para avaliar a resistência da interface dos materiais (tração e compressão simples, cisalhamento direto e indireto), o estado duplo de tensões na peça e os critérios de resistência.

- Estudo do comportamento conjunto dos diferentes materiais que compõem a peça reabilitada e da influência do uso de concretos especiais como material de reforço.

- Realização de ensaios experimentais e simulações numéricas para analisar os efeitos de variações de temperatura, retração e fluência nos diferentes materiais do substrato e reforço e no comportamento da peça reabilitada de maneira geral.

- Identificação dos mecanismos de resistência e da transferência de esforços entre a região recuperada e o substrato através de investigação experimental e analítica do comportamento da interface concreto novo / concreto antigo, do uso de conectores metálicos ou da aplicação de pontes de aderência.

- Ampliar o estudo realizado através do ensaio de vigas submetidas a carregamentos de longa duração.

É importante ressaltar que nenhuma das duas técnicas de reabilitação estudadas no programa experimental desse trabalho são usuais. No caso do reforço por adição de barras de aço tracionadas e argamassa de alto desempenho não foram utilizados estribos para envolvê-las. Já para o reforço com chapas de aço, fixou-se esse elemento ao substrato por meio de argamassa e conectores metálicos ao invés de usar resinas epóxi (técnica tradicional). O que se pretendia com esses ensaios era ampliar o conhecimento a respeito do comportamento das peças reabilitadas devido a ação do momento fletor, estudando "novas técnicas de reabilitação" e desenvolvendo outros métodos para se garantir a transmissão de esforços entre a estrutura original e o reforço.

Finalmente, constatou-se que o estudo desenvolvido, apesar de não elucidar completamente todas as dúvidas sobre a reabilitação de vigas, forneceu informações interessantes que contribuíram, mesmo que de forma parcial, para o esclarecimento do comportamento de tais peças. 


\section{REFERÊNCIAS BIBLIOGRÁFICAS}

AHMAD, W.A. et. al. (1991). Method of Reabilitation of Structural Beam Elements Using Ferrocement. Journal of Ferrocement. v.21, n 3, July .

ALFAIATE, J. (1986). Reforço por adição de elementos metálicos em vigas de betão armado - flexão simples. Lisboa. Dissertação (Mestrado) - CMEST/IST, Portugal.

AMERICAN CONCRETE INSTITUTE (1994). ACI 318/1992 - Building Code Requirementes for Reinforced Concrete (revised 1992). Detroit, ACI.

AMERICAN CONCRETE INSTITUTE. Committee 544, (1987). Measurements of properties of fiber reinforced concrete - ACI Manual of Concrete Practice, v.5, Detroit, (ACI 544.2R-86).

AMERICAN IRON AND STEEL INSTITUTE (1986). AISI - Cold formed steel design manual. Washington D.C.

AMERICAN SOCIETY FOR TESTING AND MATERIALS - ASTM A 370-92 (1992) - Standard test methods and definitions for mechanical testing fo steel products. Philadelphia.

ARAÚJO, D.L. (1997). Cisalhamento na interface entre concreto pré-moldado e concreto moldado no local em elementos submetidos à flexão. São Carlos. Dissertação (Mestrado) - Escola de Engenharia de São Carlos, Universidade de São Paulo.

ARAÚJO, D.L. (1997). Cisalhamento na interface entre concreto pré-moldado e concreto moldado no local em vigas submetidas à flexão: comparação de valores teóricos e experimentais. In: XXVIII JORNADAS SUL-AMERICANAS DE ENGENHARIA ESTRUTURAL, São Carlos, SP, Brasil, setembro 01-05, 1997.

ASSOCIAÇÃO BRASILEIRA DE NORMAS TÉCNICAS (1978). NBR 6118 Projeto e execução de obras em concreto armado. Rio de Janeiro. 
ASSOCIAÇÃO BRASILEIRA DE NORMAS TÉCNICAS (1980). NBR 6152 Materiais metálicos: determinação das propriedades mecânicas à tração. Rio de Janeiro

ASSOCIAÇÃO BRASILEIRA DE NORMAS TÉCNICAS (1986). NBR 8800 Projeto e execução de estruturas de aço de edifícios. Rio de Janeiro.

ASSOCIAÇÃO BRASILEIRA DE NORMAS TÉCNICAS (1987). NBR 7197 Projeto de estruturas em concreto protendido. Rio de Janeiro.

BASUNBUL, I.A. et. al. (1990) Repaired Reinforced Concrete Beams. ACI Materials Journal. v.87, nº 4, p.348-354, July-Aug. 1990.

CAMPAGNOLO, J.L, CAMPOS FILHO, A. \& SILVA FILHO, L.C.P. (1993). Estudo do comportamento estrutural e do problema de ancoragem em vigas de concreto armado reforçadas com chapas de aço coladas. In: XXVI JORNADAS SUDAMERICANAS DE INGENIERIA ESTRUCTURAL. Montevideu, Uruguay, novembro 15-19, 1993.

CAMPAGNOLO, J.L; CAMPOS FILHO, A.; SILVA FILHO, L.C.P. (1997). Alternativas para reforço de vigas de concreto armado: estudo teórico e experimental. In: XXVIII JORNADAS SUL-AMERICANAS DE ENGENHARIA ESTRUTURAL, São Carlos, SP, Brasil, setembro 01-05, 1997.

CANADIAN STANDARDS ASSOCIATION - CSA (1984). CAN3-.S161-M84 Steel structures for buildings (limit states design). Toronto, Canadá.

CÁNOVAS, M.F.(1988). Patologia e Terapia do Concreto Armado. São Paulo, Pini.

CLÍMACO, J.C.T. (1990). Repair of Structural Concrete Involving the Addition of New Concrete, Londres, Tese (Doutorado)-Polytechnic of Central London, U.K.

CLÍMACO, J.C.T. (1991). Uma análise crítica dos métodos de avaliação de aderência e do uso de agentes adesivos no reparo de estruturas de concreto. In: XXV JORNADAS SUL-AMERICANAS DE ENGENHARIA ESTRUTURAL. Porto Alegre, RS, Brasil, novembro 11-15, 1991.

CLÍMACO, J.C.T. (1995). Reforço à flexão de vigas de concreto armado envolvendo $a$ adição de concreto novo. In: XXVII JORNADAS SUDAMERICANAS DE INGENIERIA ESTRUCTURAL. Tucumán, Argentina, setembro 18-22, 1995.

COMMITE EURO-INTERNATIONAL DU BETON. CEB (1983), Assessment of concrete estructures and design procedures for upgrading (redesign), Bulletin d'Information $\mathrm{n}^{\circ} .162$. 
COMMITE EURO-INTERNATIONAL DU BETON. CEB(1983), Response of critical regions under large amplitude reserved action. Bulletin d'Information $\mathrm{n}^{\circ}$ 161.

HELENE, P.R.L. (1992). Manual para Reparo, Reforço e Proteção de Estruturas de Concreto. São Paulo, Pini.

LEONHARDT, F. \& MÖNNIG, E. (1977). Construções de concreto. Rio de Janeiro. Interciência. v.1.

MEHTA, P.K.; MONTEIRO, P.J.M.(1994). Concreto: estrutura, propriedades e materiais, São Paulo, Pini.

MORAIS, M. C. (1997). Reforço de vigas de concreto. Rio de Janeiro, Dissertação (Mestrado) - COPPE, Universidade Federal do Rio de Janeiro.

NUNES, N.L.; TANESI, J.; FIGUEIREDO, A.D. (1997). Aplicação do concreto reforçado com fibras de aço na recuperação de estruturas e pavimentos. In: IV CONCRESSO IBEROAMERICANO DE PATOLOGIA DAS CONSTUÇÕES E VI CONGRESSO DE CONTROLE DE QUALIDADE. Porto Alegre, RS, Brasil, outubro 21-24, 1997.

ONG,K.C.G.; PARAMASIVAM, K.C.G.; LIM,C.T.E. (1992) Flexural Strengthening of Reinforced Concrete Beams.Using Ferrocement Laminates. Journal of Ferrocement. v.22, no 4, p.331-342.

PARAMASIVAM, K.C.G.; LIM,C.T.E. (1994) Ferrocement Laminates for Strengthening RC T-Beams. Cement \& Concrete Composites v.16, p.143-52.

PEREIRA, J.P. (1997). Simulação numérica e experimental para análise do comportamento conjunto dos materiais em reparos de estruturas de concreto. São Carlos, Escola de Engenharia de São Carlos, Universidade de São Paulo / , Dissertação em andamento.

PIANCASTELLI, E.M.; CALIXTO, J.M.F. (1995). Comportamento estrutura, a baixa idade, de vigas de concrreto armado reforçadas através do aumento das seções de concreto e aço. In: XXVII JORNADAS SUDAMERICANAS DE INGENIERIA ESTRUCTURAL. Tucumán, Argentina, setembro 18-22, 1995.

PIANCASTELLI, E.M.; CALIXTO, J.M.F. (1997). Dimensionamento de reforço à flexão, executado sob carga, de vigas de concreto armado: aplicabilidade dos critérios da NBR-6118. In: XXVIII JORNADAS SUL-AMERICANAS DE ENGENHARIA ESTRUTURAL, São Carlos, SP, Brasil, setembro 01-05, 1997.

PINHEIRO, L.M.; GIONGO, J.S. (1986). Concreto Armado: propriedades dos materiais. Publicação no 018/95, São Carlos, Escola da Engenharia de São Carlos, Universidade de São Paulo. São Paulo. 
ROCHA, C.C (1997). Durabilidade - Palavra bonita mas muito pouco compreendida. Recuperar, p. 28-34. março/abril.

RODRIGUES, F.L. (1996). Estudo do dimensionamento do reforço por encamisamento aplicado a vigas de concreto armado. Rio de Janeiro, Dissertação (Mestrado). UFF, Universidade Federal Fluminense.

RODRIGUES, J. C. (1994). Chapa Colada - o reforço estrutural limpo e econômico. Recuperar, p. 7-10. setembro/outubro.

SAIIDI, M.; VRONTINOS, S. ; DOUGLAS; B.(1990) Model for the response of reinforced concrete beams strengthened by concrete overlays. ACI Structural Journal. v. $87, \mathrm{n}^{\mathrm{o}} 6$, nov/dez.

SHARMA, A.K.(1992). Test of Reinforced Concrete Continuous Beams Repair with and without Fibro-Concrete. Concrete International. mar.

SILVEIRA, S.S. (1997). Dimensionamento de vigas de concreto armado reforçadas com chapas de aço coladas com resina epoxi. Rio de Janeiro, Dissertação (Mestrado). UFF, Universidade Federal Fluminense.

SOUZA, R.H.F. (1990). Análise do Comportamento de vigas de betão armado reforçadas à flexão e ao esforço transverso. Lisboa, Tese (Doutorado) Universidade Técnica de Lisboa.

SOUZA, M.T. (1991). Clínica Geral: erros de projeto, execução, materiais, uso. Vale tudo. Construção, p. 4 - 8, São Paulo, n²277, v.30, setembro, 1991.

VANDERLEI, E.; CLÍMACO, J.C.T. (1996). Reparo de pilares de concreto armado com remoldagem d seção transversal. In: REUNIÃO DO IBRACOM, 38., Ribeirão Preto, 19-23 agosto 1996. Anais. São Paulo, IBRACON,1996. v.1., p.203-216.

TIMOSHENKO \& GERE (1984). Mecânica dos Sólidos. Rio de Janeiro., Livros Técnicos e Científicos. v.1. $1^{\mathrm{a}}$ edição.

TOTTI JR.; GIONGO, I.S. (1994). Concreto Armado: Resistência de Elementos Fletidos Submetidos à Força Cortante. Publicação no 014/95, São Carlos, Escola de Engenharia de São Carlos - Universidade de São Paulo.

ZIRABA, Y.N. et al.(1994). Guidelines toward the design of reinforced concrete beams with external plates. ACI Structural Journal. v.91. $\mathrm{n}^{\circ}$ 6. p.639-646. nov/dec. 


\section{BIBLIOGRAFIA}

AGUADO, A; AGULLÓ,L.; SALLA, L.M. (1996). Diagnóstico de dãnos y reparación de obras hidráulicas de hormigón. Madri , Colégio de Ingenieros de Caminos, Canales y Puertos.

ALVES, J. D. (1996). Avaliação e reabilitação de estruturas de concreto, In: REUNIÃO DO IBRACOM, 38., Ribeirão Preto, 19-23 agosto 1996. Anais. São Paulo, IBRACON,1996. v.1, p.153-161.

AZEVEDO, M.T. Técnicas de Recuperação de Estruturas. Salvador, Universidade Católica de Salvador. (apostila da disciplina "Materiais de Construção")

BRAGUIM, J.R. Reabilitação de estruturas: apresentação de um caso, In: REUNIÃO DO IBRACOM, 38., Ribeirão Preto, 19-23 agosto 1996. Anais. São Paulo, IBRACON,1996. v.1, p.271-286.

CAMPAGNOLO, J.L.; FILHO,A.C. \& FILHO, L.C.P.S. (1996), Estudo de peças fletidas de concreto armado com armadura exposta. In: REUNIÃO DO IBRACOM, 38., Ribeirão Preto, 19-23 agosto 1996. Anais. São Paulo, IBRACON,1996. v.1, p.131-143.

CUNHA, A.J.P.C ; LIMA, N.A; SOUZA, V.C.M. (1996). Acidentes Estruturais na Construção Civil. São Paulo, $1^{\text {a }}$ edição, Pini.

CUSSON, D.; MAILVAGANAM, N.(1996) Durability of repair materials. Concrete Internacional. v.18, n.3, p.34-38, mar.

DANTAS,F.A.S.; OLIVEIRA,I.L.O; SILVA,E. \& YANAGIHARA,C.T. (1996). Reparos em estruturas de concreto: estudo de caso envolvendo materiais e processos de aplicação., In: REUNIÃO DO IBRACOM, 38., Ribeirão Preto, 1923 agosto 1996. Anais. São Paulo, IBRACON,1996. v.1, p.245-255.

FERNANDEZ, M.C.L. (1997). Reforço de vigas T com estribos externos prétracionados. Rio de Janeiro, Dissertação (Mestrado) - COPPE, Universidade Federal do Rio de Janeiro. 
NEVILle, A.M, (1982). Propriedades do Concreto. Tradução por Salvador Giammusso. São Paulo, Pini

OLIVEIRA, P.S.F. (1987). Reforços, reparos e proteção das estruturas de concreto. In: SIMPÓSIO NACIONAL DE TECNOLOGIA DA CONSTRUÇÃO. São Paulo, 1987. Anais. São Paulo, EPUSP.

ROCHA, C.C (1995). Compatibilizando o novo material com o local da recuperação. Recuperar, $\mathrm{n}^{\circ}$ 6. p 23-25. jul/ago.

ROCHA, C.C (1996). Compatibilidade. Recuperar, p 22-26. nº 11. maio/jun.

TEIXEIRA JUNIOR, S.V.(1994). Reparos de vigas de concreto armado em cisalhamento. Rio de Janeiro, Dissertação (Mestrado). COPPE, Universidade Federal do Rio de Janeiro.

TOMAZ, E.(1989). Trincas em Edifícios - Causas, Prevenção e recuperação. São Paulo, $1^{a}$ edição, Pini.

VASAN, R.M.;KAUSHIK, S.K.; SINGH, G.; (1991). Performance Evaluation fo Ferro-Fibrocrete Composite overlays. Journal of Ferrocement. v.21, $\mathrm{n}^{\mathrm{o}} 3$, july. 


\section{Apêndice I : Análise teórica para previsão do comportamento das vigas ensaiadas}

\section{I.1. Hipóteses de Cálculo}

Para prever o comportamento das estruturas ensaiadas foram calculados vários parâmetros tais como: momento de fissuração, momento de ruptura, deformações das armaduras e conectores, deformações do concreto e deslocamentos verticais. Esta previsão foi feita admitindo-se comportamento entre o estádio I (concreto não fissurado) e estádio II (concreto fissurado). Na realidade, a seção onde aparece a fissura encontra-se no estádio II e à medida que se afasta da seção fissurada, o comportamento aproxima-se do estádio I, uma vez que o concreto retoma a capacidade de absorver o esforço de tração, configurando, deste modo, uma situação intermediária entre os dois estádios.

Desta forma, quando o momento atuante for menor que o momento fletor de fissuração, supõe-se que a peça esteja trabalhando no estádio I. Nos casos em que o momento fletor atuante supera o momento fletor de fissuração, utiliza-se uma inércia equivalente $I_{e}$, situada entre a inércia do estádio I e a inércia do estádio II, obtida através da expressão empírica (Fórmula de Branson) fornecida pelo ACI 318 (1992).

$$
\mathrm{I}_{\mathrm{e}}=\left(\frac{\mathrm{M}_{\mathrm{r}}}{\mathrm{M}}\right)^{3} \cdot \mathrm{I}_{\mathrm{I}}+\left[1-\left(\frac{\mathrm{M}_{\mathrm{r}}}{\mathrm{M}}\right)^{3}\right] \cdot \mathrm{I}_{\mathrm{II}}<\mathrm{I}_{\mathrm{I}}
$$

onde:

$\mathrm{M}_{\mathrm{r}}$ - momento de fissuração; 
M - momento aplicado;

$\mathrm{I}_{\mathrm{I}}$ - momento de inércia referente ao estádio I;

III - momento de inércia referente ao estádio II.

Para cada carregamento aplicado existe um momento de inércia equivalente e, conseqüentemente, uma posição da linha neutra. Baseando-se também na fórmula de Branson, calcula-se o valor da posição da linha neutra equivalente, $\mathrm{x}_{\mathrm{e}}$, conforme equação a seguir:

$$
\mathrm{x}_{\mathrm{e}}=\left(\frac{\mathrm{M}_{\mathrm{r}}}{\mathrm{M}}\right)^{2,5} \cdot \mathrm{x}_{\mathrm{I}}+\left[1-\left(\frac{\mathrm{M}_{\mathrm{r}}}{\mathrm{M}}\right)^{2,5}\right] \cdot \mathrm{x}_{\mathrm{II}}<\mathrm{x}_{\mathrm{I}}
$$

onde: $\quad \mathrm{x}_{\mathrm{I}}$ - Posição da linha neutra para estádio I;

$\mathrm{X}_{\mathrm{II}}$ - Posição da linha neutra para estádio II.

É importante esclarecer que, para essa análise teórica, os coeficientes de segurança foram admitidos iguais à unidade, pois se pretendia levar a peça à ruína.

Neste trabalho admitiu-se ainda como hipóteses de cálculo:

1. concreto fissurado não resiste a tração;

2. seções planas se mantêm planas após as deformações (hipótese de Bernoulli);

3. os materiais tem comportamento linear;

4. não há escorregamento da armadura com o concreto/argamassa;

5. a ligação reforço/concreto foi considerada ideal;

6. desprezou-se eventuais efeitos de assimetria que podem ocorrer no ensaio.

\section{I.2. Força de Fissuração}

O cálculo do momento de fissuração se baseou no item 1.1.2 do Anexo da NBR-7197. A notação dos parâmetros utilizados no cálculo do momento de inércia e da linha neutra estão indicados na Figura I.1. 


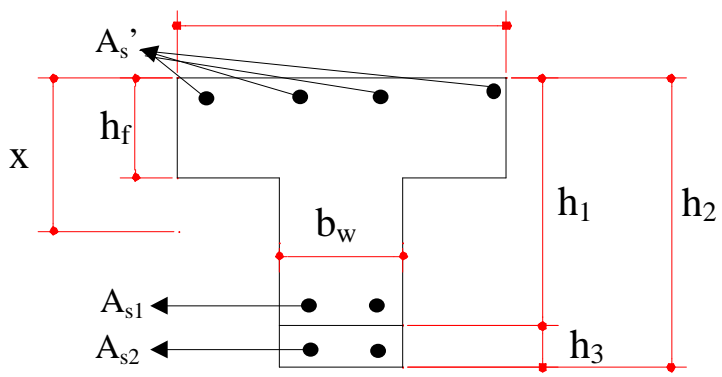

\section{Figura I.1 - Notação das características geométricas da seção transversal}

Para possibilitar a aplicação das hipóteses da Teoria Clássica da Resistência dos Materiais às peças de concreto armado, transformou-se a seção heterogênea de concreto e aço em uma seção homogênea. Esta homogeneização foi feita no cálculo dos momentos de inércia e da linha neutra. Como a viga também apresentava concretos com resistências diferentes por causa do material de reforço adicionado no bordo inferior da viga, fez-se também uma homogeneização em relação ao concreto, conforme recomenda TIMOSHENKO e GERE (1984) para seções compostas. Para isso, determinou-se o coeficiente $\alpha_{\mathrm{e}}$ que é a relação entre os módulos de elasticidade do aço e do concreto (ver equação I.3). Como esse parâmetro foi utilizado na determinação do momento de fissuração, utilizou-se o módulo de elasticidade tangente do concreto, uma vez que nesse caso, as tensões no concreto são relativamente baixas.

Para realizar a homogeneização entre os concretos do reforço e do substrato, calculou-se o coeficiente $\alpha_{c}$ (ver equação I.4). Neste cálculo, utilizou-se os módulos de elasticidade tangente, pois o concreto do reforço só vai contribuir na resistência da peça antes de ocorrer a fissuração.

$$
\begin{aligned}
& \alpha_{\mathrm{e}}=\mathrm{E}_{\mathrm{s}} / \mathrm{E}_{\mathrm{cos}} \\
& \alpha_{\mathrm{c}}=\mathrm{E}_{\mathrm{cor}} / \mathrm{E}_{\mathrm{cos}}
\end{aligned}
$$

onde:

$\mathrm{E}_{\mathrm{s}}$ - Módulo de elasticidade do aço;

$\mathrm{E}_{\mathrm{cos}}$ - Módulo de elasticidade tangente do substrato;

$\mathrm{E}_{\mathrm{cor}}$ - Módulo de elasticidade tangente do reforço. 
A linha neutra para o estádio I, x $x_{\mathrm{I}}$, é determinada em função das características geométricas da seção transversal, fazendo o momento estático da seção homogeneizada em relação à linha neutra igual a zero.

$$
\begin{gathered}
m_{\mathrm{s}}=0 \\
\left(\mathrm{~b}_{\mathrm{f}} \cdot \mathrm{h}_{\mathrm{f}}\right)\left(\mathrm{x}_{\mathrm{I}}-\frac{\mathrm{h}_{\mathrm{f}}}{2}\right)+\mathrm{b}_{\mathrm{w}} \frac{\left(\mathrm{x}_{\mathrm{I}}-\mathrm{h}_{\mathrm{f}}\right)^{2}}{2}-\mathrm{b}_{\mathrm{w}} \frac{\left(\mathrm{h}_{1}-\mathrm{x}_{\mathrm{I}}\right)^{2}}{2}+\alpha_{e 1}\left(\mathrm{~A}_{\mathrm{s}}^{\prime}\left(\mathrm{x}_{\mathrm{I}}-\mathrm{d}^{\prime}\right)-\mathrm{A}_{\mathrm{s} 1}\left(\mathrm{~d}_{1}-\mathrm{x}_{\mathrm{I}}\right)-\mathrm{A}_{\mathrm{s} 2}\left(\mathrm{~d}_{2}-\mathrm{x}_{\mathrm{I}}\right)\right)- \\
-\alpha_{\mathrm{c}} \cdot \mathrm{b}_{\mathrm{w}} \cdot \mathrm{h}_{3}\left(\mathrm{~h}_{2}-\mathrm{x}_{\mathrm{I}}-\mathrm{h}_{3} / 2\right)=0
\end{gathered}
$$

Para o cálculo do momento de inércia no estádio I, levou-se em consideração, a existência das áreas de aço dispostas tanto na região comprimida quanto na região tracionada.

$$
\begin{aligned}
& \mathrm{I}_{\mathrm{I}}=\left(\frac{\mathrm{b}_{\mathrm{f}} \cdot \mathrm{h}_{\mathrm{f}}^{3}}{12}\right)+\mathrm{b}_{\mathrm{f}} \cdot \mathrm{h}_{\mathrm{f}} \cdot\left(\mathrm{x}_{\mathrm{I}}-\frac{\mathrm{h}_{\mathrm{f}}}{2}\right)^{2}+\frac{\mathrm{b}_{\mathrm{w}} \cdot\left(\mathrm{h}_{1}-\mathrm{h}_{\mathrm{f}}\right)^{3}}{12}+\mathrm{b}_{\mathrm{w}} \cdot\left(\mathrm{h}_{1}-\mathrm{h}_{\mathrm{f}}\right)\left(\frac{\mathrm{h}_{1}-\mathrm{h}_{\mathrm{f}}}{2}-\mathrm{x}_{\mathrm{I}}+\mathrm{h}_{\mathrm{f}}\right)^{2}+\alpha_{e 1}\left[\mathrm{~A}_{\mathrm{s}}\left(\mathrm{x}_{\mathrm{I}}-\mathrm{d}^{\prime}\right)^{2}+\right. \\
& \left.+\mathrm{A}_{\mathrm{s} 1}\left(\mathrm{~d}_{1}-\mathrm{x}_{\mathrm{I}}\right)^{2}+\mathrm{A}_{\mathrm{s} 2}\left(\mathrm{~d}_{2}-\mathrm{x}_{\mathrm{I}}\right)^{2}\right]+\alpha_{c}\left[\left(\frac{\mathrm{b}_{\mathrm{w}} \cdot \mathrm{h}_{3}{ }^{3}}{12}\right)+\mathrm{b}_{\mathrm{w}} \cdot \mathrm{h}_{3} \cdot\left(\mathrm{h}_{2}-\frac{\mathrm{h}_{3}}{2}-\mathrm{x}_{\mathrm{I}}\right)^{2}\right]
\end{aligned}
$$

Obtido os valores da linha neutra, $\mathrm{x}_{\mathrm{I}}$, e do momento de inércia, $\mathrm{I}_{\mathrm{I}}$, determinase, segundo a NBR-7197 (1989), o momento de fissuração através da equação I.7.

$$
\mathrm{M}_{\mathrm{r}}=\frac{\mathrm{f}_{c t m} \cdot \mathrm{I}_{1}}{\mathrm{~h}-\mathrm{x}_{\mathrm{I}}}
$$

onde:

$\mathrm{f}_{\mathrm{ctm}}$ - resistência do concreto à tração na flexão, dada pela equação (I.8);

$f_{t}$ - resistência do concreto à tração.

$$
\mathrm{f}_{\mathrm{ctm}}=1,2 \cdot \mathrm{f}_{\mathrm{t}}
$$

Daí tem-se: $\quad \mathrm{M}_{\mathrm{r}}=$ momento de fissuração; 


$$
\mathrm{F}_{\mathrm{r}}=\mathrm{M}_{\mathrm{r}} / \mathrm{a}=\text { força de fissuração. }
$$

sendo "a" igual a distância do ponto de aplicação da força até o apoio que é de $1 \mathrm{~m}$ para o caso das vigas ensaiadas por REIS (1998).

\section{I.3. Força Máxima Aplicada}

Para obtenção da força máxima adota-se como hipóteses de cálculo, o estádio III e domínio 2 de deformações (ver Figura I.2) uma vez que as peças ensaiadas foram projetadas para atingir o colapso por deformação plástica excessiva da armadura longitudinal. De acordo com estas hipóteses, tem-se os seguintes limites para as tensões e deformações no aço e no concreto:
a) Tensões:

$$
\begin{aligned}
& \sigma_{\mathrm{s}}=\mathrm{f}_{\mathrm{y}} \\
& \sigma_{\mathrm{c}}{ }^{*} \leq \mathrm{f}_{\mathrm{c}}
\end{aligned}
$$$$
\text { (aço) }
$$$$
\text { (concreto) }
$$
b) Deformações

$$
\begin{aligned}
& \varepsilon_{\mathrm{s}}=10 \% \\
& \varepsilon_{\mathrm{c}}<3,5 \% 0
\end{aligned}
$$$$
\text { (aço) }
$$$$
\text { (concreto) }
$$

Como não se sabe o valor exato da tensão do concreto $\sigma_{\mathrm{c}}$ no instante da ruptura, adota-se inicialmente um valor $\sigma_{\mathrm{c}}{ }^{*}$ menor que a resistência à compressão do concreto $\mathrm{f}_{\mathrm{c}}$. Através deste valor estimado, calcula-se a posição da linha neutra por equilíbrio de forças internas na seção (ver equação I.9), verificando se as deformações na armadura e no concreto enquadram-se dentro dos limites preestabelecidos anteriormente. Caso as deformações estejam coerentes, é possível encontrar o valor do momento fletor máximo que a peça suporta, multiplicando-se o braço de alavanca, calculado através da posição da linha neutra, pela tensão existente no aço ou no concreto. Se os valores das deformações não forem compatíveis, faz-se novas iterações até que se encontre um valor para $\sigma_{\mathrm{c}}{ }^{*}$ que atenda aos limites das hipóteses de cálculo adotadas. 

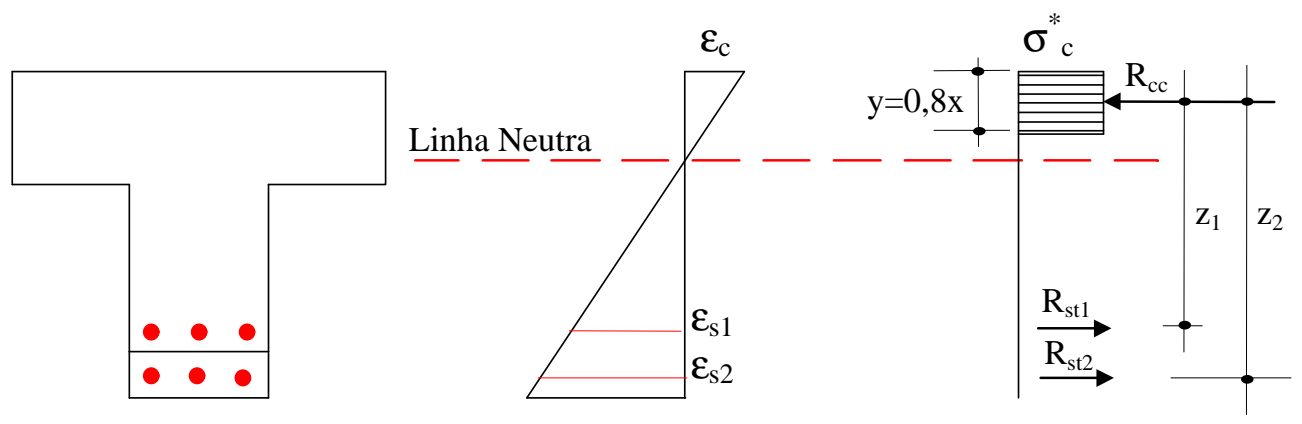

Figura I.2 - Hipóteses de cálculo para estádio III e domínio 2

Para determinar a linha neutra da seção, supõe-se que y $<12$, portanto tem-se como área de concreto resistente à compressão somente uma parcela da mesa.

$$
\begin{aligned}
& \mathrm{R}_{\mathrm{st} 1}+\mathrm{R}_{\mathrm{st} 2}=\mathrm{R}_{\mathrm{cc}} \\
& \mathrm{A}_{\mathrm{s} 1} \cdot \sigma_{\mathrm{s} 1}+\mathrm{A}_{\mathrm{s} 2} \cdot \sigma_{\mathrm{s} 2}=\mathrm{A}_{\mathrm{c}} \cdot \sigma_{\mathrm{c}}{ }^{*} \\
& \mathrm{~A}_{\mathrm{s} 1} \cdot \sigma_{\mathrm{s} 1}+\mathrm{A}_{\mathrm{s} 2} \cdot \sigma_{\mathrm{s} 2}=\mathrm{y} \cdot \mathrm{b}_{\mathrm{f}} \cdot \sigma_{\mathrm{c}}{ }^{*} \\
& \mathrm{y}=\left(\mathrm{A}_{\mathrm{s} 1} \cdot \sigma_{\mathrm{s} 1}+\mathrm{A}_{\mathrm{s} 2} \cdot \sigma_{\mathrm{s} 2}\right) /\left(\mathrm{b}_{\mathrm{f}} \cdot \sigma_{\mathrm{c}}{ }^{*}\right)
\end{aligned}
$$

onde:

$\mathrm{R}_{\mathrm{st}}$ - resistência ao escoamento do aço;

$\mathrm{R}_{\mathrm{cc}}$ - resistência à compressão do concreto;

$\mathrm{A}_{\mathrm{s} 1}$ - área de aço do substrato;

$\mathrm{A}_{\mathrm{s} 2}$ - área de aço do reforço;

$\sigma_{\mathrm{s} 1}$ - tensão de escoamento do aço do substrato;

$\sigma_{\mathrm{s} 2}$ - tensão de escoamento do aço do reforço;

$\mathrm{A}_{\mathrm{c}}$ - área de concreto comprimido;

$\sigma_{\mathrm{c}}{ }^{*}$ - estimativa da tensão de compressão do concreto .

Como está sendo admitido o diagrama retangular de tensões para o concreto, o valor da linha neutra é dado por: $\mathrm{x}=\mathrm{y} / 0,8$ 
Para verificar se a tensão de compressão inicialmente adotada é realmente aquela atuante no concreto, utiliza-se as equações de compatibilidade:

$$
\begin{aligned}
& \varepsilon_{\mathrm{c} 1}=\varepsilon_{\mathrm{s} 1} \cdot \frac{\mathrm{x}}{\mathrm{d}_{1}-\mathrm{x}} \\
& \varepsilon_{\mathrm{c} 2}=\varepsilon_{\mathrm{s} 2} \cdot \frac{\mathrm{x}}{\mathrm{d}_{2}-\mathrm{x}}
\end{aligned}
$$

onde:

$\mathrm{d}_{1}=$ altura útil da armadura do substrato;

$\mathrm{d}_{2}=$ altura útil da armadura do reforço;

$\varepsilon_{\mathrm{c} 1}=$ deformação do concreto em relação a armadura situada no substrato;

$\varepsilon_{\mathrm{c} 2}=$ deformação do concreto em relação a armadura situada no reforço;

$\varepsilon_{\mathrm{s} 1}=$ deformação da armadura do substrato;

$\varepsilon_{\mathrm{s} 2}=$ deformação da armadura do reforço.

Se a deformação do concreto for menor que 3,5\%o e estiver de acordo com a curva do gráfico tensão x deformação ilustrado na Figura 2.7, a tensão estimada $\sigma_{\mathrm{c}}{ }^{*}$ está coerente com a hipótese inicial adotada (domínio 2). Sendo assim, obtém-se a força máxima que a viga suporta igualando o momento máximo resistente da peça ao momento gerado tanto pela força de compressão no concreto quanto pela força de tração no aço. Para isso, determina-se o centro de gravidade da área de concreto que resiste à compressão e, a partir da altura útil, calcula-se o braço de alavanca $\mathrm{z}$.

$$
\begin{array}{ll}
\text { Centro de gravidade: } & \mathrm{y}_{\mathrm{CG}}=\mathrm{y} / 2 \\
\text { Braço de alavanca: } & \mathrm{z}_{1}=\mathrm{d}_{1}-\mathrm{y}_{\mathrm{CG}} \\
& \mathrm{z}_{2}=\mathrm{d}_{2}-\mathrm{y}_{\mathrm{CG}}
\end{array}
$$

O momento máximo a que a peça resiste e a força máxima a ser aplicada são obtidos através das equações I.12 e I.13 respectivamente. 


$$
\begin{aligned}
& M_{\text {máx }}=R_{\mathrm{s} 1} \cdot z_{1}+R_{\mathrm{s} 2} \cdot z_{1} \\
& F_{\text {máx }}=M_{\text {máx }} / a
\end{aligned}
$$

onde: $\mathrm{a}=$ distância do ponto de aplicação da força vertical até o apoio.

\section{I.4. Deformações no concreto e nas armaduras}

O cálculo das deformações antes da ocorrência da fissuração foi realizado admitindo-se regime elástico-linear (estádio I). Para essa situação, admitem-se tensões variando linearmente ao longo da seção transversal da peça, como ilustra a Figura I.3a. Para os valores de carregamento superiores a força de fissuração, as considerações de cálculo admitidas referem-se ao comportamento da peça no estádio II. Tais hipóteses podem ser visualizadas através da Figura I.3b.

Para determinar o valor do momento de inércia no estádio II, determinar-se inicialmente a posição da linha neutra, fazendo o momento estático em relação à ela igual a zero e desprezando a contribuição do concreto tracionado. Como as tensões no concreto para o estádio II são significativas, utiliza-se, no cálculo de $\alpha_{\mathrm{e}}$, o módulo de elasticidade secante do substrato. Supondo que a linha neutra seja menor do que $12 \mathrm{~cm}$, calcula-se $\mathrm{x}_{\text {II }}$ pela expressão I.14.

$$
\begin{gathered}
m_{\mathrm{s}}=0 \\
\mathrm{~b}_{\mathrm{f}} \cdot \frac{\mathrm{x}_{\mathrm{II}}^{2}}{2}+\alpha_{e 2} \cdot\left[\mathrm{A}_{\mathrm{s}}^{\prime}\left(\mathrm{x}_{\mathrm{II}}-\mathrm{d}^{\prime}\right)-\mathrm{A}_{\mathrm{s} 1}\left(\mathrm{~d}_{1}-\mathrm{x}_{\mathrm{II}}\right)-\mathrm{A}_{\mathrm{s} 2}\left(\mathrm{~d}_{2}-\mathrm{x}_{\mathrm{II}}\right)\right]=0
\end{gathered}
$$

O momento de inércia para o estádio II é obtido pela expressão (I.15):

$$
\mathrm{I}_{\mathrm{II}}=\left(\frac{\mathrm{b}_{\mathrm{f}} \cdot \mathrm{x}_{\mathrm{II}}^{3}}{12}\right)+\mathrm{b}_{\mathrm{f}} \cdot \mathrm{x}_{\mathrm{II}}\left(\frac{\mathrm{x}_{\mathrm{II}}}{2}\right)^{2}+\alpha_{e 2} \cdot\left[\mathrm{A}_{\mathrm{s}}^{\prime}\left(\mathrm{x}_{\mathrm{II}}-\mathrm{d}^{\prime}\right)^{2}+\mathrm{A}_{\mathrm{s} 1}\left(\mathrm{~d}_{1}-\mathrm{x}_{\mathrm{II}}\right)^{2}+\mathrm{A}_{\mathrm{s} 2}\left(\mathrm{~d}_{2}-\mathrm{x}_{\mathrm{II}}\right)^{2}\right]
$$




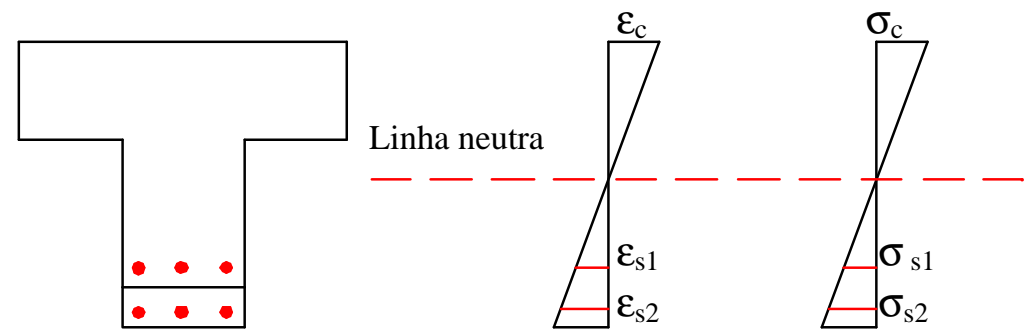

(a) estádio I

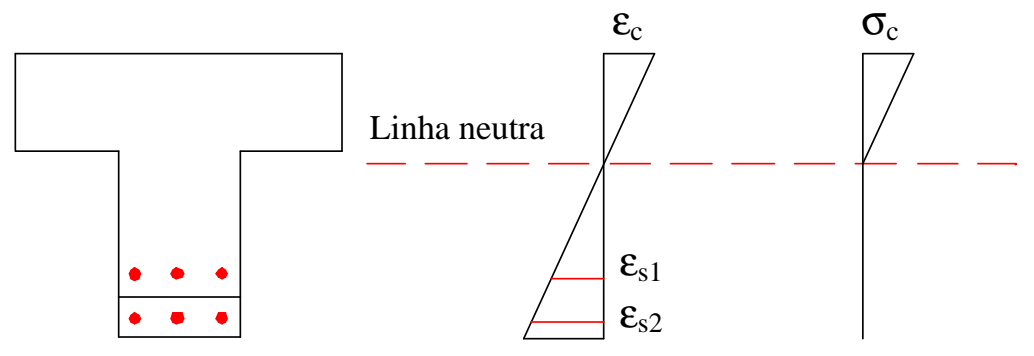

(b) estádio II

Figura I.3 - Diagrama de deformações e tensões no estádio I e II

As tensões na seção transversal de concreto são definidas por:

$$
\sigma_{c}=-\frac{\mathrm{M}}{\mathrm{I}} \cdot \mathrm{y}
$$

OBS.: O sinal negativo indica que a tensão é de compressão.

Admitindo-se a validade da Lei de Hooke, determina-se a deformação no concreto por:

$$
\varepsilon_{\mathrm{c}}=\frac{\sigma_{c}}{\mathrm{E}_{c}^{\prime}}=\frac{\mathrm{M}}{\mathrm{E}_{\mathrm{c}}^{\prime} \cdot \mathrm{I}^{*}} \cdot \mathrm{y}
$$

As deformações no aço foram obtidas através da equação de compatibilidade de deformações dada por:

$$
\frac{\varepsilon_{\mathrm{s}}}{\mathrm{d}-\mathrm{x}}=\frac{\varepsilon_{\mathrm{c}}}{\mathrm{x}} \Rightarrow\left\{\begin{aligned}
\frac{\varepsilon_{\mathrm{s} 1}}{\mathrm{~d}_{1}-\mathrm{x}}=\frac{\varepsilon_{\mathrm{c}}}{\mathrm{x}} \\
\frac{\varepsilon_{\mathrm{s} 2}}{\mathrm{~d}_{2}-\mathrm{x}}=\frac{\varepsilon_{\mathrm{c}}}{\mathrm{x}}
\end{aligned}\right.
$$


onde:

$\varepsilon_{\mathrm{s} 1}=$ deformação na armadura longitudinal situada no substrato;

$\varepsilon_{\mathrm{s} 2}=$ deformação na armadura longitudinal situada no reforço;

$\varepsilon_{\mathrm{c}}=$ deformação do concreto na região comprimida;

y = distância vertical até o ponto da seção onde se deseja calcular a tensão.

$\mathrm{E}_{c}^{\prime}=\left\{\begin{array}{l}\mathrm{E}_{\mathrm{co}}=\text { módulo de elasticidade tangente (antes da fissuração) } \\ \mathrm{E}_{\mathrm{c}}=\text { módulo de elasticidade secante (após da fissuração) }\end{array}\right.$

$I^{*}=\left\{\begin{array}{l}I_{I}=\text { Momento de inércia no estádio I } \\ I_{\mathrm{II}}=\text { Momento de inércia no estádio II } \\ I_{\mathrm{e}}=\text { variável }\end{array}\right.$

Para determinar as deformações do concreto na fibra superior da mesa, adotase y corresponde ao próprio valor da linha neutra, ou seja:

$$
y=x=\left\{\begin{array}{l}
x_{I} \\
x_{I I} \\
x_{e}
\end{array}\right.
$$

Para a região sujeita apenas a flexão, (região central), a previsão das deformações da armadura longitudinal foi feita utilizando $\mathrm{x}_{\mathrm{I}}$ antes da fissuração e $\mathrm{x}_{\mathrm{II}}$ após a fissuração. Não se utilizou a linha neutra equivalente $x_{\mathrm{e}}$ pois, para essa seção, a viga está funcionando efetivamente no estádio II, já que existem fissuras passando na seção onde o extensômetro foi posicionado.

$\mathrm{Na}$ seção situada a $50 \mathrm{~cm}$ do apoio, surgiram várias fissuras devido aos esforços de cisalhamento. Entretanto, não foi observada nenhuma fissura passando pelo local onde foram fixados os extensômetros. Sendo assim, admitiu-se, para essa seção, um estado intermediário entre estádios I e II. Desta forma, utilizaram-se $x_{e}$ e $I_{e}$ para prever os valores das deformações nas armaduras longitudinais. 


\section{I.5. Deslocamentos verticais}

O cálculo teórico para os deslocamentos verticais pode ser feito através da aplicação direta da teoria da Resistência dos Materiais. Adotando-se o esquema estático da Figura I.4 e a equação da elástica da viga, obtém-se a função deslocamento em cada trecho:

$$
\mathrm{v}^{\prime \prime}=\frac{\mathrm{d}^{2} \mathrm{v}}{\mathrm{dx}^{2}}=-\frac{\mathrm{M}}{\mathrm{EI}} \quad \text { (Equação da elástica ) }
$$

Fazendo a integração dessa equação para os trechos I, II e III e aplicando as respectivas condições de contorno, obtêm-se as funções deslocamento para cada trecho da viga.

$$
\begin{array}{ll}
\text { - trechos I e III: } & \mathrm{v}_{\mathrm{I}}=-\frac{\mathrm{F}}{6 \mathrm{EI}}\left[\mathrm{x}^{3}+3 \mathrm{a}(\mathrm{a}-l) \cdot \mathrm{x}\right] \\
\text { - trecho II: } & \mathrm{v}_{\mathrm{II}}=-\frac{\mathrm{F} \cdot \mathrm{a}}{6 \mathrm{EI}}\left[3 \cdot \mathrm{x}^{2}-3 \cdot l \cdot \mathrm{x}+\mathrm{a}^{2}\right]
\end{array}
$$

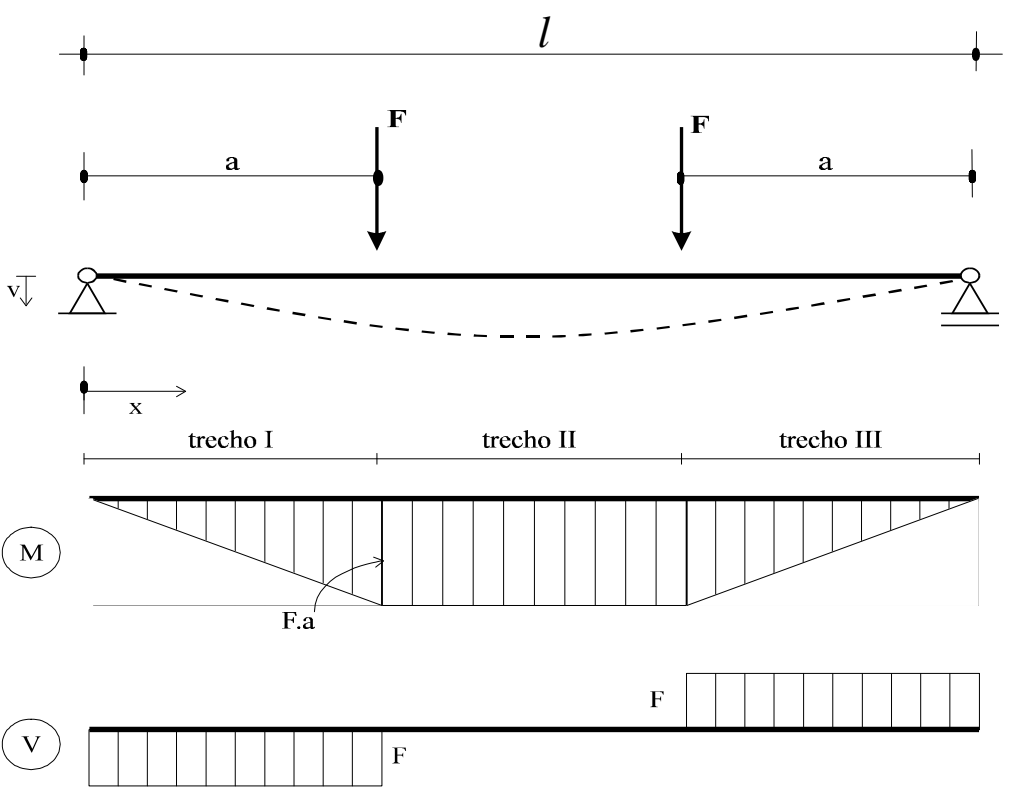

Figura I.4 - Esquema da linha elástica, diagrama de momentos fletores e força cortante para a viga ensaiada 
Substituindo-se os valores conhecidos, têm-se os deslocamentos verticais em função da força aplicada:

- Deslocamentos verticais para o ponto de aplicação da força $(x=100 \mathrm{~cm})$

$$
\mathrm{v}_{(100)}=-\frac{\mathrm{F}}{6 \mathrm{EI}}\left[100^{3}+3 \cdot 100 \cdot(100-300) \cdot 100\right] \Rightarrow \mathrm{v}_{(100)}=\frac{833.333,33 \mathrm{~F}}{\mathrm{EI}}
$$

- Deslocamentos verticais para o meio do vão $(\mathrm{x}=150 \mathrm{~cm})$

$$
\mathrm{v}_{(150)}=-\frac{\mathrm{F} \cdot 100}{6 \mathrm{EI}}\left[3 \cdot 150^{2}-3 \cdot 300 \cdot 150+100^{2}\right] \Rightarrow \mathrm{v}_{(100)}=\frac{958.333,33 \mathrm{~F}}{\mathrm{EI}}
$$

O valor da rigidez EI corresponde ao estádio I, antes da fissuração, e do estádio II, após a fissuração.

\section{I.6. Tensões nos Estribos}

Para o cálculo das tensões nos estribos utilizou-se a analogia da Treliça Generalizada proposta pela NBR-6118.

a) Taxa da armadura:

$$
\rho_{\mathrm{sw}}=\frac{\mathrm{A}_{\mathrm{sw}}}{\mathrm{b}_{\mathrm{w}} \cdot \mathrm{s}}=\frac{\tau_{\mathrm{o}}-\tau_{c}}{\sigma_{\mathrm{sw}}}
$$

onde: $\rho_{\mathrm{sw}}$ - taxa de armadura;

$\mathrm{A}_{\mathrm{sw}}$ - área de aço de todos os ramos do estribos na seção;

$\sigma_{\mathrm{sw}}$ - tensão no estribo disposto à $90^{\circ}$;

s - espaçamento entre estribos.

b) Tensões

Lembrando-se que a tensão tangencial de referência é dada por:

$$
\tau_{\mathrm{w}}=\frac{\mathrm{V}}{\mathrm{b}_{\mathrm{w}} \cdot \mathrm{d}}
$$


tem-se: $\quad \tau_{\mathrm{o}}=1,15 \cdot \tau_{\mathrm{w}}$ e $\tau_{\mathrm{c}}=0,15 \sqrt{f_{c j}}$

Portanto, a tensão nos estribos verticais é dada por:

$$
\sigma_{\mathrm{sw}}=\frac{\tau_{\mathrm{o}}-\tau_{c}}{\rho_{\mathrm{sw}}}
$$

c) Deformações

Para calcular as deformações nos estribos, basta aplicar a Lei de Hooke:

$$
\varepsilon_{\mathrm{s} 90}=\frac{\sigma_{\mathrm{s} 90}}{\mathrm{E}_{\mathrm{s}}}=\frac{\tau_{0}-\tau_{c}}{\rho_{s w} \cdot \mathrm{E}_{\mathrm{s}}}
$$

\section{I.7. Tensões de cisalhamento no concreto}

A distribuição de tensões de cisalhamento na seção é definida pela seguinte expressão:

$$
\tau_{\max }=\frac{\mathrm{V} \cdot m_{s}}{\mathrm{~b}_{\mathrm{w}} \cdot \mathrm{I}_{\mathrm{x}}}
$$

onde: $b_{w}=15 \mathrm{~cm}$;

$\mathrm{I}_{\mathrm{x}}=\mathrm{I}_{1}$ (regime elástico);

V - força cortante atuante na seção;

$m_{s}$ - momento estático parcial.

Conforme pode ser visto na Figura I.5, a tensão de cisalhamento máxima ocorre na região próxima à linha neutra. Calculando-se o momento estático em relação à posição onde foi fixada a roseta, tem-se:

$$
m_{\mathrm{s}}=\mathrm{b}_{\mathrm{f}} \cdot h_{\mathrm{f}}\left(\mathrm{y}-\frac{\mathrm{h}_{\mathrm{f}}}{2}\right)+\mathrm{b}_{\mathrm{w}} \frac{\left(\mathrm{y}-\mathrm{h}_{\mathrm{f}}\right)^{2}}{2}+\alpha_{e} \cdot \mathrm{A}_{\mathrm{s}}^{\prime}\left(\mathrm{y}-\mathrm{d}^{\prime}\right)
$$

onde: $y=15 \mathrm{~cm}$ (posição em que foi fixada a roseta em relação a mesa das vigas);

$\mathrm{A}_{\mathrm{s}}{ }^{\prime}=$ armadura situada na mesa de concreto;

$\alpha_{\mathrm{e}}=$ coeficiente entre o módulo de elasticidade do aço e o do concreto; 


$$
\text { d' = altura útil da } \mathrm{A}_{\mathrm{s}} \text { '. }
$$

Através do diagrama de esforço cortante (ver Figura I.4) percebe-se que a força cortante atuante na seção é igual à força aplicada ( V=F ). Substituindo-se esse valor na equação de cisalhamento I.27, obtém-se o valor máximo dessa tensão para cada etapa de carregamento aplicado na viga.

A tensão de cisalhamento experimental é fornecida diretamente pelo Sistema de Aquisição de Dados e corresponde às tensões máximas e mínimas. Caso não fossem fornecidos estes valores, poder-se-ia calcular a tensão experimental de cisalhamento a partir das deformações obtidas nas três direções das rosetas.

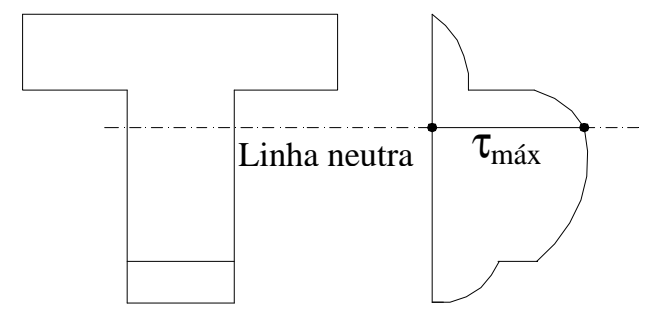

Figura I.5 - Distribuição de tensões de cisalhamento na seção transversal 


\section{Apêndice II :Dados coletados através do Sistema de Aquisição de Dados}

Neste Anexo descreve-se as leitura dos instrumentos utilizados para monitorar o comportamento das vigas ensaiadas. As posições correspondentes a cada instrumento utilizado, bem como sua nomenclatura, estão ilustradas nas Figuras 4.12 e 4.13. O valor da força, indicada nas tabelas, corresponde a força total fornecida pelo macaco hidráulico e deve ser dividida por dois caso se deseje saber o valor de cada uma das forças concentradas aplicadas nas vigas. É importante observar que nem sempre a força de ruína corresponde à última leitura feita pelo Sistema de Aquisição de Dados. 


\section{Resultados da viga VA-1}

Tabela II.1 - Leitura dos deslocamentos verticais ao longo do eixo longitudinal da viga VA-1

\begin{tabular}{|c|c|c|c|c|c|c|c|}
\hline $\begin{array}{c}\text { Força } \\
\text { kN }\end{array}$ & $\begin{array}{c}\text { Trans. 1 } \\
\mathrm{mm}\end{array}$ & $\begin{array}{c}\text { Trans. 2 } \\
\mathrm{mm}\end{array}$ & $\begin{array}{c}\text { Trans. 3 } \\
\mathrm{mm}\end{array}$ & $\begin{array}{c}\text { Trans. 4 } \\
\mathrm{mm}\end{array}$ & $\begin{array}{c}\text { Trans. 5 } \\
\mathrm{mm}\end{array}$ & $\begin{array}{c}\text { Trans. 6 } \\
\mathrm{mm}\end{array}$ & $\begin{array}{c}\text { Trans. 7 } \\
\mathrm{mm}\end{array}$ \\
\hline 0 & 0,000 & 0,000 & 0,000 & 0,000 & 0,000 & 0,000 & 0,000 \\
\hline 5 & 0,000 & 0,075 & 0,320 & 0,069 & $-0,073$ & 0,000 & 0,182 \\
\hline 11 & $-0,037$ & 0,225 & 0,676 & 0,172 & $-0,110$ & 0,146 & 0,291 \\
\hline 15 & $-0,037$ & 0,262 & 0,889 & 0,241 & $-0,147$ & 0,183 & 0,327 \\
\hline 21 & $-0,074$ & 0,337 & 1,067 & 0,344 & $-0,184$ & 0,329 & 0,436 \\
\hline 26 & $-0,110$ & 0,450 & 1,209 & 0,447 & $-0,220$ & 0,439 & 0,545 \\
\hline 31 & $-0,147$ & 0,525 & 1,387 & 0,551 & $-0,257$ & 0,512 & 0,655 \\
\hline 35 & $-0,184$ & 0,600 & 1,422 & 0,585 & $-0,257$ & 0,621 & 0,727 \\
\hline 43 & $-0,221$ & 0,787 & 1,671 & 0,791 & $-0,294$ & 0,841 & 0,945 \\
\hline 46 & $-0,221$ & 0,862 & 1,743 & 0,860 & $-0,330$ & 0,914 & 1,018 \\
\hline 49 & $-0,258$ & 0,937 & 1,814 & 0,964 & $-0,330$ & 1,023 & 1,091 \\
\hline 47 & $-0,258$ & 0,937 & 1,849 & 0,964 & $-0,330$ & 0,987 & 1,636 \\
\hline 54 & $-0,294$ & 1,049 & 1,885 & 1,101 & $-0,367$ & 1,133 & 1,782 \\
\hline 59 & $-0,294$ & 1,199 & 2,240 & 1,239 & $-0,404$ & 1,316 & 2,000 \\
\hline 82 & $-0,368$ & 2,061 & 3,058 & 2,065 & $-0,477$ & 2,266 & 2,945 \\
\hline 122 & $-0,478$ & 3,598 & 4,765 & 3,613 & $-0,551$ & 4,130 & 4,545 \\
\hline 162 & $-0,552$ & 5,172 & 6,508 & 5,196 & $-0,698$ & 6,067 & 6,182 \\
\hline 203 & $-0,699$ & 6,897 & 8,357 & 6,882 & $-0,808$ & 8,077 & 7,927 \\
\hline 243 & $-0,846$ & 8,733 & 10,420 & 8,741 & $-0,954$ & 10,051 & 9,927 \\
\hline 282 & $-0,846$ & 10,645 & 12,411 & 10,564 & $-1,065$ & 12,135 & 12,036 \\
\hline 304 & $-0,920$ & 11,994 & 13,869 & 11,838 & $-1,101$ & 13,560 & 13,491 \\
\hline 321 & $-0,957$ & 13,268 & 15,149 & 12,904 & $-1,138$ & 14,803 & 14,691 \\
\hline
\end{tabular}


Tabela II.2 - Leitura dos deslocamentos horizontais entre o reforço e o substrato ao longo do eixo longitudinal da viga VA-1

\begin{tabular}{|c|c|c|c|c|}
\hline $\begin{array}{c}\text { Força } \\
\text { kN }\end{array}$ & $\begin{array}{c}\text { Rel. 1 } \\
\mathrm{mm}\end{array}$ & $\begin{array}{c}\text { Rel. 2 } \\
\mathrm{mm}\end{array}$ & $\begin{array}{c}\text { Rel. 3 } \\
\mathrm{mm}\end{array}$ & $\begin{array}{c}\text { Rel. 5 } \\
\mathrm{mm}\end{array}$ \\
\hline 0 & 0.000 & 0.000 & 0.000 & 0.000 \\
\hline 5 & 0.000 & 0.000 & 0.000 & 0.000 \\
\hline 11 & 0.000 & 0.000 & 0.000 & 0.000 \\
\hline 15 & -0.003 & 0.000 & 0.000 & 0.000 \\
\hline 21 & 0.000 & 0.000 & 0.000 & 0.003 \\
\hline 26 & 0.000 & 0.000 & 0.000 & 0.003 \\
\hline 31 & -0.003 & 0.000 & -0.003 & 0.003 \\
\hline 35 & 0.000 & -0.003 & -0.003 & 0.003 \\
\hline 43 & -0.003 & -0.003 & -0.003 & 0.003 \\
\hline 46 & -0.003 & -0.003 & -0.003 & 0.003 \\
\hline 49 & -0.003 & -0.003 & -0.003 & -0.003 \\
\hline 47 & -0.003 & -0.003 & -0.003 & -0.006 \\
\hline 54 & -0.003 & -0.003 & -0.006 & -0.006 \\
\hline 59 & -0.003 & -0.003 & -0.006 & -0.009 \\
\hline 82 & -0.006 & -0.006 & -0.009 & -0.025 \\
\hline 122 & -0.009 & -0.037 & -0.069 & -0.037 \\
\hline 162 & -0.009 & -0.067 & -0.119 & -0.049 \\
\hline 203 & -0.013 & -0.086 & -0.151 & -0.055 \\
\hline 243 & -0.016 & -0.089 & -0.167 & -0.058 \\
\hline 282 & -0.016 & -0.064 & -0.182 & -0.062 \\
\hline 304 & -0.013 & -0.104 & -0.233 & -0.062 \\
\hline 321 & -0.009 & -0.205 & -0.339 & -0.062 \\
\hline
\end{tabular}


Tabela II.3 - Leitura das deformações nas armaduras longitudinais do substrato $\left(A_{\text {sl }}\right)$ e do reforço $\left(A_{\text {slr }}\right)$ da viga VA-1

\begin{tabular}{|c|c|c|c|c|c|c|c|c|}
\hline $\begin{array}{c}\text { Força } \\
\text { kN }\end{array}$ & $\begin{array}{c}\text { Ext. 1 } \\
\mu \mathrm{e}\end{array}$ & $\begin{array}{c}\text { Ext. 3 } \\
\mu \mathrm{e}\end{array}$ & $\begin{array}{c}\text { Ext. 4 } \\
\mu \mathrm{e}\end{array}$ & $\begin{array}{c}\text { Ext. 6 } \\
\mu \mathrm{e}\end{array}$ & $\begin{array}{c}\text { Ext. 13 } \\
\mu \mathrm{e}\end{array}$ & $\begin{array}{c}\text { Ext. 15 } \\
\mu \mathrm{e}\end{array}$ & $\begin{array}{c}\text { Ext. 16 } \\
\mu \mathrm{e}\end{array}$ & $\begin{array}{c}\text { Ext. 18 } \\
\mu \mathrm{e}\end{array}$ \\
\hline 0 & 0 & 1 & 0 & 0 & 0 & 0 & 0 & 0 \\
\hline 5 & 9 & 9 & 14 & 13 & 6 & 5 & 7 & 6 \\
\hline 11 & 20 & 21 & 32 & 30 & 11 & 10 & 15 & 14 \\
\hline 15 & 26 & 27 & 42 & 39 & 14 & 14 & 20 & 19 \\
\hline 21 & 38 & 39 & 61 & 58 & 21 & 21 & 28 & 27 \\
\hline 26 & 48 & 50 & 80 & 71 & 26 & 26 & 35 & 34 \\
\hline 31 & 61 & 62 & 114 & 88 & 31 & 31 & 43 & 42 \\
\hline 35 & 69 & 71 & 132 & 104 & 34 & 35 & 48 & 46 \\
\hline 43 & 97 & 105 & 203 & 149 & 45 & 45 & 62 & 59 \\
\hline 46 & 108 & 118 & 234 & 165 & 49 & 50 & 69 & 64 \\
\hline 49 & 133 & 157 & 303 & 210 & 52 & 53 & 74 & 67 \\
\hline 47 & 140 & 164 & 311 & 219 & 53 & 52 & 74 & 67 \\
\hline 54 & 176 & 196 & 368 & 275 & 60 & 60 & 83 & 77 \\
\hline 59 & 234 & 239 & 448 & 347 & 68 & 66 & 95 & 84 \\
\hline 82 & 438 & 431 & 708 & 591 & 97 & 95 & 185 & 112 \\
\hline 122 & 703 & 746 & 1086 & 992 & 352 & 328 & 507 & 364 \\
\hline 162 & 963 & 1037 & 1464 & 1378 & 665 & 684 & 810 & 711 \\
\hline 203 & 1225 & 1328 & 1847 & 1761 & 824 & 845 & 1077 & 1003 \\
\hline 243 & 1484 & 1613 & 2232 & 2146 & 973 & 974 & 1338 & 1253 \\
\hline 282 & 1731 & 1870 & 2591 & 2507 & 1135 & 1175 & 1746 & 1594 \\
\hline 304 & 1874 & 2022 & 2801 & 2724 & 1188 & 1239 & 2133 & 1893 \\
\hline 321 & 1990 & 2147 & 2902 & 2897 & 1230 & 1265 & 2435 & 2070 \\
\hline
\end{tabular}


Tabela II.4- Leitura das deformações do estribo e do concreto comprimido da viga VA-1

\begin{tabular}{|c|c|c|c|c|c|}
\hline \multirow[b]{2}{*}{$\begin{array}{c}\text { Força } \\
\mathrm{kN}\end{array}$} & \multicolumn{2}{|c|}{ Estribo } & \multicolumn{3}{|c|}{ Concreto } \\
\hline & $\begin{array}{c}\text { Ext. } 19 \\
\mu \mathrm{e}\end{array}$ & $\begin{array}{c}\text { Ext. } 20 \\
\mu \mathrm{e}\end{array}$ & $\begin{array}{c}\text { Ext. } 21 \\
\mu \mathrm{e}\end{array}$ & $\begin{array}{c}\text { Ext. } 22 \\
\mu \mathrm{e}\end{array}$ & $\begin{array}{c}\text { Ext. 23 } \\
\mu \mathrm{e}\end{array}$ \\
\hline$\overline{0}$ & -1 & 0 & $\overline{0}$ & 0 & 0 \\
\hline 5 & -1 & 0 & -10 & -11 & -6 \\
\hline 11 & 0 & 1 & -19 & -20 & -16 \\
\hline 15 & 0 & 2 & -26 & -27 & -21 \\
\hline 21 & 0 & 2 & -36 & -37 & -31 \\
\hline 26 & 0 & 2 & -45 & -46 & -40 \\
\hline 31 & 1 & 3 & -55 & -56 & -47 \\
\hline 35 & 2 & 4 & -58 & -59 & -53 \\
\hline 43 & 3 & 5 & -77 & -77 & -70 \\
\hline 46 & 3 & 5 & -84 & -83 & -76 \\
\hline 49 & 3 & 4 & -93 & -92 & -84 \\
\hline 47 & 3 & 4 & -96 & -91 & -83 \\
\hline 54 & 4 & 6 & -108 & -106 & $\begin{array}{l}-95 \\
\end{array}$ \\
\hline 59 & 6 & 8 & -118 & -119 & -107 \\
\hline 82 & 7 & 8 & -186 & -189 & $\begin{array}{l}-170 \\
\end{array}$ \\
\hline 122 & 5 & 17 & $\begin{array}{l}-303 \\
\end{array}$ & -312 & -275 \\
\hline 162 & 102 & 31 & -425 & -442 & -380 \\
\hline 203 & 587 & 433 & -548 & -571 & -487 \\
\hline 243 & 931 & 717 & -679 & -709 & -601 \\
\hline 282 & 1237 & 964 & -807 & -845 & -715 \\
\hline 304 & 1327 & 1059 & $\begin{array}{l}-893 \\
\end{array}$ & -937 & $\begin{array}{l}-797 \\
\end{array}$ \\
\hline 321 & 1428 & 1144 & $\begin{array}{l}-952 \\
\end{array}$ & -1003 & $\begin{array}{l}-852 \\
\end{array}$ \\
\hline
\end{tabular}


Tabela II.5 - Leitura das tensões e deformações máximas e mínimas dadas pelas rosetas da viga $\mathrm{VA-1}$

\begin{tabular}{|c|c|c|c|c|c|c|c|c|}
\hline \multirow{2}{*}{$\begin{array}{c}\text { Força } \\
\mathrm{kN}\end{array}$} & \begin{tabular}{c}
$\varepsilon_{\max }$ \\
\cline { 2 - 9 }
\end{tabular} & $\begin{array}{c}\varepsilon_{\min } \\
\mu \mathrm{e}\end{array}$ & $\begin{array}{c}\sigma_{\max } \\
\mathrm{kN} / \mathrm{cm}^{2}\end{array}$ & $\begin{array}{c}\sigma_{\min } \\
\mathrm{kN} / \mathrm{cm}^{2}\end{array}$ & $\begin{array}{c}\varepsilon_{\max } \\
\mu \mathrm{e}\end{array}$ & $\begin{array}{c}\varepsilon_{\min } \\
\mu \mathrm{e}\end{array}$ & $\begin{array}{c}\sigma_{\max } \\
\mathrm{kN} / \mathrm{cm}^{2}\end{array}$ & $\begin{array}{c}\sigma_{\min } \\
\mathrm{kN} / \mathrm{cm}^{2}\end{array}$ \\
\hline 0 & 0.00 & 0.00 & 0.00 & 0.00 & 0.00 & 0.00 & 0.00 & 0.00 \\
\hline 5 & 1.89 & -2.82 & 0.01 & -0.01 & 2.00 & -3.84 & 0.00 & -0.01 \\
\hline 11 & 6.47 & -4.62 & 0.02 & -0.01 & 5.62 & -5.62 & 0.02 & -0.02 \\
\hline 15 & 7.40 & -6.48 & 0.02 & -0.02 & 7.40 & -6.48 & 0.02 & -0.02 \\
\hline 21 & 11.08 & -9.24 & 0.04 & -0.03 & 10.17 & -9.25 & 0.03 & -0.03 \\
\hline 26 & 13.85 & -12.01 & 0.05 & -0.04 & 12.94 & -12.02 & 0.04 & -0.04 \\
\hline 31 & 17.55 & -13.85 & 0.06 & -0.04 & 15.73 & -13.88 & 0.05 & -0.04 \\
\hline 35 & 18.48 & -13.86 & 0.06 & -0.04 & 18.48 & -13.86 & 0.06 & -0.04 \\
\hline 43 & 24.96 & -17.57 & 0.09 & -0.05 & 24.06 & -17.59 & 0.08 & -0.05 \\
\hline 46 & 26.83 & -18.51 & 0.09 & -0.05 & 25.94 & -18.55 & 0.09 & -0.05 \\
\hline 49 & 27.78 & -20.39 & 0.10 & -0.06 & 26.83 & -20.36 & 0.09 & -0.06 \\
\hline 47 & 26.80 & -21.26 & 0.09 & -0.06 & 25.94 & -20.39 & 0.09 & -0.06 \\
\hline 54 & 31.46 & -22.23 & 0.11 & -0.06 & 30.58 & -22.27 & 0.11 & -0.07 \\
\hline 59 & 37.03 & -23.18 & 0.13 & -0.06 & 35.23 & -22.30 & 0.13 & -0.06 \\
\hline 82 & 50.18 & -32.64 & 0.18 & -0.09 & 49.39 & -33.69 & 0.17 & -0.10 \\
\hline 122 & 61.59 & -36.67 & 0.22 & -0.10 & 67.68 & -44.59 & 0.24 & -0.13 \\
\hline 162 & 66.35 & -45.14 & 0.23 & -0.13 & 90.10 & -42.08 & 0.33 & -0.10 \\
\hline
\end{tabular}




\section{Resultados da viga VA-2}

Tabela II.6 - Leitura dos deslocamentos verticais ao longo do eixo longitudinal da viga VA-2

\begin{tabular}{|c|c|c|c|c|c|c|c|}
\hline $\begin{array}{c}\text { Força } \\
\text { kN }\end{array}$ & $\begin{array}{c}\text { Trans. 1 } \\
\mathrm{mm}\end{array}$ & $\begin{array}{c}\text { Trans. 2 } \\
\mathrm{mm}\end{array}$ & $\begin{array}{c}\text { Trans. 3 } \\
\mathrm{mm}\end{array}$ & $\begin{array}{c}\text { Trans. 4 } \\
\mathrm{mm}\end{array}$ & $\begin{array}{c}\text { Trans. 5 } \\
\mathrm{mm}\end{array}$ & $\begin{array}{c}\text { Trans. 6 } \\
\mathrm{mm}\end{array}$ & $\begin{array}{c}\text { Trans. 7 } \\
\mathrm{mm}\end{array}$ \\
\hline 0 & 0.00 & 0.00 & 0.00 & 0.00 & 0.00 & 0.00 & 0.000 \\
\hline 12 & 0.00 & 0.22 & 0.28 & 0.29 & -0.07 & 0.22 & 0.392 \\
\hline 22 & 0.00 & 0.55 & 0.58 & 0.57 & -0.15 & 0.56 & 0.712 \\
\hline 31 & -0.04 & 0.74 & 0.86 & 0.79 & -0.22 & 0.78 & 0.962 \\
\hline 41 & -0.07 & 1.11 & 1.27 & 1.15 & -0.25 & 1.19 & 1.353 \\
\hline 52 & -0.07 & 1.51 & 1.79 & 1.54 & -0.33 & 1.67 & 1.852 \\
\hline 62 & -0.11 & 1.99 & 2.31 & 2.04 & -0.40 & 2.15 & 2.386 \\
\hline 71 & -0.15 & 2.40 & 2.75 & 2.40 & -0.44 & 2.60 & 2.849 \\
\hline 81 & -0.15 & 2.88 & 3.30 & 2.87 & -0.47 & 3.12 & 3.419 \\
\hline 92 & -0.15 & 3.32 & 3.79 & 3.26 & -0.47 & 3.60 & 3.882 \\
\hline 101 & -0.15 & 3.73 & 4.27 & 3.66 & -0.51 & 4.08 & 4.380 \\
\hline 112 & -0.19 & 4.21 & 4.78 & 4.12 & -0.55 & 4.64 & 4.915 \\
\hline 122 & -0.19 & 4.69 & 5.30 & 4.63 & -0.58 & 5.27 & 5.449 \\
\hline 130 & -0.19 & 5.09 & 5.68 & 4.99 & -0.65 & 5.83 & 5.912 \\
\hline 140 & -0.19 & 5.57 & 6.23 & 5.45 & -0.65 & 6.31 & 6.410 \\
\hline 151 & -0.22 & 6.09 & 6.81 & 5.95 & -0.69 & 6.90 & 7.123 \\
\hline 162 & -0.30 & 6.61 & 7.36 & 6.46 & -0.73 & 7.50 & 7.728 \\
\hline 181 & -0.30 & 7.53 & 8.43 & 7.42 & -0.73 & 8.57 & 8.761 \\
\hline 202 & -0.33 & 8.60 & 9.60 & 8.46 & -0.76 & 9.73 & 9.936 \\
\hline 219 & -0.41 & 9.52 & 10.60 & 9.33 & -0.80 & 10.80 & 10.933 \\
\hline 244 & -0.41 & 10.92 & 12.11 & 10.80 & -0.84 & 12.47 & 12.500 \\
\hline 259 & -0.41 & 12.03 & 13.35 & 12.02 & -0.87 & 13.81 & 13.782 \\
\hline & & & & & & & \\
\hline
\end{tabular}


Tabela II.7 - Leitura dos deslocamentos horizontais entre o reforço e o substrato ao longo do eixo longitudinal da viga VA-2

\begin{tabular}{|c|c|c|c|c|c|c|c|c|}
\hline $\begin{array}{c}\text { Força } \\
\text { kN }\end{array}$ & $\begin{array}{c}\text { Rel.1 } \\
\mathrm{mm}\end{array}$ & $\begin{array}{c}\text { Rel.2 } \\
\mathrm{mm}\end{array}$ & $\begin{array}{c}\text { Rel.3 } \\
\mathrm{mm}\end{array}$ & $\begin{array}{c}\text { Rel.4 } \\
\mathrm{mm}\end{array}$ & $\begin{array}{c}\text { Rel.5 } \\
\mathrm{mm}\end{array}$ & $\begin{array}{c}\text { Rel.6 } \\
\mathrm{mm}\end{array}$ & $\begin{array}{c}\text { Rel.7 } \\
\mathrm{mm}\end{array}$ & $\begin{array}{c}\text { Rel.8 } \\
\mathrm{mm}\end{array}$ \\
\hline 0 & 0.000 & -0.005 & -0.005 & 0.000 & 0.000 & 0.000 & -0.005 & 0.000 \\
\hline 12 & 0.000 & -0.005 & -0.005 & 0.000 & 0.000 & -0.005 & 0.000 & -0.003 \\
\hline 22 & 0.000 & -0.005 & -0.005 & -0.019 & -0.006 & -0.005 & 0.000 & 0.000 \\
\hline 31 & 0.000 & -0.005 & -0.005 & -0.033 & -0.012 & -0.015 & -0.005 & -0.003 \\
\hline 41 & 0.000 & -0.010 & -0.005 & -0.066 & -0.040 & -0.025 & -0.005 & -0.003 \\
\hline 52 & -0.003 & -0.015 & -0.005 & -0.114 & -0.061 & -0.039 & -0.005 & -0.003 \\
\hline 62 & -0.003 & -0.020 & -0.005 & -0.171 & -0.089 & -0.049 & -0.005 & -0.006 \\
\hline 71 & -0.003 & -0.020 & -0.005 & -0.199 & -0.113 & -0.059 & -0.005 & -0.006 \\
\hline 81 & -0.003 & -0.020 & -0.019 & -0.242 & -0.144 & -0.089 & -0.005 & -0.006 \\
\hline 92 & -0.003 & -0.020 & -0.034 & -0.266 & -0.168 & -0.108 & -0.009 & -0.006 \\
\hline 101 & -0.003 & -0.030 & -0.039 & -0.285 & -0.190 & -0.128 & -0.009 & -0.006 \\
\hline 112 & -0.003 & -0.040 & -0.048 & -0.313 & -0.208 & -0.143 & -0.009 & -0.006 \\
\hline 122 & -0.006 & -0.045 & -0.048 & -0.337 & -0.235 & -0.163 & -0.005 & -0.006 \\
\hline 130 & -0.006 & -0.060 & -0.039 & -0.356 & -0.254 & -0.177 & -0.005 & -0.006 \\
\hline 140 & -0.006 & -0.065 & -0.077 & -0.365 & -0.281 & -0.187 & -0.005 & -0.006 \\
\hline 151 & -0.006 & -0.075 & -0.106 & -0.389 & -0.315 & -0.202 & -0.005 & -0.006 \\
\hline 162 & -0.009 & -0.085 & -0.130 & -0.413 & -0.349 & -0.217 & -0.005 & -0.003 \\
\hline 181 & -0.009 & -0.095 & -0.169 & -0.465 & -0.404 & -0.227 & 0.000 & -0.003 \\
\hline 202 & -0.006 & -0.115 & -0.222 & -0.536 & -0.465 & -0.217 & 0.009 & -0.006 \\
\hline 219 & -0.006 & -0.125 & -0.265 & -0.579 & -0.526 & -0.207 & 0.019 & -0.006 \\
\hline 244 & -0.006 & -0.140 & -0.323 & -0.669 & -0.618 & -0.207 & 0.028 & -0.003 \\
\hline 259 & -0.003 & -0.145 & -0.371 & -0.716 & -0.676 & -0.212 & -0.071 & -0.003 \\
\hline
\end{tabular}


Tabela II.8 - Leitura das deformações nas armaduras longitudinais do substrato $\left(\mathrm{A}_{\mathrm{sl}}\right)$ e do reforço ( $\left.\mathrm{A}_{\text {slr }}\right)$ da viga VA-2

\begin{tabular}{|c|c|c|c|c|c|c|c|c|c|c|c|c|c|c|c|c|c|c|}
\hline $\begin{array}{c}\text { Força } \\
\mathrm{kN}\end{array}$ & $\begin{array}{c}\text { Ext.1 } \\
\mu \mathrm{e}\end{array}$ & $\begin{array}{c}\text { Ext.2 } \\
\mu \mathrm{e}\end{array}$ & $\begin{array}{c}\text { Ext.3 } \\
\mu \mathrm{e}\end{array}$ & $\begin{array}{c}\text { Ext.4 } \\
\mu \mathrm{e}\end{array}$ & $\begin{array}{c}\text { Ext.5 } \\
\mu \mathrm{e}\end{array}$ & $\begin{array}{c}\text { Ext.6 } \\
\mu \mathrm{e}\end{array}$ & $\begin{array}{c}\text { Ext.7 } \\
\mu \mathrm{e}\end{array}$ & $\begin{array}{c}\text { Ext.8 } \\
\mu \mathrm{e}\end{array}$ & $\begin{array}{c}\text { Ext.9 } \\
\mu \mathrm{e}\end{array}$ & $\begin{array}{c}\text { Ext.10 } \\
\mu \mathrm{e}\end{array}$ & $\begin{array}{c}\text { Ext.11 } \\
\mu \mathrm{e}\end{array}$ & $\begin{array}{c}\text { Ext. } 12 \\
\mu \mathrm{e}\end{array}$ & $\begin{array}{c}\text { Ext. 13 } \\
\mu \mathrm{e}\end{array}$ & $\begin{array}{c}\text { Ext. 14 } \\
\mu \mathrm{e}\end{array}$ & $\begin{array}{c}\text { Ext. } 15 \\
\mu \mathrm{e}\end{array}$ & $\begin{array}{c}\text { Ext. 16 } \\
\mu \mathrm{e}\end{array}$ & $\begin{array}{c}\text { Ext. } 17 \\
\mu \mathrm{e}\end{array}$ & $\begin{array}{c}\text { Ext. 18 } \\
\mu \mathrm{e}\end{array}$ \\
\hline 12 & 35 & 34 & 40 & 44 & 41 & 38 & 31 & 31 & 30 & 39 & 48 & 37 & 14 & 14 & 14 & 19 & 19 & 17 \\
\hline 22 & 110 & 83 & 101 & 111 & 90 & 91 & 106 & 82 & 69 & 140 & 142 & 97 & 27 & 26 & 26 & 36 & 35 & 31 \\
\hline 41 & 259 & 226 & 251 & 234 & 285 & 243 & 233 & 196 & 175 & 271 & 266 & 210 & 81 & 66 & 56 & 145 & 80 & 57 \\
\hline 52 & 349 & 324 & 333 & 315 & 391 & 325 & 292 & 274 & 259 & 354 & 352 & 296 & 130 & 96 & 80 & 223 & 133 & 84 \\
\hline 62 & 437 & 414 & 415 & 415 & 501 & 417 & 370 & 381 & 379 & 455 & 460 & 432 & 169 & 122 & 114 & 275 & 181 & 121 \\
\hline 92 & 639 & 645 & 652 & 686 & 803 & 707 & 564 & 608 & 607 & 704 & 724 & 712 & 294 & 272 & 339 & 414 & 360 & 315 \\
\hline 101 & 708 & 720 & 725 & 776 & 898 & 802 & 629 & 678 & 683 & 785 & 810 & 799 & 353 & 330 & 404 & 481 & 423 & 377 \\
\hline 112 & 782 & 802 & 808 & 874 & 1002 & 902 & 704 & 757 & 763 & 877 & 904 & 894 & 412 & 390 & 462 & 560 & 494 & 449 \\
\hline 122 & 860 & 886 & 890 & 975 & 1103 & 1006 & 783 & 837 & 840 & 974 & 1001 & 993 & 462 & 447 & 508 & 632 & 572 & 520 \\
\hline 130 & 919 & 951 & 953 & 1052 & 1182 & 1082 & 841 & 897 & 897 & 1046 & 1075 & 1064 & 501 & 486 & 542 & 688 & 628 & 572 \\
\hline 140 & 991 & 1028 & 1029 & 1144 & 1275 & 1172 & 909 & 969 & 968 & 1132 & 1164 & 1149 & 545 & 531 & 578 & 756 & 694 & 632 \\
\hline 244 & 1790 & 1847 & 1844 & 2189 & 2264 & 2160 & 1677 & 1746 & 1739 & 2025 & 2100 & 2065 & 1068 & 1062 & 1038 & 1291 & 1361 & 1228 \\
\hline 259 & 1910 & 1971 & 1964 & 2346 & 2413 & 2307 & 1807 & 1858 & 1854 & 2154 & 2239 & 2198 & 1170 & 1162 & 1133 & 1340 & 1445 & 1314 \\
\hline
\end{tabular}


Tabela II.9 - Leitura das deformações do estribo e do concreto comprimido da viga VA-2

\begin{tabular}{|c|c|c|c|c|c|}
\hline \multirow[b]{2}{*}{$\begin{array}{c}\text { Força } \\
\text { kN }\end{array}$} & \multicolumn{2}{|c|}{ Estribo } & \multicolumn{3}{|c|}{ Concreto } \\
\hline & $\begin{array}{c}\text { Ext. } 19 \\
\mu \mathrm{e}\end{array}$ & $\begin{array}{c}\text { Ext. } 20 \\
\mu e\end{array}$ & $\begin{array}{c}\text { Ext. } 21 \\
\mu e\end{array}$ & $\begin{array}{c}\text { Ext. } 22 \\
\mu \mathrm{e}\end{array}$ & $\begin{array}{c}\text { Ext. } 23 \\
\mu \mathrm{e}\end{array}$ \\
\hline 0 & 2 & 0 & 0 & $\overline{1}$ & 0 \\
\hline 12 & 4 & 1 & -31 & -25 & -24 \\
\hline 22 & 4 & 0 & -61 & -50 & -49 \\
\hline 31 & 5 & 1 & -91 & -76 & -74 \\
\hline 41 & 8 & 2 & -130 & -108 & -106 \\
\hline 52 & 11 & 5 & -173 & -144 & -144 \\
\hline 62 & 12 & 7 & -216 & -178 & -179 \\
\hline 71 & 14 & 9 & -254 & -208 & -211 \\
\hline 81 & 16 & 3 & -296 & -243 & -247 \\
\hline 92 & 8 & -6 & -338 & -275 & -281 \\
\hline 101 & -1 & -9 & -378 & -307 & -316 \\
\hline 112 & -2 & -7 & -422 & -338 & -352 \\
\hline 122 & 13 & 24 & -467 & -372 & -391 \\
\hline 130 & 42 & 84 & -504 & -399 & -421 \\
\hline 140 & 109 & 208 & -545 & -430 & -455 \\
\hline 151 & 222 & 337 & -596 & -466 & -495 \\
\hline 162 & 288 & 412 & -642 & -499 & -532 \\
\hline 181 & 424 & 558 & -723 & -558 & -598 \\
\hline 202 & 543 & 701 & -820 & -624 & -671 \\
\hline 219 & 637 & 819 & -916 & -684 & -739 \\
\hline 244 & 823 & 1034 & -1049 & -767 & -837 \\
\hline 259 & 941 & 1152 & -1131 & -815 & -895 \\
\hline
\end{tabular}

Tabela II.10 - Leitura das tensões e deformações máximas e mínimas dadas pelas rosetas da viga $\mathrm{VA}-2$

\begin{tabular}{|c|c|c|c|c|c|c|c|c|}
\hline \multirow{2}{*}{$\begin{array}{c}\text { Força } \\
\mathrm{kN}\end{array}$} & $\begin{array}{c}\varepsilon_{\max } \\
\mu \mathrm{e}\end{array}$ & $\begin{array}{c}\varepsilon_{\min } \\
\mu \mathrm{e}\end{array}$ & $\begin{array}{c}\sigma_{\max } \\
\mathrm{kN} / \mathrm{cm}^{2}\end{array}$ & $\begin{array}{c}\sigma_{\min } \\
\mathrm{kN} / \mathrm{cm}^{2}\end{array}$ & $\begin{array}{c}\varepsilon_{\max } \\
\mu \mathrm{e}\end{array}$ & $\begin{array}{c}\varepsilon_{\min } \\
\mu \mathrm{e}\end{array}$ & $\begin{array}{c}\sigma_{\max } \\
\mathrm{kN} / \mathrm{cm}^{2}\end{array}$ & $\begin{array}{c}\sigma_{\min } \\
\mathrm{kN} / \mathrm{cm}^{2}\end{array}$ \\
\hline 0 & 0.94 & -0.94 & 0.003 & -0.003 & 0.00 & 0.00 & 0.000 & 0.000 \\
\hline 12 & 6.92 & -3.17 & 0.023 & -0.007 & 15.06 & -10.38 & 0.048 & -0.027 \\
\hline 22 & 13.13 & -6.57 & 0.044 & -0.015 & 25.47 & -17.98 & 0.081 & -0.048 \\
\hline 31 & 20.98 & -8.80 & 0.071 & -0.017 & 37.75 & -23.70 & 0.122 & -0.060 \\
\hline 41 & 29.46 & -9.78 & 0.102 & -0.014 & 53.11 & -32.50 & 0.172 & -0.081 \\
\hline 52 & 41.23 & -12.18 & 0.143 & -0.015 & 69.02 & -40.92 & 0.225 & -0.100 \\
\hline 62 & 53.91 & -16.43 & 0.187 & -0.021 & 81.72 & -46.12 & 0.268 & -0.110 \\
\hline 71 & 59.71 & -18.48 & 0.207 & -0.024 & 100.09 & -56.06 & 0.329 & -0.133 \\
\hline 81 & 67.27 & -24.17 & 0.231 & -0.040 & 93.53 & -59.79 & 0.302 & -0.152 \\
\hline 92 & 77.58 & -30.73 & 0.264 & -0.056 & 66.58 & -53.45 & 0.207 & -0.148 \\
\hline 101 & 56.39 & -28.28 & 0.188 & -0.063 & 54.66 & -50.90 & 0.164 & -0.148 \\
\hline 112 & 37.58 & -28.21 & 0.118 & -0.077 & 57.58 & -60.38 & 0.168 & -0.181 \\
\hline 122 & 44.60 & -39.92 & 0.135 & -0.115 & 71.32 & -75.07 & 0.208 & -0.225 \\
\hline 130 & 60.80 & -56.11 & 0.183 & -0.163 & 286.21 & -94.21 & 0.989 & -0.137 \\
\hline
\end{tabular}




\section{Resultados da viga VA-3}

Tabela II.11 - Leitura dos deslocamentos verticais ao longo do eixo longitudinal da viga VA-3

\begin{tabular}{|c|c|c|c|c|c|c|c|}
\hline $\begin{array}{c}\text { Força } \\
\text { kN }\end{array}$ & $\begin{array}{c}\text { Trans. 1 } \\
\mathrm{mm}\end{array}$ & $\begin{array}{c}\text { Trans. 2 } \\
\mathrm{mm}\end{array}$ & $\begin{array}{c}\text { Trans. 3 } \\
\mathrm{mm}\end{array}$ & $\begin{array}{c}\text { Trans. 4 } \\
\mathrm{mm}\end{array}$ & $\begin{array}{c}\text { Trans. 5 } \\
\mathrm{mm}\end{array}$ & $\begin{array}{c}\text { Trans. 6 } \\
\mathrm{mm}\end{array}$ & $\begin{array}{c}\text { Trans. 7 } \\
\mathrm{mm}\end{array}$ \\
\hline 0 & 0.00 & 0.00 & 0.00 & 0.00 & 0.00 & 0.00 & 0.04 \\
\hline 12 & -0.15 & 0.26 & 0.21 & 0.22 & 0.00 & 0.30 & 0.36 \\
\hline 21 & -0.22 & 0.44 & 0.00 & 0.39 & -0.04 & 0.45 & 0.57 \\
\hline 31 & -0.30 & 0.70 & 0.28 & 0.65 & -0.11 & 0.71 & 0.75 \\
\hline 41 & -0.37 & 1.11 & 0.48 & 1.00 & -0.15 & 1.08 & 1.18 \\
\hline 50 & -0.41 & 1.44 & 0.52 & 1.33 & -0.18 & 1.48 & 1.53 \\
\hline 61 & -0.44 & 1.92 & 0.93 & 1.76 & -0.22 & 1.97 & 1.99 \\
\hline 72 & -0.48 & 2.36 & 1.27 & 2.19 & -0.22 & 2.49 & 2.49 \\
\hline 82 & -0.52 & 2.77 & 2.68 & 2.58 & -0.33 & 3.01 & 2.92 \\
\hline 91 & -0.56 & 3.21 & 3.03 & 2.98 & -0.44 & 3.41 & 3.35 \\
\hline 101 & -0.63 & 3.58 & 3.37 & 3.34 & -0.44 & 3.86 & 3.74 \\
\hline 111 & -0.67 & 4.02 & 4.54 & 3.77 & -0.44 & 4.31 & 4.17 \\
\hline 122 & -0.70 & 4.50 & 5.02 & 4.20 & -0.47 & 4.86 & 4.67 \\
\hline 131 & -0.74 & 4.87 & 4.78 & 4.52 & -0.51 & 5.27 & 5.02 \\
\hline 141 & -0.78 & 5.28 & 5.23 & 4.91 & -0.58 & 5.75 & 5.45 \\
\hline 152 & -0.85 & 5.79 & 5.78 & 5.38 & -0.58 & 6.35 & 5.98 \\
\hline 162 & -0.89 & 6.16 & 6.16 & 5.74 & -0.62 & 6.79 & 6.37 \\
\hline 181 & -0.96 & 6.90 & 7.19 & 6.49 & -0.65 & 7.61 & 7.19 \\
\hline 201 & -1.04 & 7.79 & 8.16 & 7.35 & -0.73 & 8.57 & 8.08 \\
\hline 221 & -1.11 & 8.60 & 9.50 & 8.11 & -0.76 & 9.50 & 8.97 \\
\hline 242 & -1.22 & 9.45 & 10.50 & 8.93 & -0.76 & 10.47 & 9.94 \\
\hline 261 & -1.33 & 10.30 & 11.53 & 9.76 & -0.84 & 11.40 & 10.83 \\
\hline 281 & -1.37 & 11.14 & 12.46 & 10.62 & -0.84 & 12.40 & 11.75 \\
\hline 300 & -1.44 & 11.99 & 13.42 & 11.41 & -0.80 & 13.33 & 12.71 \\
\hline 319 & -1.48 & 12.92 & 13.32 & 12.30 & -0.84 & 14.33 & 13.68 \\
\hline 342 & -1.56 & 14.02 & 13.11 & 13.45 & -0.84 & 15.66 & 14.96 \\
\hline 341 & -1.56 & 14.06 & 13.04 & 13.49 & -0.84 & 15.70 & 14.96 \\
\hline 360 & -1.63 & 15.09 & 16.00 & 14.49 & -0.87 & 16.85 & 16.17 \\
\hline 374 & -1.63 & 15.83 & 14.21 & 15.21 & -0.91 & 17.71 & 17.02 \\
\hline 381 & -1.67 & 16.31 & 14.69 & 15.64 & -0.91 & 18.26 & 17.52 \\
\hline 392 & -1.70 & 17.08 & 17.38 & 16.46 & -0.94 & 19.08 & 18.38 \\
\hline 394 & -1.70 & 17.90 & 18.48 & 17.29 & -0.94 & 20.23 & 19.52 \\
\hline 397 & -1.70 & 19.45 & 20.54 & 18.87 & -0.94 & 22.53 & 21.76 \\
\hline 404 & -1.74 & 22.95 & 24.47 & 22.70 & -0.87 & 27.36 & 26.82 \\
\hline
\end{tabular}


Tabela II.12 - Leitura dos deslocamentos horizontais entre o reforço/substrato ao longo do eixo longitudinal da viga VA-3

\begin{tabular}{|c|c|c|c|c|c|c|c|c|}
\hline $\begin{array}{c}\text { Força } \\
\mathrm{kN}\end{array}$ & $\begin{array}{c}\text { Rel.1 } \\
\mathrm{mm}\end{array}$ & $\begin{array}{c}\text { Rel.2 } \\
\mathrm{mm}\end{array}$ & $\begin{array}{c}\text { Rel.3 } \\
\mathrm{mm}\end{array}$ & $\begin{array}{c}\text { Rel.4 } \\
\mathrm{mm}\end{array}$ & $\begin{array}{c}\text { Rel.5 } \\
\mathrm{mm}\end{array}$ & $\begin{array}{c}\text { Rel.6 } \\
\mathrm{mm}\end{array}$ & $\begin{array}{c}\text { Rel.7 } \\
\mathrm{mm}\end{array}$ & $\begin{array}{c}\text { Rel.8 } \\
\mathrm{mm}\end{array}$ \\
\hline 0 & 0.000 & 0.005 & 0.000 & 0.000 & 0.003 & 0.000 & 0.000 & 0.000 \\
\hline 12 & 0.000 & 0.000 & 0.000 & 0.000 & 0.003 & -0.005 & 0.000 & 0.000 \\
\hline 21 & 0.000 & 0.000 & 0.000 & 0.000 & 0.003 & -0.005 & 0.000 & 0.000 \\
\hline 31 & -0.003 & 0.000 & -0.005 & 0.000 & 0.003 & -0.010 & -0.005 & 0.000 \\
\hline 41 & 0.000 & 0.000 & -0.005 & 0.000 & 0.006 & -0.025 & -0.005 & 0.000 \\
\hline 50 & 0.000 & -0.005 & 0.000 & 0.000 & 0.006 & -0.034 & -0.005 & 0.000 \\
\hline 61 & -0.003 & 0.000 & 0.000 & 0.005 & 0.006 & -0.049 & -0.005 & 0.000 \\
\hline 72 & -0.003 & 0.000 & -0.005 & 0.000 & 0.006 & -0.064 & -0.005 & -0.003 \\
\hline 82 & -0.003 & -0.005 & -0.019 & 0.000 & 0.009 & -0.079 & -0.005 & -0.003 \\
\hline 91 & -0.003 & -0.020 & -0.029 & -0.005 & 0.012 & -0.094 & -0.005 & -0.003 \\
\hline 101 & -0.003 & -0.030 & -0.039 & -0.009 & 0.012 & -0.108 & 0.000 & -0.006 \\
\hline 111 & -0.003 & -0.045 & -0.058 & -0.009 & 0.012 & -0.118 & 0.000 & -0.006 \\
\hline 122 & -0.003 & -0.060 & -0.072 & -0.019 & -0.003 & -0.133 & 0.000 & -0.009 \\
\hline 131 & -0.003 & -0.075 & -0.082 & -0.024 & -0.018 & -0.143 & 0.000 & -0.009 \\
\hline 141 & -0.003 & -0.080 & -0.092 & -0.028 & -0.043 & -0.153 & 0.000 & -0.013 \\
\hline 152 & -0.003 & -0.095 & -0.101 & -0.033 & -0.064 & -0.167 & 0.000 & -0.016 \\
\hline 162 & -0.003 & -0.105 & -0.111 & -0.038 & -0.076 & -0.177 & 0.000 & -0.019 \\
\hline 181 & -0.006 & -0.130 & -0.130 & -0.047 & -0.095 & -0.202 & 0.005 & -0.019 \\
\hline 201 & -0.006 & -0.155 & -0.154 & -0.062 & -0.113 & -0.232 & 0.005 & -0.022 \\
\hline 221 & -0.006 & -0.170 & -0.173 & -0.071 & -0.131 & -0.266 & 0.009 & -0.022 \\
\hline 242 & -0.006 & -0.175 & -0.197 & -0.085 & -0.147 & -0.296 & 0.009 & -0.025 \\
\hline 261 & -0.003 & -0.180 & -0.222 & -0.100 & -0.159 & -0.325 & 0.014 & -0.022 \\
\hline 281 & 0.000 & -0.190 & -0.246 & -0.109 & -0.168 & -0.350 & 0.019 & -0.022 \\
\hline 300 & 0.000 & -0.200 & -0.279 & -0.123 & -0.180 & -0.374 & 0.024 & -0.025 \\
\hline 319 & 0.000 & -0.215 & -0.323 & -0.142 & -0.193 & -0.404 & 0.024 & -0.025 \\
\hline 342 & 0.000 & -0.235 & -0.376 & -0.166 & -0.205 & -0.443 & 0.024 & -0.025 \\
\hline 341 & 0.006 & -0.235 & -0.376 & -0.166 & -0.202 & -0.448 & 0.024 & -0.025 \\
\hline 360 & 0.013 & -0.255 & -0.424 & -0.185 & -0.208 & -0.488 & 0.019 & -0.028 \\
\hline 374 & 0.016 & -0.270 & -0.458 & -0.199 & -0.211 & -0.512 & 0.019 & -0.025 \\
\hline 381 & 0.016 & -0.275 & -0.472 & -0.209 & -0.217 & -0.527 & 0.019 & -0.028 \\
\hline 392 & 0.019 & -0.285 & -0.506 & -0.223 & -0.223 & -0.542 & 0.019 & -0.028 \\
\hline 394 & 0.019 & -0.290 & -0.520 & -0.232 & -0.431 & -0.552 & 0.014 & -0.028 \\
\hline 397 & 0.019 & -0.295 & -0.564 & -0.242 & -0.963 & -0.557 & 0.014 & -0.025 \\
\hline 404 & - & - & - & - & - & - & - & - \\
\hline
\end{tabular}


Tabela II.13 - Leitura das deformações nas armaduras longitudinais do substrato $\left(A_{\text {sl }}\right)$ e do reforço $\left(A_{\text {slr }}\right)$ da viga $\mathrm{VA-3}$

\begin{tabular}{|c|c|c|c|c|c|c|c|c|c|c|c|c|}
\hline $\begin{array}{l}\text { Força } \\
\mathrm{kN}\end{array}$ & $\begin{array}{c}\text { Ext.1 } \\
\mu \mathrm{e}\end{array}$ & $\begin{array}{c}\text { Ext.3 } \\
\mu \mathrm{e}\end{array}$ & $\begin{array}{c}\text { Ext.4 } \\
\mu \mathrm{e}\end{array}$ & $\begin{array}{c}\text { Ext.6 } \\
\mu \mathrm{e}\end{array}$ & $\begin{array}{c}\text { Ext.7 } \\
\mu \mathrm{e}\end{array}$ & $\begin{array}{c}\text { Ext.9 } \\
\mu \mathrm{e}\end{array}$ & $\begin{array}{c}\text { Ext.10 } \\
\mu \mathrm{e}\end{array}$ & $\begin{array}{c}\text { Ext.12 } \\
\mu \mathrm{e}\end{array}$ & $\begin{array}{c}\text { Ext.13 } \\
\mu \mathrm{e}\end{array}$ & $\begin{array}{c}\text { Ext.15 } \\
\mu \mathrm{e}\end{array}$ & $\begin{array}{c}\text { Ext.16 } \\
\mu \mathrm{e}\end{array}$ & $\begin{array}{c}\text { Ext.18 } \\
\mu \mathrm{e}\end{array}$ \\
\hline$\overline{0}$ & 0 & 0 & 0 & 0 & 0 & 0 & 0 & 0 & 0 & 0 & 0 & 0 \\
\hline 12 & 27 & 27 & 33 & 35 & 30 & 27 & 36 & 39 & 14 & 13 & 16 & 18 \\
\hline 21 & 47 & 48 & 59 & 62 & 55 & 48 & 63 & 68 & 24 & 24 & 28 & 32 \\
\hline 31 & 79 & 76 & 97 & 108 & 101 & 79 & 107 & 109 & 37 & 36 & 44 & 49 \\
\hline 41 & 145 & 120 & 197 & 197 & 183 & 128 & 198 & 176 & 56 & 52 & 66 & 69 \\
\hline 50 & 216 & 165 & 283 & 285 & 252 & 198 & 284 & 274 & 79 & 71 & 91 & 96 \\
\hline 61 & 290 & 224 & 376 & 381 & 324 & 328 & 374 & 450 & 106 & 91 & 117 & 127 \\
\hline 72 & 386 & 310 & 520 & 501 & 414 & 400 & 502 & 549 & 140 & 129 & 159 & 177 \\
\hline 82 & 465 & 406 & 625 & 592 & 484 & 482 & 592 & 650 & 176 & 167 & 211 & 245 \\
\hline 91 & 533 & 582 & 713 & 764 & 546 & 556 & 671 & 741 & 229 & 212 & 268 & 298 \\
\hline 101 & 05 & 59 & 801 & 859 & 612 & 626 & 755 & 831 & 273 & 268 & 313 & 363 \\
\hline 111 & 682 & 31 & 887 & 946 & 683 & 692 & 841 & 917 & 325 & 334 & 363 & 431 \\
\hline 122 & 790 & 13 & 1026 & 1051 & 766 & 773 & 944 & 1020 & 389 & 430 & 431 & 535 \\
\hline 131 & 866 & 875 & 1115 & 1125 & 828 & 834 & 1019 & 1096 & 433 & 481 & 480 & 583 \\
\hline 141 & 958 & 941 & 1219 & 1208 & 897 & 902 & 1103 & 1183 & 480 & 542 & 538 & 638 \\
\hline 152 & 1055 & 1024 & 1327 & 1307 & 978 & 987 & 1204 & 1288 & 547 & 611 & 633 & 707 \\
\hline 162 & \begin{tabular}{|l|}
1127 \\
\end{tabular} & 1088 & 1410 & \begin{tabular}{|c|}
1385 \\
\end{tabular} & 1040 & 1053 & 1280 & 1369 & 597 & 664 & 703 & 765 \\
\hline 181 & 1269 & 1221 & 1575 & 1544 & 1167 & 1187 & 1434 & 1532 & 698 & 768 & 825 & 870 \\
\hline 201 & 1428 & 1371 & 1759 & 1722 & 1311 & 1334 & 1609 & 1717 & 819 & 873 & 990 & 994 \\
\hline 221 & 1575 & 1512 & 1929 & 1891 & 1447 & 1474 & 1775 & 1890 & 946 & 977 & 1107 & 1119 \\
\hline 242 & 1728 & 1661 & \begin{tabular}{|l|}
2110 \\
\end{tabular} & 2074 & 1594 & 1622 & 1952 & 2072 & 1079 & 1090 & \begin{tabular}{|c|}
1215 \\
\end{tabular} & 1257 \\
\hline 261 & \begin{tabular}{|l|}
1865 \\
\end{tabular} & 1796 & 2271 & 2236 & 1721 & 1754 & 2109 & 2231 & 1187 & 1188 & 1311 & 1377 \\
\hline 281 & \begin{tabular}{|l|}
2014 \\
\end{tabular} & 1945 & 2448 & 2418 & 1866 & 1903 & 2281 & 2406 & 1296 & 1280 & \begin{tabular}{|l|}
1416 \\
\end{tabular} & 1507 \\
\hline 300 & 2152 & 2086 & 2611 & 2589 & 1998 & 2041 & 2442 & 2567 & 1402 & 1361 & \begin{tabular}{|l|}
1514 \\
\end{tabular} & 1642 \\
\hline 319 & 2326 & 2262 & 2932 & \begin{tabular}{|l|}
2869 \\
\end{tabular} & 2149 & 2197 & 2682 & 2860 & 1506 & \begin{tabular}{|l|}
1449 \\
\end{tabular} & \begin{tabular}{|l|}
1613 \\
\end{tabular} & 1787 \\
\hline 342 & 2552 & 2488 & 3227 & 3145 & 2367 & 2420 & 2945 & 3176 & 1631 & 1564 & 1733 & 1933 \\
\hline 341 & 2553 & 2491 & 3223 & 3144 & 2369 & 2421 & 2943 & 3182 & 1633 & 1568 & 1731 & 1929 \\
\hline 360 & 2750 & 2693 & 3498 & 3517 & 2559 & 2611 & 3204 & 3482 & 1732 & 1668 & 1841 & 2048 \\
\hline 374 & \begin{tabular}{|l|}
2891 \\
\end{tabular} & 2840 & \begin{tabular}{|l|}
3692 \\
\end{tabular} & $\begin{array}{l}3725 \\
\end{array}$ & 2696 & 2747 & $\begin{array}{l}3372 \\
\end{array}$ & 3712 & 1801 & 1737 & 1916 & 2133 \\
\hline 381 & 2987 & 2940 & 3856 & 3936 & 2785 & 2836 & 3509 & 3923 & 1842 & 1776 & 1951 & 2171 \\
\hline 392 & \begin{tabular}{|l|}
3149 \\
\end{tabular} & 3117 & \begin{tabular}{|l|l|}
449 \\
\end{tabular} & \begin{tabular}{|l|}
5202 \\
\end{tabular} & 2919 & 2980 & 3768 & 5525 & \begin{tabular}{|l|}
1909 \\
\end{tabular} & \begin{tabular}{|l|l|}
1842 \\
\end{tabular} & \begin{tabular}{|l|}
2018 \\
\end{tabular} & 2246 \\
\hline 394 & & 8835 & 11085 & 11526 & 2981 & 3059 & 4021 & 7986 & \begin{tabular}{|l|}
1924 \\
\end{tabular} & \begin{tabular}{|l|}
1856 \\
\end{tabular} & \begin{tabular}{|l|}
2024 \\
\end{tabular} & \begin{tabular}{|l|}
2249 \\
\end{tabular} \\
\hline 397 & \begin{tabular}{|l|}
13687 \\
\end{tabular} & 8709 & \begin{tabular}{|l|}
11911 \\
\end{tabular} & \begin{tabular}{|l|}
12174 \\
\end{tabular} & 3048 & 3319 & 4852 & 10243 & 1942 & 1869 & \begin{tabular}{|l|}
2032 \\
\end{tabular} & 2265 \\
\hline 404 & 13384 & 9282 & 12186 & 12375 & 3347 & 4824 & 9661 & 14035 & 1990 & 1904 & 2041 & 2295 \\
\hline
\end{tabular}


Tabela II.14 - Leitura das deformações do estribo e do concreto comprimido da viga VA-3

\begin{tabular}{|c|c|c|c|c|c|}
\hline \multirow[b]{2}{*}{$\begin{array}{c}\text { Força } \\
\text { kN }\end{array}$} & \multicolumn{2}{|c|}{ Estribo } & \multicolumn{3}{|c|}{ Concreto } \\
\hline & $\begin{array}{c}\text { Ext. } 19 \\
\mu \mathrm{e}\end{array}$ & $\begin{array}{c}\text { Ext. } 20 \\
\mu \mathrm{e}\end{array}$ & $\begin{array}{c}\text { Ext. 21 } \\
\mu \mathrm{e}\end{array}$ & $\begin{array}{c}\text { Ext. } 22 \\
\mu \mathrm{e}\end{array}$ & $\begin{array}{c}\text { Ext. } 23 \\
\mu \mathrm{e}\end{array}$ \\
\hline 0 & 0 & -1 & 0 & -1 & $\overline{1}$ \\
\hline 12 & 14 & 1 & -21 & -16 & -17 \\
\hline 21 & 27 & 3 & -37 & -27 & -30 \\
\hline 31 & 51 & 6 & -58 & -44 & -49 \\
\hline 41 & 86 & 14 & -87 & -65 & -71 \\
\hline 50 & 116 & 25 & -113 & -84 & -91 \\
\hline 61 & 153 & 41 & -141 & -108 & -116 \\
\hline 72 & 198 & 71 & -175 & -137 & -145 \\
\hline 82 & 236 & 112 & -208 & -163 & -174 \\
\hline 91 & 279 & 145 & -236 & -188 & -199 \\
\hline 101 & 322 & 167 & -266 & -216 & -225 \\
\hline 111 & 367 & 189 & -294 & -241 & -252 \\
\hline 122 & 424 & 218 & -332 & -275 & -283 \\
\hline 131 & 469 & 242 & -359 & -301 & -307 \\
\hline 141 & 525 & 270 & $\begin{array}{l}-392 \\
\end{array}$ & -328 & $\begin{array}{l}-334 \\
\end{array}$ \\
\hline 152 & 587 & 307 & -429 & -362 & $\begin{array}{l}-366 \\
\end{array}$ \\
\hline 162 & 636 & 335 & -459 & -390 & -390 \\
\hline 181 & 733 & 384 & -517 & -445 & $\begin{array}{l}-443 \\
\end{array}$ \\
\hline 201 & 843 & 432 & -584 & -506 & -502 \\
\hline 221 & 946 & 488 & -650 & -566 & -558 \\
\hline 242 & 1055 & 566 & -717 & -629 & -619 \\
\hline 261 & 1151 & 643 & -782 & -686 & -676 \\
\hline 281 & 1257 & 727 & -852 & -749 & $\begin{array}{l}-738 \\
\end{array}$ \\
\hline 300 & 1358 & 810 & -922 & -812 & -800 \\
\hline 319 & 1466 & 893 & -999 & -881 & -868 \\
\hline 342 & 1605 & 1000 & -1100 & -969 & $\begin{array}{l}-952 \\
\end{array}$ \\
\hline 341 & 1603 & 998 & -1099 & -967 & -951 \\
\hline 360 & 1735 & 1096 & -1192 & -1046 & -1028 \\
\hline 374 & 1852 & 1177 & -1274 & -1108 & -1091 \\
\hline 381 & 1902 & 1208 & -1301 & -1134 & -1115 \\
\hline 392 & 2031 & 1270 & -1381 & -1198 & -1176 \\
\hline 394 & 2067 & 1280 & -1610 & -1482 & -1356 \\
\hline 397 & 2101 & 1291 & -1966 & -1732 & -1567 \\
\hline 404 & 2170 & 1315 & -2726 & -1710 & -1976 \\
\hline
\end{tabular}




\section{Resultados da viga VC-1}

Tabela II.15 - Leitura dos deslocamentos verticais ao longo do eixo longitudinal da viga $\mathrm{VC}-1$

\begin{tabular}{|c|c|c|c|c|c|c|c|}
\hline $\begin{array}{c}\text { Força } \\
\text { kN }\end{array}$ & $\begin{array}{c}\text { Trans1 } \\
\mathrm{mm}\end{array}$ & $\begin{array}{c}\text { Trans.2 } \\
\mathrm{mm}\end{array}$ & $\begin{array}{c}\text { Trans.3 } \\
\mathrm{mm}\end{array}$ & $\begin{array}{c}\text { Trans.4 } \\
\mathrm{mm}\end{array}$ & $\begin{array}{c}\text { Trans.5 } \\
\mathrm{mm}\end{array}$ & $\begin{array}{c}\text { Trans.6 } \\
\mathrm{mm}\end{array}$ & $\begin{array}{c}\text { Trans.7 } \\
\mathrm{mm}\end{array}$ \\
\hline 0 & 0.00 & 0.04 & -0.04 & 0.04 & 0.00 & 0.00 & 0.00 \\
\hline 22 & -0.15 & 0.44 & 0.48 & 0.48 & -0.18 & 0.59 & 0.43 \\
\hline 31 & -0.18 & 0.70 & 0.73 & 0.74 & -0.22 & 0.81 & 0.76 \\
\hline 42 & -0.29 & 1.04 & 1.10 & 1.07 & -0.33 & 1.18 & 1.15 \\
\hline 51 & -0.40 & 1.37 & 1.43 & 1.37 & -0.40 & 1.51 & 1.47 \\
\hline 61 & -0.44 & 1.63 & 1.73 & 1.62 & -0.47 & 1.80 & 1.80 \\
\hline 71 & -0.55 & 2.04 & 2.13 & 1.99 & -0.55 & 2.24 & 2.19 \\
\hline 81 & -0.62 & 2.30 & 2.46 & 2.32 & -0.58 & 2.61 & 2.52 \\
\hline 78 & -0.62 & 2.37 & 2.46 & 2.36 & -0.62 & 2.65 & 2.52 \\
\hline 101 & -0.73 & 3.15 & 3.34 & 3.17 & -0.69 & 3.61 & 3.38 \\
\hline 122 & -0.91 & 3.96 & 4.15 & 3.95 & -0.84 & 4.49 & 4.21 \\
\hline 141 & -1.02 & 4.74 & 4.96 & 4.69 & -0.95 & 5.33 & 5.00 \\
\hline 162 & -1.13 & 5.67 & 5.95 & 5.65 & -1.05 & 6.40 & 6.01 \\
\hline 181 & -1.28 & 6.67 & 6.98 & 6.61 & -1.20 & 7.51 & 7.05 \\
\hline 201 & -1.39 & 8.07 & 8.41 & 7.93 & -1.31 & 9.01 & 8.49 \\
\hline 220 & -1.46 & 10.00 & 10.35 & 9.74 & -1.42 & 11.00 & 10.43 \\
\hline
\end{tabular}

Tabela II.16 - Leitura dos deslocamentos horizontais entre o reforço e o substrato ao longo do eixo longitudinal da viga VC-1

\begin{tabular}{|c|c|c|c|c|c|c|c|}
\hline $\begin{array}{c}\text { Força } \\
\mathrm{kN}\end{array}$ & $\begin{array}{c}\text { Rel.1 } \\
\mathrm{mm}\end{array}$ & $\begin{array}{c}\text { Rel.2 } \\
\mathrm{mm}\end{array}$ & $\begin{array}{c}\text { Rel.3 } \\
\mathrm{mm}\end{array}$ & $\begin{array}{c}\text { Rel.4 } \\
\mathrm{mm}\end{array}$ & $\begin{array}{c}\text { Rel.5 } \\
\mathrm{mm}\end{array}$ & $\begin{array}{c}\text { Rel.6 } \\
\mathrm{mm}\end{array}$ & $\begin{array}{c}\text { Rel.8 } \\
\mathrm{mm}\end{array}$ \\
\hline 0 & 0.003 & 0.000 & 0.000 & 0.000 & 0.000 & 0.000 & 0.000 \\
\hline 22 & 0.000 & 0.000 & 0.000 & -0.005 & -0.005 & 0.003 & -0.005 \\
\hline 31 & -0.006 & 0.000 & 0.000 & -0.009 & -0.005 & 0.003 & -0.009 \\
\hline 42 & -0.019 & -0.003 & -0.005 & -0.009 & -0.005 & 0.003 & -0.019 \\
\hline 51 & -0.028 & -0.006 & -0.010 & -0.009 & -0.005 & 0.003 & -0.024 \\
\hline 61 & -0.038 & -0.009 & -0.025 & -0.009 & -0.005 & 0.006 & -0.028 \\
\hline 71 & -0.057 & -0.012 & -0.035 & -0.009 & -0.010 & 0.006 & -0.028 \\
\hline 81 & -0.072 & -0.009 & -0.045 & -0.009 & -0.010 & 0.009 & -0.024 \\
\hline 78 & -0.079 & -0.009 & -0.045 & -0.005 & -0.010 & 0.009 & -0.028 \\
\hline 101 & -0.107 & -0.006 & -0.065 & -0.005 & -0.010 & 0.019 & -0.028 \\
\hline 122 & -0.126 & 0.003 & -0.075 & -0.014 & -0.005 & 0.025 & -0.028 \\
\hline 141 & -0.135 & 0.034 & -0.090 & -0.024 & 0.005 & 0.022 & -0.028 \\
\hline 162 & -0.145 & 0.104 & -0.105 & -0.038 & 0.005 & -0.003 & -0.024 \\
\hline 181 & -0.148 & 0.223 & -0.115 & -0.047 & -0.005 & -0.035 & -0.028 \\
\hline 201 & -0.154 & -0.067 & -0.130 & -0.047 & -0.015 & -0.075 & -0.038 \\
\hline 220 & -0.148 & -0.294 & -0.180 & -0.038 & -0.044 & 0.035 & -0.052 \\
\hline
\end{tabular}


Tabela II.17 - Leitura das deformações nas armaduras longitudinais do substrato $\left(A_{\text {sl }}\right)$ e do reforço $\left(A_{\text {slr }}\right)$ da viga $\mathrm{VC}-1$

\begin{tabular}{|c|c|c|c|c|c|c|c|c|c|c|c|c|}
\hline $\begin{array}{c}\text { Força } \\
\mathrm{kN}\end{array}$ & $\begin{array}{c}\text { Ext.1 } \\
\mu \mathrm{e}\end{array}$ & $\begin{array}{c}\text { Ext.3 } \\
\mu \mathrm{e}\end{array}$ & $\begin{array}{c}\text { Ext.4 } \\
\mu \mathrm{e}\end{array}$ & $\begin{array}{c}\text { Ext.6 } \\
\mu \mathrm{e}\end{array}$ & $\begin{array}{c}\text { Ext.7 } \\
\mu \mathrm{e}\end{array}$ & $\begin{array}{c}\text { Ext.9 } \\
\mu \mathrm{e}\end{array}$ & $\begin{array}{c}\text { Ext.10 } \\
\mu \mathrm{e}\end{array}$ & $\begin{array}{c}\text { Ext.12 } \\
\mu \mathrm{e}\end{array}$ & $\begin{array}{c}\text { Ext.13 } \\
\mu \mathrm{e}\end{array}$ & $\begin{array}{c}\text { Ext.15 } \\
\mu \mathrm{e}\end{array}$ & $\begin{array}{c}\text { Ext.16 } \\
\mu \mathrm{e}\end{array}$ & $\begin{array}{c}\text { Ext.18 } \\
\mu \mathrm{e}\end{array}$ \\
\hline 0 & 0 & 0 & 0 & 0 & 0 & 0 & -1 & 0 & 0 & 0 & 0 & 0 \\
\hline 22 & 49 & 50 & 67 & 65 & 50 & 48 & 64 & 67 & 21 & 21 & 34 & 31 \\
\hline 31 & 76 & 83 & 106 & 104 & 78 & 77 & 100 & 103 & 31 & 31 & 51 & 48 \\
\hline 42 & 109 & 123 & 161 & 159 & 116 & 113 & 161 & 142 & 44 & 43 & 71 & 66 \\
\hline 51 & 140 & 157 & 212 & 211 & 189 & 157 & 207 & 200 & 55 & 53 & 89 & 84 \\
\hline 61 & 175 & 198 & 260 & 256 & 252 & 205 & 253 & 248 & 68 & 64 & 109 & 103 \\
\hline 71 & 217 & 244 & 319 & 311 & 322 & 283 & 307 & 313 & 80 & 73 & 148 & 149 \\
\hline 81 & 256 & 285 & 376 & 360 & 381 & 348 & 355 & 368 & 87 & 71 & 193 & 229 \\
\hline 78 & 259 & 285 & 382 & 359 & 381 & 353 & 354 & 371 & 88 & 67 & 197 & 236 \\
\hline 101 & 371 & 384 & 519 & 477 & 516 & 500 & 459 & 507 & 198 & 159 & 272 & 356 \\
\hline 122 & 488 & 477 & 643 & 584 & 633 & 624 & 553 & 648 & 363 & 317 & 350 & 455 \\
\hline 141 & 596 & 568 & 758 & 685 & 752 & 741 & 638 & 792 & 447 & 377 & 421 & 539 \\
\hline 162 & 722 & 681 & 888 & 794 & 896 & 880 & 739 & 964 & 525 & 413 & 523 & 628 \\
\hline 181 & 846 & 794 & 1007 & 893 & 1018 & 1009 & 842 & 1126 & 592 & 460 & 626 & 699 \\
\hline 201 & 1004 & 945 & 1139 & 1004 & 1149 & 1143 & 966 & 1314 & 717 & 607 & 751 & 784 \\
\hline 220 & 1176 & 1123 & 1259 & 1105 & 1312 & 1330 & 1057 & 1496 & 749 & 769 & 963 & 773 \\
\hline
\end{tabular}

Tabela II.18 - Leitura das deformações do estribo e do concreto comprimido da viga $\mathrm{VC}-1$

\begin{tabular}{|c|c|c|c|c|c|}
\hline \multirow[b]{2}{*}{$\begin{array}{c}\text { Força } \\
\mathrm{kN}\end{array}$} & \multicolumn{2}{|c|}{ Estribo } & \multicolumn{3}{|c|}{ Concreto } \\
\hline & $\begin{array}{c}\text { Ext.19 } \\
\mu \mathrm{e}\end{array}$ & $\begin{array}{c}\text { Ext.20 } \\
\mu \mathrm{e}\end{array}$ & $\begin{array}{c}\text { Ext.21 } \\
\mu \mathrm{e}\end{array}$ & $\begin{array}{c}\text { Ext.22 } \\
\mu \mathrm{e}\end{array}$ & $\begin{array}{c}\text { Ext.23 } \\
\mu \mathrm{e}\end{array}$ \\
\hline 0 & 0 & 0 & $\overline{0}$ & 0 & $\overline{0}$ \\
\hline 22 & 1 & 0 & -44 & -46 & -41 \\
\hline 31 & 0 & 0 & -66 & -70 & -62 \\
\hline 42 & -1 & 0 & -96 & -99 & -87 \\
\hline 51 & -2 & 0 & -120 & -124 & -108 \\
\hline 61 & -2 & 2 & -144 & -149 & -128 \\
\hline 71 & -6 & 3 & -171 & -178 & -151 \\
\hline 81 & -10 & -3 & -196 & -204 & $\begin{array}{l}-172 \\
\end{array}$ \\
\hline 78 & -9 & -4 & -193 & -202 & -168 \\
\hline 101 & -5 & -6 & -252 & -266 & -220 \\
\hline 122 & 459 & 320 & -310 & -328 & -268 \\
\hline 141 & 711 & 585 & -363 & -387 & -316 \\
\hline 162 & 954 & 814 & -429 & -458 & -370 \\
\hline 181 & 1139 & 1007 & -493 & -526 & -421 \\
\hline 201 & 1230 & 1127 & -567 & -603 & -483 \\
\hline 220 & 1217 & 1094 & -641 & -677 & -543 \\
\hline
\end{tabular}


Tabela II.19 - Leitura das tensões e deformações máximas e mínimas dadas pelas rosetas da viga $\mathrm{VC}-1$

\begin{tabular}{|c|c|c|c|c|c|c|c|c|}
\hline \multirow{2}{*}{$\begin{array}{c}\text { Força } \\
\mathrm{kN}\end{array}$} & \multicolumn{6}{|c|}{ Roseta 1 } & \multicolumn{4}{c|}{ Roseta 2 } \\
\cline { 2 - 9 } & $\begin{array}{c}\varepsilon_{\max } \\
\mu \mathrm{e}\end{array}$ & $\begin{array}{c}\varepsilon_{\min } \\
\mu \mathrm{e}\end{array}$ & $\begin{array}{c}\sigma_{\max } \\
\mathrm{kN} / \mathrm{cm}^{2}\end{array}$ & $\begin{array}{c}\sigma_{\min } \\
\mathrm{kN} / \mathrm{cm}^{2}\end{array}$ & $\begin{array}{c}\varepsilon_{\max } \\
\mu \mathrm{e}\end{array}$ & $\begin{array}{c}\varepsilon_{\min } \\
\mu \mathrm{e}\end{array}$ & $\begin{array}{c}\sigma_{\max } \\
\mathrm{kN} / \mathrm{cm}^{2}\end{array}$ & $\begin{array}{c}\sigma_{\min } \\
\mathrm{kN} / \mathrm{cm}^{2}\end{array}$ \\
\hline 0 & 0.00 & 0.00 & 0.000 & 0.000 & 0.00 & 0.00 & 0.000 & 0.000 \\
\hline 22 & 6.20 & -27.57 & 0.003 & -0.097 & 7.73 & -4.02 & 0.026 & -0.009 \\
\hline 31 & 9.73 & -42.24 & 0.005 & -0.149 & 11.60 & -6.02 & 0.038 & -0.014 \\
\hline 42 & 11.84 & -59.21 & 0.000 & -0.210 & 15.46 & -8.03 & 0.051 & -0.018 \\
\hline 51 & 12.65 & -72.09 & -0.007 & -0.257 & 19.51 & -9.30 & 0.065 & -0.020 \\
\hline 61 & 13.99 & -83.65 & -0.010 & -0.299 & 23.24 & -10.24 & 0.078 & -0.021 \\
\hline 71 & 14.24 & -99.69 & -0.021 & -0.358 & 22.67 & -13.39 & 0.074 & -0.033 \\
\hline 81 & 12.67 & -111.13 & -0.035 & -0.402 & 24.51 & -15.23 & 0.079 & -0.038 \\
\hline 78 & 9.85 & -106.45 & -0.042 & -0.386 & 20.84 & -13.41 & 0.067 & -0.034 \\
\hline 101 & 0.27 & -101.52 & -0.074 & -0.375 & 29.58 & -14.72 & 0.098 & -0.033 \\
\hline 122 & -8.44 & -90.01 & -0.098 & -0.339 & 35.52 & -26.23 & 0.112 & -0.071 \\
\hline
\end{tabular}




\section{Resultados da viga VC-2}

Tabela II.20 - Leitura dos deslocamentos verticais ao longo do eixo longitudinal da viga $\mathrm{VC}-2$

\begin{tabular}{|c|c|c|c|c|c|c|c|}
\hline $\begin{array}{c}\text { Força } \\
\text { kN }\end{array}$ & $\begin{array}{c}\text { Trans.1 } \\
\mathrm{mm}\end{array}$ & $\begin{array}{c}\text { Trans.2 } \\
\mathrm{mm}\end{array}$ & $\begin{array}{c}\text { Trans.3 } \\
\mathrm{mm}\end{array}$ & $\begin{array}{c}\text { Trans.4 } \\
\mathrm{mm}\end{array}$ & $\begin{array}{c}\text { Trans.5 } \\
\mathrm{mm}\end{array}$ & $\begin{array}{c}\text { Trans.6 } \\
\mathrm{mm}\end{array}$ & $\begin{array}{c}\text { Trans.7 } \\
\mathrm{mm}\end{array}$ \\
\hline 0 & 0.00 & 0.00 & 0.00 & 0.00 & 0.00 & 0.00 & 0.00 \\
\hline 11 & 0.00 & 0.26 & 0.28 & 0.22 & -0.04 & 0.15 & 0.36 \\
\hline 20 & -0.04 & 0.48 & 0.48 & 0.43 & -0.07 & 0.37 & 0.61 \\
\hline 32 & -0.15 & 0.85 & 0.86 & 0.75 & -0.11 & 0.71 & 1.00 \\
\hline 42 & -0.19 & 1.18 & 1.24 & 1.04 & -0.18 & 1.00 & 1.32 \\
\hline 51 & -0.22 & 1.48 & 1.55 & 1.33 & -0.22 & 1.30 & 1.82 \\
\hline 61 & -0.30 & 1.81 & 1.93 & 1.61 & -0.25 & 1.63 & 2.21 \\
\hline 70 & -0.33 & 2.07 & 2.20 & 1.90 & -0.25 & 1.93 & 2.53 \\
\hline 80 & -0.41 & 2.44 & 2.58 & 2.26 & -0.33 & 2.23 & 2.92 \\
\hline 90 & -0.44 & 2.77 & 2.96 & 2.51 & -0.36 & 2.60 & 3.31 \\
\hline 101 & -0.52 & 3.14 & 3.37 & 2.94 & -0.36 & 2.97 & 3.77 \\
\hline 111 & -0.56 & 3.47 & 3.75 & 3.26 & -0.36 & 3.38 & 4.17 \\
\hline 120 & -0.59 & 3.80 & 4.13 & 3.62 & -0.40 & 3.75 & 4.59 \\
\hline 132 & -0.67 & 4.24 & 4.65 & 4.02 & -0.44 & 4.23 & 5.09 \\
\hline 142 & -0.70 & 4.65 & 5.09 & 4.45 & -0.47 & 4.71 & 5.56 \\
\hline 152 & -0.78 & 5.06 & 5.51 & 4.84 & -0.47 & 5.20 & 6.02 \\
\hline 161 & -0.81 & 5.54 & 5.99 & 5.24 & -0.51 & 5.68 & 6.52 \\
\hline 181 & -0.89 & 6.49 & 6.99 & 6.06 & -0.55 & 6.68 & 7.48 \\
\hline 203 & -0.96 & 7.53 & 8.05 & 7.10 & -0.55 & 7.80 & 8.58 \\
\hline 221 & -1.19 & 8.56 & 9.15 & 8.03 & -0.55 & 8.87 & 9.69 \\
\hline 241 & -1.26 & 9.67 & 10.25 & 9.11 & -0.55 & 10.06 & 10.86 \\
\hline 261 & -1.37 & 11.00 & 11.70 & 10.40 & -0.55 & 11.51 & 12.32 \\
\hline 281 & -1.44 & 12.21 & 13.04 & 11.66 & -0.55 & 12.84 & 13.68 \\
\hline 302 & -1.48 & 13.84 & 14.69 & 13.16 & -0.55 & 14.51 & 15.38 \\
\hline 320 & -1.56 & 15.28 & 16.28 & 14.53 & -0.55 & 16.11 & 16.99 \\
\hline 341 & -1.63 & 17.05 & 18.24 & 16.28 & -0.55 & 18.04 & 18.95 \\
\hline 360 & -1.70 & 18.97 & 20.30 & 18.04 & -0.58 & 20.12 & 21.01 \\
\hline 376 & -1.81 & 26.94 & 29.53 & 25.32 & -0.55 & 29.62 & 30.45 \\
\hline 385 & -1.81 & 31.00 & 34.27 & 29.34 & -0.58 & 34.56 & 35.33 \\
\hline 389 & -1.81 & 34.83 & 38.78 & 33.25 & -0.58 & 39.20 & 39.85 \\
\hline & & & & & & & \\
\hline
\end{tabular}


Tabela II.21 - Leitura dos deslocamentos horizontais entre o reforço/substrato ao longo do eixo longitudinal da viga $\mathrm{VC}-2$

\begin{tabular}{|c|c|c|c|c|c|c|c|c|}
\hline $\begin{array}{c}\text { Força } \\
\text { kN }\end{array}$ & $\begin{array}{c}\text { Rel.1 } \\
\mathrm{mm}\end{array}$ & $\begin{array}{c}\text { Rel.2 } \\
\mathrm{mm}\end{array}$ & $\begin{array}{c}\text { Rel.3 } \\
\mathrm{mm}\end{array}$ & $\begin{array}{c}\text { Rel.4 } \\
\mathrm{mm}\end{array}$ & $\begin{array}{c}\text { Rel.5 } \\
\mathrm{mm}\end{array}$ & $\begin{array}{c}\text { Rel.6 } \\
\mathrm{mm}\end{array}$ & $\begin{array}{c}\text { Rel.7 } \\
\mathrm{mm}\end{array}$ & $\begin{array}{c}\text { Rel.8 } \\
\mathrm{mm}\end{array}$ \\
\hline 0 & 0.000 & 0.000 & 0.000 & 0.000 & 0.003 & 0.005 & 0.000 & 0.000 \\
\hline 11 & 0.000 & 0.000 & 0.000 & 0.000 & 0.000 & 0.005 & 0.000 & 0.000 \\
\hline 20 & 0.000 & 0.000 & -0.005 & 0.000 & 0.000 & 0.005 & 0.000 & 0.000 \\
\hline 32 & 0.000 & -0.015 & -0.005 & 0.019 & 0.000 & 0.010 & 0.000 & -0.003 \\
\hline 42 & 0.000 & -0.025 & -0.005 & 0.028 & 0.018 & 0.015 & -0.005 & -0.003 \\
\hline 51 & -0.003 & -0.030 & -0.010 & 0.028 & 0.031 & 0.015 & -0.005 & -0.003 \\
\hline 61 & -0.003 & -0.035 & -0.014 & 0.033 & 0.040 & 0.015 & -0.009 & -0.003 \\
\hline 70 & -0.003 & -0.035 & -0.019 & 0.038 & 0.049 & 0.015 & -0.009 & -0.003 \\
\hline 80 & -0.003 & -0.040 & -0.024 & 0.033 & 0.055 & 0.015 & -0.014 & -0.003 \\
\hline 90 & -0.003 & -0.045 & -0.034 & 0.033 & 0.058 & 0.010 & -0.019 & -0.003 \\
\hline 101 & -0.006 & -0.060 & -0.048 & 0.033 & 0.061 & 0.010 & -0.100 & -0.003 \\
\hline 111 & -0.006 & -0.070 & -0.058 & 0.033 & 0.064 & 0.020 & -0.147 & -0.003 \\
\hline 120 & -0.006 & -0.080 & -0.067 & 0.033 & 0.064 & 0.039 & -0.185 & -0.003 \\
\hline 132 & -0.006 & -0.085 & -0.077 & 0.038 & 0.067 & 0.064 & -0.223 & -0.003 \\
\hline 142 & -0.009 & -0.090 & -0.082 & 0.038 & 0.067 & 0.084 & -0.237 & -0.003 \\
\hline 152 & -0.009 & -0.095 & -0.092 & 0.043 & 0.067 & 0.108 & -0.251 & 0.000 \\
\hline 161 & -0.009 & -0.130 & -0.092 & 0.043 & 0.064 & 0.128 & -0.261 & 0.000 \\
\hline 181 & -0.013 & -0.125 & -0.092 & 0.038 & 0.058 & 0.172 & -0.266 & 0.003 \\
\hline 203 & -0.013 & -0.130 & -0.087 & -0.062 & 0.049 & 0.212 & -0.242 & 0.003 \\
\hline 221 & -0.006 & -0.140 & -0.077 & -0.104 & 0.040 & 0.246 & -0.209 & 0.006 \\
\hline 241 & 0.006 & -0.135 & -0.072 & -0.147 & 0.021 & 0.291 & -0.175 & 0.006 \\
\hline 261 & 0.016 & -0.130 & -0.082 & -0.223 & -0.006 & 0.374 & -0.138 & 0.006 \\
\hline 281 & 0.028 & -0.115 & -0.116 & -0.280 & -0.031 & 0.448 & -0.128 & 0.009 \\
\hline 302 & 0.041 & -0.170 & -0.149 & -0.342 & -0.058 & 0.562 & -0.119 & 0.009 \\
\hline 320 & 0.057 & -0.205 & -0.169 & -0.403 & -0.086 & 0.670 & -0.109 & 0.009 \\
\hline 341 & 0.066 & -0.240 & -0.188 & -0.498 & -0.119 & 0.793 & -0.081 & 0.013 \\
\hline 360 & 0.072 & -0.280 & -0.207 & -0.593 & -0.156 & 0.872 & -0.066 & 0.013 \\
\hline 376 & 0.076 & -0.325 & -0.250 & -0.664 & -0.508 & 0.877 & -0.057 & 0.013 \\
\hline 385 & - & - & - & - & - & - & - & - \\
\hline 389 & - & - & - & - & - & - & - & - \\
\hline & & & & & & & & \\
\hline
\end{tabular}


Tabela II.22 - Leitura das deformações nas armaduras longitudinais do substrato $\left(A_{\text {sl }}\right)$ e do reforço $\left(A_{\text {slr }}\right)$ da viga $\mathrm{VC}-2$

\begin{tabular}{|c|c|c|c|c|c|c|c|c|c|c|c|c|}
\hline $\begin{array}{l}\text { Força } \\
\mathrm{kN}\end{array}$ & $\begin{array}{c}\text { Ext.1 } \\
\mu \mathrm{e}\end{array}$ & $\begin{array}{c}\text { Ext.3 } \\
\mu \mathrm{e}\end{array}$ & $\begin{array}{c}\text { Ext.4 } \\
\mu \mathrm{e}\end{array}$ & $\begin{array}{c}\text { Ext.6 } \\
\mu \mathrm{e}\end{array}$ & $\begin{array}{c}\text { Ext.7 } \\
\mu \mathrm{e}\end{array}$ & $\begin{array}{c}\text { Ext.9 } \\
\mu \mathrm{e}\end{array}$ & $\begin{array}{l}\text { Ext.10 } \\
\mu \mathrm{e}\end{array}$ & $\begin{array}{c}\begin{array}{c}\text { Ext.12 } \\
\mu \mathrm{e}\end{array} \\
\end{array}$ & $\begin{array}{c}\text { Ext.13 } \\
\mu \mathrm{e}\end{array}$ & $\begin{array}{c}\text { Ext.15 } \\
\mu \mathrm{e}\end{array}$ & $\begin{array}{c}\text { Ext.16 } \\
\mu \mathrm{e}\end{array}$ & $\begin{array}{c}\text { Ext.18 } \\
\mu \mathrm{e}\end{array}$ \\
\hline 0 & 0 & 0 & 0 & 0 & 0 & 0 & 0 & 0 & 0 & 0 & 1 & 1 \\
\hline$\overline{11}$ & 26 & 26 & 32 & 29 & 24 & 26 & 32 & 33 & 14 & 13 & 17 & 19 \\
\hline 20 & 51 & 51 & 65 & 58 & 54 & 66 & 69 & 76 & 30 & 23 & 34 & 41 \\
\hline 32 & 81 & 85 & 113 & 98 & 194 & 223 & 154 & 165 & 119 & 32 & 70 & 91 \\
\hline 42 & 114 & 125 & 154 & 150 & 258 & 279 & 204 & 217 & 182 & 49 & 103 & 140 \\
\hline 51 & 161 & 191 & 191 & 217 & 311 & 324 & 254 & 265 & 217 & 68 & 131 & 186 \\
\hline 61 & 218 & 253 & 254 & 274 & 372 & 375 & 310 & 320 & 247 & 93 & 163 & 241 \\
\hline 70 & 259 & 296 & 304 & 315 & 424 & 413 & 357 & 365 & 276 & 111 & 190 & 283 \\
\hline 80 & 311 & 348 & 364 & 369 & 491 & 470 & 415 & 426 & 298 & 132 & 223 & 344 \\
\hline 90 & 359 & 401 & 422 & 420 & 556 & 513 & 471 & 485 & 309 & 163 & 247 & 398 \\
\hline 101 & 412 & 460 & 484 & 474 & 628 & 562 & 528 & 545 & 326 & 197 & 274 & 453 \\
\hline 111 & 462 & 513 & 544 & 522 & 696 & 611 & 581 & 603 & 343 & 230 & 302 & 503 \\
\hline 120 & 520 & 566 & 603 & 572 & 762 & 654 & 629 & 661 & 363 & 258 & 328 & 551 \\
\hline 132 & 594 & 636 & 682 & 636 & 847 & 712 & 691 & 740 & 392 & 302 & 363 & 639 \\
\hline 142 & 654 & 692 & 744 & 685 & 914 & 757 & 740 & 803 & 429 & 359 & 383 & 716 \\
\hline 152 & 725 & 749 & 817 & 742 & 987 & 809 & 795 & 880 & 492 & 426 & 406 & 797 \\
\hline 161 & 796 & 806 & 891 & 799 & 1059 & 850 & 845 & 958 & 546 & 479 & 431 & 860 \\
\hline 181 & 953 & 931 & 1061 & 932 & 1184 & 955 & 953 & 1131 & 646 & 596 & 485 & 986 \\
\hline 203 & 1119 & 1071 & 1248 & 1076 & 1315 & 1072 & 1076 & 1320 & 759 & 718 & 538 & 1119 \\
\hline 221 & 1279 & 1207 & 1423 & 1215 & 1453 & 1180 & 1190 & 1502 & 885 & 850 & 581 & 1240 \\
\hline 241 & 1452 & 1362 & 1612 & 1368 & 1614 & 1311 & 1317 & 1716 & 1009 & 979 & 634 & 1376 \\
\hline 261 & 1656 & 1550 & 1833 & 1545 & 1801 & 1471 & 1468 & 2008 & 1146 & 1153 & 701 & 1536 \\
\hline 281 & 1856 & 1737 & 2046 & 1716 & 1988 & 1646 & 1617 & 2335 & 1275 & 1340 & 781 & 1677 \\
\hline 302 & 2103 & 1974 & 2304 & 1925 & 2226 & 1853 & 1789 & 2798 & 1553 & 1529 & 898 & 1816 \\
\hline 320 & 2349 & 2211 & 2549 & 2126 & 2465 & 2067 & 1951 & 3317 & 1702 & 1662 & 971 & 1984 \\
\hline 341 & 2664 & 2506 & 2857 & 2380 & 2780 & 2340 & 2152 & 4055 & 1871 & 1819 & 1047 & 2174 \\
\hline 360 & 3069 & 2769 & 3198 & 2670 & 4477 & 2636 & 2426 & 5030 & 2025 & 1962 & 1109 & 2344 \\
\hline 376 & 10849 & 2970 & 5235 & 4452 & 10570 & 7924 & 4014 & 7651 & 2196 & 2111 & 1166 & 2513 \\
\hline 385 & 11312 & 9012 & 6463 & 5649 & 12355 & 11284 & 4763 & \begin{tabular}{|l|l|}
8358 \\
\end{tabular} & 2281 & 2185 & 1187 & 2555 \\
\hline 389 & 11823 & 10110 & 4920 & 7188 & 12681 & 11715 & 5577 & 9158 & 2354 & 2256 & 1186 & 2553 \\
\hline
\end{tabular}


Tabela II.23 - Leitura das deformações do estribo, do concreto comprimido e dos conectores metálicos da viga $\mathrm{VC}-2$

\begin{tabular}{|c|c|c|c|c|c|c|c|c|c|c|}
\hline \multirow[b]{2}{*}{$\begin{array}{c}\text { Força } \\
\text { kN }\end{array}$} & \multicolumn{2}{|c|}{ Estribo } & \multicolumn{3}{|c|}{ Concreto } & \multicolumn{5}{|c|}{ Conectores metálicos } \\
\hline & $\begin{array}{c}\text { Ext.19 } \\
\mu \mathrm{e}\end{array}$ & $\begin{array}{c}\text { Ext.20 } \\
\mu \mathrm{e}\end{array}$ & $\begin{array}{c}\text { Ext.21 } \\
\mu \mathrm{e}\end{array}$ & $\begin{array}{c}\text { Ext.22 } \\
\mu \mathrm{e}\end{array}$ & $\begin{array}{c}\text { Ext.23 } \\
\mu \mathrm{e}\end{array}$ & $\begin{array}{c}\text { Ext.24 } \\
\mu \mathrm{e}\end{array}$ & $\begin{array}{c}\text { Ext.25 } \\
\mu \mathrm{e}\end{array}$ & $\begin{array}{c}\text { Ext.26 } \\
\mu \mathrm{e}\end{array}$ & $\begin{array}{c}\text { Ext.27 } \\
\mu \mathrm{e}\end{array}$ & $\begin{array}{c}\text { Ext.28 } \\
\mu \mathrm{e}\end{array}$ \\
\hline 0 & 1 & $\overline{0}$ & 1 & $\overline{1}$ & $\overline{1}$ & $\overline{0}$ & 0 & 1 & 1 & 0 \\
\hline 11 & 1 & 1 & -24 & -20 & -17 & 2 & -2 & -1 & -3 & -3 \\
\hline 20 & 0 & 7 & -48 & -40 & -34 & 15 & -3 & 2 & 4 & -1 \\
\hline 32 & -4 & 3 & -78 & -65 & -55 & 14 & 6 & 29 & 66 & 22 \\
\hline 42 & -5 & 9 & -105 & -88 & -75 & 16 & 27 & 63 & 112 & 39 \\
\hline 51 & -6 & 17 & -136 & -111 & -96 & 1 & 53 & 106 & 139 & 56 \\
\hline 61 & -5 & 23 & -172 & -137 & -121 & 26 & 82 & 165 & 162 & 75 \\
\hline 70 & -5 & 27 & -201 & -159 & -140 & 13 & 107 & 212 & 183 & 90 \\
\hline 80 & -4 & 35 & -236 & -183 & -165 & 27 & 156 & 273 & 214 & 106 \\
\hline 90 & 2 & 50 & -269 & -206 & -188 & 108 & 267 & 333 & 244 & 121 \\
\hline 101 & 14 & 83 & -307 & -230 & -214 & 255 & 385 & 383 & 273 & 137 \\
\hline 111 & 18 & 110 & -343 & -254 & -237 & 605 & 457 & 429 & 300 & 151 \\
\hline 120 & 22 & 136 & -379 & -276 & -259 & 721 & 520 & 465 & 324 & 167 \\
\hline 132 & 27 & 167 & -426 & -307 & -288 & 829 & 626 & 416 & 352 & 186 \\
\hline 142 & 38 & 193 & -465 & $\begin{array}{l}-332 \\
\end{array}$ & -313 & 913 & 712 & 404 & 373 & 197 \\
\hline 152 & 49 & 231 & -506 & -360 & -339 & 1053 & 794 & 434 & 397 & 206 \\
\hline 161 & 279 & 456 & -546 & -385 & -364 & 1178 & 749 & 459 & 419 & 212 \\
\hline 181 & 532 & 608 & -628 & -442 & -419 & 1361 & 851 & 519 & 461 & 227 \\
\hline 203 & 672 & 740 & -721 & -504 & -481 & 1536 & 951 & 586 & 508 & 243 \\
\hline 221 & 839 & 944 & -806 & -558 & -537 & 1860 & 1052 & 659 & 526 & 249 \\
\hline 241 & 967 & 1072 & -899 & -619 & -598 & 2056 & 1152 & 732 & 560 & 253 \\
\hline 261 & 1106 & 1188 & -1019 & -688 & -666 & 2261 & 1264 & 823 & 616 & 258 \\
\hline 281 & 1223 & 1266 & -1133 & -754 & -732 & 2422 & 1373 & 903 & 674 & 264 \\
\hline 302 & 1290 & 1361 & -1279 & -833 & -815 & 2627 & 1679 & 1034 & 723 & 266 \\
\hline 320 & 1404 & 1465 & -1420 & -897 & -892 & 2749 & 1848 & 1203 & 767 & 269 \\
\hline 341 & 1553 & 1596 & -1589 & -976 & -987 & 2933 & 2016 & 1324 & 828 & 275 \\
\hline 360 & 1693 & 1718 & -1772 & -1056 & -1084 & 3065 & 2162 & 1428 & 885 & 285 \\
\hline 376 & 1870 & 1854 & -2653 & -1484 & -1519 & 3153 & 2311 & 1582 & 989 & 266 \\
\hline 385 & 1950 & 1917 & -3075 & -1656 & -1662 & 3225 & 2378 & 1681 & 1027 & 290 \\
\hline 389 & 2019 & 1976 & \begin{tabular}{|l|}
-3387 \\
\end{tabular} & -1722 & \begin{tabular}{|l|}
-1682 \\
\end{tabular} & 3224 & 2442 & 1802 & 1054 & 302 \\
\hline
\end{tabular}


Tabela II.24 - Leitura das tensões e deformações máximas e mínimas dadas pelas rosetas da viga $\mathrm{VC}-2$

\begin{tabular}{|c|c|c|c|c|c|c|c|c|}
\hline \multirow{2}{*}{$\begin{array}{c}\text { Força } \\
\mathrm{kN}\end{array}$} & $\begin{array}{c}\varepsilon_{\max } \\
\mu \mathrm{e}\end{array}$ & $\begin{array}{c}\varepsilon_{\min } \\
\mu \mathrm{e}\end{array}$ & $\begin{array}{c}\sigma_{\max } \\
\mathrm{kN} / \mathrm{cm}^{2}\end{array}$ & $\begin{array}{c}\sigma_{\min } \\
\mathrm{kN} / \mathrm{cm}^{2}\end{array}$ & $\begin{array}{c}\varepsilon_{\max } \\
\mu \mathrm{e}\end{array}$ & $\begin{array}{c}\varepsilon_{\min } \\
\mu \mathrm{e}\end{array}$ & $\begin{array}{c}\sigma_{\max } \\
\mathrm{kN} / \mathrm{cm}^{2}\end{array}$ & $\begin{array}{c}\sigma_{\min } \\
\mathrm{kN} / \mathrm{cm}^{2}\end{array}$ \\
\hline 0 & 0.95 & -0.95 & 0.003 & -0.003 & 0.00 & 0.00 & 0.000 & 0.000 \\
\hline 11 & 6.82 & -3.98 & 0.022 & -0.010 & 7.56 & -6.62 & 0.023 & -0.019 \\
\hline 20 & 15.76 & -8.19 & 0.052 & -0.019 & 15.16 & -14.22 & 0.046 & -0.041 \\
\hline 32 & 40.22 & -65.78 & 0.100 & -0.214 & 14.16 & -21.72 & 0.036 & -0.070 \\
\hline 42 & 45.71 & -96.83 & 0.097 & -0.324 & 22.69 & -30.26 & 0.062 & -0.095 \\
\hline 51 & 46.10 & -103.85 & 0.094 & -0.350 & 37.79 & -42.52 & 0.108 & -0.129 \\
\hline 61 & 44.61 & -109.93 & 0.084 & -0.374 & 53.85 & -53.85 & 0.159 & -0.159 \\
\hline 70 & 43.18 & -120.81 & 0.070 & -0.415 & 65.17 & -66.12 & 0.192 & -0.196 \\
\hline 80 & 38.14 & -128.08 & 0.046 & -0.445 & 90.64 & -79.29 & 0.277 & -0.226 \\
\hline 90 & 36.71 & -134.22 & 0.036 & -0.469 & 153.18 & -105.88 & 0.488 & -0.278 \\
\hline 101 & 33.67 & -149.17 & 0.014 & -0.527 & 268.70 & -151.39 & 0.882 & -0.361 \\
\hline 111 & 11.67 & -151.79 & -0.069 & -0.553 & 412.89 & -217.98 & 1.366 & -0.501 \\
\hline 120 & 4.30 & -154.82 & -0.099 & -0.569 & 515.30 & -259.84 & 1.713 & -0.580 \\
\hline 132 & 1.56 & -157.76 & -0.111 & -0.582 & 600.91 & -288.67 & 2.009 & -0.623 \\
\hline 142 & 2.88 & -162.88 & -0.110 & -0.600 & 603.10 & -288.96 & 2.017 & -0.623 \\
\hline 152 & 5.68 & -166.62 & -0.102 & -0.612 & 611.38 & -282.10 & 2.052 & -0.591 \\
\hline 161 & -51.42 & -164.43 & -0.312 & -0.646 & 561.43 & -231.19 & 1.905 & -0.440 \\
\hline
\end{tabular}




\section{Resultados da viga VC-3}

Tabela II.25 - Leitura dos deslocamentos verticais ao longo do eixo longitudinal

da viga $\mathrm{VC}-3$

\begin{tabular}{|c|c|c|c|c|c|c|c|}
\hline $\begin{array}{c}\text { Força } \\
\mathrm{kN}\end{array}$ & $\begin{array}{c}\text { Trans. } 1 \\
\mathrm{~mm}\end{array}$ & $\begin{array}{c}\text { Trans.2 } \\
\mathrm{mm}\end{array}$ & $\begin{array}{c}\text { Trans.3 } \\
\mathrm{mm}\end{array}$ & $\begin{array}{c}\text { Trans. } 4 \\
\mathrm{~mm}\end{array}$ & $\begin{array}{c}\text { Trans.5 } \\
\mathrm{mm}\end{array}$ & $\begin{array}{c}\text { Trans.6 } \\
\mathrm{mm}\end{array}$ & $\begin{array}{c}\text { Trans.7 } \\
\mathrm{mm}\end{array}$ \\
\hline 0 & 0.00 & -0.04 & 0.00 & 0.00 & -0.07 & 0.00 & 0.00 \\
\hline 12 & -0.07 & 0.26 & 0.28 & 0.25 & -0.11 & 0.33 & 0.25 \\
\hline 21 & -0.15 & 0.52 & 0.28 & 0.50 & -0.18 & 0.59 & 0.53 \\
\hline 32 & -0.19 & 0.85 & 0.58 & 0.82 & -0.22 & 0.93 & 0.93 \\
\hline 41 & -0.22 & 1.11 & 0.86 & 1.08 & -0.29 & 1.19 & 1.21 \\
\hline 51 & -0.30 & 1.40 & 1.14 & 1.36 & -0.36 & 1.52 & 1.50 \\
\hline 62 & -0.33 & 1.70 & 1.41 & 1.65 & -0.40 & 1.86 & 1.82 \\
\hline 72 & -0.33 & 1.99 & 1.69 & 1.97 & -0.44 & 2.19 & 2.14 \\
\hline 82 & -0.37 & 2.29 & 1.48 & 2.30 & -0.55 & 2.49 & 2.46 \\
\hline 92 & -0.41 & 2.62 & 2.37 & 2.62 & -0.58 & 2.86 & 2.81 \\
\hline 103 & -0.41 & 2.92 & 2.68 & 2.91 & -0.62 & 3.19 & 3.17 \\
\hline 114 & -0.44 & 3.28 & 3.10 & 3.26 & -0.65 & 3.60 & 3.60 \\
\hline 121 & -0.44 & 3.51 & 3.30 & 3.48 & -0.69 & 3.79 & 3.81 \\
\hline 141 & -0.52 & 4.17 & 3.85 & 4.05 & -0.73 & 4.45 & 4.52 \\
\hline 161 & -0.56 & 4.87 & 4.58 & 4.73 & -0.80 & 5.16 & 5.13 \\
\hline 180 & -0.63 & 5.54 & 5.23 & 5.27 & -0.84 & 5.86 & 5.84 \\
\hline 203 & -0.67 & 6.31 & 7.23 & 6.03 & -0.87 & 6.76 & 6.70 \\
\hline 220 & -0.70 & 6.86 & 7.88 & 6.64 & -0.91 & 7.39 & 7.37 \\
\hline 241 & $\begin{array}{l}-0.74 \\
\end{array}$ & 7.64 & 8.77 & 7.39 & -0.94 & 8.24 & 8.23 \\
\hline 262 & -0.74 & 8.41 & 9.67 & 8.21 & $\begin{array}{l}-1.02 \\
\end{array}$ & 9.13 & 9.15 \\
\hline 282 & -0.78 & 9.23 & 10.74 & 9.04 & -1.05 & 10.10 & 10.08 \\
\hline 301 & -0.78 & 10.04 & 12.04 & 9.86 & -1.09 & 11.02 & 11.00 \\
\hline 308 & -0.78 & 10.44 & 12.39 & 10.22 & -1.09 & 11.47 & 11.43 \\
\hline 321 & -0.78 & 11.00 & 13.08 & 10.83 & -1.13 & 12.18 & 12.11 \\
\hline 340 & -0.81 & 11.99 & 14.18 & 11.84 & -1.16 & 13.25 & 13.21 \\
\hline 351 & -0.81 & 12.62 & 14.97 & 12.48 & -1.16 & 14.03 & 14.00 \\
\hline 360 & -0.81 & 13.06 & 15.49 & 12.98 & -1.16 & 14.55 & 14.53 \\
\hline 360 & -0.81 & 13.14 & 15.59 & 13.06 & -1.16 & 14.70 & 14.64 \\
\hline 379 & -0.81 & 14.43 & 16.86 & 14.38 & -1.20 & 16.18 & 16.20 \\
\hline 387 & -0.81 & 15.20 & 17.76 & 15.10 & -1.24 & 17.04 & 17.13 \\
\hline 389 & -0.85 & 15.68 & 18.48 & 15.67 & -1.20 & 17.74 & 17.84 \\
\hline 387 & -0.81 & 15.94 & 18.79 & 15.96 & -1.24 & 18.11 & 18.20 \\
\hline 389 & -0.85 & 16.20 & 19.17 & 16.25 & $\begin{array}{l}-1.24 \\
\end{array}$ & 18.45 & 18.55 \\
\hline 392 & -0.85 & 16.86 & 20.03 & 16.97 & -1.24 & 19.38 & 19.44 \\
\hline 390 & -0.81 & 17.71 & 21.23 & 17.93 & -1.24 & 20.53 & 20.62 \\
\hline 396 & -0.81 & 19.23 & 23.43 & 19.62 & -1.24 & 22.53 & 22.69 \\
\hline 394 & -0.78 & 19.70 & 24.16 & 20.34 & $\begin{array}{l}-1.24 \\
\end{array}$ & 23.31 & 23.43 \\
\hline 400 & -0.67 & 21.70 & 26.46 & 22.74 & -1.24 & 26.10 & 26.21 \\
\hline 399 & -0.67 & 22.55 & 27.63 & 23.92 & -1.24 & 27.32 & 27.46 \\
\hline 401 & -0.67 & 23.73 & 29.04 & 25.22 & -1.24 & 28.92 & 28.99 \\
\hline 403 & -0.63 & 25.17 & 30.94 & 26.83 & -1.24 & 30.73 & 30.88 \\
\hline 404 & -0.59 & 26.68 & 33.04 & 28.62 & -1.24 & 32.89 & 33.01 \\
\hline
\end{tabular}


Tabela II.26 - Leitura dos deslocamentos horizontais entre o reforço e o

substrato ao longo do eixo longitudinal da viga $\mathrm{VC}-3$

\begin{tabular}{|c|c|c|c|c|c|c|c|c|}
\hline $\begin{array}{c}\text { Força } \\
\mathrm{kN}\end{array}$ & $\begin{array}{c}\text { Rel.1 } \\
\mathrm{mm}\end{array}$ & $\begin{array}{c}\text { Rel.2 } \\
\mathrm{mm}\end{array}$ & $\begin{array}{c}\text { Rel.3 } \\
\mathrm{mm}\end{array}$ & $\begin{array}{c}\text { Rel.4 } \\
\mathrm{mm}\end{array}$ & $\begin{array}{c}\text { Rel.5 } \\
\mathrm{mm}\end{array}$ & $\begin{array}{c}\text { Rel.6 } \\
\mathrm{mm}\end{array}$ & $\begin{array}{c}\text { Rel.7 } \\
\mathrm{mm}\end{array}$ & $\begin{array}{c}\text { Rel.8 } \\
\mathrm{mm}\end{array}$ \\
\hline 0 & 0.000 & 0.000 & 0.000 & 0.000 & 0.000 & 0.000 & 0.000 & 0.000 \\
\hline 12 & 0.000 & 0.000 & 0.000 & 0.000 & -0.003 & 0.000 & 0.000 & 0.000 \\
\hline 21 & 0.000 & -0.005 & 0.000 & 0.000 & -0.003 & 0.000 & 0.000 & 0.000 \\
\hline 32 & -0.003 & -0.005 & -0.005 & 0.000 & 0.006 & 0.000 & 0.000 & 0.000 \\
\hline 41 & -0.003 & -0.005 & -0.010 & 0.000 & 0.012 & 0.000 & 0.000 & 0.000 \\
\hline 51 & -0.003 & -0.005 & -0.014 & -0.005 & 0.024 & 0.005 & 0.000 & 0.000 \\
\hline 62 & -0.006 & -0.005 & -0.019 & -0.005 & 0.031 & 0.005 & 0.000 & 0.000 \\
\hline 72 & -0.006 & 0.000 & -0.019 & -0.009 & 0.034 & -0.010 & 0.000 & 0.000 \\
\hline 82 & -0.009 & 0.000 & -0.024 & -0.009 & 0.037 & -0.015 & 0.000 & -0.003 \\
\hline 92 & -0.009 & 0.005 & -0.029 & -0.014 & 0.043 & -0.020 & 0.000 & -0.003 \\
\hline 103 & -0.009 & 0.000 & -0.034 & -0.014 & 0.043 & -0.020 & 0.005 & -0.003 \\
\hline 114 & -0.013 & -0.065 & -0.034 & -0.019 & 0.046 & -0.020 & 0.009 & -0.003 \\
\hline 121 & -0.013 & -0.075 & -0.029 & -0.019 & 0.046 & -0.020 & 0.009 & -0.006 \\
\hline 141 & -0.016 & -0.130 & -0.024 & -0.024 & 0.040 & -0.025 & 0.028 & -0.006 \\
\hline 161 & -0.019 & -0.120 & -0.010 & -0.024 & 0.015 & -0.025 & 0.033 & -0.006 \\
\hline 180 & -0.022 & -0.070 & 0.005 & -0.033 & 0.003 & -0.025 & 0.038 & -0.006 \\
\hline 203 & -0.022 & -0.030 & 0.014 & -0.038 & -0.003 & -0.030 & 0.043 & -0.006 \\
\hline 220 & -0.025 & -0.010 & 0.019 & -0.043 & -0.009 & -0.025 & 0.043 & -0.003 \\
\hline 241 & -0.025 & 0.005 & 0.014 & -0.057 & -0.015 & -0.025 & 0.047 & -0.006 \\
\hline 262 & -0.025 & 0.015 & 0.005 & -0.062 & -0.021 & -0.020 & 0.047 & -0.003 \\
\hline 282 & -0.022 & 0.030 & 0.000 & -0.066 & -0.028 & -0.010 & 0.043 & -0.006 \\
\hline 301 & -0.022 & 0.045 & 0.000 & -0.071 & -0.034 & 0.000 & 0.043 & -0.006 \\
\hline 308 & -0.019 & 0.060 & 0.000 & -0.076 & -0.037 & 0.010 & 0.043 & -0.003 \\
\hline 321 & -0.019 & 0.065 & -0.005 & -0.071 & -0.046 & 0.020 & 0.043 & -0.003 \\
\hline 340 & -0.019 & 0.075 & -0.024 & -0.071 & -0.058 & 0.030 & 0.043 & -0.003 \\
\hline 351 & -0.016 & 0.085 & -0.039 & -0.076 & -0.067 & 0.039 & 0.043 & -0.003 \\
\hline 360 & -0.016 & 0.085 & -0.043 & -0.076 & -0.070 & 0.044 & 0.043 & -0.003 \\
\hline 360 & -0.016 & 0.085 & -0.043 & -0.076 & -0.073 & 0.044 & 0.043 & -0.003 \\
\hline 379 & -0.016 & 0.105 & -0.053 & -0.076 & -0.092 & 0.049 & 0.085 & -0.003 \\
\hline 387 & -0.013 & 0.110 & -0.058 & -0.081 & -0.116 & 0.044 & 0.090 & -0.003 \\
\hline 389 & -0.013 & 0.110 & -0.058 & -0.081 & -0.122 & 0.044 & 0.090 & -0.003 \\
\hline 387 & -0.013 & 0.110 & -0.063 & -0.081 & -0.122 & 0.044 & 0.090 & -0.003 \\
\hline 389 & -0.013 & 0.110 & -0.063 & -0.081 & -0.125 & 0.044 & 0.090 & -0.003 \\
\hline 392 & -0.013 & 0.115 & -0.063 & -0.081 & -0.131 & 0.039 & 0.090 & -0.003 \\
\hline 390 & -0.009 & 0.115 & -0.067 & -0.081 & -0.235 & 0.005 & 0.090 & -0.003 \\
\hline 396 & -0.009 & 0.115 & -0.072 & -0.085 & -0.385 & -0.069 & 0.090 & -0.003 \\
\hline 394 & -0.006 & 0.115 & -0.072 & -0.085 & -0.425 & -0.099 & 0.090 & -0.003 \\
\hline 400 & - & - & - & - & - & - & - & - \\
\hline 399 & - & - & - & - & - & - & - & - \\
\hline 401 & - & - & - & - & - & - & - & - \\
\hline 403 & - & - & - & - & - & $\begin{array}{ll}- & \text { r }\end{array}$ & - & - \\
\hline 404 & - & - & - & $\begin{array}{ll}- \\
-\end{array}$ & - & - & 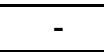 & - \\
\hline
\end{tabular}


Tabela II.27 - Leitura das deformações nas armaduras longitudinais do substrato $\left(A_{\text {sl }}\right)$ e do reforço $\left(A_{\text {slr }}\right)$ da viga $\mathrm{VC}-3$

\begin{tabular}{|c|c|c|c|c|c|c|c|c|c|c|c|c|}
\hline $\begin{array}{l}\text { Força } \\
\text { kN }\end{array}$ & $\begin{array}{c}\text { Ext.1 } \\
\mu \mathrm{e}\end{array}$ & $\begin{array}{c}\text { Ext.3 } \\
\mu \mathrm{e}\end{array}$ & $\begin{array}{c}\text { Ext.4 } \\
\mu \mathrm{e}\end{array}$ & $\begin{array}{c}\text { Ext.6 } \\
\mu \mathrm{e}\end{array}$ & $\begin{array}{c}\text { Ext.7 } \\
\mu \mathrm{e}\end{array}$ & $\begin{array}{c}\text { Ext.9 } \\
\mu \mathrm{e}\end{array}$ & $\begin{array}{c}\text { Ext.10 } \\
\mu \mathrm{e}\end{array}$ & $\begin{array}{c}\text { Ext.12 } \\
\mu \mathrm{e}\end{array}$ & $\begin{array}{c}\text { Ext.13 } \\
\mu \mathrm{e}\end{array}$ & $\begin{array}{c}\text { Ext.15 } \\
\mu \mathrm{e}\end{array}$ & $\begin{array}{c}\text { Ext.16 } \\
\mu \mathrm{e}\end{array}$ & $\begin{array}{c}\text { Ext.18 } \\
\mu \mathrm{e}\end{array}$ \\
\hline 0 & 0 & 0 & $\overline{0}$ & $\overline{0}$ & 1 & 0 & $\overline{0}$ & $\overline{0}$ & 0 & $\overline{0}$ & 0 & 0 \\
\hline 12 & 26 & 29 & 44 & 39 & 24 & 29 & 36 & 40 & 10 & 10 & 15 & 15 \\
\hline 21 & 46 & 55 & 94 & 80 & 38 & 80 & 72 & 81 & 17 & 17 & 27 & 26 \\
\hline 32 & 76 & $\overline{92}$ & 63 & 40 & 67 & 159 & 128 & 152 & 25 & 25 & 45 & 41 \\
\hline 41 & $\overline{54}$ & 26 & 219 & 185 & 127 & 212 & 80 & 209 & 32 & 33 & 66 & 54 \\
\hline 51 & 138 & 174 & 282 & 236 & 178 & 256 & 230 & 263 & 40 & 41 & 94 & 68 \\
\hline 62 & 176 & 232 & 347 & 290 & 221 & 302 & 283 & 320 & 55 & 63 & 126 & 89 \\
\hline 72 & 217 & 289 & 412 & 343 & 265 & 345 & 335 & 377 & 119 & 209 & 155 & 140 \\
\hline 82 & 257 & 337 & 470 & 392 & 320 & 388 & 388 & 438 & 151 & 244 & 182 & 165 \\
\hline 92 & 321 & 394 & 539 & 449 & 397 & 433 & 442 & 498 & 194 & 288 & 218 & 195 \\
\hline$\overline{103}$ & 464 & 458 & 607 & $\overline{506}$ & 454 & 475 & 491 & 553 & 240 & 328 & 252 & 226 \\
\hline 114 & 535 & 522 & 83 & 568 & 517 & 523 & 548 & 16 & 11 & 373 & 296 & 269 \\
\hline 121 & 568 & 554 & 723 & 601 & 551 & 549 & 580 & 649 & 39 & 397 & 313 & 289 \\
\hline 141 & 665 & 654 & 855 & 703 & 621 & 638 & 681 & 753 & 416 & 450 & 380 & 350 \\
\hline 161 & 772 & 769 & 1017 & 810 & 725 & 713 & 783 & 860 & 450 & 483 & 442 & 445 \\
\hline 180 & 867 & 872 & 1173 & 909 & 823 & 796 & 879 & 961 & 485 & 535 & 500 & 510 \\
\hline 203 & 987 & 1000 & 1362 & 1033 & 944 & $\overline{906}$ & 993 & 1083 & 524 & 599 & 574 & 583 \\
\hline 220 & 1086 & 1106 & 1514 & 1138 & 1050 & 998 & 1083 & 1179 & 549 & 648 & 632 & 638 \\
\hline 241 & 1219 & 1248 & 1717 & 1277 & 1192 & 11 & 1200 & 1300 & 574 & 714 & 703 & 707 \\
\hline 262 & 1362 & 397 & 1923 & 1419 & 1333 & 124 & 1320 & 1425 & $\overline{06}$ & 779 & 775 & 771 \\
\hline 282 & 1517 & 1561 & 2139 & 1562 & 1474 & 1392 & 1444 & 1561 & 643 & 851 & 848 & 836 \\
\hline 301 & 1668 & 1721 & 2349 & 1700 & 1611 & 1525 & 1561 & 1689 & 678 & 913 & 917 & 892 \\
\hline 308 & \begin{tabular}{|l|}
1739 \\
\end{tabular} & 1799 & 2448 & 1759 & 1675 & 1586 & 1613 & 1748 & 692 & 937 & 950 & 917 \\
\hline 321 & 1865 & 1931 & 2626 & 1865 & 1787 & 1696 & 1714 & 1866 & 721 & 983 & 993 & 954 \\
\hline 340 & 2062 & 2145 & 2897 & 2018 & 1953 & 1864 & 1869 & 2044 & 760 & 1055 & 1058 & 1007 \\
\hline 351 & 2200 & 2284 & 3070 & 111 & 2061 & 1973 & 1972 & 2160 & 787 & 102 & 103 & 1045 \\
\hline 360 & 2313 & 2383 & 3203 & 2185 & 2144 & 2060 & 2059 & 2262 & 807 & 1135 & 1128 & 1067 \\
\hline 360 & 2335 & 2396 & 3228 & 2197 & 2158 & 2073 & 2069 & 2269 & 806 & 1133 & 1124 & 1062 \\
\hline$\overline{379}$ & 2711 & 31 & 3600 & 2369 & 2390 & 2294 & 2306 & 2524 & 850 & 1205 & 1185 & 1121 \\
\hline 387 & 2810 & 9467 & 3890 & 2514 & 2477 & 2379 & 2408 & 2636 & 866 & 1231 & 207 & 1140 \\
\hline 389 & 2825 & 0433 & 4053 & 2611 & 2500 & 2404 & 2440 & 2670 & 867 & 1234 & 1209 & 1143 \\
\hline 387 & 2828 & 536 & 4106 & 2643 & 2509 & 2413 & 2450 & 2683 & 868 & 1235 & 1209 & 1143 \\
\hline 389 & 2846 & 2673 & 4166 & 2676 & 2524 & 2428 & 2467 & 2701 & 870 & 1239 & 1212 & 1146 \\
\hline 392 & 2871 & $\overline{470}$ & 4326 & 2756 & 2556 & 2464 & 2511 & 2754 & 880 & 1252 & 1227 & \begin{tabular}{|l|}
1163 \\
\end{tabular} \\
\hline 390 & 2855 & 12451 & 4825 & 2779 & 2562 & 2477 & 2524 & \begin{tabular}{|l|}
2767 \\
\end{tabular} & 874 & 1247 & 1217 & 1150 \\
\hline 396 & 9047 & 13234 & 5340 & 2933 & 2575 & 2529 & 2587 & 2838 & 885 & 1264 & 1236 & 1170 \\
\hline 394 & 606 & & 5437 & 2967 & 2572 & 2532 & 2587 & 2836 & 881 & 1258 & 1227 & 1160 \\
\hline 400 & 585 & 1213 & 5830 & 3191 & 2644 & 2590 & 2667 & 2929 & 892 & 1279 & 1244 & \begin{tabular}{|l|}
1178 \\
\end{tabular} \\
\hline 399 & 549 & 11289 & 5965 & 3274 & 2701 & 2617 & 2701 & \begin{tabular}{|l|}
2967 \\
\end{tabular} & 897 & 1284 & 1250 & \begin{tabular}{|l|}
1184 \\
\end{tabular} \\
\hline 401 & 575 & 11315 & 6110 & 3358 & 2728 & 2605 & 2732 & 2992 & 891 & 1279 & 1241 & \begin{tabular}{|l|}
1174 \\
\end{tabular} \\
\hline 403 & 674 & 11382 & 6319 & 3441 & 2818 & 2630 & 2775 & 3040 & 894 & 1282 & 1245 & \begin{tabular}{|l|}
1177 \\
\end{tabular} \\
\hline 404 & 1748 & 11418 & 6757 & 3659 & 3069 & 2658 & 2820 & 3096 & 896 & 1285 & 1248 & 1179 \\
\hline
\end{tabular}


Tabela II.28 - Leitura das deformações do estribo, do concreto comprimido e

dos conectores metálicos da viga $\mathrm{VC}-3$

\begin{tabular}{|c|c|c|c|c|c|c|c|c|c|c|}
\hline \multirow[b]{2}{*}{$\begin{array}{c}\text { Força } \\
\text { kN }\end{array}$} & \multicolumn{2}{|c|}{ Estribo } & \multicolumn{3}{|c|}{ Concreto } & \multicolumn{5}{|c|}{ Conectores metálicos } \\
\hline & $\begin{array}{c}\text { Ext.19 } \\
\mu \mathrm{e}\end{array}$ & $\begin{array}{c}\text { Ext.20 } \\
\mu \mathrm{e}\end{array}$ & $\begin{array}{c}\text { Ext.21 } \\
\mu \mathrm{e}\end{array}$ & $\begin{array}{c}\text { Ext.22 } \\
\mu \mathrm{e}\end{array}$ & $\begin{array}{c}\text { Ext.23 } \\
\mu \mathrm{e}\end{array}$ & $\begin{array}{c}\text { Ext.24 } \\
\mu \mathrm{e}\end{array}$ & $\begin{array}{c}\text { Ext.25 } \\
\mu \mathrm{e}\end{array}$ & $\begin{array}{c}\text { Ext.26 } \\
\mu \mathrm{e}\end{array}$ & $\begin{array}{c}\text { Ext.27 } \\
\mu \mathrm{e}\end{array}$ & $\begin{array}{c}\text { Ext.28 } \\
\mu \mathrm{e}\end{array}$ \\
\hline$\overline{0}$ & 1 & $\overline{0}$ & 0 & 0 & 0 & 0 & 0 & $\overline{0}$ & 0 & 0 \\
\hline 12 & 2 & 3 & 1 & -2 & -3 & -3 & -2 & -26 & -32 & -22 \\
\hline 21 & 3 & 7 & 1 & -4 & -4 & -2 & 0 & -45 & -57 & -39 \\
\hline 32 & 7 & 11 & 2 & -3 & -1 & 5 & 0 & -74 & -94 & -65 \\
\hline 41 & 11 & 16 & 4 & -1 & 4 & 12 & 10 & -99 & -123 & -86 \\
\hline 51 & 22 & 24 & 6 & 7 & 14 & 24 & 23 & -123 & $\begin{array}{l}-155 \\
\end{array}$ & -107 \\
\hline 62 & 47 & 41 & 9 & 20 & 22 & 40 & 35 & -150 & \begin{tabular}{|c|}
-188 \\
\end{tabular} & -131 \\
\hline 72 & 69 & 108 & 24 & 74 & 37 & 54 & 43 & -176 & -222 & -155 \\
\hline 82 & 82 & 140 & 32 & 93 & 53 & 86 & 47 & -201 & -251 & -176 \\
\hline 92 & 107 & 193 & 65 & 119 & 84 & 142 & 51 & -228 & -286 & -201 \\
\hline 103 & 139 & 233 & 89 & 140 & 110 & 178 & 56 & -252 & -316 & -225 \\
\hline 114 & 208 & 289 & 144 & 164 & 174 & 246 & 64 & -283 & -355 & -251 \\
\hline 121 & 244 & 319 & 165 & 179 & 194 & 275 & 68 & -299 & -376 & -267 \\
\hline 141 & 358 & 432 & 295 & 221 & 284 & 383 & 115 & -349 & -437 & -311 \\
\hline 161 & 560 & 657 & 531 & 222 & 380 & 430 & 141 & -406 & -509 & -359 \\
\hline 180 & 693 & 789 & 639 & 226 & 453 & 476 & 163 & -458 & -575 & -405 \\
\hline 203 & 848 & 942 & 770 & 232 & 528 & 543 & 192 & -521 & -655 & -461 \\
\hline 220 & 977 & 1071 & 865 & 235 & 586 & 610 & 213 & -574 & -720 & -506 \\
\hline 241 & 1133 & 1228 & 983 & 231 & 653 & 708 & 241 & -640 & -801 & -563 \\
\hline 262 & 1299 & 1398 & 1073 & 227 & 722 & 802 & 264 & -708 & -886 & -620 \\
\hline 282 & 1461 & 1568 & 1163 & 203 & 788 & 886 & 289 & -782 & -976 & -679 \\
\hline 301 & 1598 & 1702 & 1247 & 201 & 845 & 960 & 309 & -852 & -1064 & -739 \\
\hline 308 & 1657 & 1759 & 1284 & 208 & 872 & 991 & 315 & -886 & -1113 & -769 \\
\hline 321 & 1749 & 1850 & 1350 & 216 & 910 & 1042 & 329 & -937 & -1171 & -811 \\
\hline 340 & 1896 & 1994 & 1439 & 236 & 962 & 1112 & 343 & -1017 & -1278 & -881 \\
\hline 351 & 2009 & 2108 & 1504 & 260 & 1011 & 1161 & 351 & -1077 & -1365 & -936 \\
\hline 360 & 2070 & 2159 & 1544 & 271 & 1030 & 1181 & 356 & -1108 & -1405 & $\begin{array}{l}-967 \\
\end{array}$ \\
\hline 360 & 2061 & 2149 & 1540 & 273 & 1025 & 1177 & 353 & -1106 & -1406 & -965 \\
\hline 379 & 2207 & 2294 & 1631 & 309 & 1075 & 1228 & 366 & -1197 & -1554 & -1071 \\
\hline 387 & 2262 & 2344 & 1659 & 332 & 1088 & 1243 & 380 & -1266 & -1673 & -1183 \\
\hline 389 & 2274 & 2352 & 1666 & 336 & 1092 & 1247 & 386 & \begin{tabular}{|l|}
-1315 \\
\end{tabular} & $\begin{array}{l}-1727 \\
\end{array}$ & -1253 \\
\hline 387 & 2280 & 2356 & 1669 & 337 & 1093 & 1246 & 386 & -1307 & -1730 & -1265 \\
\hline 389 & 2286 & 2359 & 1673 & 341 & 1099 & 1253 & 390 & -1324 & -1765 & -1306 \\
\hline 392 & 2324 & 2392 & 1691 & 349 & 1116 & 1265 & 394 & -1361 & -1855 & -1410 \\
\hline 390 & 2312 & 2371 & 1681 & 347 & 1105 & 1249 & 390 & \begin{tabular}{|l|}
-1354 \\
\end{tabular} & -2024 & -1513 \\
\hline 396 & 2362 & 2409 & 1704 & 361 & 1133 & 1270 & 397 & -1320 & -2331 & -1734 \\
\hline 394 & 2351 & 2390 & 1696 & 357 & 1122 & 1255 & 391 & -1295 & -2373 & -1774 \\
\hline 400 & 2401 & 2433 & 1710 & 374 & 1146 & 1269 & 400 & -1327 & -2752 & -2115 \\
\hline 399 & 2419 & 2441 & 1718 & 377 & 1154 & 1278 & 413 & $\begin{array}{l}-1321 \\
\end{array}$ & -2879 & -2191 \\
\hline 401 & 2413 & 2425 & 1714 & 373 & 1148 & 1276 & 435 & -1276 & -2964 & -2235 \\
\hline 403 & 2427 & 2432 & 1720 & 374 & 1149 & 1271 & 433 & -1197 & -3029 & -2268 \\
\hline 404 & 2440 & 2437 & 1727 & 376 & 1155 & 1274 & 434 & -1103 & -3131 & -2275 \\
\hline
\end{tabular}




\section{Resultados da viga VM}

Tabela II.29 - Leitura dos deslocamentos verticais ao longo do eixo longitudinal da viga $\mathrm{VM}$

\begin{tabular}{|c|c|c|c|c|c|c|c|}
\hline $\begin{array}{c}\text { Força } \\
\text { kN }\end{array}$ & $\begin{array}{c}\text { Trans.1 } \\
\mathrm{mm}\end{array}$ & $\begin{array}{c}\text { Trans.2 } \\
\mathrm{mm}\end{array}$ & $\begin{array}{c}\text { Trans.3 } \\
\mathrm{mm}\end{array}$ & $\begin{array}{c}\text { Trans.4 } \\
\mathrm{mm}\end{array}$ & $\begin{array}{c}\text { Trans.5 } \\
\mathrm{mm}\end{array}$ & $\begin{array}{c}\text { Trans.6 } \\
\mathrm{mm}\end{array}$ & $\begin{array}{c}\text { Trans.7 } \\
\mathrm{mm}\end{array}$ \\
\hline 0 & 0.00 & 0.00 & -0.04 & 0.00 & 0.00 & 0.00 & -0.04 \\
\hline 12 & -0.07 & 0.26 & 0.26 & 0.22 & -0.07 & 0.29 & 0.22 \\
\hline 21 & -0.15 & 0.48 & 0.48 & 0.44 & -0.11 & 0.55 & 0.43 \\
\hline 31 & -0.22 & 0.74 & 0.77 & 0.66 & -0.18 & 0.88 & 0.72 \\
\hline 43 & -0.40 & 1.22 & 1.25 & 1.11 & -0.22 & 1.36 & 1.22 \\
\hline 52 & -0.44 & 1.48 & 1.54 & 1.37 & -0.29 & 1.66 & 1.51 \\
\hline 60 & -0.51 & 1.74 & 1.87 & 1.62 & -0.33 & 1.95 & 1.87 \\
\hline 71 & -0.55 & 2.22 & 2.39 & 2.10 & -0.33 & 2.47 & 2.48 \\
\hline 83 & -0.62 & 2.85 & 3.08 & 2.77 & -0.40 & 3.09 & 3.24 \\
\hline 93 & -0.69 & 3.33 & 3.63 & 3.21 & -0.44 & 3.61 & 3.74 \\
\hline 101 & -0.73 & 3.59 & 3.96 & 3.51 & -0.47 & 3.94 & 4.03 \\
\hline 121 & -0.80 & 4.48 & 4.96 & 4.39 & -0.55 & 4.93 & 5.00 \\
\hline 142 & -0.88 & 5.44 & 6.06 & 5.31 & -0.62 & 6.00 & 5.76 \\
\hline 163 & -0.95 & 6.33 & 7.01 & 6.20 & -0.65 & 7.03 & 6.65 \\
\hline 182 & -0.95 & 7.37 & 8.22 & 7.23 & -0.69 & 8.20 & 7.84 \\
\hline 200 & -1.02 & 8.22 & 9.10 & 8.08 & -0.76 & 9.09 & 8.67 \\
\hline 219 & -1.06 & 9.26 & 10.17 & 9.04 & -0.84 & 10.12 & 9.82 \\
\hline 223 & -1.10 & 9.52 & 10.46 & 9.34 & -0.84 & 10.41 & 10.11 \\
\hline 241 & -1.13 & 10.48 & 11.53 & 10.30 & -0.87 & 11.41 & 11.29 \\
\hline 242 & -1.13 & 10.59 & 11.64 & 10.41 & -0.91 & 11.52 & 11.44 \\
\hline 263 & -1.17 & 11.78 & 12.92 & 11.59 & -0.95 & 12.80 & 12.70 \\
\hline 283 & -1.21 & 13.00 & 14.21 & 12.69 & -0.98 & 14.09 & 13.96 \\
\hline 302 & -1.24 & 14.22 & 15.60 & 13.95 & -1.05 & 15.53 & 15.29 \\
\hline 323 & -1.28 & 16.52 & 17.77 & 15.72 & -1.05 & 17.77 & 17.34 \\
\hline
\end{tabular}


Tabela II.30 - Leitura dos deslocamentos horizontais entre o reforço e o substrato ao longo do eixo longitudinal da viga VM

\begin{tabular}{|c|c|c|c|c|c|c|c|}
\hline $\begin{array}{c}\text { Força } \\
\mathrm{kN}\end{array}$ & $\begin{array}{c}\text { Rel.1 } \\
\mathrm{mm}\end{array}$ & $\begin{array}{c}\text { Rel.2 } \\
\mathrm{mm}\end{array}$ & $\begin{array}{c}\text { Rel.3 } \\
\mathrm{mm}\end{array}$ & $\begin{array}{c}\text { Rel.4 } \\
\mathrm{mm}\end{array}$ & $\begin{array}{c}\text { Rel.5 } \\
\mathrm{mm}\end{array}$ & $\begin{array}{c}\text { Rel.6 } \\
\mathrm{mm}\end{array}$ & $\begin{array}{c}\text { Rel.8 } \\
\mathrm{mm}\end{array}$ \\
\hline 0 & 0.000 & 0.000 & 0.000 & 0.000 & 0.000 & 0.000 & 0.000 \\
\hline 12 & 0.000 & 0.000 & 0.000 & 0.000 & -0.003 & 0.000 & 0.000 \\
\hline 21 & -0.003 & -0.005 & -0.005 & 0.000 & -0.003 & -0.005 & 0.000 \\
\hline 31 & -0.003 & -0.010 & -0.005 & -0.020 & -0.003 & -0.005 & 0.000 \\
\hline 43 & -0.003 & -0.035 & -0.005 & -0.039 & -0.003 & -0.014 & -0.003 \\
\hline 52 & -0.003 & -0.050 & -0.009 & -0.049 & -0.003 & -0.024 & -0.003 \\
\hline 60 & -0.003 & -0.065 & -0.014 & -0.059 & -0.003 & -0.033 & -0.006 \\
\hline 71 & -0.003 & -0.085 & -0.033 & -0.074 & -0.003 & -0.052 & -0.006 \\
\hline 83 & -0.006 & -0.115 & -0.052 & -0.099 & -0.003 & -0.076 & -0.015 \\
\hline 93 & -0.006 & -0.130 & -0.062 & -0.118 & -0.003 & -0.090 & -0.021 \\
\hline 101 & -0.006 & -0.140 & -0.071 & -0.133 & -0.003 & -0.095 & -0.028 \\
\hline 121 & -0.009 & -0.170 & -0.090 & -0.167 & -0.006 & -0.114 & -0.055 \\
\hline 142 & -0.013 & -0.205 & -0.119 & -0.197 & -0.006 & -0.133 & -0.083 \\
\hline 163 & -0.019 & -0.240 & -0.142 & -0.227 & -0.006 & -0.152 & -0.101 \\
\hline 182 & -0.028 & -0.280 & -0.171 & -0.256 & -0.006 & -0.171 & -0.144 \\
\hline 200 & -0.038 & -0.310 & -0.194 & -0.281 & -0.013 & -0.185 & -0.168 \\
\hline 219 & -0.041 & -0.345 & -0.218 & -0.305 & -0.009 & -0.199 & -0.205 \\
\hline 223 & -0.044 & -0.350 & -0.223 & -0.310 & -0.009 & -0.199 & -0.220 \\
\hline 241 & -0.054 & -0.385 & -0.247 & -0.330 & -0.009 & -0.213 & -0.275 \\
\hline 242 & -0.050 & -0.390 & -0.247 & -0.335 & -0.006 & -0.213 & -0.281 \\
\hline 263 & -0.041 & -0.425 & -0.275 & -0.365 & -0.003 & -0.223 & -0.352 \\
\hline 283 & -0.019 & -0.460 & -0.304 & -0.379 & 0.000 & -0.232 & -0.459 \\
\hline 302 & 0.009 & -0.501 & -0.327 & -0.399 & 0.003 & -0.247 & -0.627 \\
\hline 323 & -0.016 & -0.551 & -0.361 & -0.409 & 0.009 & -0.256 & -1.107 \\
\hline
\end{tabular}


Tabela II.31 - Leitura das deformações nas armaduras longitudinais do substrato $\left(A_{\text {sl }}\right)$ e do reforço $\left(A_{\text {slr }}\right)$ da viga $V M$

\begin{tabular}{|c|c|c|c|c|c|c|c|c|c|c|c|c|}
\hline $\begin{array}{c}\text { Força } \\
\mathrm{kN}\end{array}$ & $\begin{array}{c}\text { Ext.1 } \\
\text { ue }\end{array}$ & $\begin{array}{c}\text { Ext.3 } \\
\text { ue }\end{array}$ & $\begin{array}{c}\text { Ext.4 } \\
\text { ue }\end{array}$ & $\begin{array}{c}\text { Ext.6 } \\
\text { ue }\end{array}$ & $\begin{array}{c}\text { Ext.7 } \\
\mu \mathrm{e}\end{array}$ & $\begin{array}{c}\text { Ext.9 } \\
\text { ue }\end{array}$ & $\begin{array}{c}\text { Ext.10 } \\
\mu \mathrm{e}\end{array}$ & $\begin{array}{c}\text { Ext.12 } \\
\mu \mathrm{e}\end{array}$ & $\begin{array}{c}\text { Ext.13 } \\
\mu \mathrm{e}\end{array}$ & $\begin{array}{c}\text { Ext.15 } \\
\text { pe }\end{array}$ & $\begin{array}{c}\text { Ext.16 } \\
\text { ue }\end{array}$ & $\begin{array}{c}\text { Ext.18 } \\
\text { ue }\end{array}$ \\
\hline$\overline{0}$ & 1 & 1 & 1 & 1 & 1 & 0 & 1 & 1 & 1 & 1 & 1 & 0 \\
\hline 12 & 28 & 29 & 39 & 40 & 26 & 24 & 35 & 34 & 13 & 12 & 16 & 17 \\
\hline 21 & 55 & 59 & 75 & 88 & 46 & 44 & 69 & 65 & 23 & 22 & 28 & 29 \\
\hline 31 & 87 & 98 & 121 & 153 & 86 & 73 & 188 & 111 & 31 & 30 & 40 & 42 \\
\hline 43 & 144 & 177 & 214 & 281 & 185 & 146 & 318 & 216 & 47 & 46 & 58 & 65 \\
\hline 52 & 189 & 226 & 263 & 342 & 237 & 190 & 388 & 275 & 58 & 59 & 70 & 85 \\
\hline 60 & 239 & 276 & 323 & 406 & 303 & 256 & 458 & 356 & 67 & 69 & 80 & 102 \\
\hline 71 & 340 & 363 & 461 & 521 & 394 & 371 & 562 & 498 & 83 & 89 & 98 & 136 \\
\hline 83 & 451 & 477 & 624 & 674 & 500 & 506 & 684 & 665 & 128 & 127 & 139 & 204 \\
\hline 93 & 530 & 557 & 730 & 781 & 578 & 590 & 779 & 775 & 174 & 171 & 193 & 275 \\
\hline 101 & 581 & 607 & 798 & 851 & 657 & 651 & 865 & 845 & 203 & 199 & 223 & 315 \\
\hline 121 & 733 & 762 & 998 & 1052 & 841 & 807 & 1055 & 1043 & 457 & 428 & 442 & 509 \\
\hline 142 & 887 & 929 & 1200 & 1262 & 1002 & 956 & 1244 & 1240 & 629 & 577 & 625 & 657 \\
\hline 163 & 1029 & 1079 & 1388 & 1464 & 1153 & 1098 & 1428 & 1427 & 724 & 683 & 758 & 778 \\
\hline 182 & 1183 & 1242 & 1587 & 1672 & 1306 & 1239 & 1623 & 1623 & 792 & 795 & 892 & 912 \\
\hline 200 & 1306 & 1368 & 1750 & 1841 & 1435 & 1361 & 1783 & 1786 & 873 & 884 & 993 & 1009 \\
\hline 219 & 1443 & 1511 & 1927 & 2027 & 1575 & 1494 & 1961 & 1957 & 966 & 986 & 11144 & \begin{tabular}{|l|l}
1184 \\
\end{tabular} \\
\hline 223 & 1472 & 1542 & 1966 & 2067 & 1607 & 1523 & \begin{tabular}{|l|l|}
2002 \\
\end{tabular} & 1990 & 984 & 1009 & 1185 & 1231 \\
\hline 241 & 1601 & 1676 & 2135 & 2244 & 1751 & 1666 & 2167 & 2143 & 1058 & 1112 & 1330 & 1368 \\
\hline 242 & 1612 & 1687 & 2150 & 2258 & 1764 & 1679 & \begin{tabular}{|l|l|}
2179 \\
\end{tabular} & 2152 & 1063 & 1119 & 1347 & 1387 \\
\hline 263 & 1763 & 1843 & 2352 & 2463 & 1944 & 1862 & 2371 & 2316 & 1144 & 1232 & 1510 & 1560 \\
\hline 283 & 1907 & 1989 & 2543 & 2658 & 2117 & 2051 & 2541 & 2473 & 1225 & 1333 & 1675 & \begin{tabular}{|l|l}
1723 \\
\end{tabular} \\
\hline 302 & 2057 & 2144 & 2738 & 2832 & 2314 & 2264 & 2694 & 2616 & 1298 & 1427 & 1865 & 1899 \\
\hline 323 & 2241 & 2356 & 3358 & 5286 & 2558 & 2559 & 2817 & 2733 & 1378 & 1515 & 2074 & 2090 \\
\hline
\end{tabular}


Tabela II.32 - Leitura das deformações do estribo e do concreto comprimido da viga VM

\begin{tabular}{|c|c|c|c|c|c|}
\hline \multirow[b]{2}{*}{$\begin{array}{c}\text { Força } \\
\mathrm{kN}\end{array}$} & \multicolumn{2}{|c|}{ Estribo } & \multicolumn{3}{|c|}{ Concreto } \\
\hline & $\begin{array}{c}\text { Ext.19 } \\
\mu \mathrm{e}\end{array}$ & $\begin{array}{c}\text { Ext.20 } \\
\mu \mathrm{e}\end{array}$ & $\begin{array}{c}\text { Ext.21 } \\
\mu \mathrm{e}\end{array}$ & $\begin{array}{c}\text { Ext.22 } \\
\mu \mathrm{e}\end{array}$ & $\begin{array}{c}\text { Ext.23 } \\
\mu \mathrm{e}\end{array}$ \\
\hline 0 & 1 & $\overline{1}$ & 0 & $\overline{0}$ & $\overline{1}$ \\
\hline 12 & 2 & 2 & -45 & -25 & -27 \\
\hline 21 & 3 & 1 & -87 & -49 & -51 \\
\hline 31 & 2 & 0 & -138 & -75 & -80 \\
\hline 43 & 2 & 0 & -232 & $\begin{array}{l}-122 \\
\end{array}$ & -128 \\
\hline 52 & 3 & -1 & -290 & -150 & $\begin{array}{l}-159 \\
\end{array}$ \\
\hline 60 & 3 & -1 & -347 & $\begin{array}{l}-179 \\
\end{array}$ & $\begin{array}{l}-189 \\
\end{array}$ \\
\hline 71 & 3 & 0 & -429 & -223 & $\begin{array}{l}-232 \\
\end{array}$ \\
\hline 83 & 1 & 6 & -521 & -272 & -287 \\
\hline 93 & 4 & 3 & -583 & -309 & -327 \\
\hline 101 & 4 & 5 & -624 & -336 & -356 \\
\hline 121 & 130 & 212 & $\begin{array}{l}-733 \\
\end{array}$ & -405 & -433 \\
\hline 142 & 419 & 628 & -850 & -480 & -518 \\
\hline 163 & 624 & 868 & -960 & -555 & -604 \\
\hline 182 & 881 & 1172 & -1085 & -631 & -694 \\
\hline 200 & 1018 & 1348 & -1189 & -698 & -777 \\
\hline 219 & 1117 & 1533 & -1295 & -766 & -862 \\
\hline 223 & 1132 & 1582 & -1328 & $\begin{array}{l}-781 \\
\end{array}$ & -884 \\
\hline 241 & 1221 & 1731 & -1445 & -844 & $\begin{array}{l}-970 \\
\end{array}$ \\
\hline 242 & 1230 & 1738 & -1464 & -849 & -980 \\
\hline 263 & 1354 & 1854 & -1604 & -919 & -1085 \\
\hline 283 & 1446 & 1955 & $\begin{array}{l}-1736 \\
\end{array}$ & $\begin{array}{l}-982 \\
\end{array}$ & -1179 \\
\hline 302 & 1535 & 2055 & -1887 & -1038 & -1285 \\
\hline 323 & 1631 & 2151 & -2067 & $\begin{array}{l}-1101 \\
\end{array}$ & -1404 \\
\hline
\end{tabular}

Tabela II.33 - Leitura das tensões e deformações máximas e mínimas dadas pelas rosetas da viga VM

\begin{tabular}{|c|c|c|c|c|c|c|c|c|}
\hline \multirow{2}{*}{$\begin{array}{c}\text { Força } \\
\mathrm{kN}\end{array}$} & \multicolumn{6}{|c|}{ Roseta 1 } & \multicolumn{4}{|c|}{ Roseta2 } \\
\cline { 2 - 9 } & $\begin{array}{c}\varepsilon_{\max } \\
\mu \mathrm{e}\end{array}$ & $\begin{array}{c}\varepsilon_{\min } \\
\mu \mathrm{e}\end{array}$ & $\begin{array}{c}\sigma_{\max } \\
\mathrm{kN} / \mathrm{cm}^{2}\end{array}$ & $\begin{array}{c}\sigma_{\min } \\
\mathrm{kN} / \mathrm{cm}^{2}\end{array}$ & $\begin{array}{c}\varepsilon_{\max } \\
\mu \mathrm{e}\end{array}$ & $\begin{array}{c}\varepsilon_{\min } \\
\mu \mathrm{e}\end{array}$ & $\begin{array}{c}\sigma_{\max } \\
\mathrm{kN} / \mathrm{cm}^{2}\end{array}$ & $\begin{array}{c}\sigma_{\min } \\
\mathrm{kN} / \mathrm{cm}^{2}\end{array}$ \\
\hline 0 & 0.00 & 0.00 & 0.000 & 0.000 & 1.87 & 0.00 & 0.007 & 0.001 \\
\hline 12 & 8.66 & -4.93 & 0.028 & -0.012 & 7.54 & -3.81 & 0.025 & -0.009 \\
\hline 21 & 14.31 & -10.58 & 0.045 & -0.029 & 11.31 & -6.64 & 0.037 & -0.016 \\
\hline 31 & 21.24 & -16.57 & 0.066 & -0.046 & 17.16 & -12.50 & 0.054 & -0.034 \\
\hline 43 & 32.02 & -26.43 & 0.099 & -0.074 & 22.40 & -17.74 & 0.070 & -0.049 \\
\hline 52 & 38.08 & -31.56 & 0.118 & -0.089 & 26.53 & -21.87 & 0.082 & -0.061 \\
\hline 60 & 43.40 & -36.87 & 0.133 & -0.104 & 29.94 & -26.21 & 0.091 & -0.075 \\
\hline 71 & 49.36 & -40.96 & 0.152 & -0.115 & 33.54 & -27.01 & 0.104 & -0.075 \\
\hline 83 & 58.71 & -44.72 & 0.184 & -0.122 & 29.51 & -29.51 & 0.087 & -0.087 \\
\hline 93 & 65.47 & -47.74 & 0.207 & -0.128 & 34.58 & -32.71 & 0.104 & -0.096 \\
\hline 101 & 72.50 & -51.98 & 0.230 & -0.139 & 38.05 & -35.25 & 0.115 & -0.102 \\
\hline 121 & 66.80 & -71.47 & 0.194 & -0.215 & 22.68 & -35.75 & 0.058 & -0.116 \\
\hline
\end{tabular}

